\title{
THE ISLES OF IWI
}

The exploration of how an offshore island in Pōneke Wellington can become a valuable, community focused space that acts as a cultural and educational node within the region.

CLAUDIA BOYO

A 120-point thesis

Victoria University of Wellington

Master of Landscape Architecture

Victoria University of Wellington

School of Architecture 

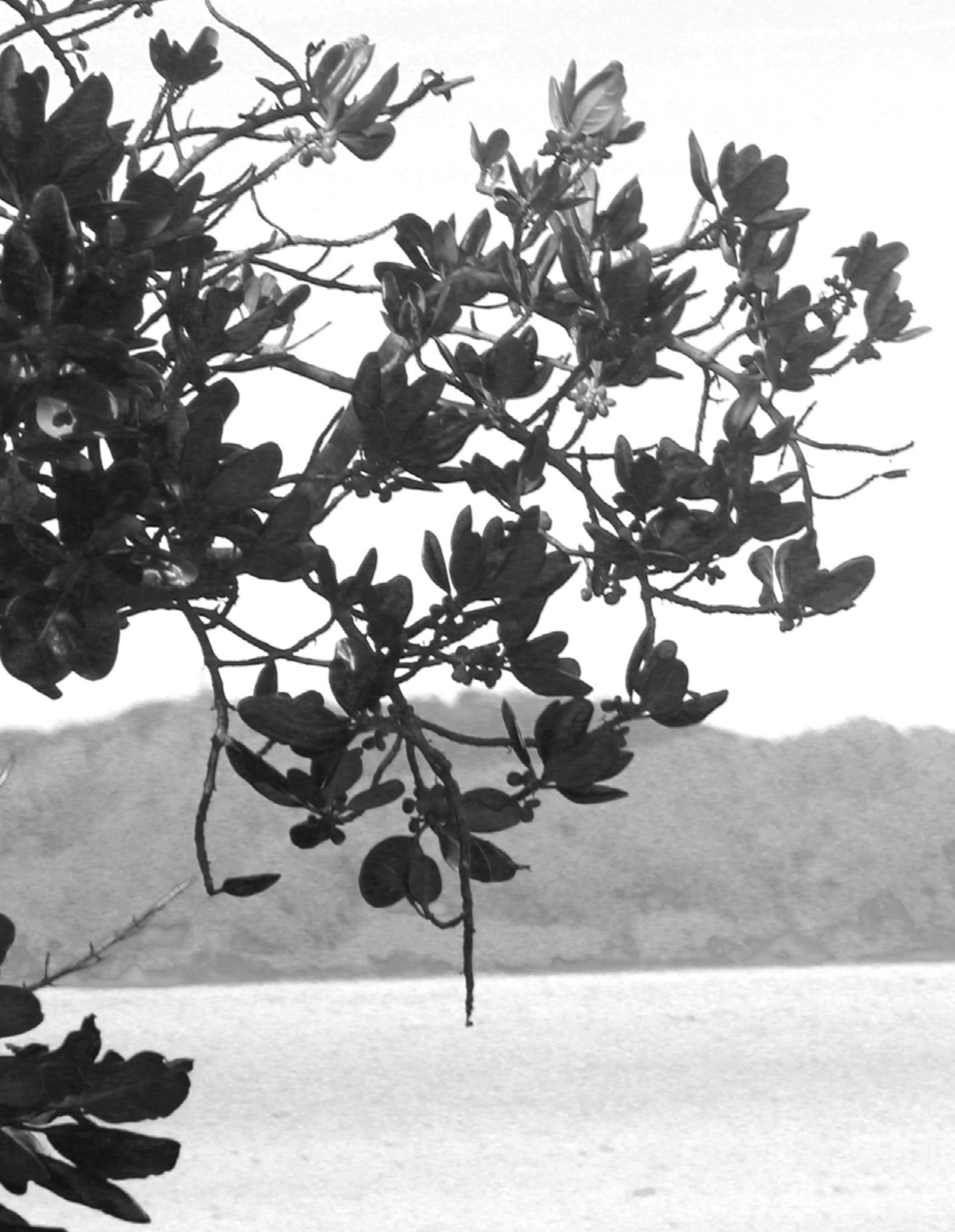

\section{4}

S

Whot in

Jol the

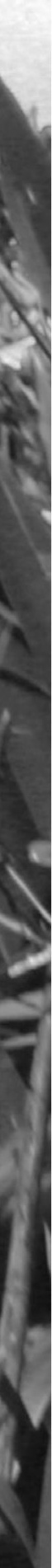


As Māori we have a unique sense of our cultural landscapes. It includes past present and future. It includes both physical and spiritual dimensions. It is how we express ourselves in our environments, it connects whānau, whenua, awa and moana through whakapapa, it includes both urban and rural, it is not just where we live, IT IS WHO WE ARE. 


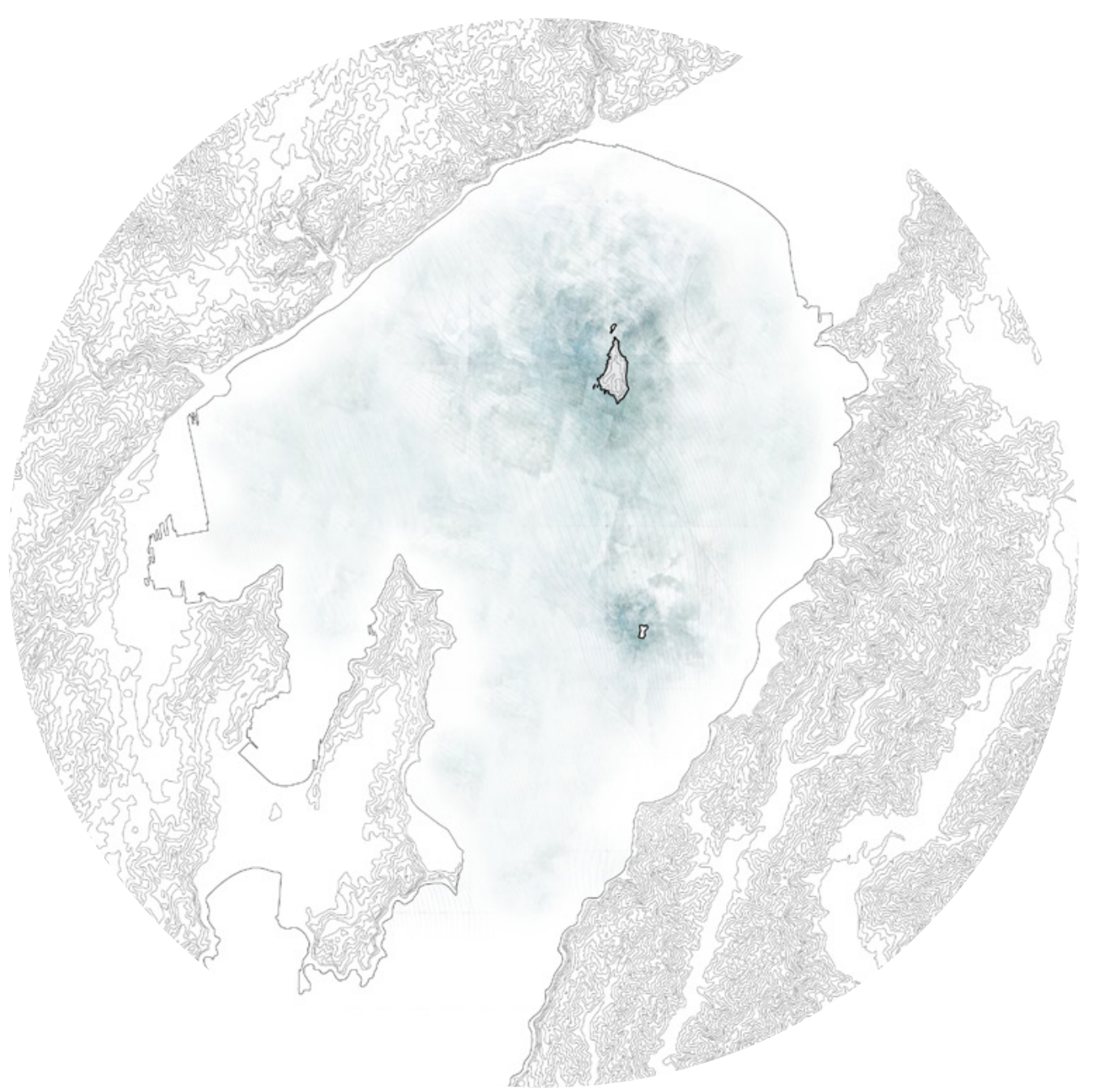

Fig. 2 Map of the three Wellington Harbour Islands

\section{PREFACE}

THE THREE M'S

Matiu, Makaro and Mokopuna are Wellington's harbour islands. Until recently these islands have been off-limits to the public as the Crown utilised them for a range of private purposes, including a human quarantine, wartime internment camp, military defence and animal quarantine station. (Board 2012) Prior to this, Māori tribes had occupied the islands for centuries, establishing Pā sites for defence and communication.(Walton, 2001)

The Iwi of the Islands believe that "harbour Islands should be a living base to revive Māori culture and tikanga, a central hub for the expression of cultural identity to ensure the survival of our culture, language and tikanga for future generations"(Board, 2012,P. 11). However, due to the ownership of the islands under the Crown, Iwi have been excluded from any involvement with the Islands for the last 170 years. (O'Neil, 2015) 


\title{
THE ISLES OF IWI
}

\author{
BY \\ CLAUDIA BOYO
}

A thesis

submitted to the Victoria University of Wellington in

fulfilment of the requirements for a Masters of

Landscape Architecture

Victoria University of Wellington

2021 


\section{ACKNOWLEDGEMENTS}

Firstly I would like to acknowledge my parents for their undivided support, kindness and encouragement. I am so grateful for your enthusiasm and your faith in me.

To Bruno Marques, my supervisor. Thank you for helping me find my passion within the landscape architecture realm, you are truly one of the most dedicated and inspiring teachers I have ever met. What you have taught me will stay with me my entire career and I cannot thank you enough.

To my university friends, thank you for making my time at university so memorable. I have never met a more fun, supportive and crazy group of people, you always managed to lift my spirits, even on the most stressful hand in days.

Lastly, to all my work colleagues that I have had the pleasure of working with throughout my time at university. It was an honour to have received guidance from some of the most creative and inspiring people in the industry. 


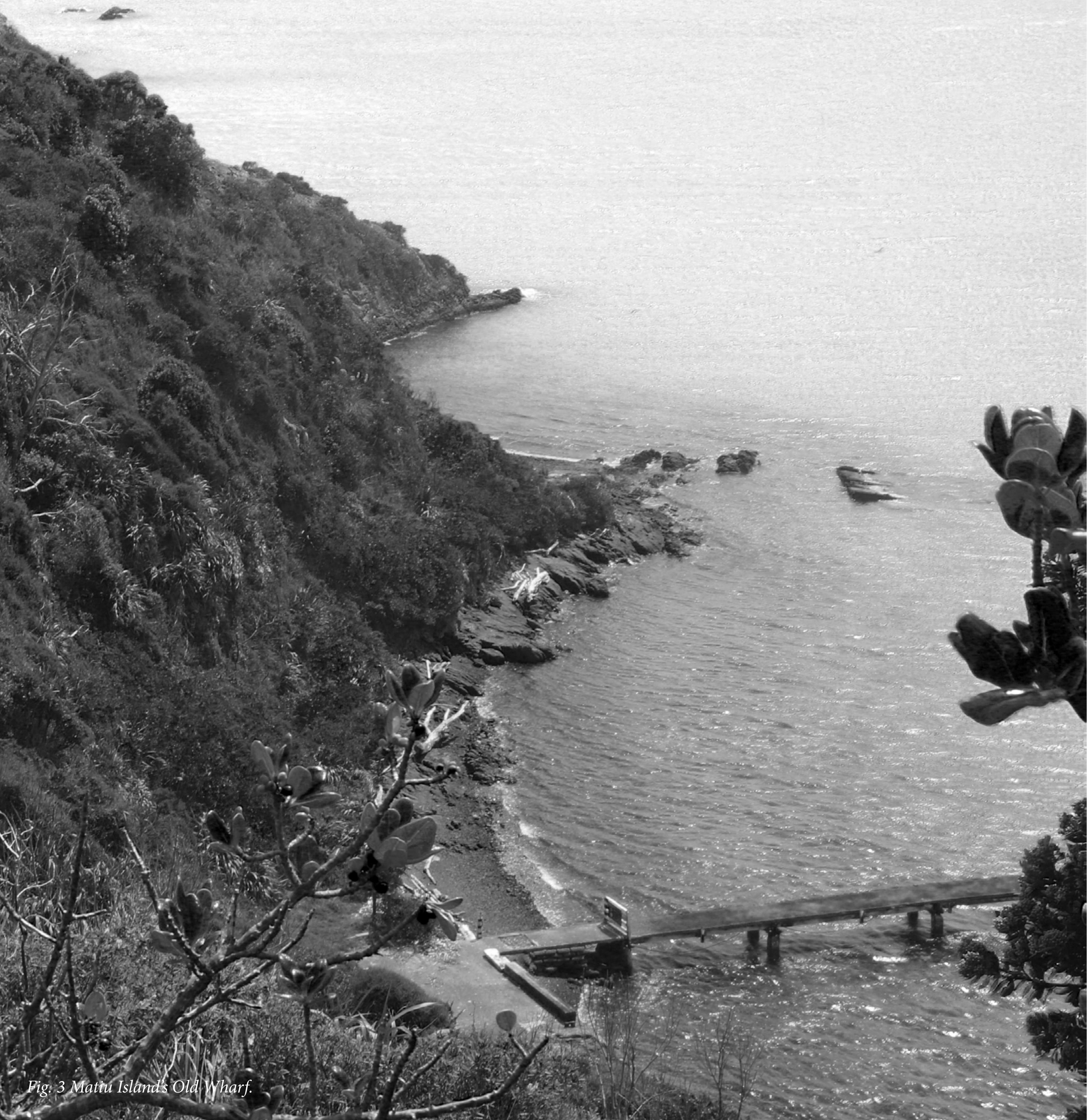




\section{ABSTRACT}

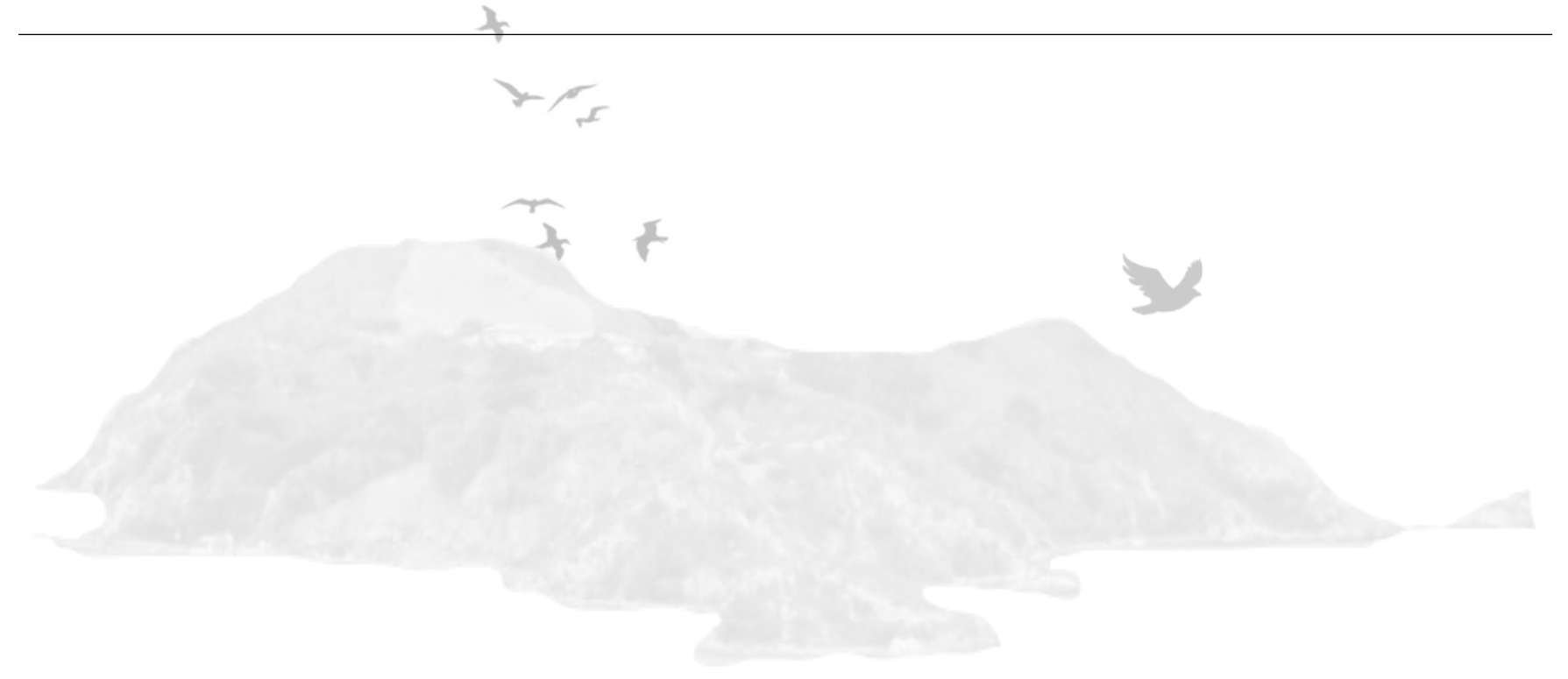

Many offshore islands in Aotearoa New Zealand are currently caught in their colonial past by housing non-native flora and fauna species, irrelevant buildings and fail to reference their cultural past. However, due to their close proximity to the mainland, rich native ecosystems and extensive history, offshore islands have the immediate potential to become valuable spaces that present a unique opportunity for users to become immersed in Aotearoa New Zealand's native biodiversity and bicultural landscape. Matiu, Makaro, and Mokopuna are Pōneke Wellington's harbour islands in the capital city of Aotearoa New Zealand. For centuries, indigenous Māori tribes occupied Matiu Island, establishing Pā sites and using them for defence and communication. However, for the past 170 years; iwi have been excluded from involvement with these Islands.

Islands in indigenous Māori culture are closely associated with narratives of long waka voyages, star navigation, Kaimoana and the establishment of Pā's, a base for Māori traditions and way of life. Therefore, many of these islands are of great cultural and historical significance to Māori, but many of these narratives and events have been forgotten or overshadowed by the later European influences.

Set upon Matiu Island, the design aims to transform Wellington's largest harbour island into a cultural and educational node comprised of journeys and culturally focused destinations that are influenced by narratives significant to Iwi. This design-led research explores solutions that unite Māori and the local community, through a diverse range of spaces that enable Matiu Island to become an integral part of Pōneke Wellington's culture and identity. The design solutions explore the development of the site's entrance, the founding of a marae and a range of spaces for traditional practices to take place which are tied together with connecting pathways that speak of the islands significant narratives. Studying the pre-colonised state of the island and its time as a Pà will provide cultural clues into how the island can embrace and convey its mauri, creating a cultural experience that aims to educate and inspire. 


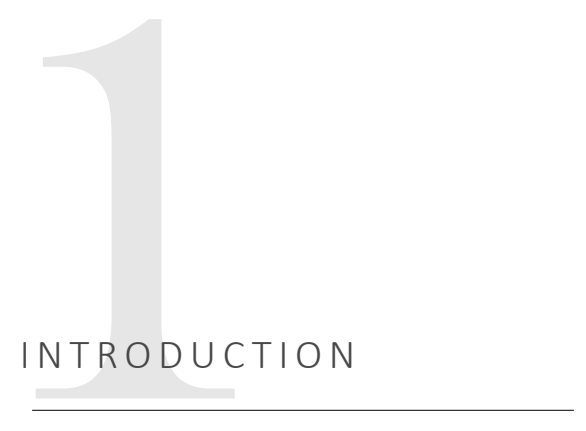

1.1 The Problem

1.2 Scope

1.3 Intention

1.4 Research Methodology

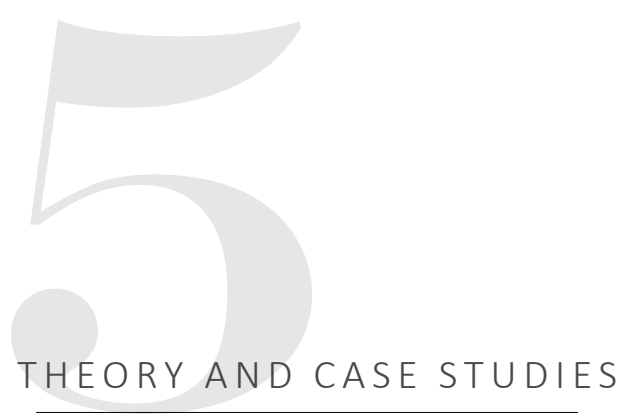

5.1 Introduction

5.2 Co-governance

5.3 Common Motivations

5.4 Culture

5.5 The Importance of Identity

5.6 Aotearoa New Zealand's Identity

5.7 Indigenous Narratives

5.8 Mātauranga Māori

5.9 Environmental Sustainability

5.10 Rongoā

5.11 Te Aranga Principles

5.12 Theory and Case Study Findings

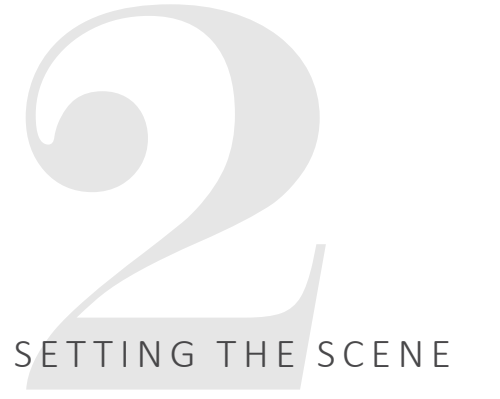

2.1 European Settlement

10

2.2 The Treaty of Waitangi 11

2.3 Māori Suppression $\quad 12$

2.4 The Treaty of Waitangi Settlements 12

2.5 Biculturalism

2.6 The Department of Conservation

2.7 Offshore Islands, A Change in Ownership

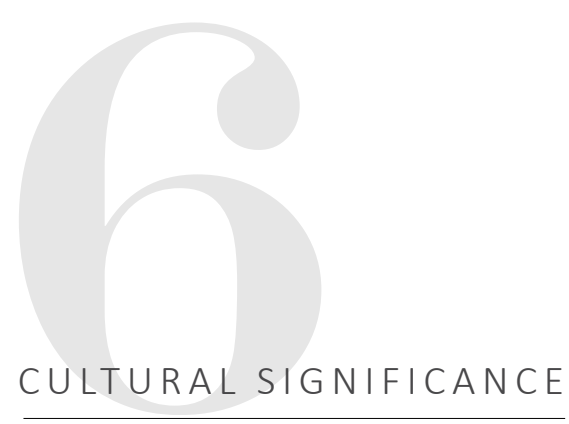

6.1 The Use of Narratives

6.2 Taranaki Whānui's key narratives

6.3 Foundational Waka Narratives

87

54
$55-57$

$58-59$

6.3 The Importance of Waka and Wayfinding

6.4 Narratives of Migration In New Zealand

6.6 Māori In Wellington

6.7 Cultural Significance Findings

96-97

98-99 


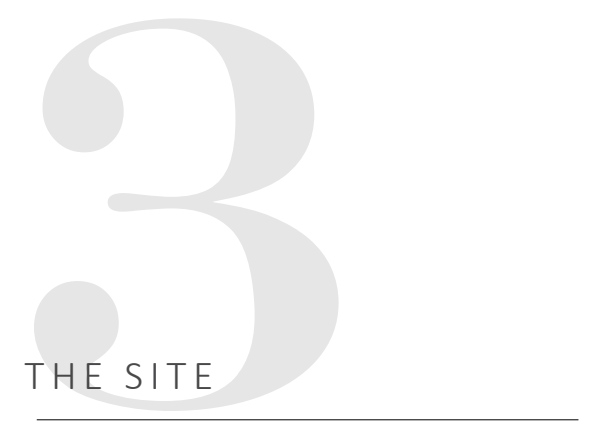

3.1 Islands in the Wellington Region 3.2 Wellington Harbour Islands

3.3 Matiu Island

3.4 The Port Nicholson Block Trust

3.5 The Kaitiaki Board

3.6 Physical Cultural Imbalance

3.7 The Research Question

\section{SITE ANALYSIS}

4.1 Biophysical Analysis 34-35

4.2 A Visual Journey 36-37

4.3 Experiential Moments 38-39

4.4 The Wharf 40-41

4.5 The Quarantine 42-43

4.6 The Peak 44-45

4.7 The Walkways 46-49

4.8 Findings
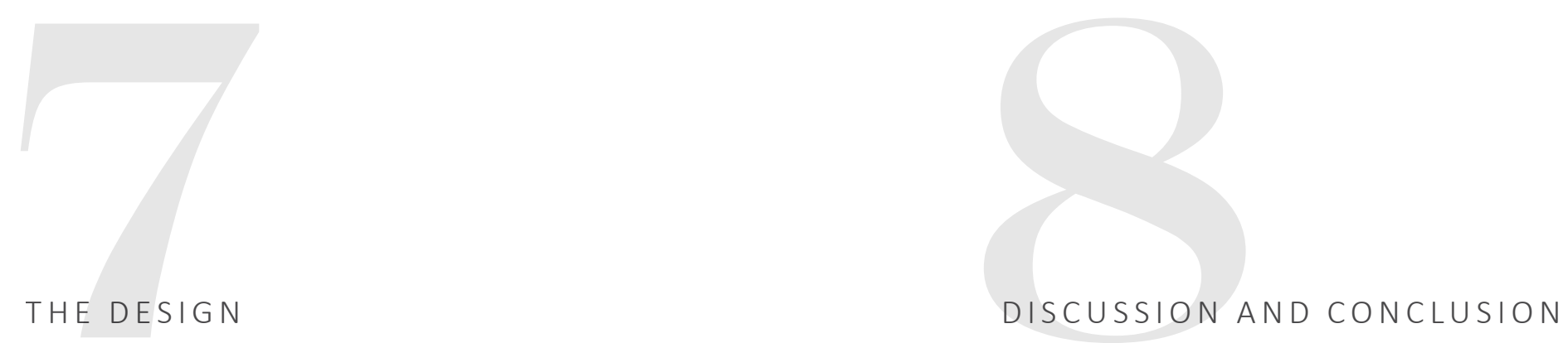

7.1 Project overview

102-103

104-105

7.2 Framework strategy

106-107

7.3 Programmatic strategy

$108-112$

$116-127$

7.5 Site One - The Entrance

$128-141$

142-159

$\begin{array}{ll}7.8 \text { Site Four - The Peak } & 160-173 \\ 7.9 \text { Detailed Design } & 175-181\end{array}$

ISCUSSION AND CONCLUSION

8.1 Conclusion

$185-188$

REFERENCE

9.1 Glossary

192-193

9.2 Bibliography

194-199

9.3 List of Figures

199 



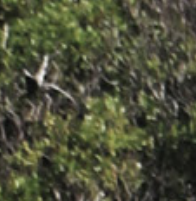
So.
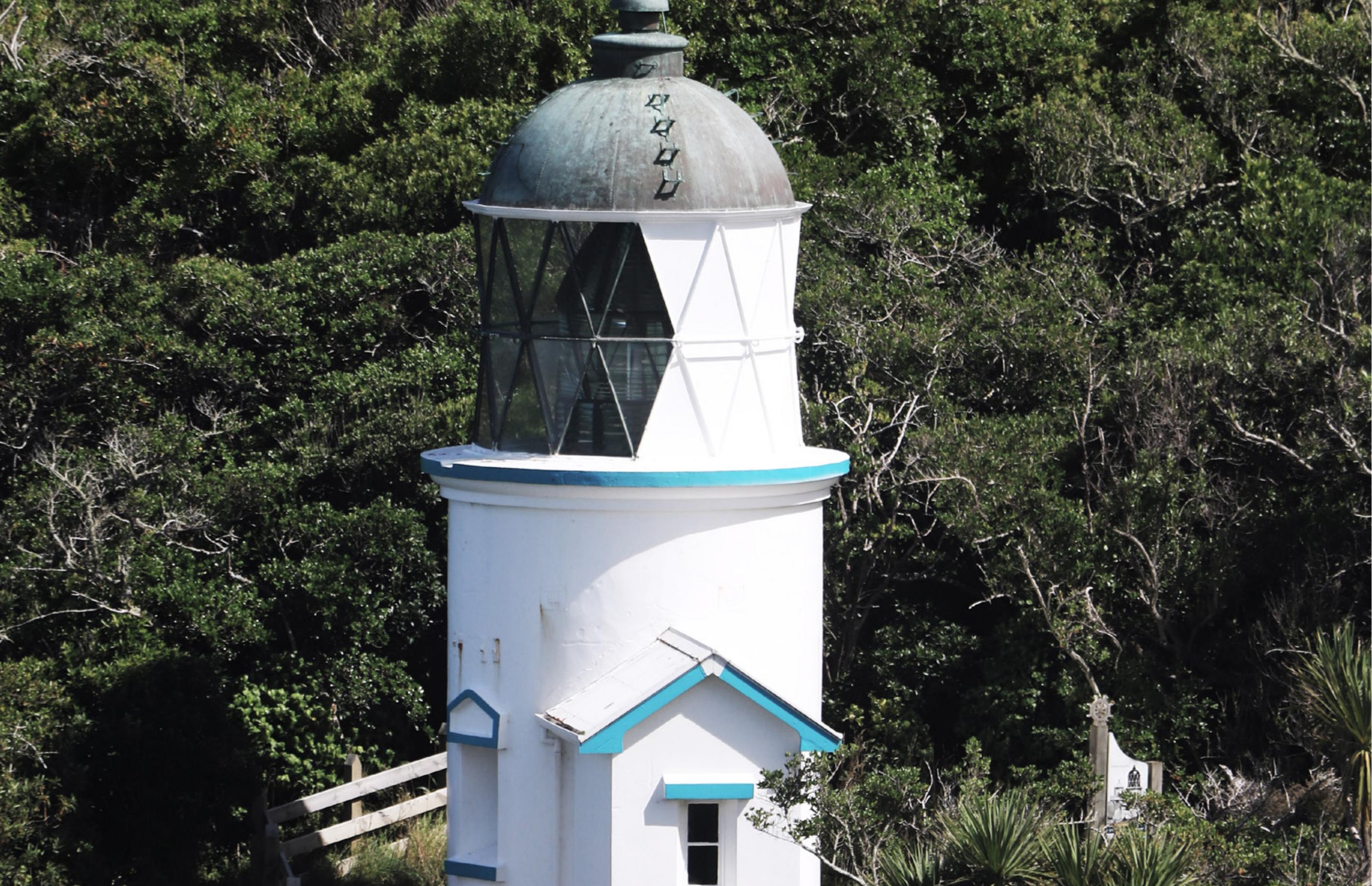

14the
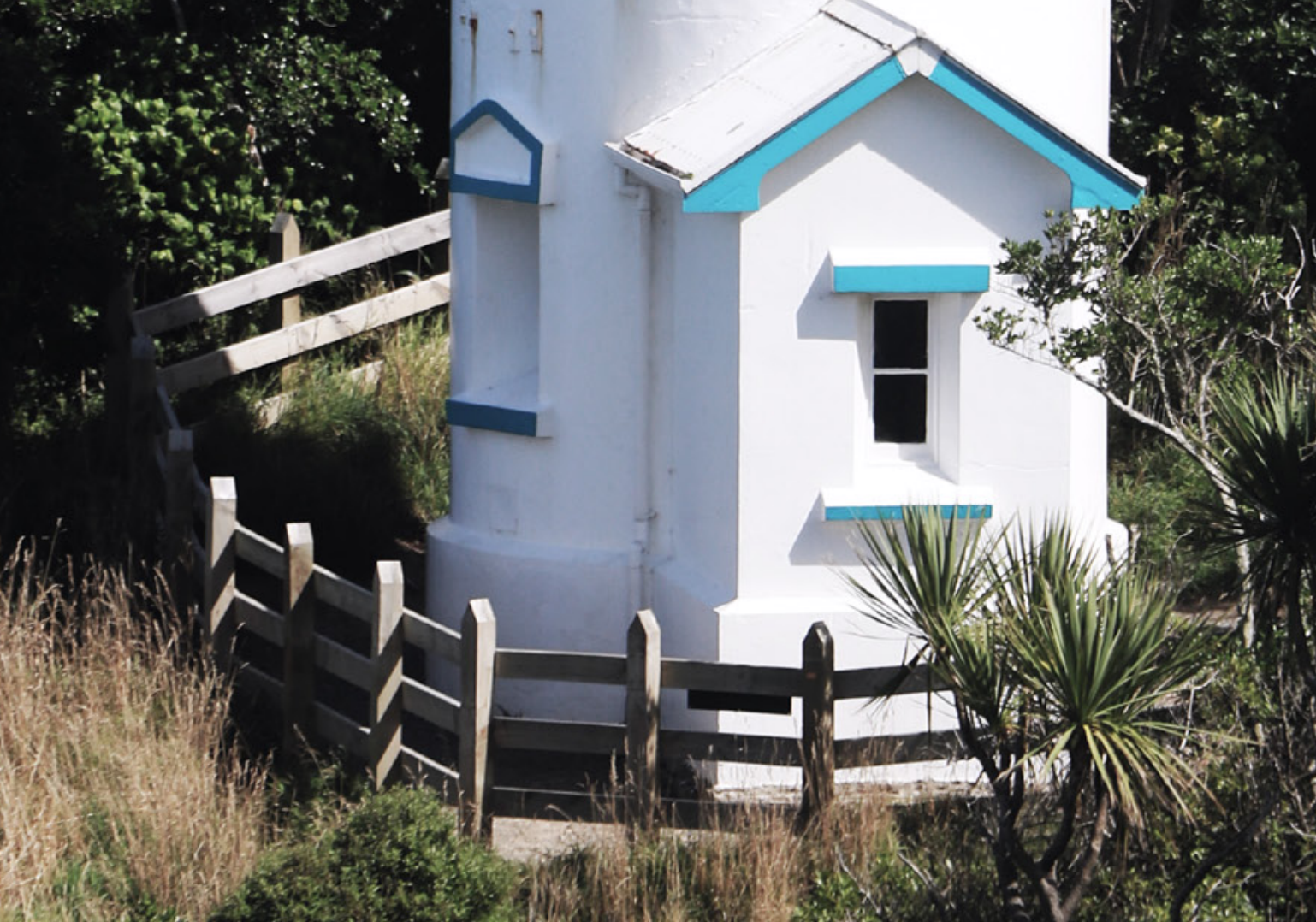

$\frac{1}{7}+1$

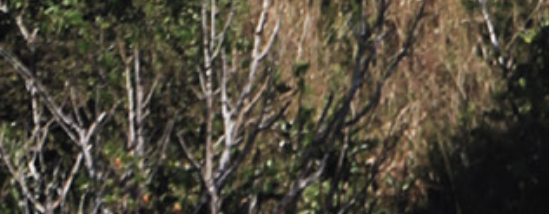

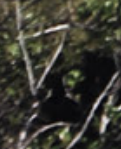




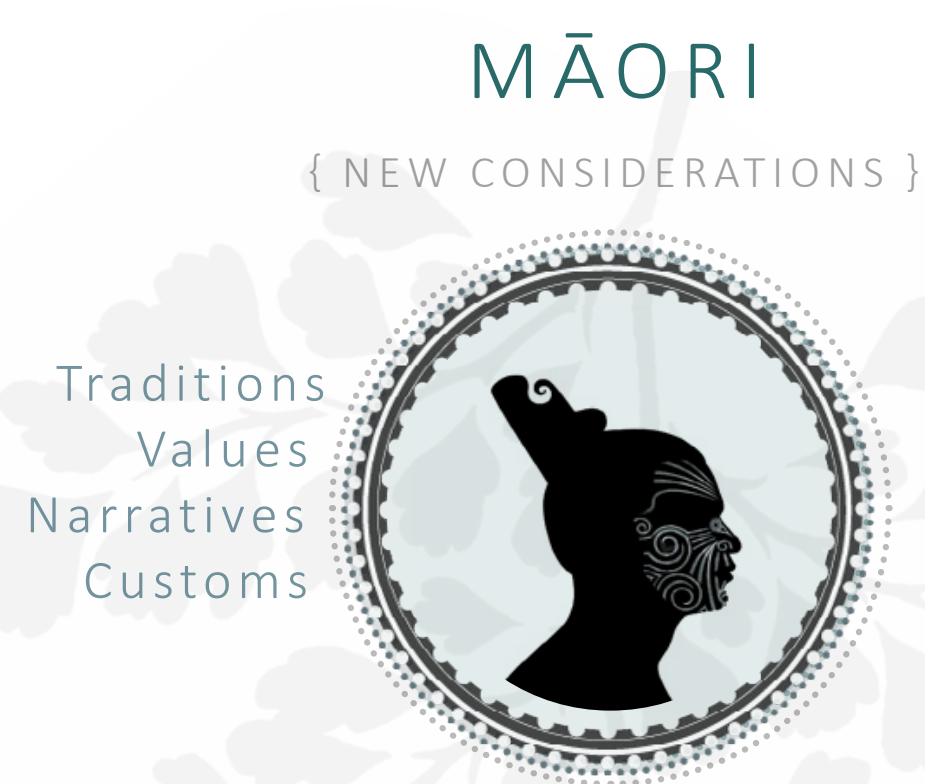

CURRENT INFLUENCERS

CURRENT INFLUENCERS

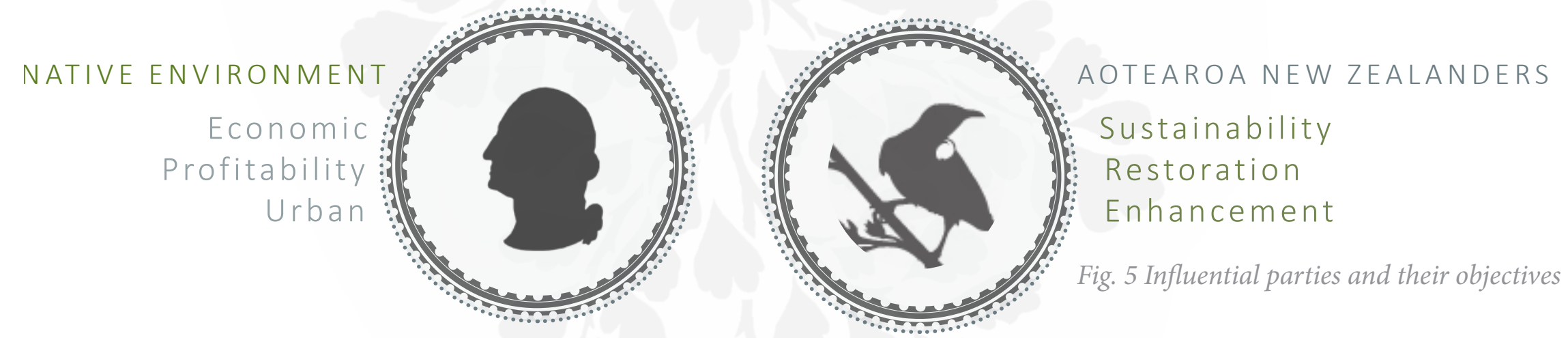




\subsection{THE PROBLEM}

Many offshore islands in Aotearoa New Zealand are owned by the Government and managed by the Department of Conservation (DOC), but with the Waitangi Settlement Act reinstating part or full ownership of these islands to Māori, many islands are now being "managed under public-private partnerships, as traditional Māori land and as freehold private land" (Clarkson, 2007 p.2). With Māori now involved in the planning, management and future utilisation of these islands, there is a"rise in over arching issues of land tenure, responsible agencies and appropriate land management" (Clarkson, 2007, p.3). The co-management of these islands between Iwi groups and DOC is changing their programmatic focus too which "greatly complicates the decision making process because there are a multitude of goals, which unless clearly stated and owned by all parties, can lead to conflict" (Clarkson, 2007, p.3).

Matiu Island, one of three harbour islands in Wellington, is a prime example of an island being managed under a co-management act. The island is owned by local iwi (Taranaki Whānui) who are the mana whenua of the region, but governed by the Harbour Islands Kaitiaki Board, a unique Iwi-Crown partnership model made up of iwi, DOC and local Wellingtonians. Despite Māori being restored as the owners of the land in 2009, little work has been done to address the new cultural and programmatic aspirations for the island that Māori have stipulated in the Island's planning document.

This provides the opportunity to suggest a new method for dealing with the physical and programmatic progression of offshore islands, within Aotearoa New Zealand, using design research to address key issues that arise regarding the development of land that is managed by co-governing bodies. 


\subsection{SCOPE}

This research investigates how offshore islands, managed by co-governing bodies, can be spatially developed to cater for the public and the environment, while also reflecting the motivations and identity of the Iwi who own them. It focuses on Matiu Island, the largest harbour island in Wellington and the only island accessible to the public, as a site to test design explorations.

Matiu Island is an offshore island in the centre of the Wellington harbour. Its once damaged native environment has mostly been restored and the island, which was once off limits to the public, now caters to the visitors by providing a series of nature walks and site seeing opportunities based on the historic European sites on the island. However, the indigenous culture of the island is not expressed within the landscape, leaving the Iwi feeling misrepresented and a key educational opportunity missed.

An offshore island is an isolated parcel of land that is surrounded by water and located off the shore of a mainland. The geographical scope of this research is confined to the land of Matiu Island that is above sea level, which is 25 ha in size.

\subsection{INTENTION}

The role of this experimental design thesis is to find ways to integrate Māori values, customs and traditions (that are significant to the Iwi of the island) alongside the existing and envisioned environmental and social objectives.

The research places a strong emphasis on bringing through the cultural identity of the Iwi and their values and customs as the presence of indigenous culture on the island is currently absent.

It aims to do this by exploring commonalities between Māori culture, contemporary sustainable concepts and the utilisation of public space. Finding ways to integrate Māori ideals, values and desired cultural programmes harmoniously with current conservation efforts and the recreational areas of the site will provide beneficial outcomes for all. 


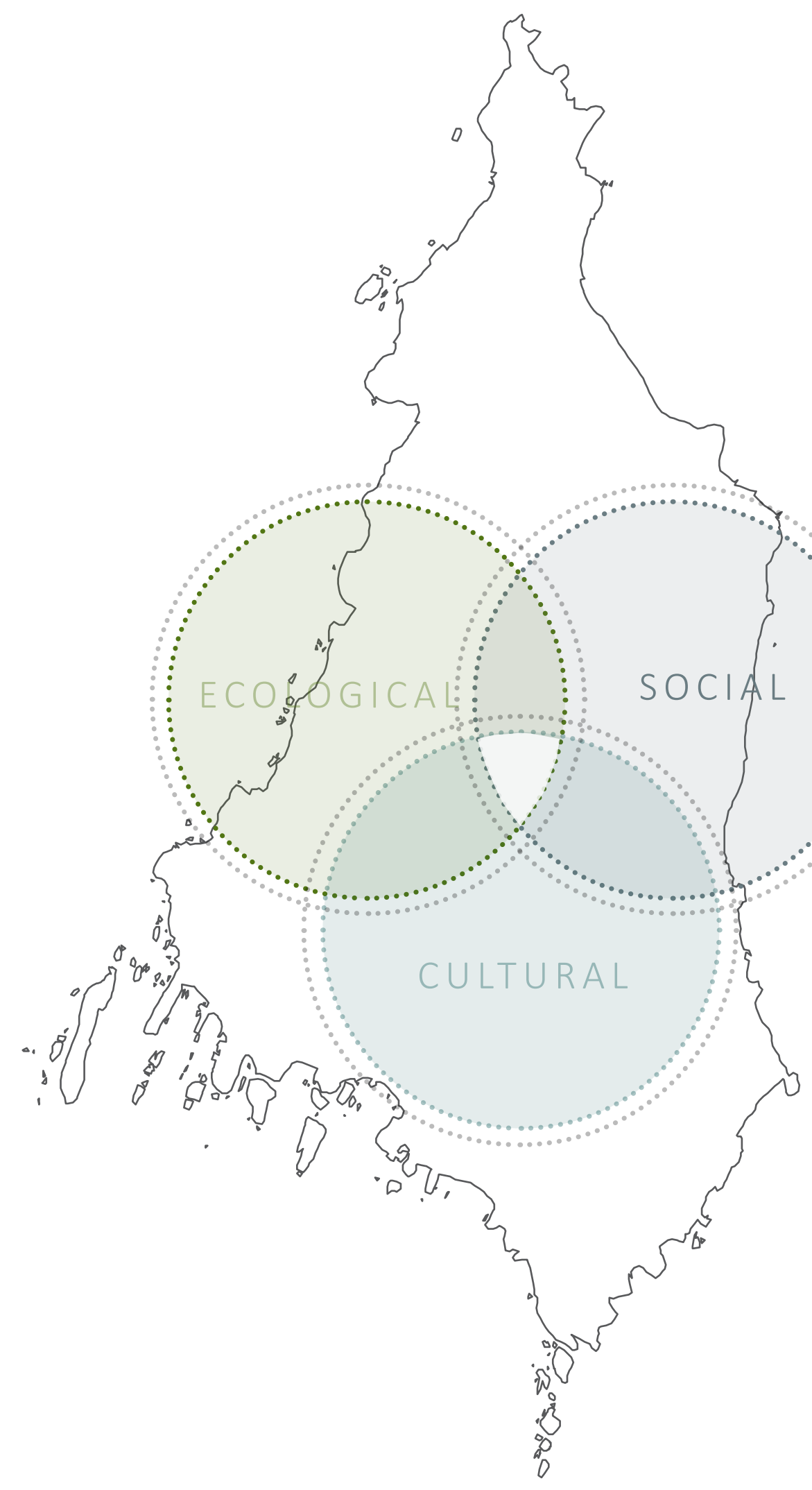

Fig. 6 The three areas of focus for the Island 


\subsection{RESEARCH METHODOLOGY}

With the rising number of parties involved in land development and more specifically the introduction of new aspirations for land owned by Māori, it is becoming increasingly important to approach the urban development of ecologically rich land through a multifaceted lens. The empowerment of communities, professionals and Māori through the establishment of collaborating bodies has the potential to produce land-based decisions that are more attuned, catering more sufficiently to the needs of all involved and affected.

In the past, institutionalised planning processes for land with ecological value had been often one dimensional and disregarded the opinion of indigenous and local people. These processes also discouraged interactions between people and protected ecosystems. Design methodologies and explorations have the capacity to thoroughly investigate and reconceptualise innovative concepts that explore the creation of multifunctional landscape that satisfy the needs of Māori, locals, the existing ecosystem and its associated restoration efforts, "which test and confront the fine-grained cultural, social and ecological processes of urbanisation" (Bryant, 2017, P.2).

This research seeks to address how offshore islands can play a role in the reintegration of Māori Culture within Aotearoa New Zealand, using design exploration as a medium to do so successfully.

\section{DISCOVERING:}

A site responsive design interwoven with participatory design will be the foundation for this design process. Gaining a mixture of experiential and factual information from the outset is essential in ensuring the development of appropriate and multifaceted spaces that respect the integrity of the land and its associated ecosystems.

Conducting a range of site visits in different conditions is important to establish which spaces are important, how they function and are utilised, the quality of these spaces, key access routes and the ecology within them. This will provide important insight into the essence of each of these spaces and the island as a whole. These site visits are followed up with a comprehensive research investigation to fill in any gaps of knowledge regarding the physical or historical nature of the site, that the visit alone could not provide. This will immediately highlight the strengths, weaknesses, opportunities and threats of the island.

The participatory approach comes directly after the first few site visits and the initial research has been completed. Its role is to provide insight into the intangible layers of the site that cannot be discovered through experience alone. 
This will include narratives, memories, historical events and milestones. The process will rely heavily on consultation and interaction with Iwi. This mixture of tangible and intangible information will create an initial design hunch that aims to improve the threats and weakness of the site and build upon the strengths and opportunities.

\section{DISCOVERING + PRODUCING:}

From here, the process is no longer linear. The landscape, and consultation with the people that use it, provides information that informs a series of initial design responses in the form of iterative concepts at a range of different scales. These concepts will uncover issues or knowledge that is missing, creating a cyclical process where the research feeds the design and the development of the design relies on further research.

Researching Māori practices, traditions, narratives and design within Pōneke Wellington and the pre-colonised state of the island will provide cultural clues into how the island can become a cultural base for Māori and an educational and recreational tool for the wider community. Mātauranga Māori will provide anyone involved in the design process with an understanding of Māori values while frameworks such as the Te Aranga principles will provide designers with a way to successfully engage and work alongside iwi throughout the design process to produce a culturally and ecologically sensitive design that caters to all the parties involved.

These research avenues and frameworks will influence the development of these iterative, preliminary concepts which will be tested through diagrams, mapping, plans, perspectives, sections and iterative modelling.

\section{PRODUCING:}

These iterations are critically analysed against the design criteria and objectives of the project and a final design is selected, based on its ability to satisfy these objectives and its aesthetic qualities. This design is refined through the development the details of the site. This includes the development of structures, specifying plant species, selecting materials and patterns and the detailing of any important systems within the site. Ultimatley producing a well considered and highly functional design that responds to the 

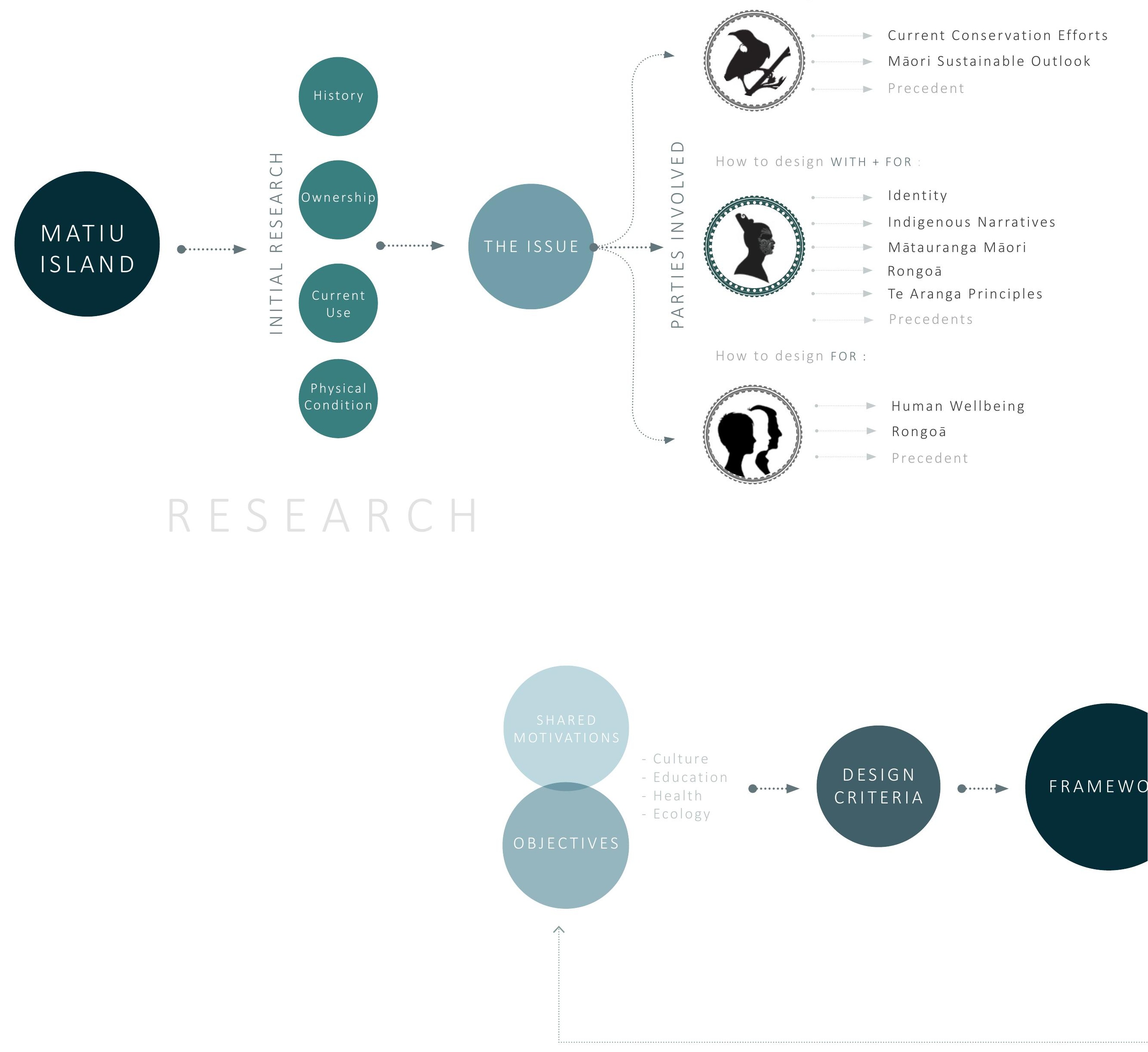

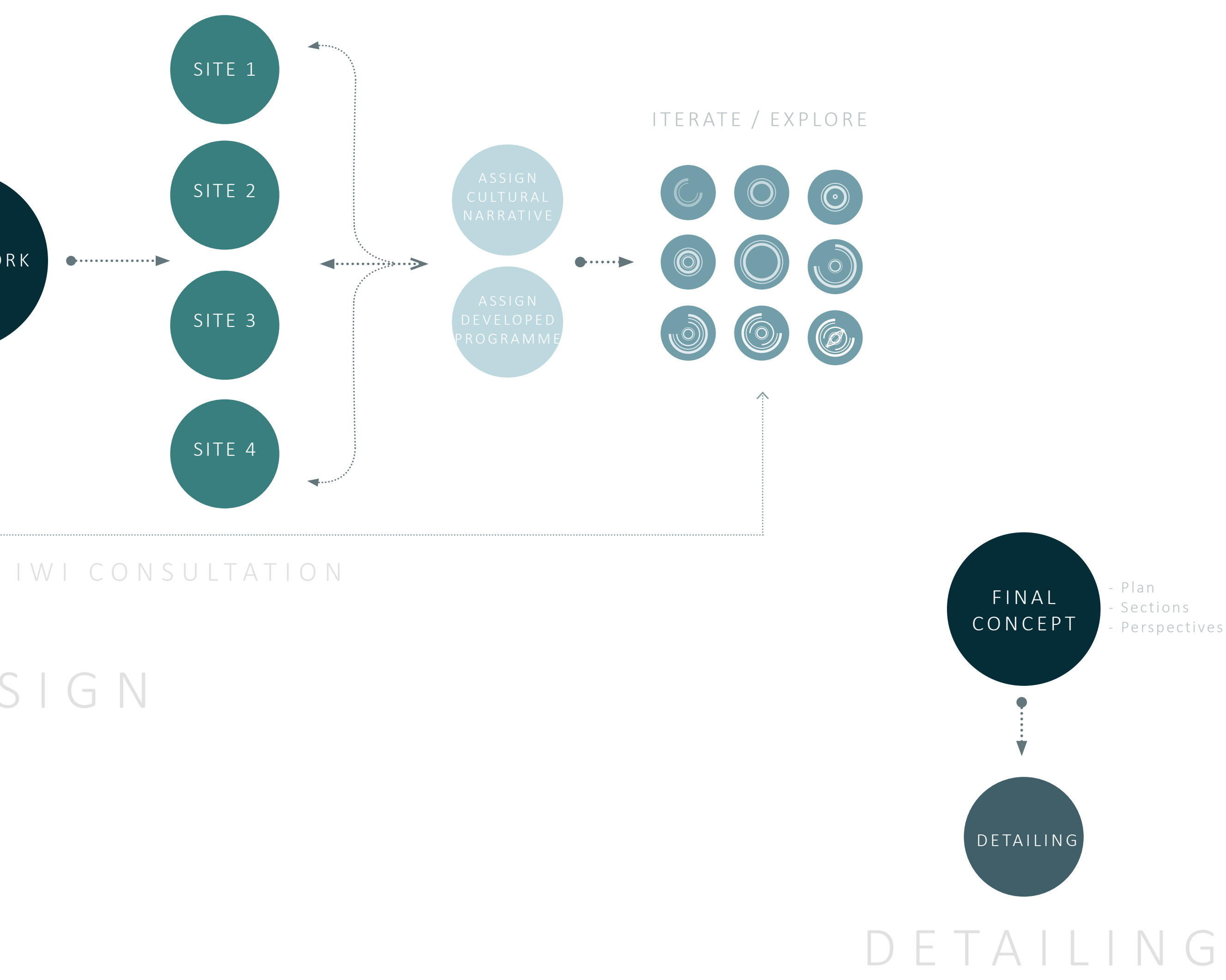

Fig. 7 The design process 



\section{SETTING THE SCENE}

AOTEAROA NEW ZEALAND'S BICULTURAL PAST

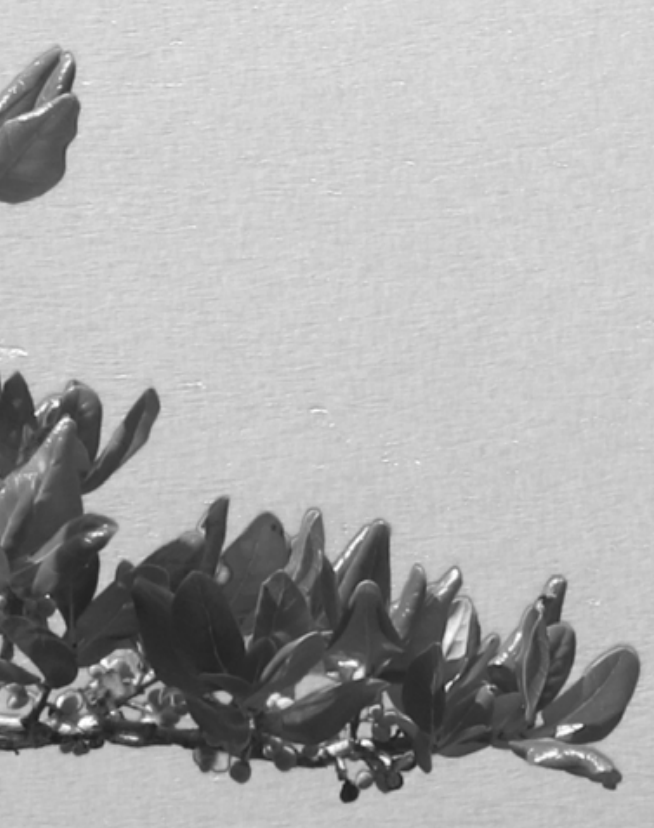

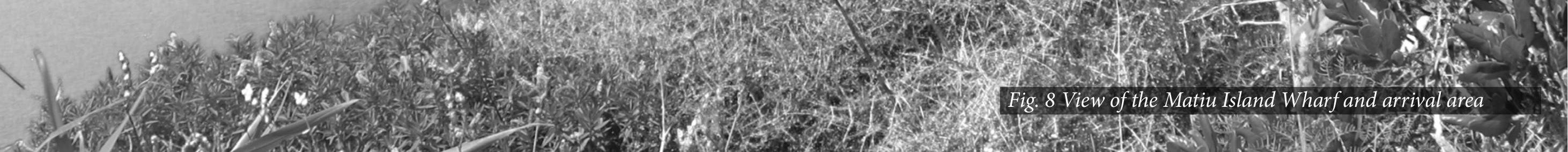

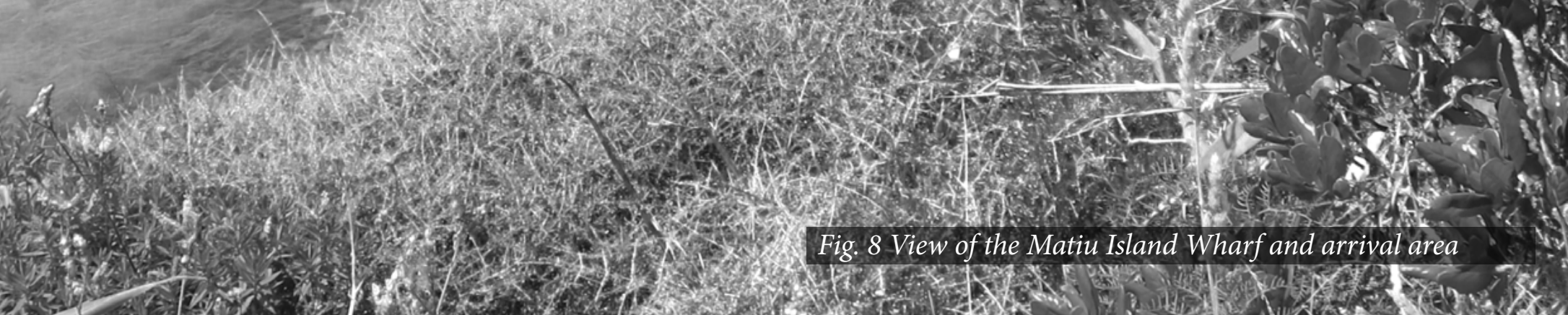




\subsection{EUROPEAN SETTLEMENT}

Aotearoa New Zealand's native environment is an integral part of Māori culture. It has shaped Māori language as well as its customs, values and practises. (University, 2016) However, the settlement of Europeans in Aotearoa New Zealand from 1764 onwards not only saw the integrity of the native environment diminish but Māori's right to owning land.

"Traditional Māori society did not have a concept of absolute ownership of land. Whānau (Extended families) and hapū (sub-tribes) could have different rights to the same piece of land. Exclusive boundaries were rare and rights were constantly being renegotiated"(McAloon, 2008, P.1). This loose, relationship-based way of owning and obtaining land did not fit in with the European land ownership construct. This created tension and conflict when it came to the Europeans desire to purchase or control defined pieces of land.

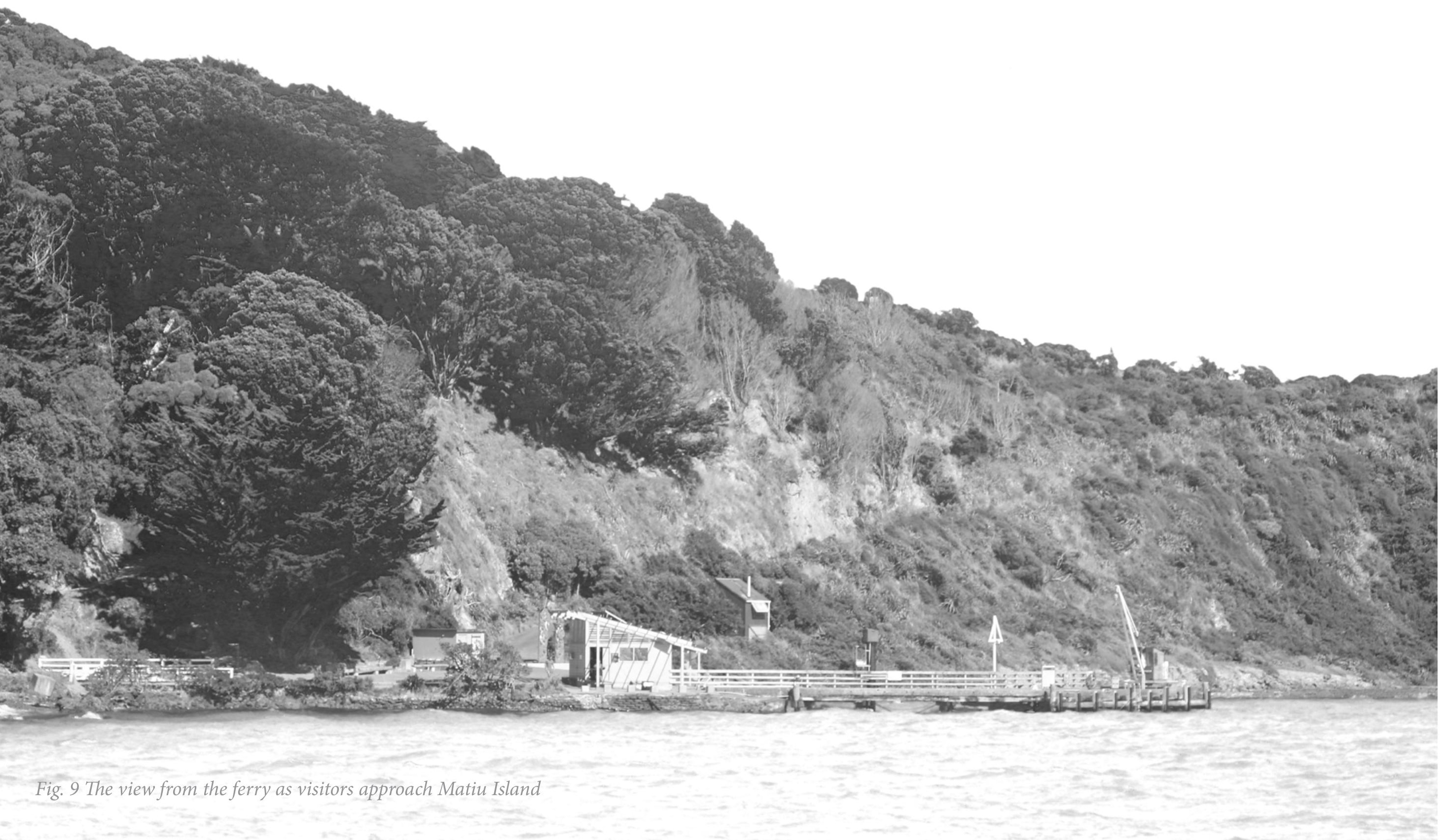




\subsection{THE TREATY OF WAITANGI}

The settlement of Europeans into Māori territory throughout Aotearoa New Zealand created the need for an agreement that resonated with both parties in regards to the attainment and ownership of land. The Treaty of Waitangi was created to recognise Māori ownership of their lands, forests and other possessions, and giving Māori the rights of British Heritage, 2017. The treaty was signed on February 6th in 1840, giving Queen Victoria's Government the right to purchase land. The bilingual document enabled the signing parties, the Māori chiefs and representatives of the British crown, to understand its contents. However, issues began to arise as the meaning of the English text differed from Māori regarding land ownership laws. These issues related to "Māori losing control of the majority of land they had owned in the second half of the 19th century, some through legitimate sale, but often due to unfair land deals or outright seizure" (Heritage, 2017, P. 1). The legitimacy of the treaty was undermined and therefore mostly ignored, causing even more land to be acquired unjustly. (Heritage, 2017)

Around two-thirds of Aotearoa New Zealand's land area was "purchased" from Māori by the crown. The head of the Native Land Purchase Office, Donald McLean, persuaded many chiefs to sell land to the Government at low prices by arguing that Māori would gain economic advantage from British settlement. Māori who sold land to the Government usually did so on the basis that they would retain certain areas where the people could continue to live, however these deeds were not always clear as to the size and location of these reserves, and many turned out to be very small, inaccessible, and insufficient to support local Māori (Boast, 2015). 


\subsection{MĀORI SUPPRESSION}

"Māori, As individuals and communities, were the subject of racism and discrimination as Europeans settled in Aotearoa New Zealand in this time period"(Spoonley, 2011, P. 1). Negative societal values and attitudes were connected with Māori language and the practising of cultural traditions and this heavily impacted the Aotearoa New Zealand education system and the home environment. As a result, English became the dominant language in Aotearoa New Zealand and as many Māori came to see English as the language of success, achievement and advancement (Keane, 2018). Laws were also passed to suppress the presence of Māori culture and their traditions in society. The discrimination and suppression of Māori culture meant that Māori were unfairly treated and robbed of their authority and ownership regarding land, contributing to Aotearoa New Zealand's diminishing physical and cultural identity.

\subsection{THE TREATY OF WAITANGI SETTLEMENTS:}

In the 1950's, Māori began to use the Treaty as evidence to try and regain control over lost land. The New Zealand Government acknowledged these arguments, giving the Treaty an increasingly central role in the interpretation of land rights and relations between Māori people and the state. (Heritage, 2017) The Waitangi Tribunal was established in 1975 as a permanent commission of inquiry, where the tribunal member's role was to interpret the treaty and research claimed breaches by the British Crown and its representatives. The Tribunal then sought to provide the associated tribes of the breach with compensation for the Crowns wrong doing. The Government also acknowledged the damage inflicted upon a large portion of culturally significant land and began to address this issues as well.

\subsection{BICULTURALISM}

The Governments acknowledgment of wrong doing and the reinstatement of Māori as a fundamental part of Aotearoa New Zealand and its identity gave rise to the biculturalism era in Aotearoa New Zealand. This reinforced that Māori culture and the native environment are two of the only factors that give Aotearoa New Zealand a unique sense of identity. The commercial, financial and culture redress of treaty claims was only the start of the Bicultural shift. 

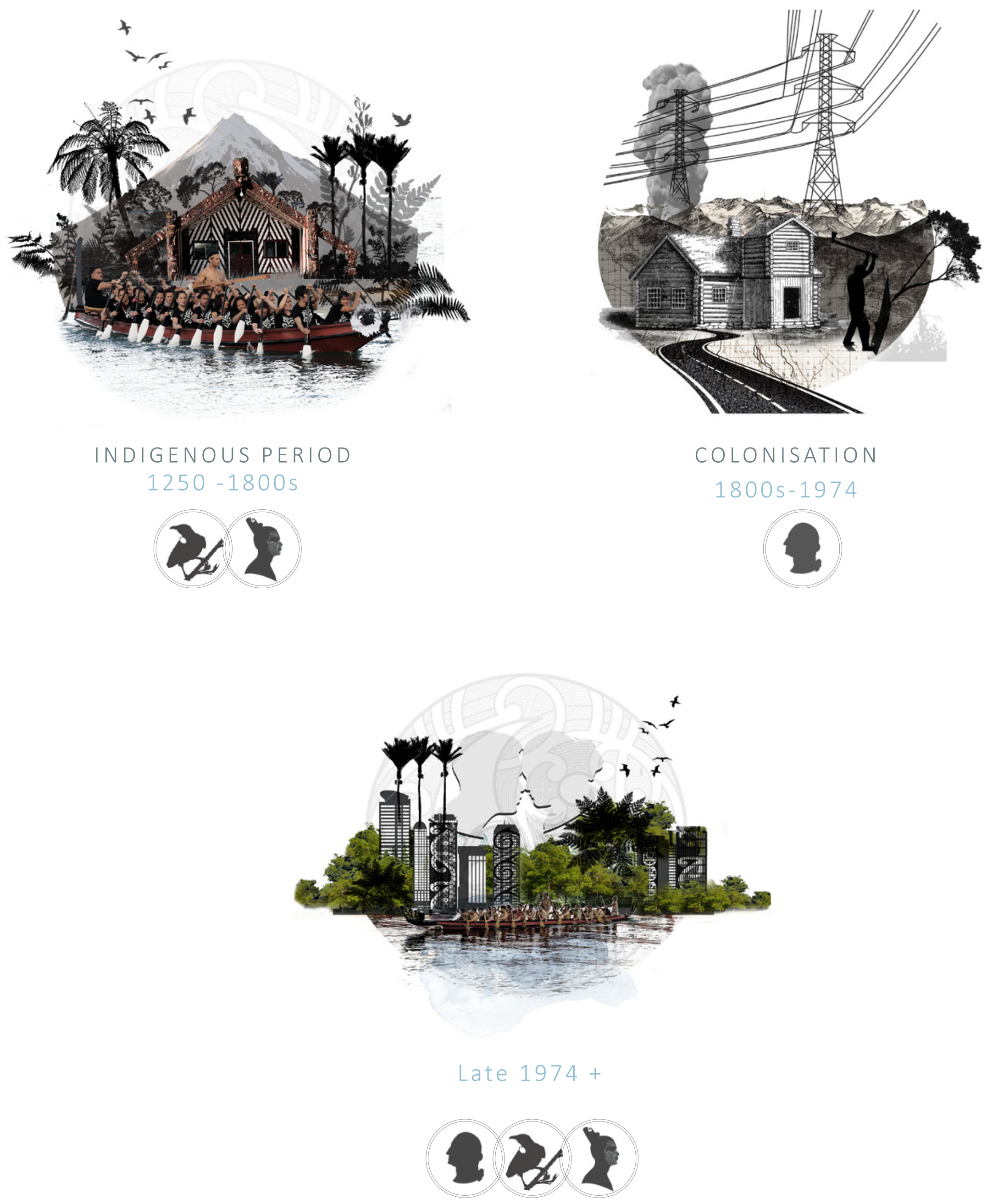

Fig. 10 New Zealand's cultural Profession over the centuries

$\{13\}$ 


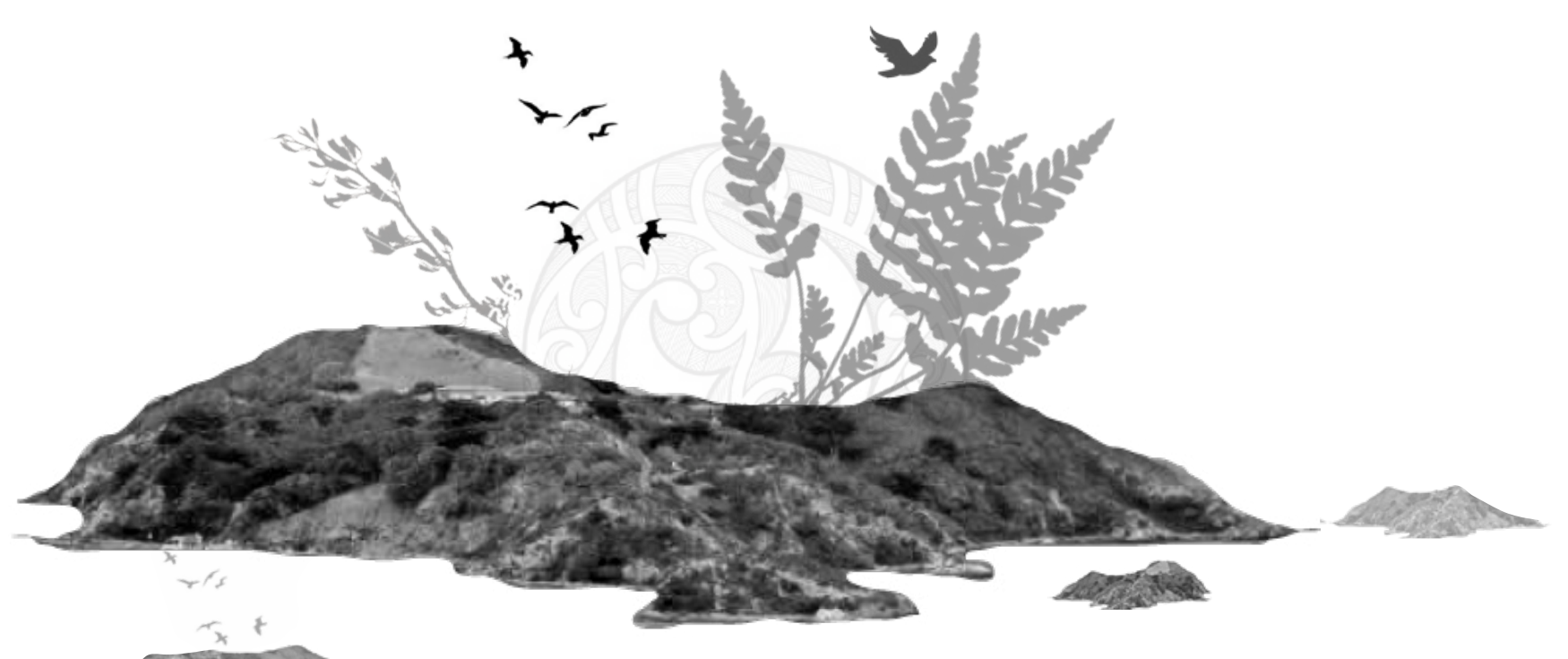

Fig. 11 Matiu Island Collage

The colonisation of Aotearoa New Zealand in the mid 1800's saw the beginning of an era that exploited the environment rather than working with it. The arrival of Europeans in Aotearoa New Zealand led to the harvesting of native species, some beyond recuperation, and the introduction of invasive species. "The effects of predators and human modification was described as one of the worst tragedies to befall on any island archipelago"(David R Towns, 2009, P.2). Now in the twenty first century, cities and towns continue to expand and densify, leaving less space for natural ecosystems to function accordingly, hindering the effectiveness of vital ecosystem services.

The Department of Conservation (DOC) was founded as the Aotearoa New Zealand Governments answer to the degradation of Aotearoa New Zealand's native and historical environments. DOC is "the Government agency that is charged with conserving Aotearoa New Zealand's natural and historic heritage" (Conservation, 2018, P.1). Their founding principles work to protect, manage, restore and enhance the native environment, whilst supporting and encouraging recreational use of public parks and reserves for the purpose of education around the native environment and the work they do. (Conservation, 2018)

One of DOCs key focuses quickly became restoring Aotearoa New Zealand's offshore islands. (Clarkson, 2007) These small masses of land with fragile ecosystems were heavily impacted by the arrival of the Europeans and quickly became unbalanced due to pests such as wild cattle, pigs, goats and cats, rats and gorse (Conservation, 2018). However, these offshore islands also presented an exciting opportunity. DOC declared that as part of their mission to conserve Aotearoa New Zealand's natural and historical heritage they would utilise offshore Islands as an opportunity to create safe zones for native species to recuperate and thrive before they are reintroduced onto the mainland (Clarkson, 2007). 


\subsection{OFFSHORE ISLANDS}

Offshore islands were identified as a key resource for the restoration of Aotearoa New Zealand's native environment due to their geographical location and topographical nature, limiting physical access to the land. This allowed DOC to create a controllable environment with the ability to reduce or stop interactions between the native wildlife, invasive species and humans. DOC focused their efforts on creating native island reserves, transforming around 220 of Aotearoa New Zealand's 770 islands into nature reserves, with at least 70 of these free of all introduced mammals (Clarkson, 2007). It is for this reason that islands across Aotearoa New Zealand have been primarily developed to "maximise ecological integrity through ecological restoration and the management of iconic species" (Clarkson, 2007 P. 2).

220

PRISTINE

OFFSHORE

ISLANDS

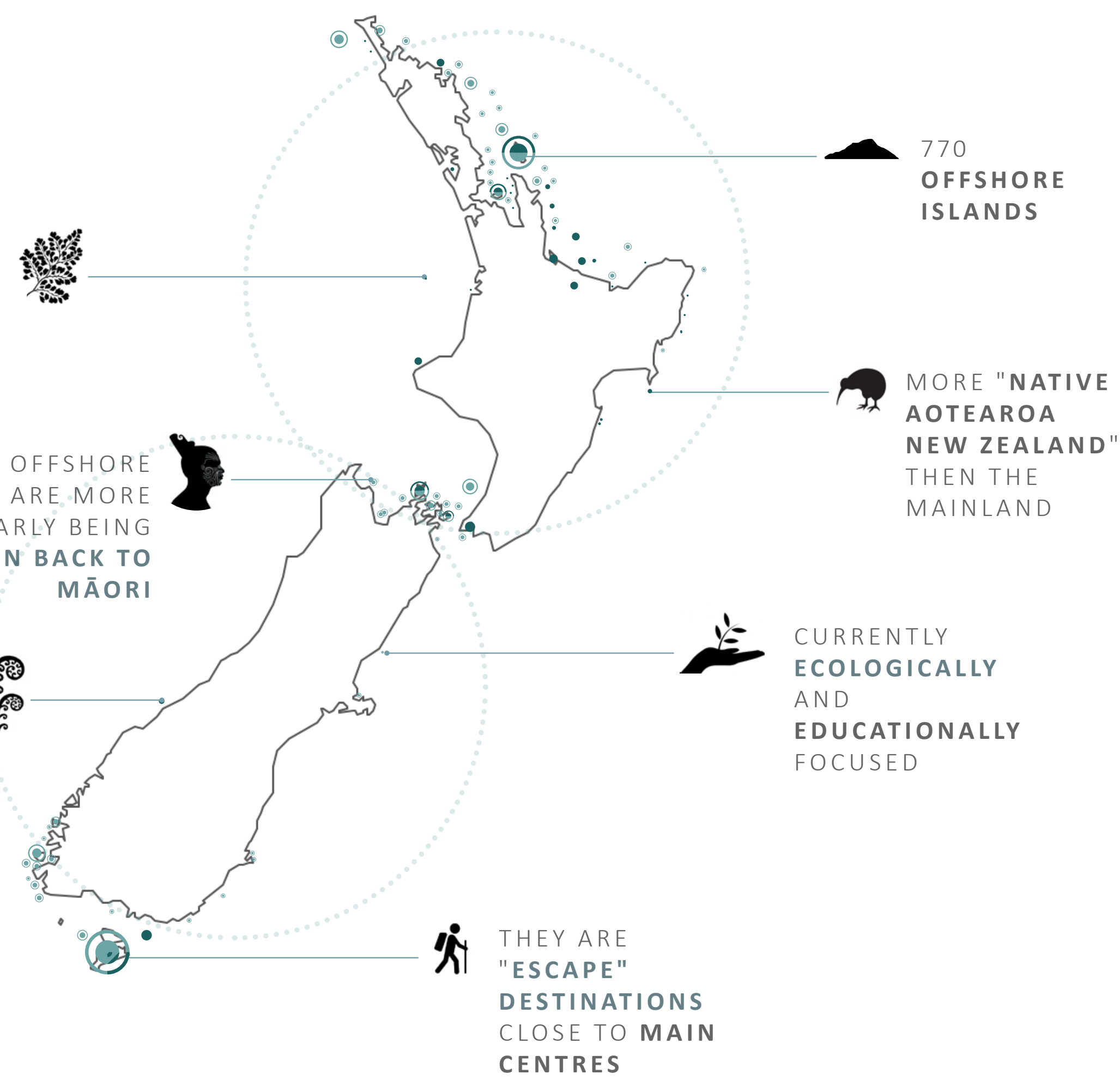

Fig. 12 Aotearoa New Zealand's Offshore Islands and their uses 



\section{THE SITE}

MATIU ISLAND
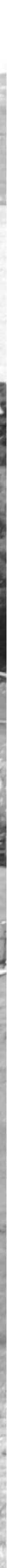



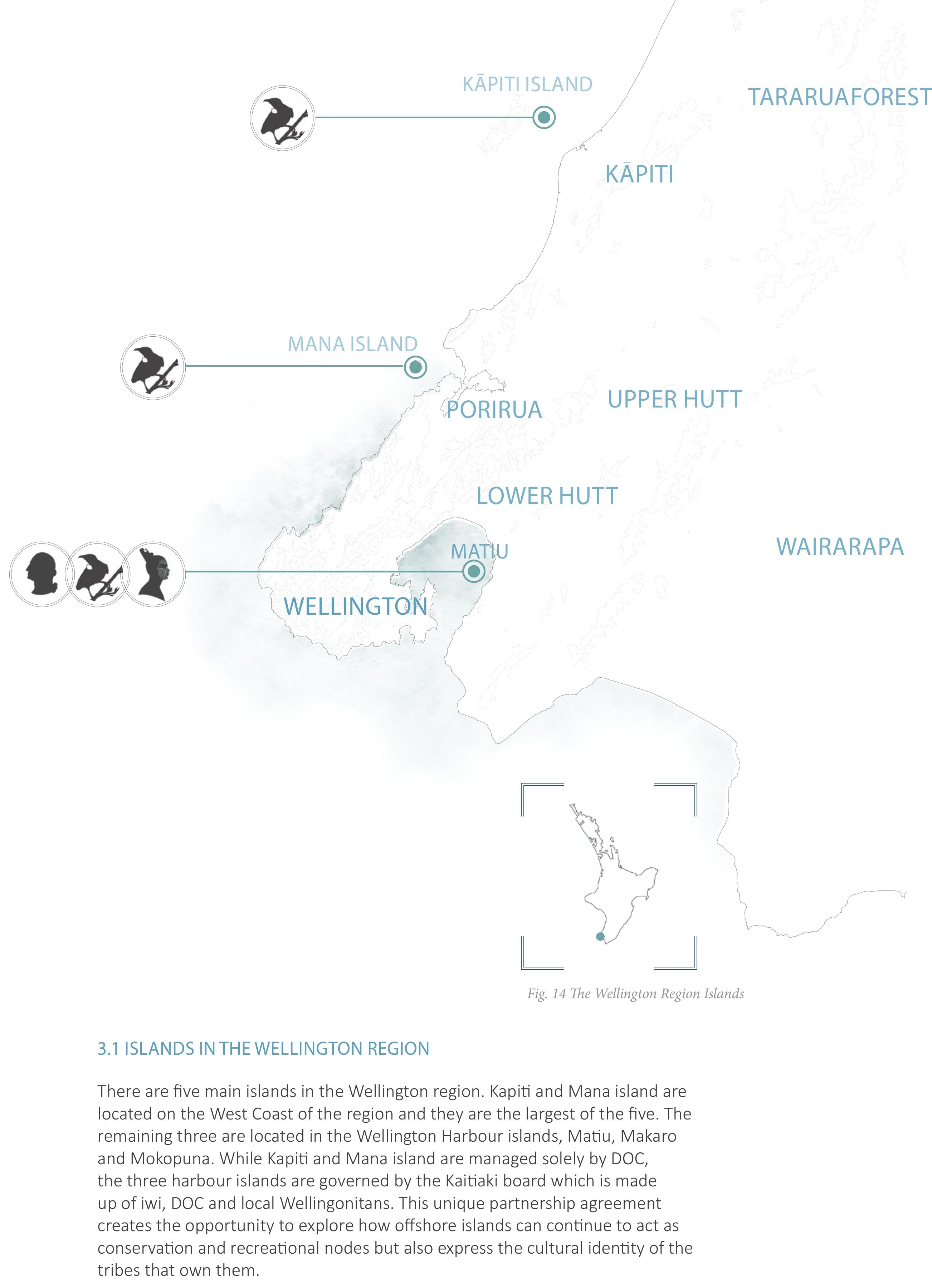




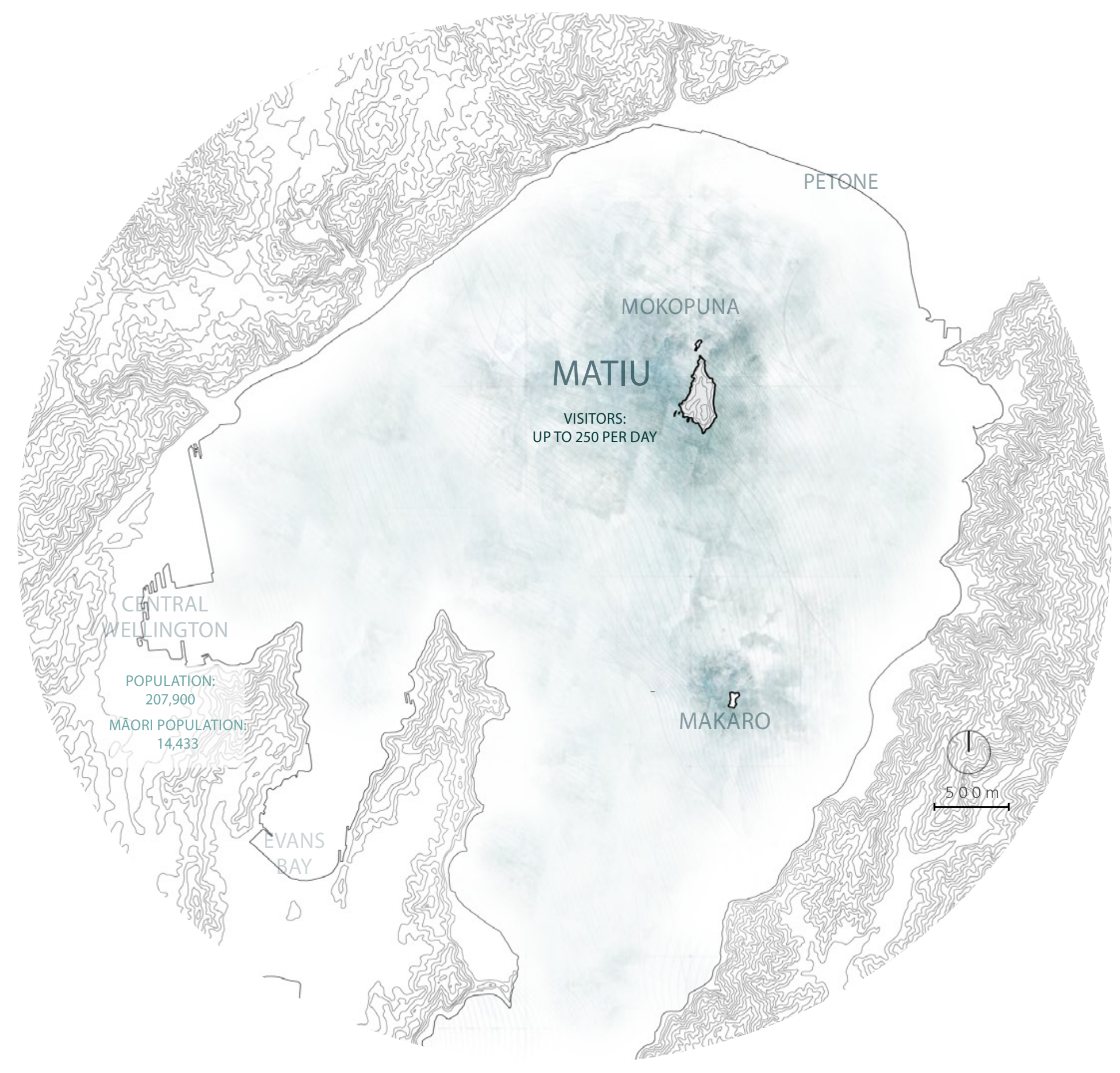

\subsection{THE WELLINGTON HARBOUR ISLANDS}

Matiu, Makaro and Mokopuna are Wellington's harbour islands. They are an important feature of the region as they are visible from almost any angle of the harbour, they have a rich, bicultural history and they are home to hundreds of native species.

Until recently, these islands have been off-limits to the public as the Crown utilised them for a range of private purposes including a human quarantine, wartime internment camp, military defence and animal quarantine station. (Board 2012) Prior to this, Māori tribes had occupied the islands for centuries, establishing Pā sites for defence and communication.(Walton, 2001)

Matiu Island is the only island of the three that is accessible to the public, making it the most well-known and an important historical and educational node in Wellington. It is easily accessible as it is located 20 minutes (by boat) from the capital city of Aotearoa New Zealand and it also acts as an ecological refuge for native wildlife and flora.

Fig. 15 The Wellington Region and Harbour Islands 


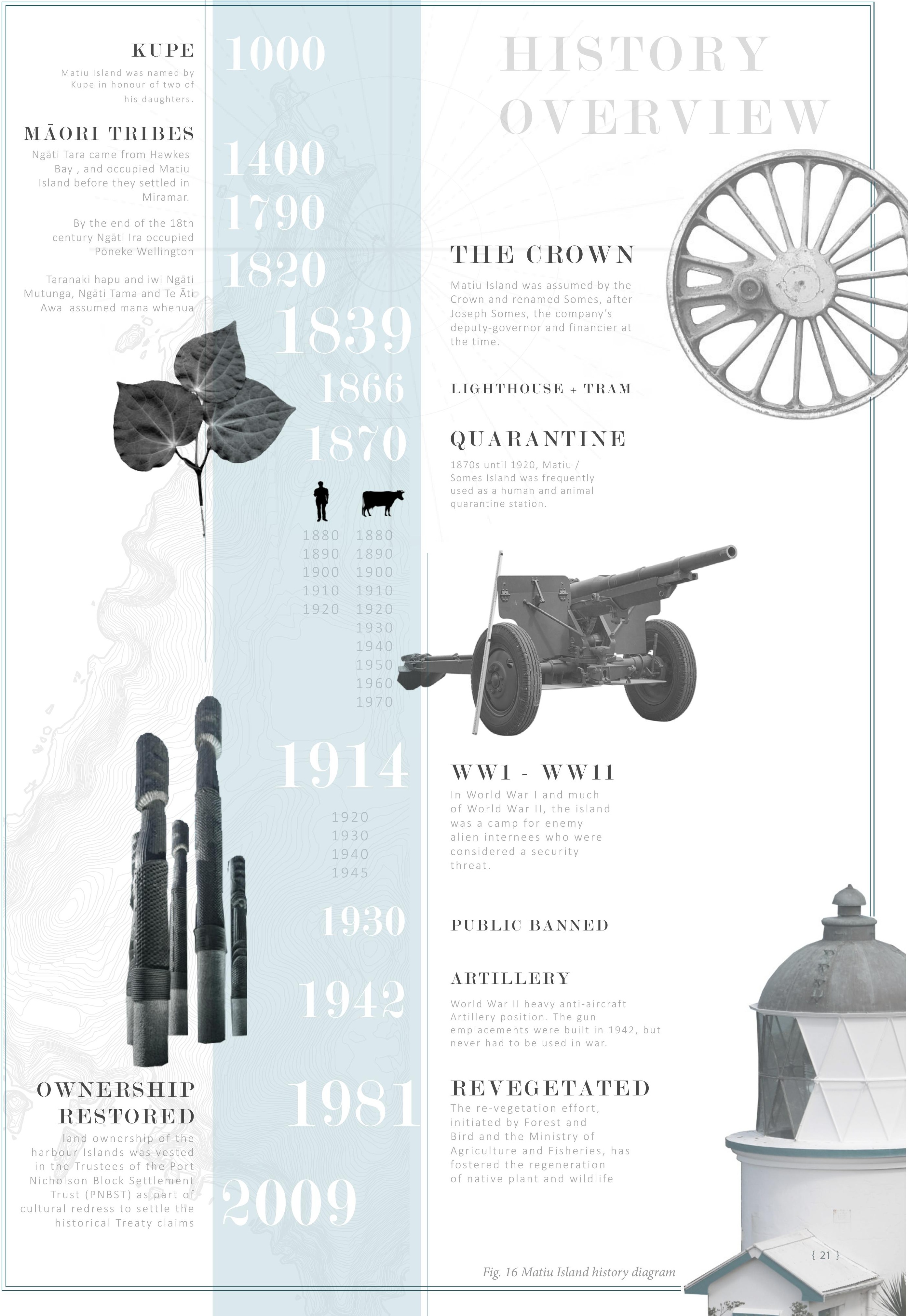




\subsection{MATIU ISLAND}

Matiu Island is located in the Pōneke Wellington harbour, just over $7.5 \mathrm{~km}$ from Pōneke Wellington's Central Body District and it is the largest of the three harbour islands. The moderately developed island is $25 \mathrm{ha}$ in size and contains a $2 \mathrm{~km}$ walking track, cemetery, quarantine building, lighthouse, campsite, two sole-occupancy buildings, education house, oxidation pond and a plant nursery, as seen in figure 17 (Conservation). Although the site has been lightly developed, most of the development has failed to recognise the islands important cultural history and ecological value.

For generations, Māori used Matiu as a strategic Pā in Pōneke Wellington Harbour (Board 2012). These tribes included Ngāti Ira, Ngāi Tara, Ngāti Kahungunu, Ngāti Mutunga, Ngāti Tama and Te Āti Awa. For a long period of time the island was only accessible by waka, creating a strategic position for Māori to live and defend their land.

A century of farming on the island meant that, until very recently, Matiu Island had been naked of native vegetation and wildlife. It is only in the last 30 years that the Department of Conservation and volunteers have planted over 110,000 trees, creating "A new cloak for Matiu". The Crown also use Matiu Island as a war station with gun emplacements, a light house and a human and animal quarantine, many of which are now used as the islands core attractions.

THE ISSUE Matiu Island, of all three islands, best conveys a bicultural disparity due to being utilised for many different purposes throughout its time under the rule of the Crown. The strong presence of European history and the absence of any relating to mana whenua has created a landscape with a physically imbalance bicultural history. The historic Pa's are nowhere to be seen while historic European landmarks are visually evident everywhere. 


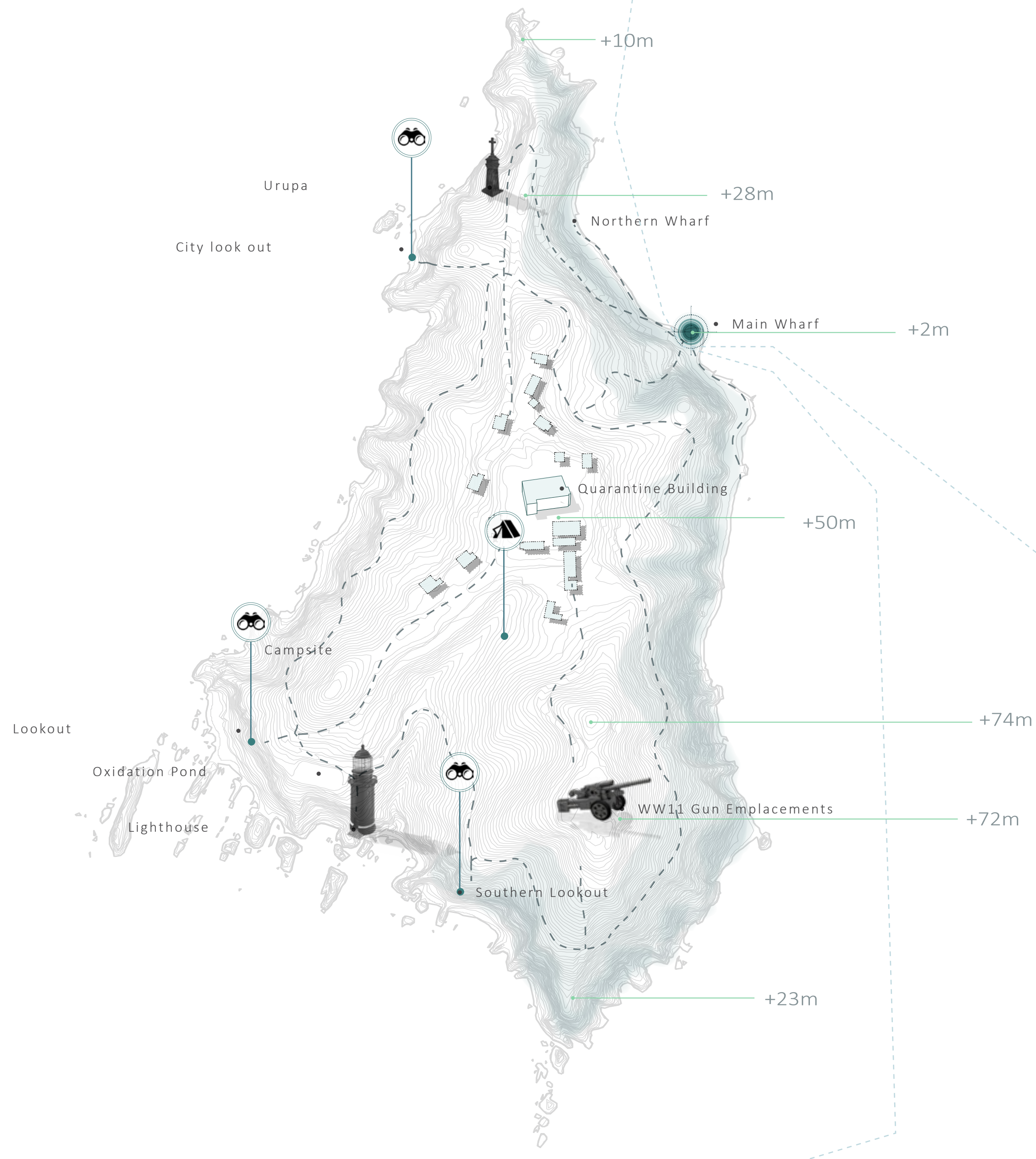

Fig. 17 Matiu Island attraction and elevation map 


\subsection{THE PORT NICHOLSON BLOCK TRUST}

Matiu Island was originally inhabited by Māori from the Taranaki region, who settled in Pōneke Wellington. These tribes are collectively called Taranaki Whānui ki Te Upoko o Te Ika and they include Te Āti Awa, Ngāti Ruanui, Ngāti Tama and Ngāti Mutunga, some of which inhabited Matiu island between the 15th and 19th century (Nester, 2001). These tribes used Matiu Island as a settlement point and a base during their travels across the North and South Island of Aotearoa New Zealand (Nester, 2001).

In 2018 The Port Nicholson Block Settlement Trust (PNBST) was established to receive and manage the Treaty settlement package for Taranaki Whānui ki Te Upoko o Te Ika. This appointed them as the mana whenua of the region and the traditional guardians of the Wellington Harbour and associated lands. (Trust, 2018)

\section{$N G \bar{A} T \mid R \cup A N U$}

\section{TARANAKI W H A N U I}

TE $\bar{A} T I$ A W A

\section{$\because$}
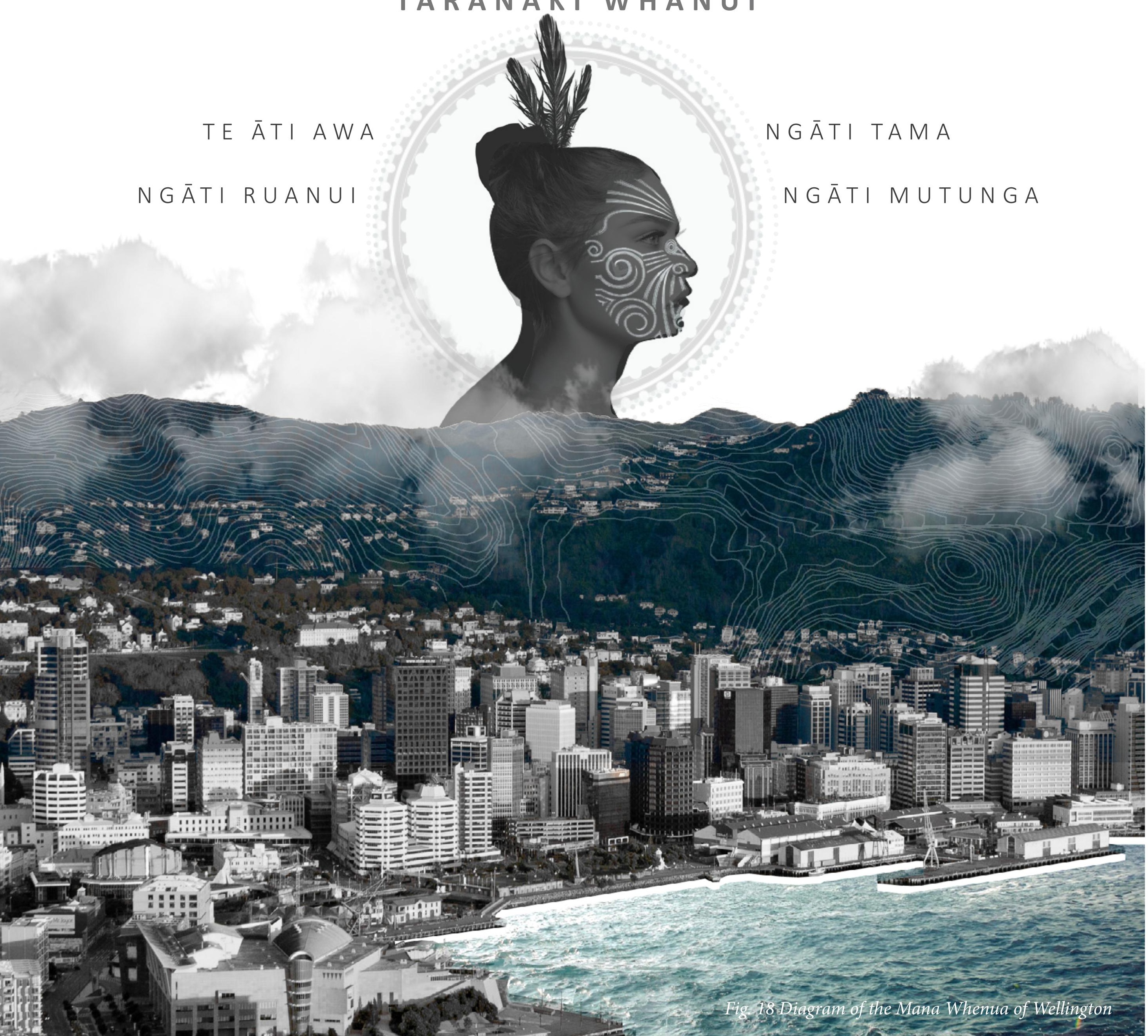
TARANAKI I W I

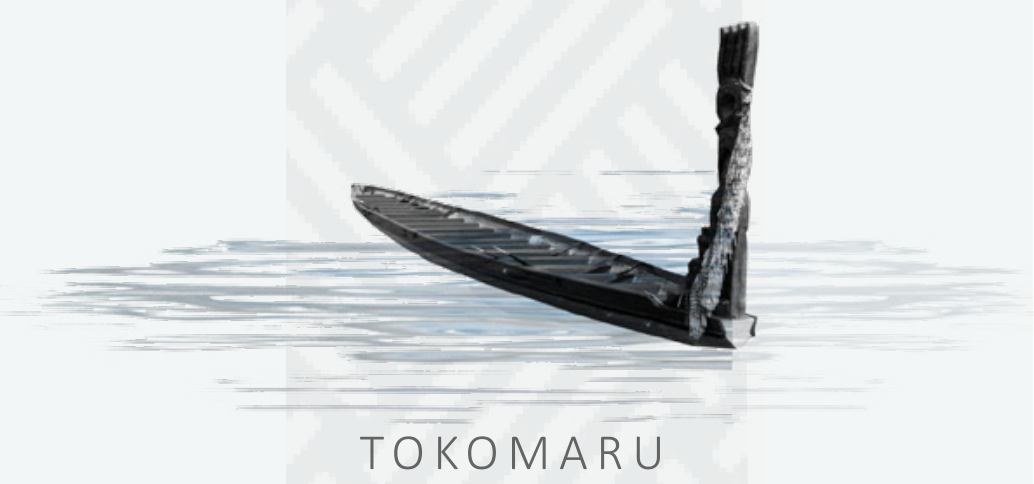

THEIR ANCESTRAL CANOE

FROM HAWAIKI

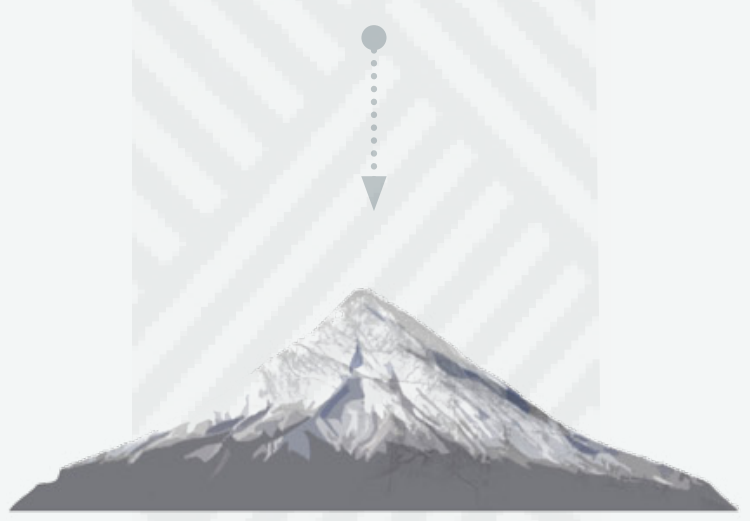

TARANAKI

ANCESTRAL LAND

$?$
$\vdots$
$\vdots$
$\vdots$

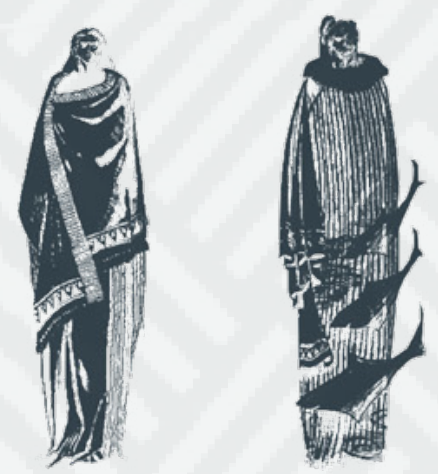

RONGOUEROA AND TAMARAU

SPIRIT ANCESTOR

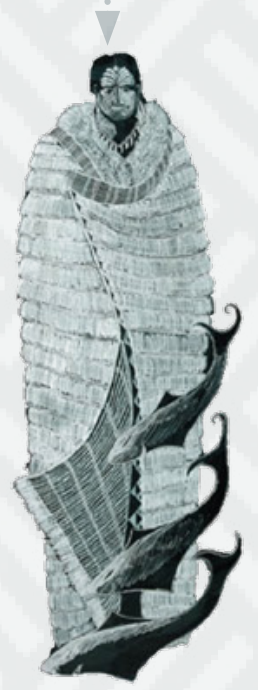

AWANU|ARANG|

FOUNDING ANCESTOR

Fig. 19 Taranaki ancestry diagram 


\section{MIGRATION}

The drive of the migration of tribes situated in Taranaki came from the musket wars, where newly acquired muskets, bought in by Europeans, changed the balance of power from tribes. (Love, 2005)

\author{
TE HEKE TATARAMOA \\ Taranaki - Kapiti \\ 1822
}

The first migration from Taranaki was made in 1822 by people from Ngāti Toa, Ngāti Tama, Ngāti Mutunga and Te Āti Awa, all fleeing the potential threat of the Waikato forces. This first group migrated to the Kapiti Coast, known to Māori as Te Heke Tataramoa.

\section{TE HEKE NIHOPUTA \\ Taranaki - Wellington 1824}

A second migration to Wellington included Ngāti Mutunga, Ngāti Tama and Te Āti Awa. Rongoueroa married Ruarangi, son of noted Polynesian explorer Toi. Her grandson was Tara, who lent his name to the area of Wellington Harbour, which became Te Whanganuia-Tara

\section{TE HEKE TAMATEUAUA \\ Taranaki - Petone \\ 1832}

Waikato and Ngāti Maniapoto forces combined and invaded the Taranaki region, reaching the Ngamotu people of Te Āti Awa. Large numbers of Ngamotu moved to Wellington, joined by some Ngāti Tama, settling at Petone with a hapu of Ngāti Mutunga, who arrived from a previous migration.

TE HEKE PAUKENA

Wellington - Chatham Islands 1834

A battle with Ngāti Toa led to the breakdown of relations between tribal settlements in Kapiti Coast. In 1835, Ngāti Mutunga and some of Ngāti Tama transferred control of their lands to Te Āti Awa and other tribes, on Matiu Island, before leaving to invade the Chatham islands to attack the Moriori. 


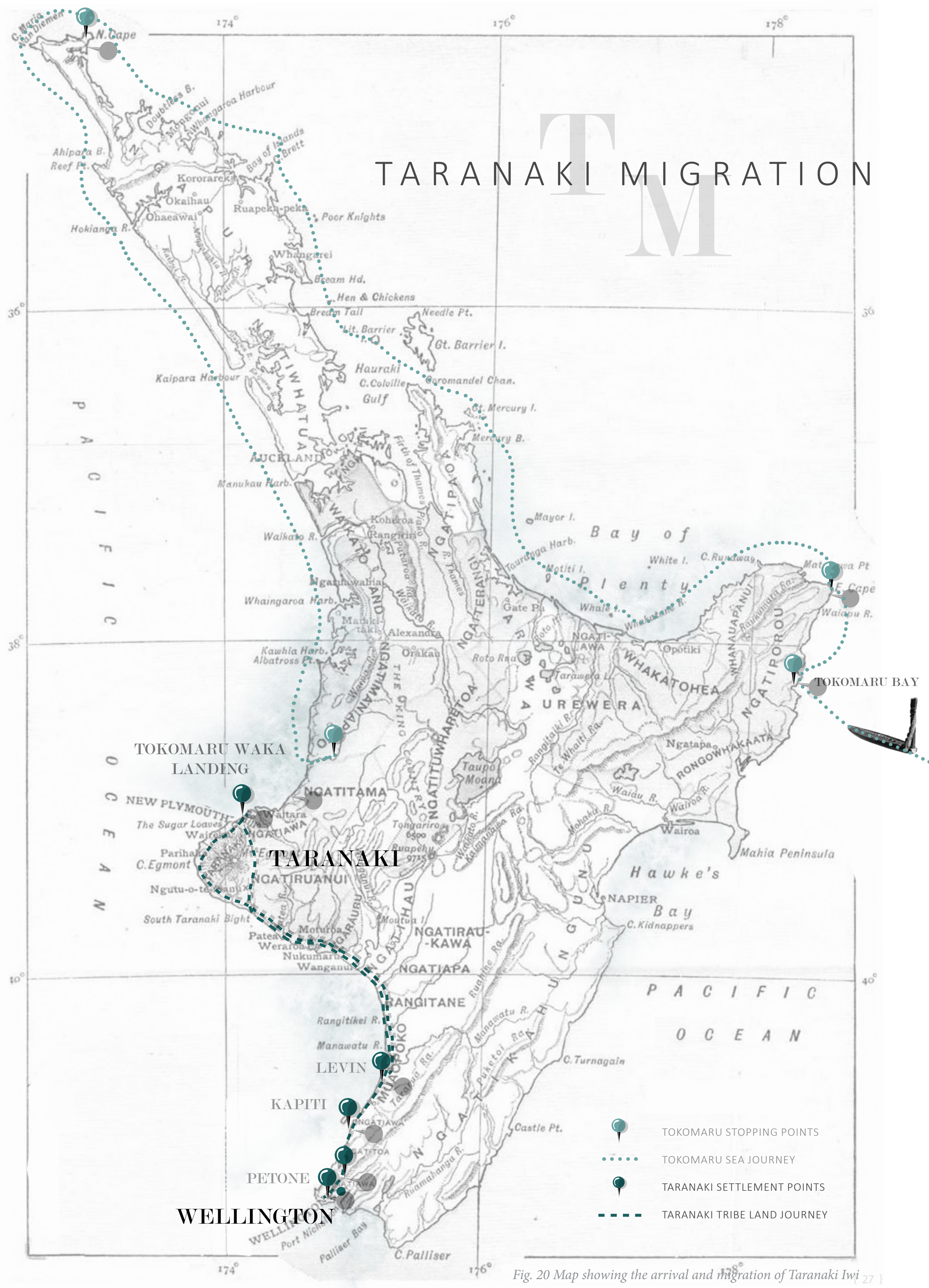




\subsection{THE KAITIAKI BOARD}

As the Wellington Harbour Islands hold historical, cultural and ecological importance to the Iwi and the region, the Port Nicholson Block Settlement Trust established the Kaitiaki Board. "This board consists of a unique IwiCrown partnership model that presents positive opportunities for the PNBST, the Department of Conservation and the general public to work cooperatively together to strengthen the Mauri of the Harbour Islands" (Board, 2012, P.7).

The Kaitiaki Plan was developed by the Kaitiaki Board to establish "the vision, values, and guiding principles for management, long-term triple sustainability outcomes (cultural, ecological and financial), and management objectives" (Board, 2012, P.8). Within this plan are two major visions agreed on by all parties. The first is that the "Harbour Islands should be a living base to revive Taranaki Whānui ki Te Upoko o Te Ika culture and tikanga, and a central hub for the expression of cultural identity to ensure the survival of Māori culture, language and tikanga for future generations" (Board, 2012, P. 11 ). And secondly that the "healing, restorative and peaceful nature of the Harbour Islands and the indigenous flora and fauna should be protected and maintained" (Board, 2012, P. 11). Working with these objectives is important to ensure the needs of the board and the iwi are met. 


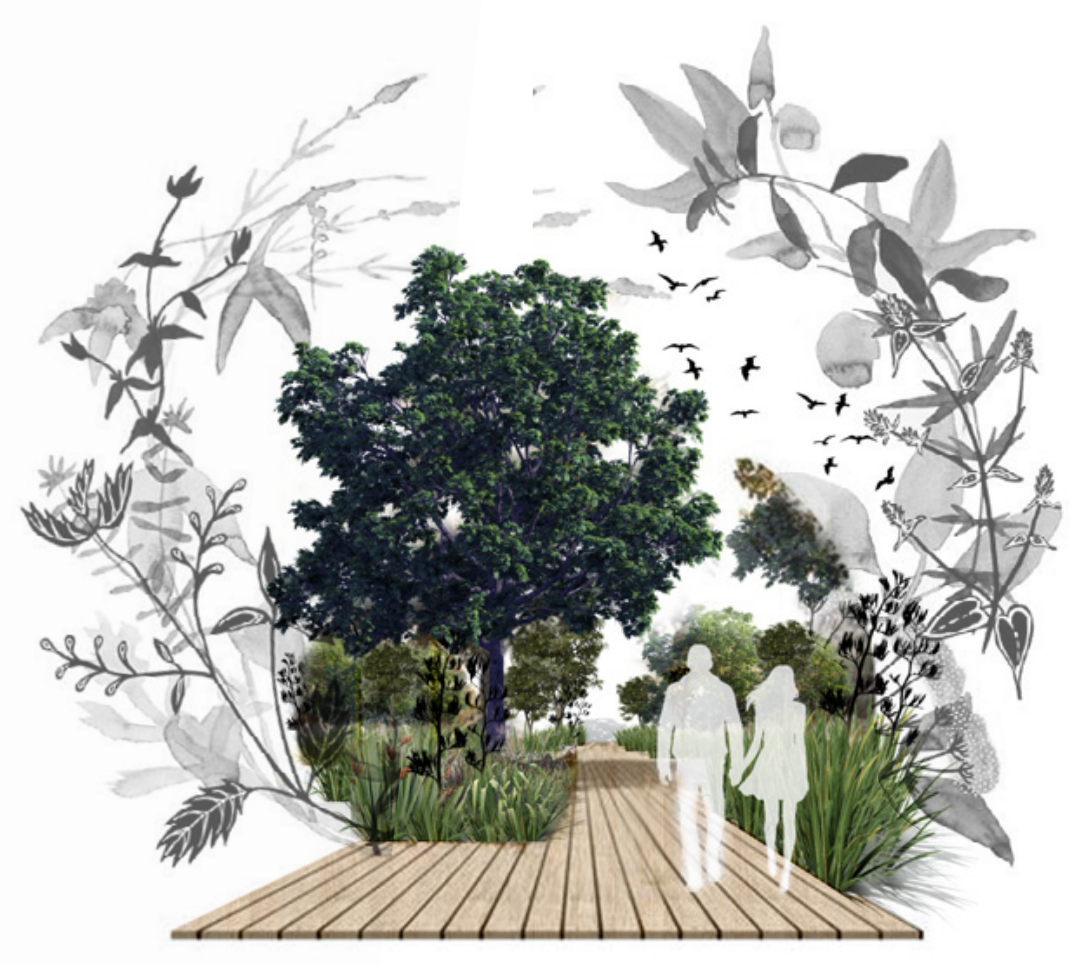

ENVIRONMENTAL HARMONY

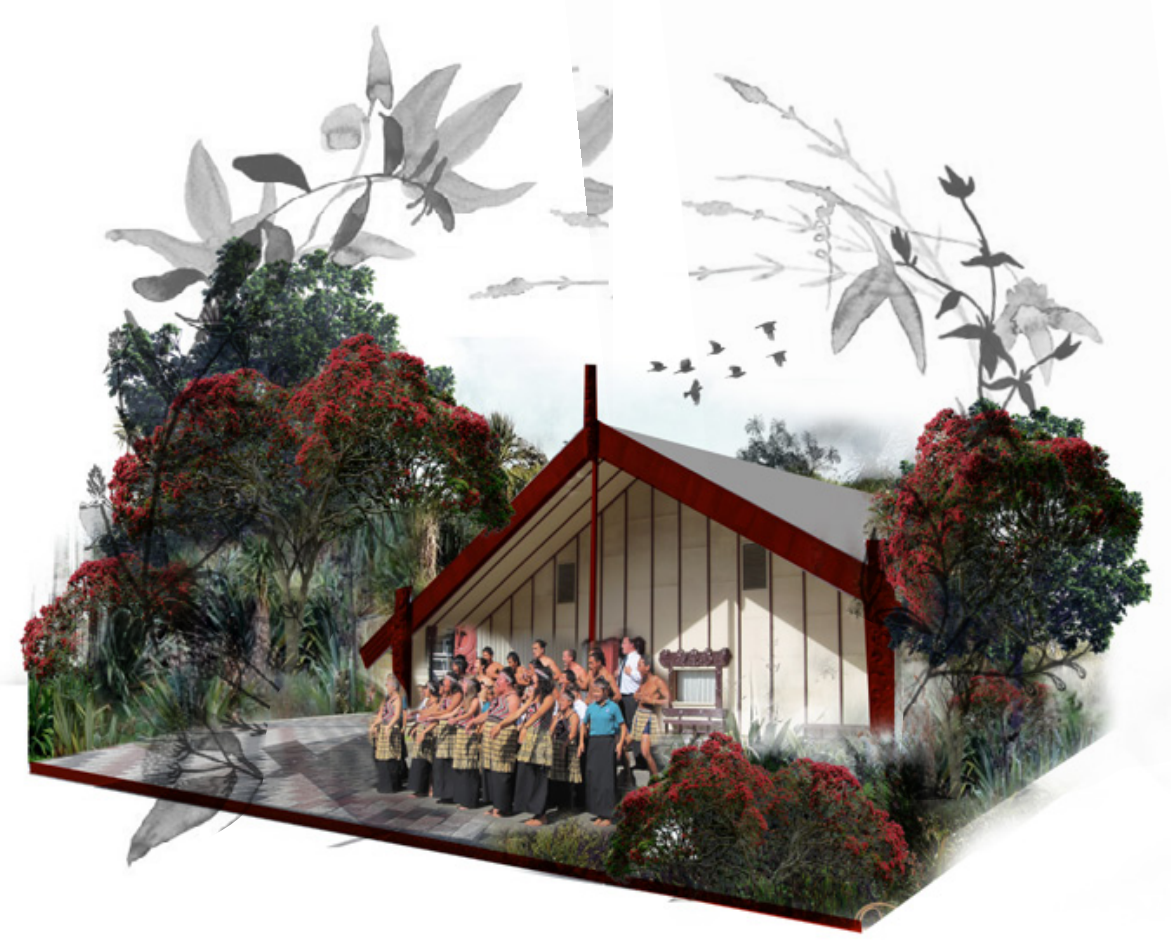

CULTURAL BASE

Fig. 21 The Kaitiaki Board's two main visions 


\subsection{A PHYSICAL CULTURAL IMBALANCE}

Matiu Island has seen great ecological advancement since its time under the rule of the Crown. However, since Māori were restored as the owners of the land in 2009, very little work has been done to addresses the culture aspects Māori stipulated in the Kaitiaki Plan. There has been almost no physical work done on the island in terms of the presence and representation of Taranaki Whānui, and their Identity as a tribe.

As seen in figure 22, the strong presence of European history on the island, in the form of physical landmarks and signage, and the absence of any of these acknowledging the Māori history, has created a landscape that fails to represent its rich bicultural past and its indigenous guardians.

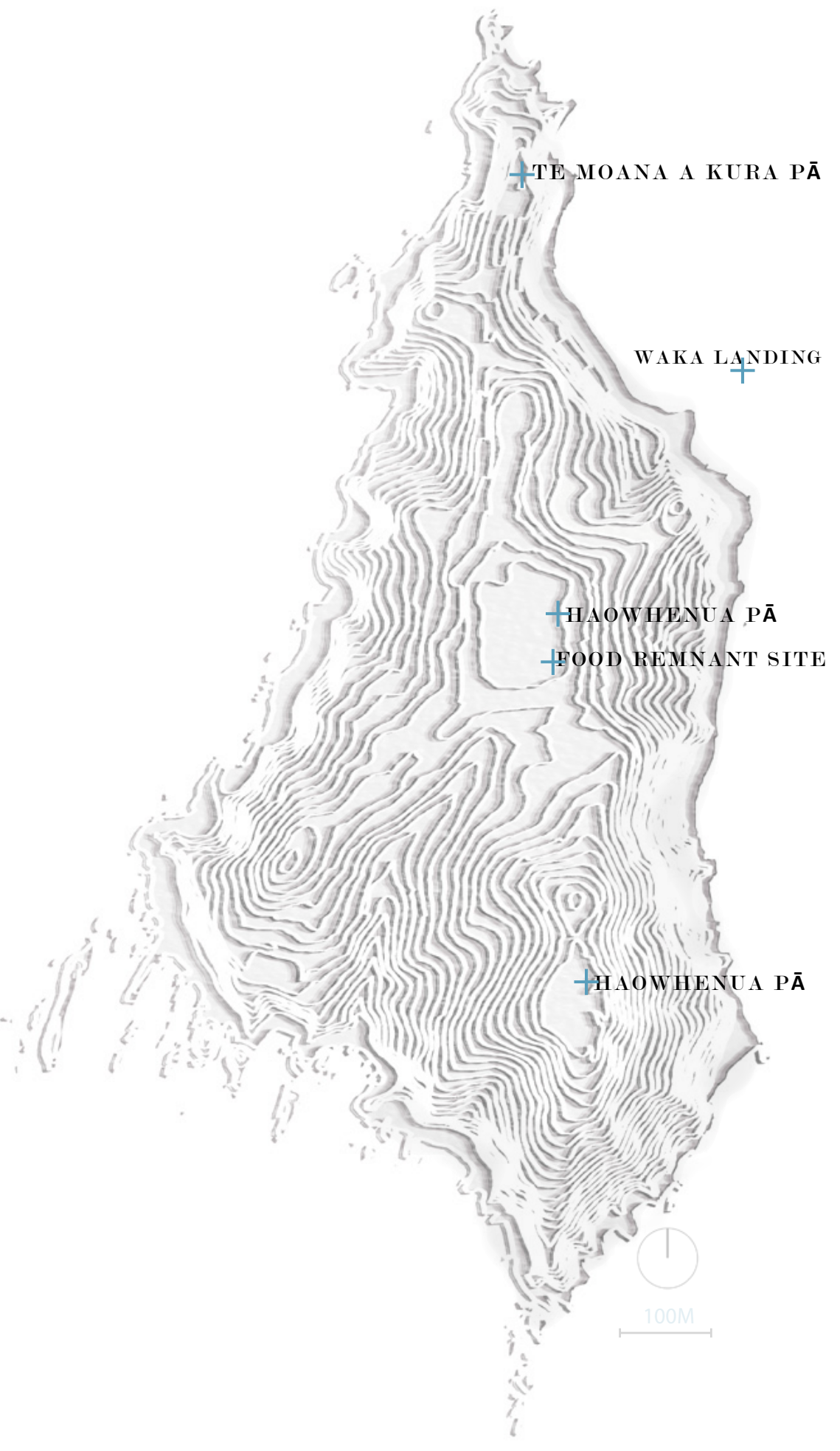

IGNORED SITES

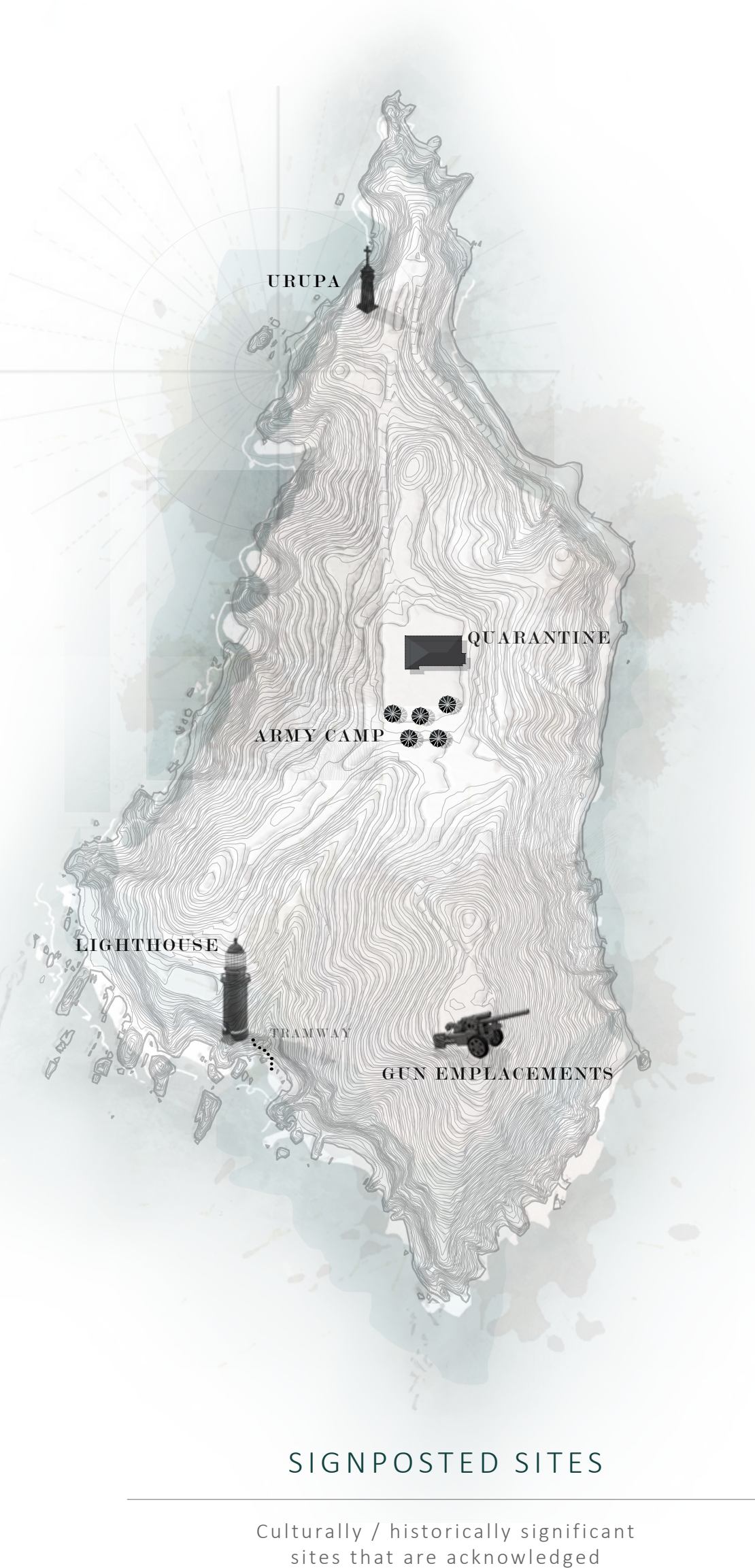


HOW CAN OFFSHORE ISLANDS BECOME CULTURALLY AND EDUCATIONALLY FOCUSED SPACES FOR IWI AND LOCAL COMMUNITIES? 



\section{SITE ANALYSIS}

\section{EXPERIENTIAL INVESTIGATION}

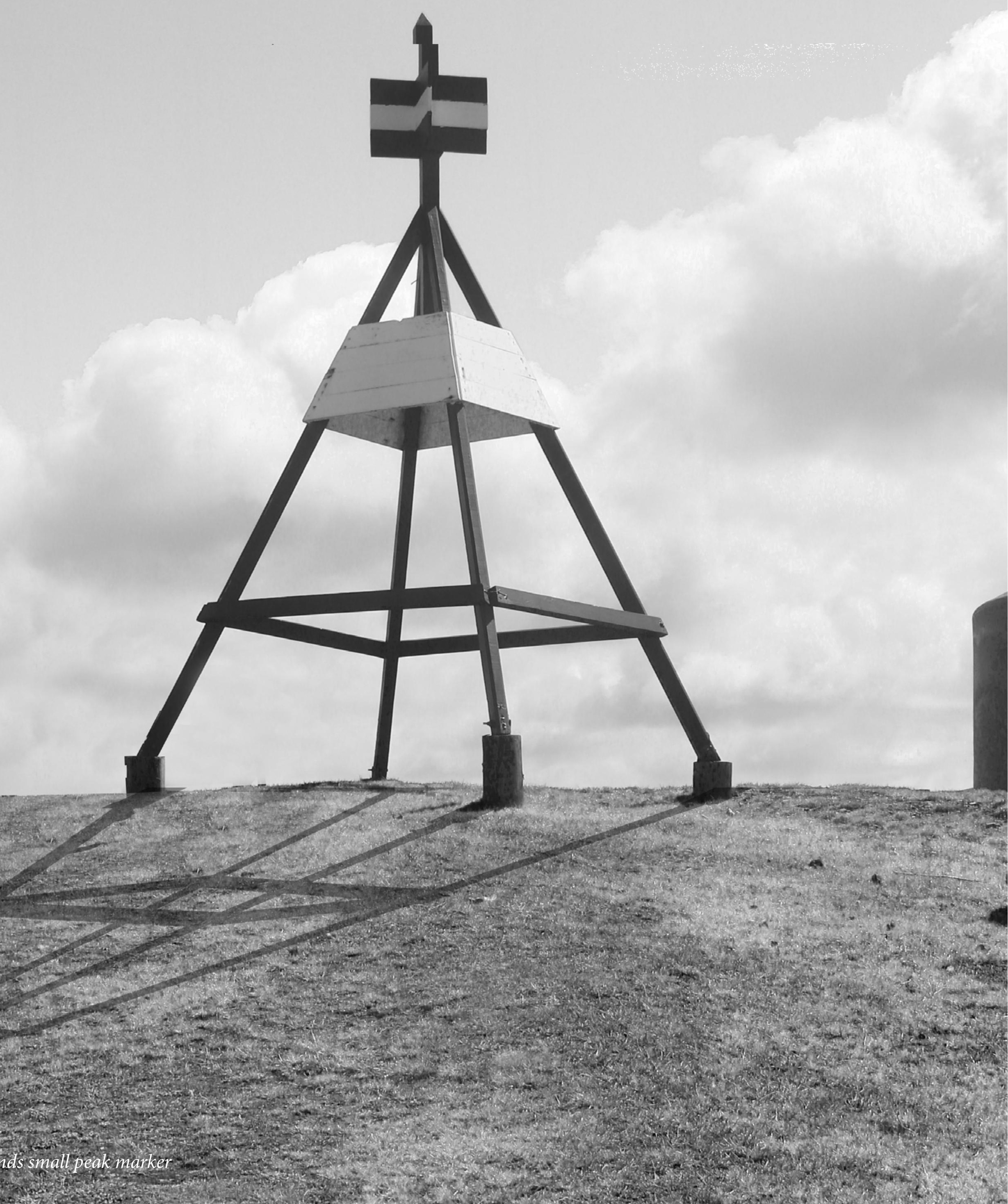




\subsection{BIOPHYSICAL ANALYSIS}

GEOGRAPHY Matiu, Makaro, and Mokopuna Island are peaks on a ridge formed 1.5 million years ago. When land southeast of the Wellington fault tilted down, the Port Nicholson Basin flooded, forming the Wellington Harbour which submerged the ridge and created the three islands. Further uplift during the 1855 Pōneke Wellington earthquake brought Matiu Island higher above sea level so that much of the present shore line is now surrounded by cliffs, creating the steep profile of the island. (Chronis, 2009)

CONDITIONS Matiu island is situated in the centre of the Wellington harbour, leaving it constantly exposed to harsh sun and strong winds. "Gusty northwesterlies alternate with southerlies. North-westerly winds predominate in spring and summer, while southerlies dominate in winter" (Maclean, 2007, P.7).

ECOLOGY Most of the original vegetation on the Island was cleared by European settlers, however the islands native environment has since be restored. "Native vegetation now covers the eastern cliff faces and gullies and southern, western and some inland slopes. Although half of the island is pasture, of which half is grazed for fire control purposes, this will decrease as planting continues" (Chronis, 2009, P. 38). Kohekohe, Tawa, Karaka and Pigeonwood are the dominant forest species found on the island, while Melicytus Crassifolius, Phormium Cookianum, Tauhinu, Olearia Solandri, Toetoe, Matagouri, Speargrass, Coprosma Propinqua and Taupata are the dominant coastal scrub species (Chronis, 2009).

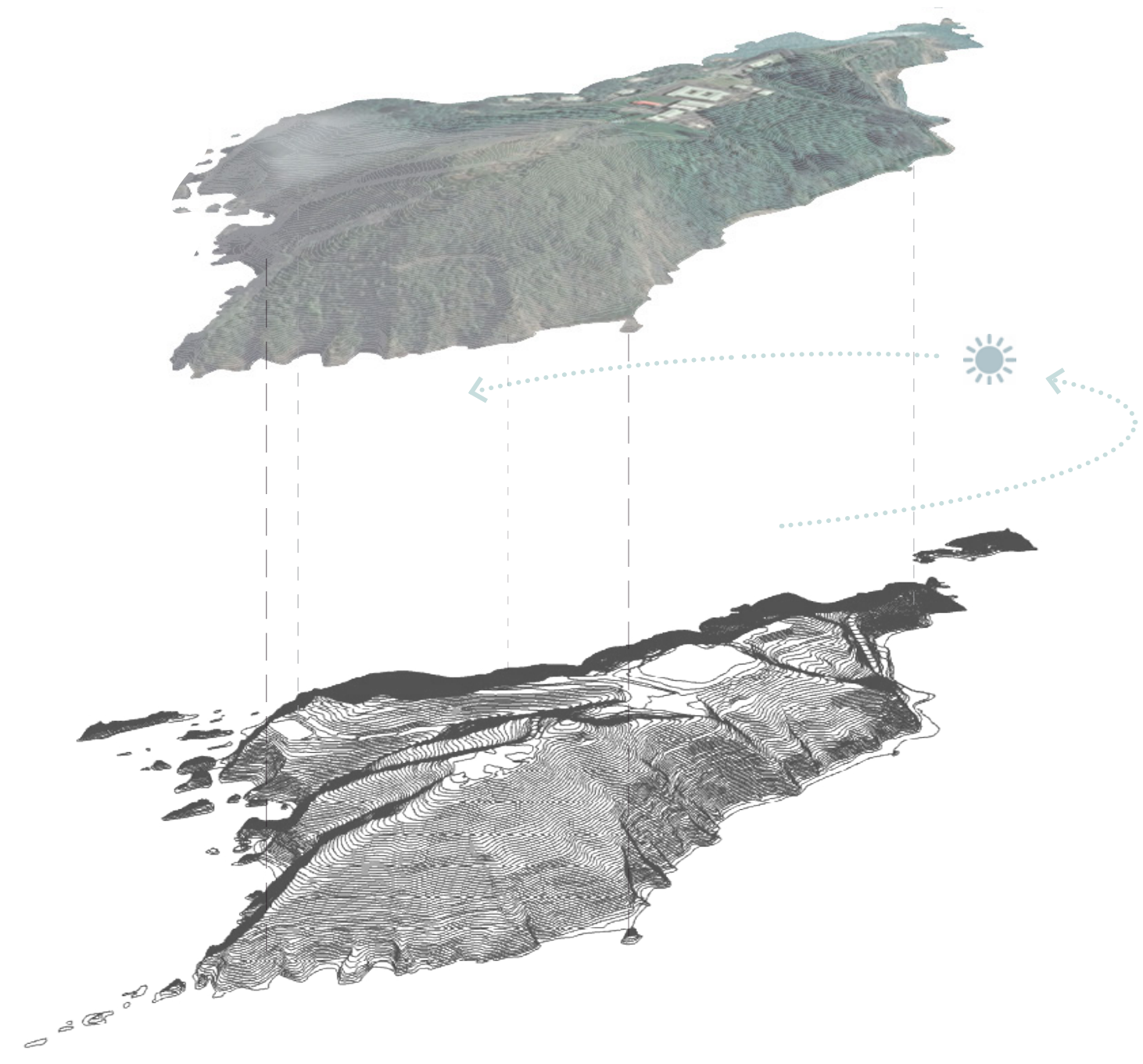

Fig. 24 Matiu Island exploded sun, topography and vegetation diagram 

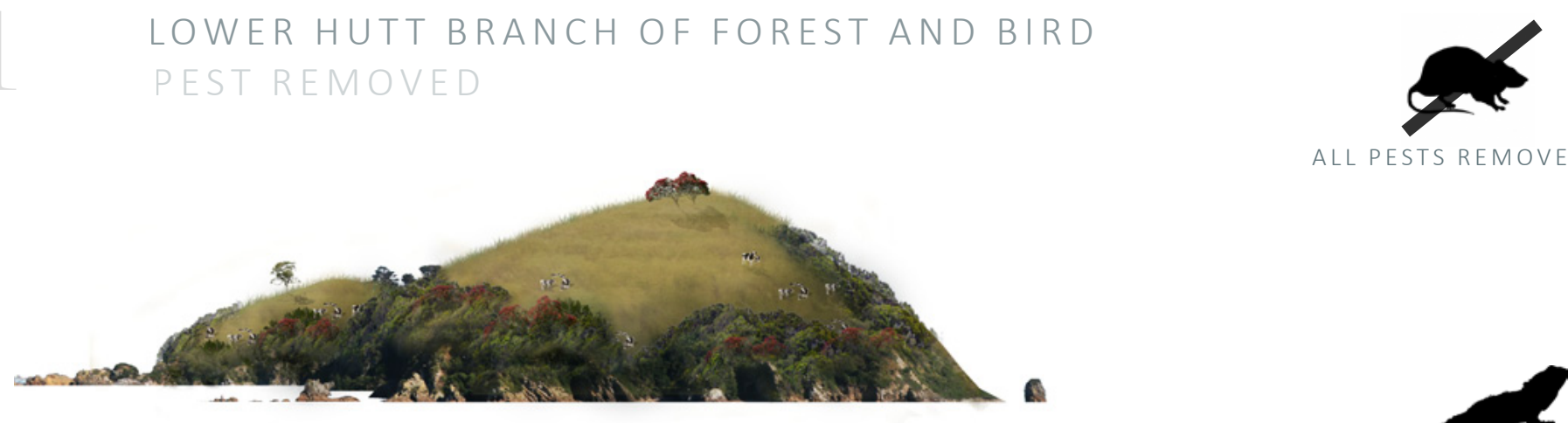

ALL PESTS REMOVED
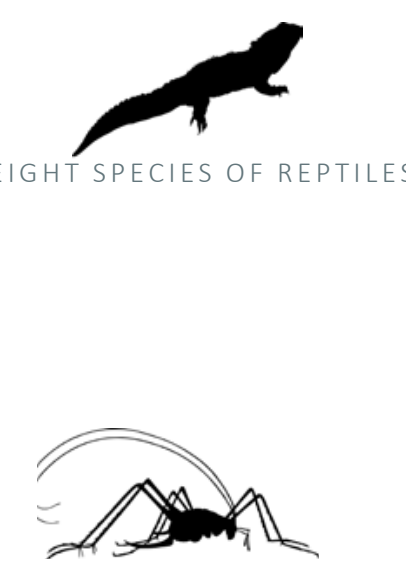

500 SPECIES OF INVERTEBRATES
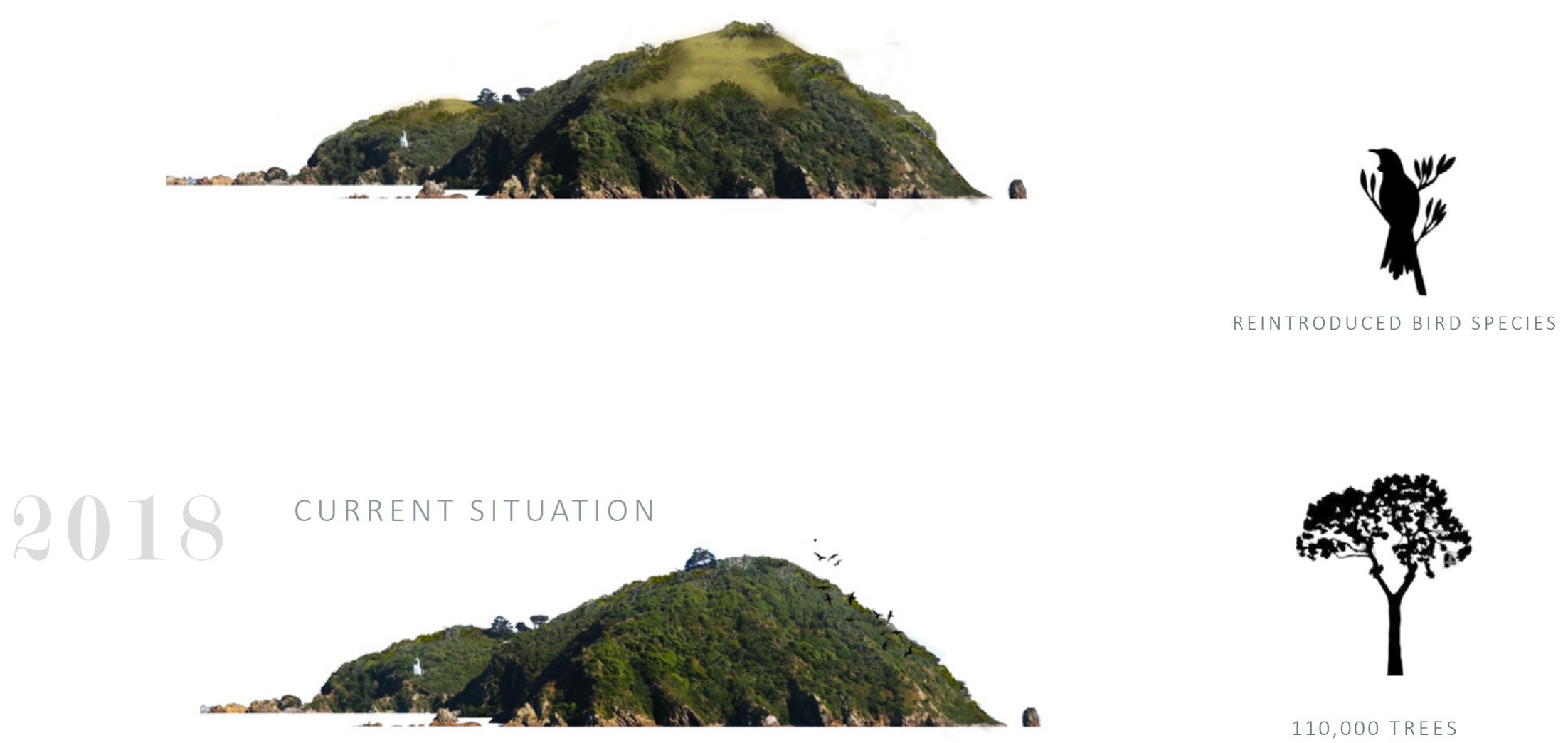

110,000 TREES 


\subsection{A VISUAL JOURNEY}

The Visual documention of the journey

across Matiu Island enabled key experiences,

structures and pathways to be identified.
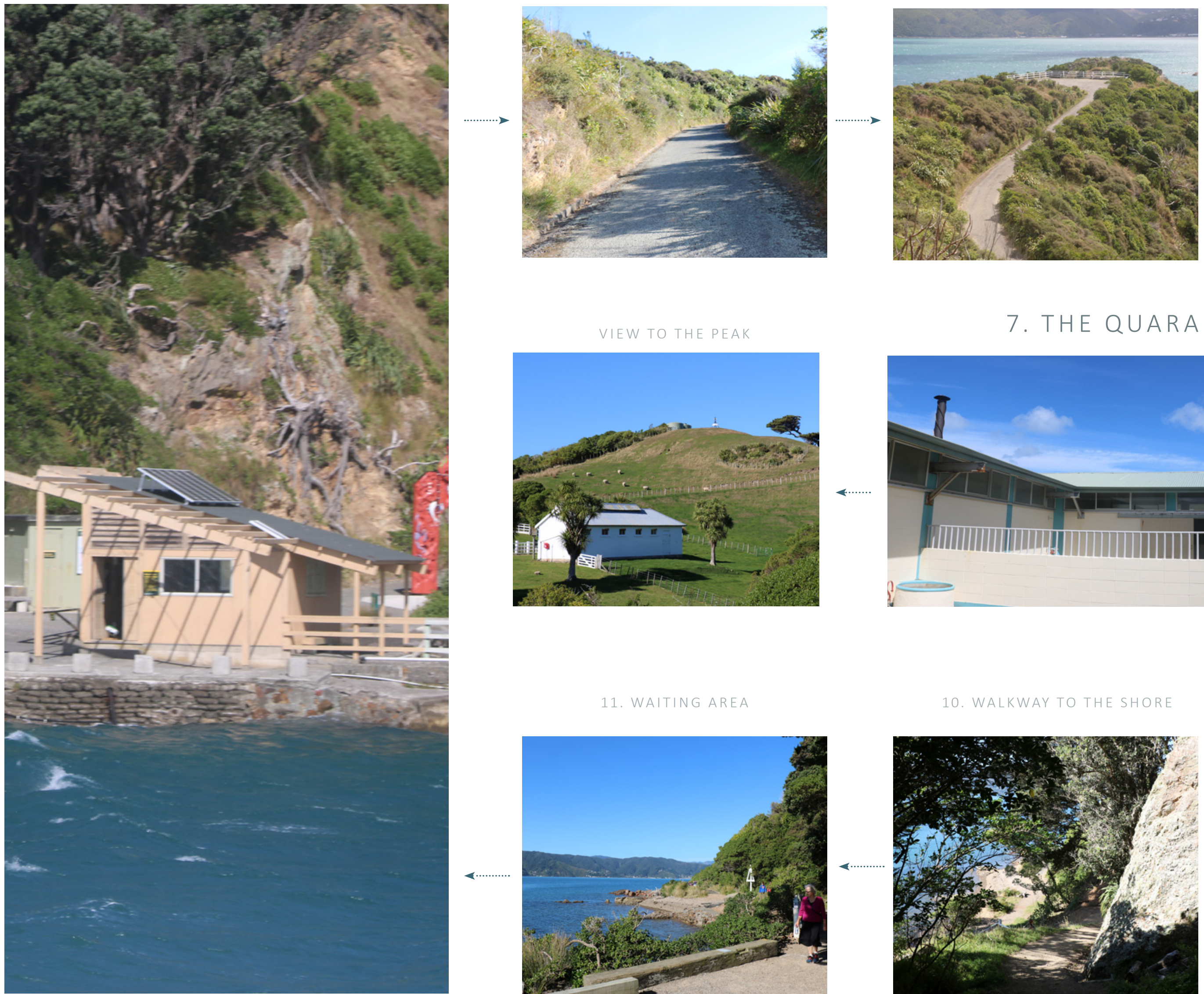

VIEW TO THE PEAK

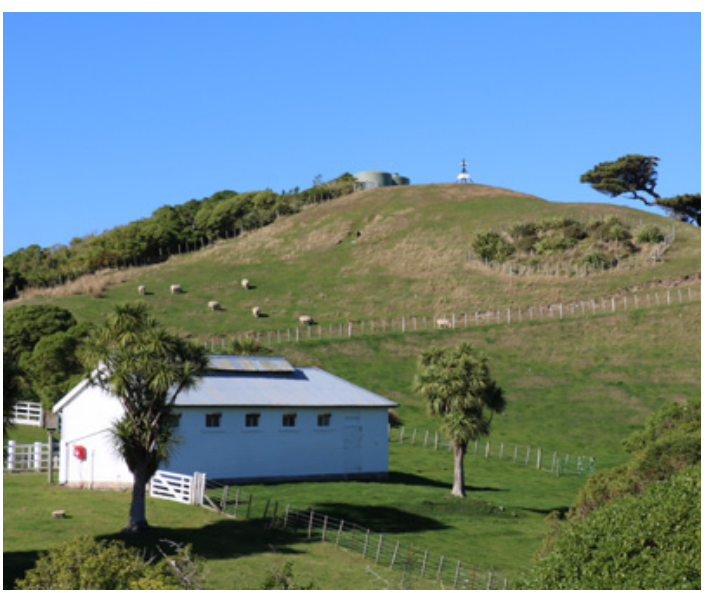

11. WAITING AREA

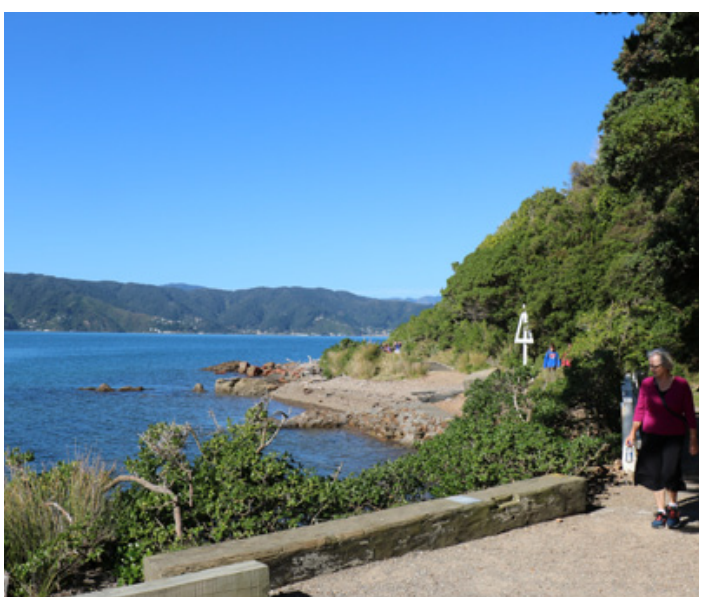

7. THE QUARANT

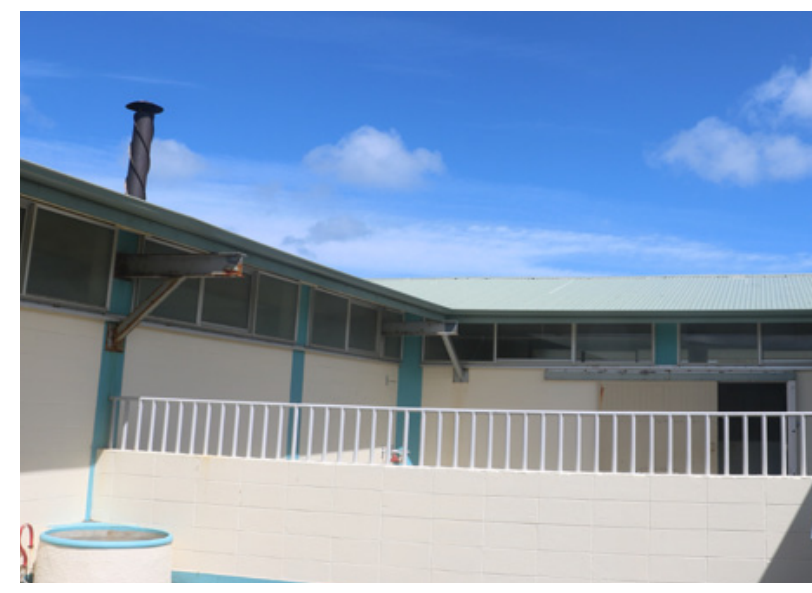

10. WALKWAY TO THE SHORE

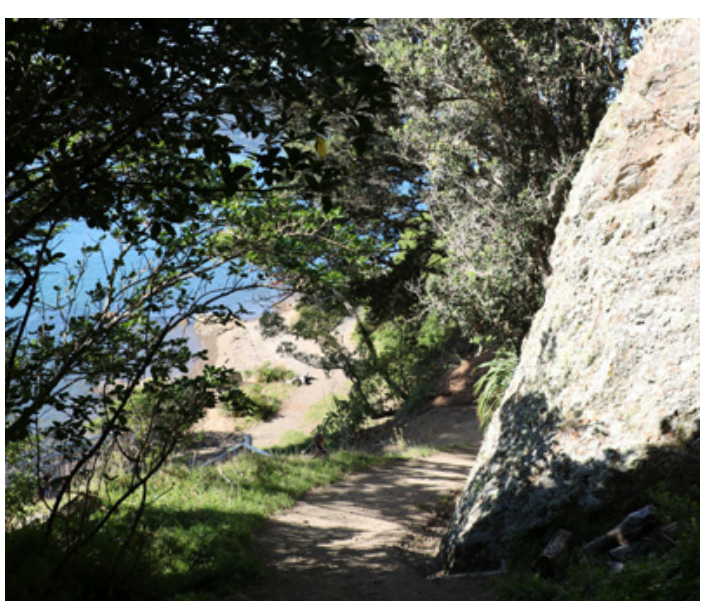




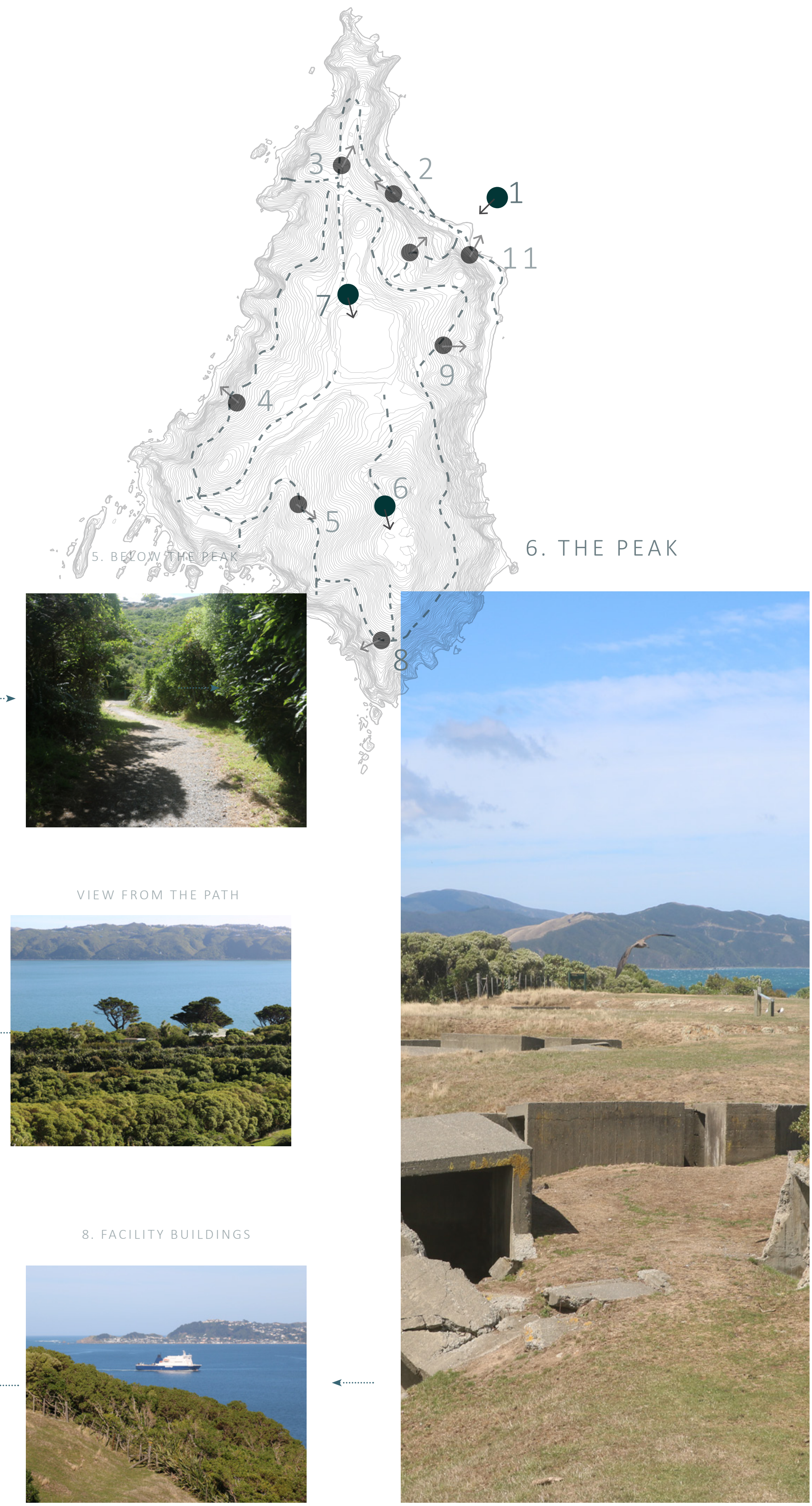

Fig. 26 Photo series showcasing a visitors typical journey across the island 


\subsection{EXPERIENTIAL MOMENTS}

The islands key experiential moments were determined by observing how long people spent in one space. The three key destination sites were the Wharf, the Quarantine building and the peak. All three sites were aged and worn, failing to provide visitors with the optimum experience of within one. Interestingly these were all sites with rich Māori history. Due to these factors, these sites were selected as the key sites that the design investigation will focus on.

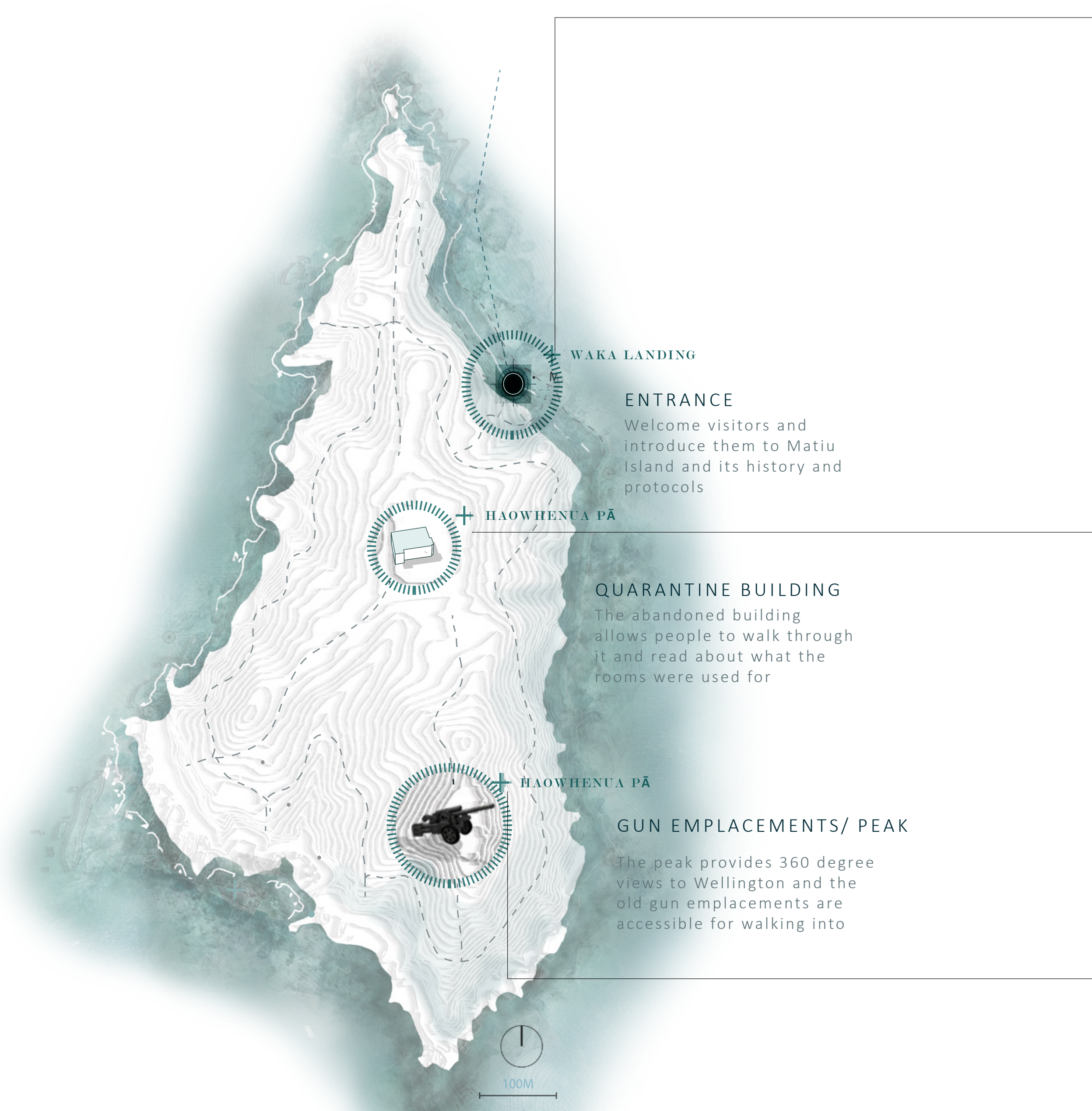



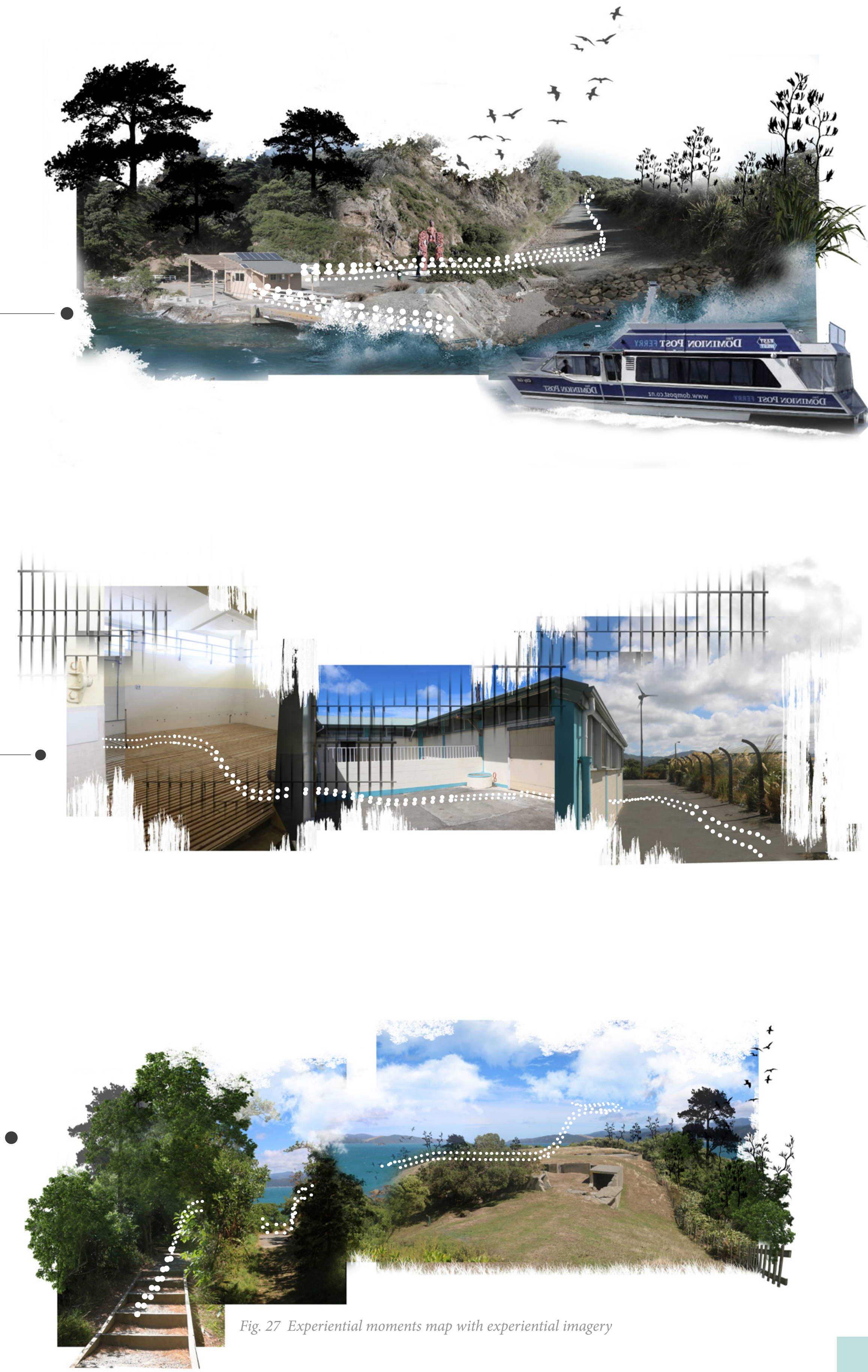


\subsection{THE WHARF}

Upon their arrival to the island, visitors first contact is with the wharf. This site is historically significant as it was where the first Māori waka landed.

The Wharf area and the entrance to the site should be a space that represents the holistic essence of the island. However, the experience of arriving on the island is currently underwhelming as the wharf area is worn and the native surroundings are poorly maintained and scraggly. Despite the fact this area is one of the few places on the island that the visitors can interact with the marine environment, the site provides very few ways in which to do this.

\section{ENTRY AREA}

\section{Plain space}

with little

consideration

for the entry

and experience

of the user

MAIN WHARF

Worn wharf with little

character in an exposed

setting with views to the

entry space

BIO SHED

small

uninviting

building

that is too

small and

outdated

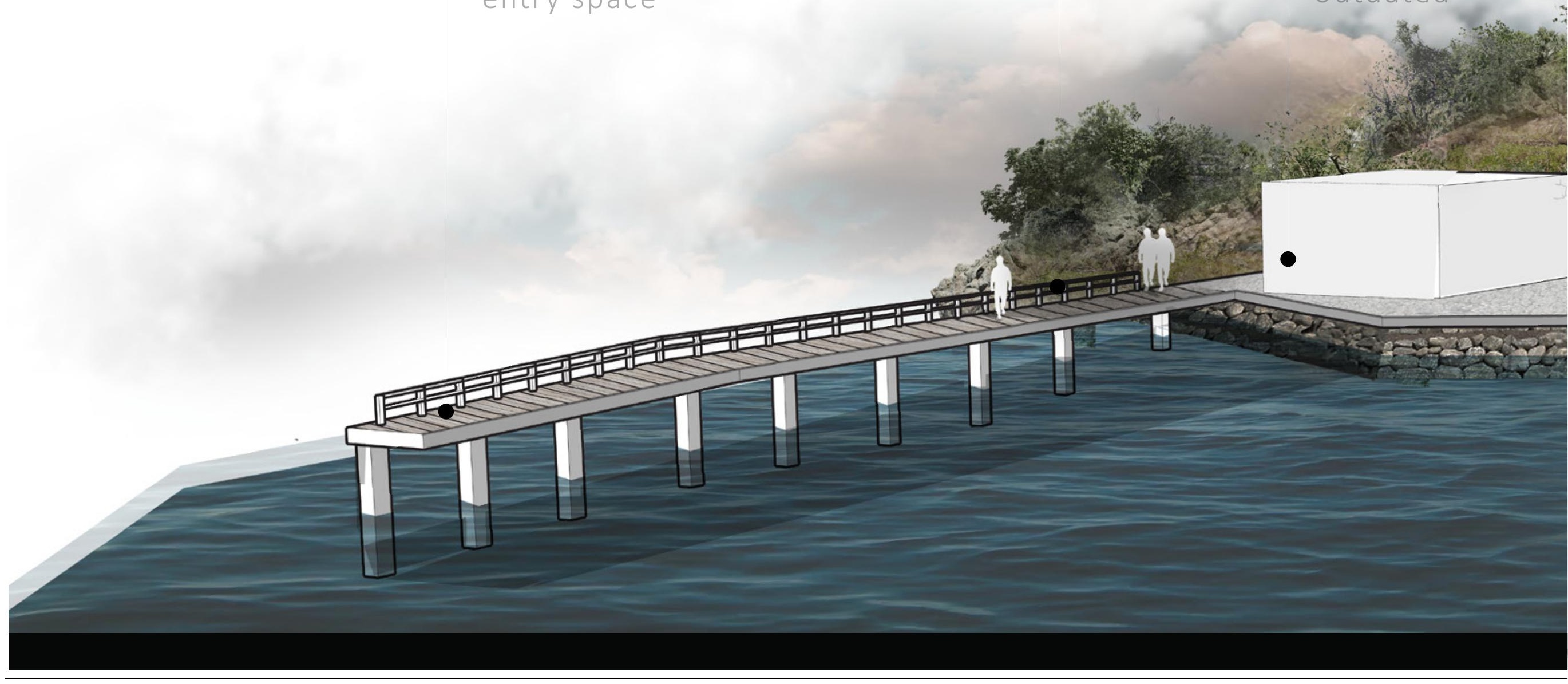




\subsection{THE QUARANTINE}

The Quarantine Building located at the top of the island is an unused and empty building that was once used to monitor the health of both animal and humans in the Wellington region. The building has no specific purpose other than to show visitors what the building once looked like and how it functioned and the layout is a confusing maze of empty and poor maintained rooms, as seen in figures 29 and 30 .

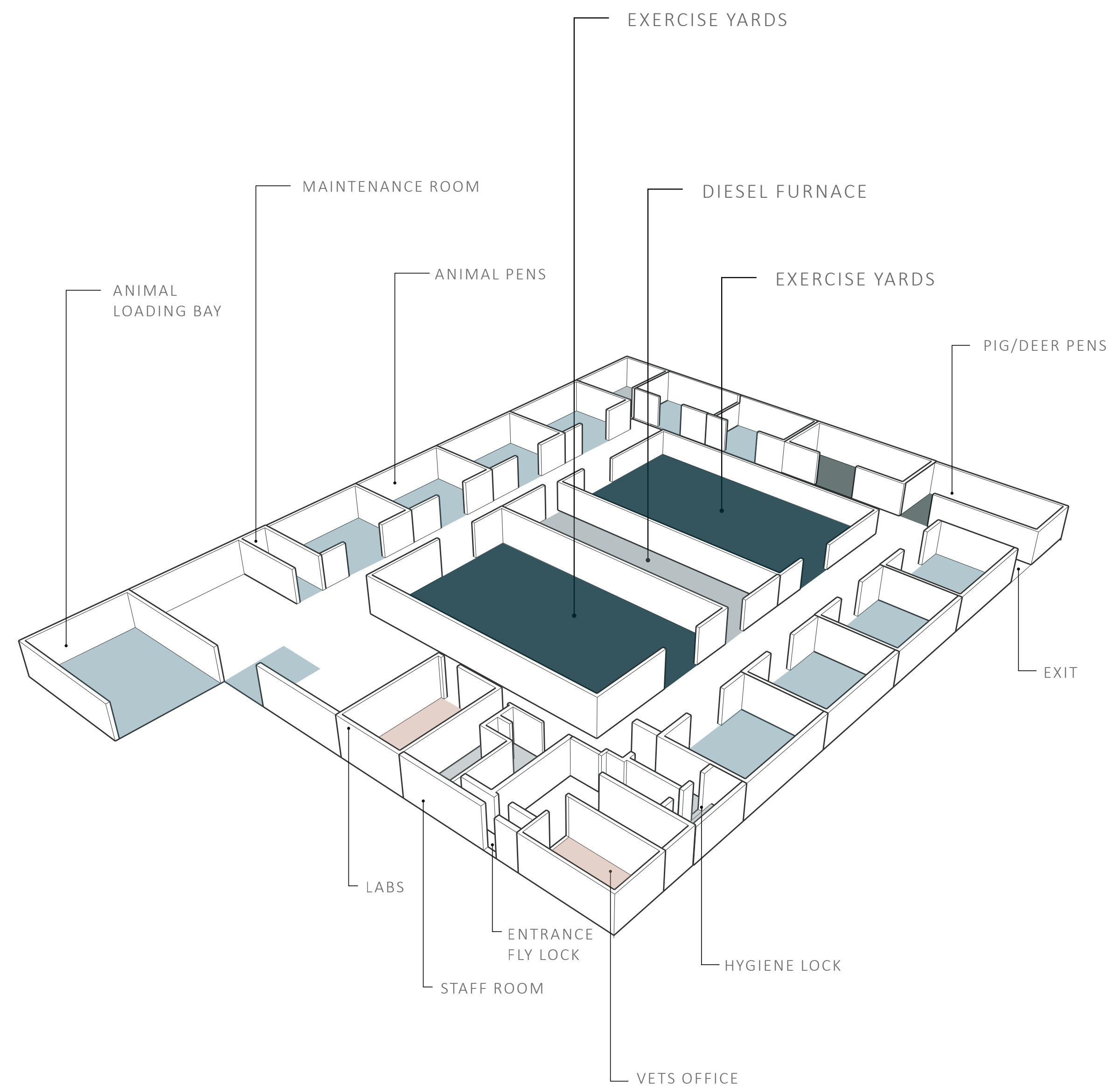



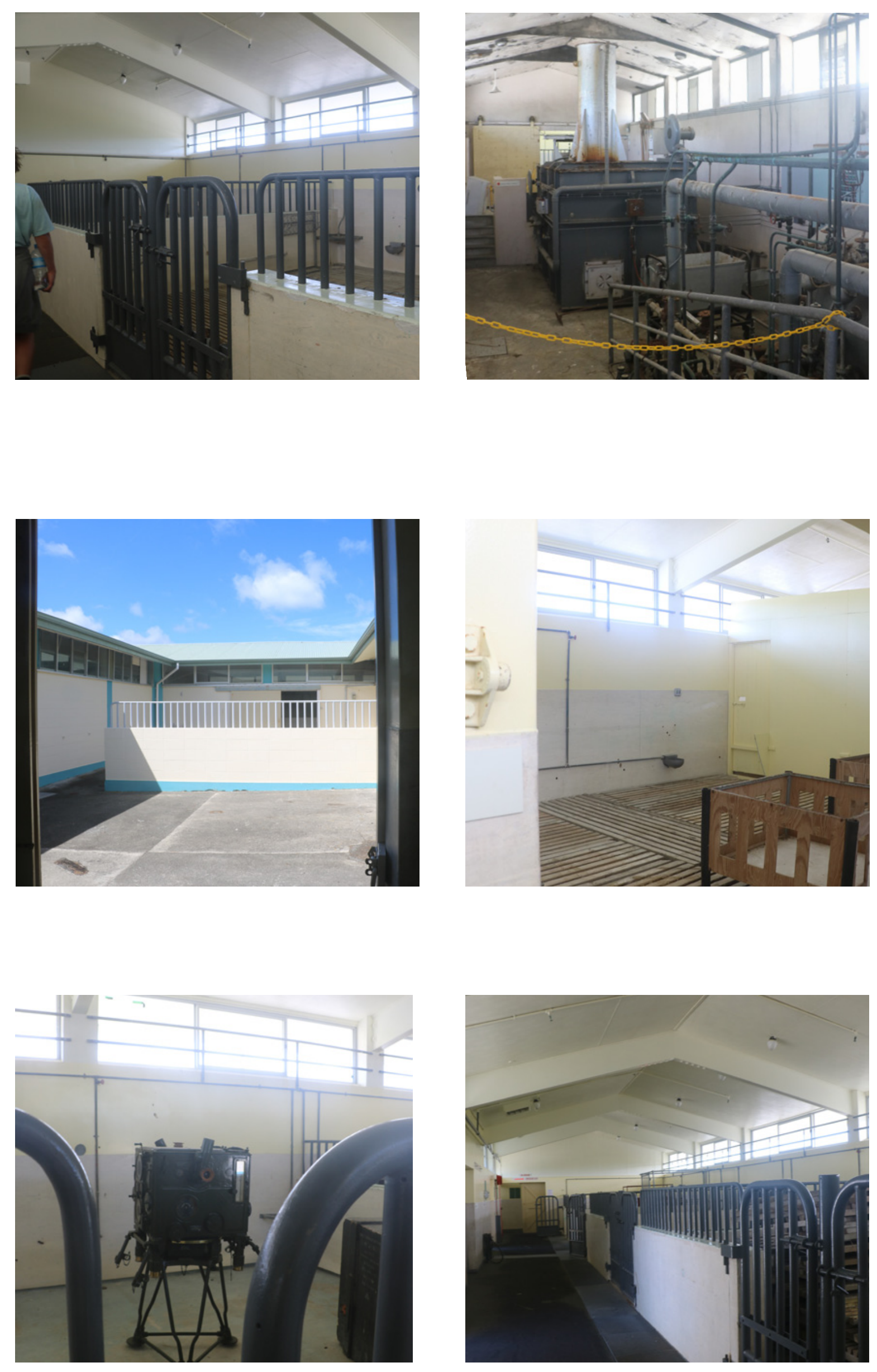

Fig. 30 Photo series showcasing the interior of the Quarantine Building 


\subsection{THE PEAK}

The flat space located in front of the Quarantine building is a culturally significant site as it was once the Haowhenua Pā, one of two Pā's on the island. Although all the European sites on the island have information boards providing an overview of the history of each site, the Pa site is not recognised or sign posted.

The path that leads visitors from the Pā site to the highest peak is steep and uneven, making it hard for young children and elderly to use it. The peak provides visitors with a 360-degree view to Pōneke Wellington and Petone, making it the most appreciated site on the island. Apart from the views, the space recreationally has little to offer visitors, with a few picnic benches and a flat lawn space. While the views meet the visitor's expectations, the actual peak itself is a barren and worn.

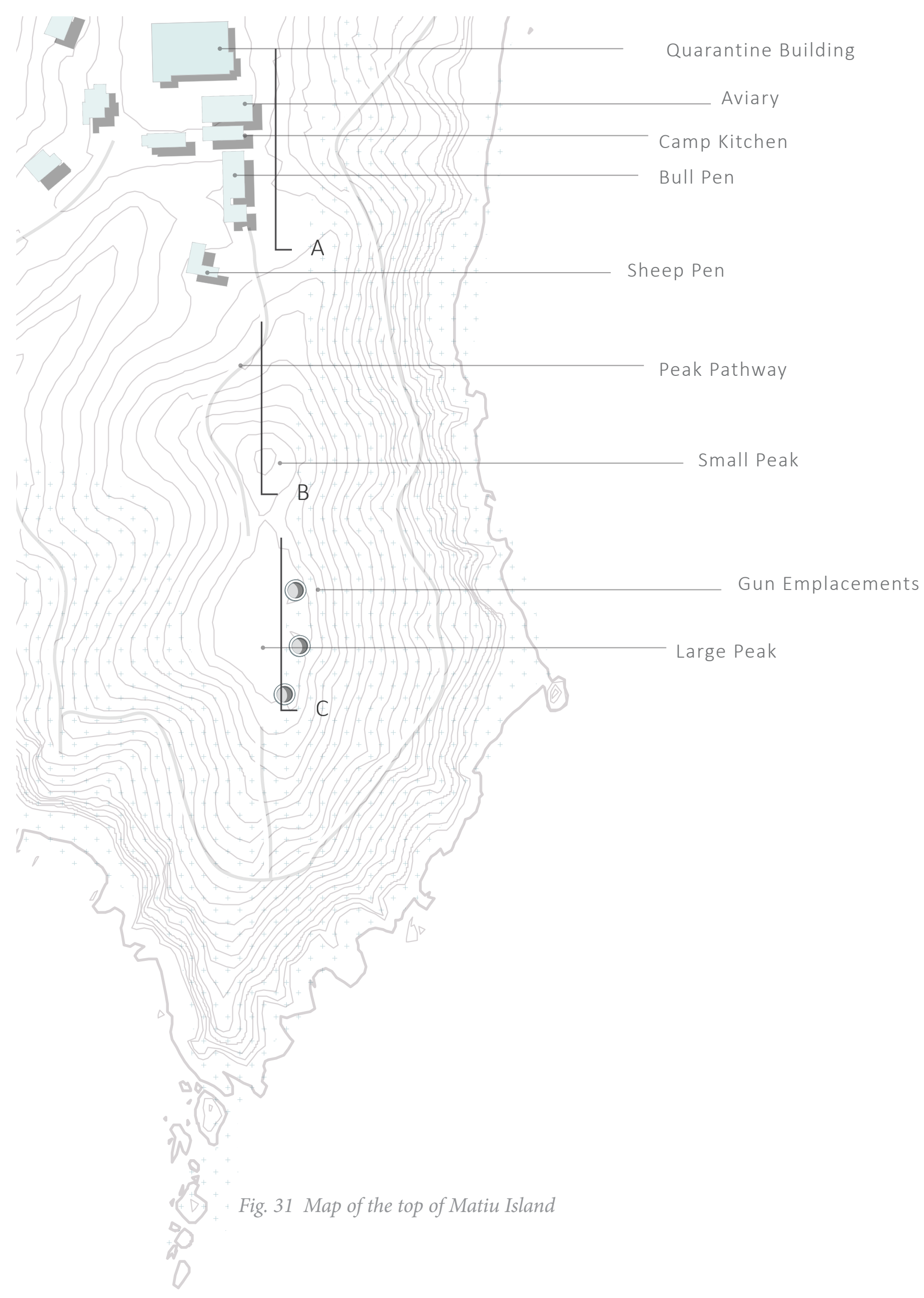




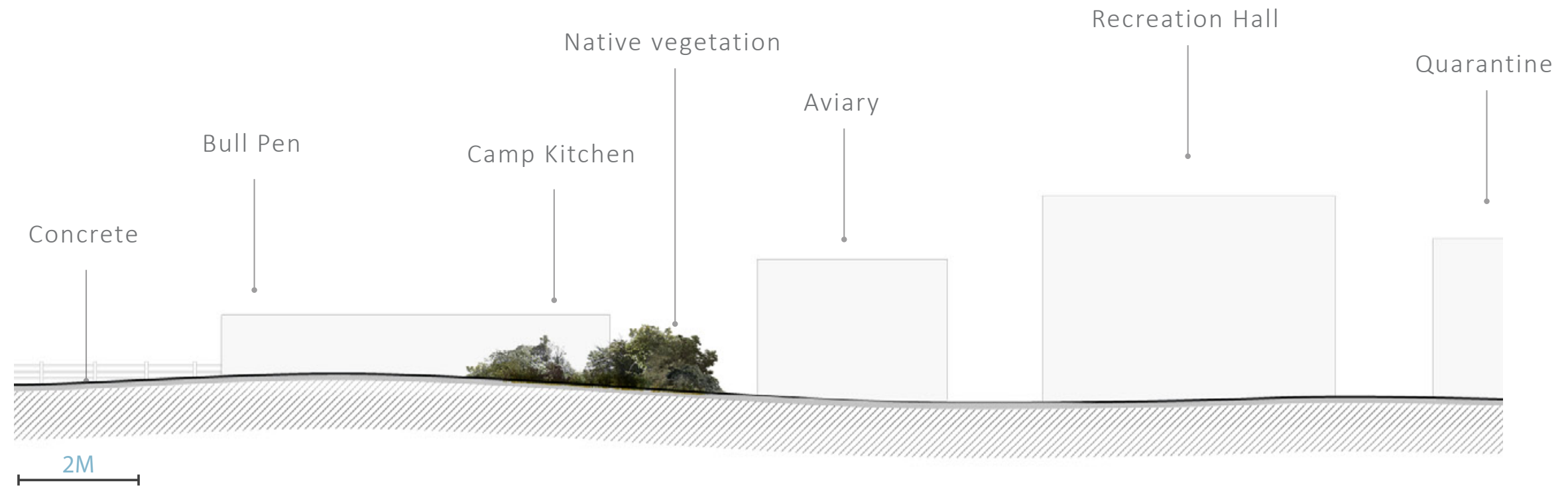

Section B: Small Peak

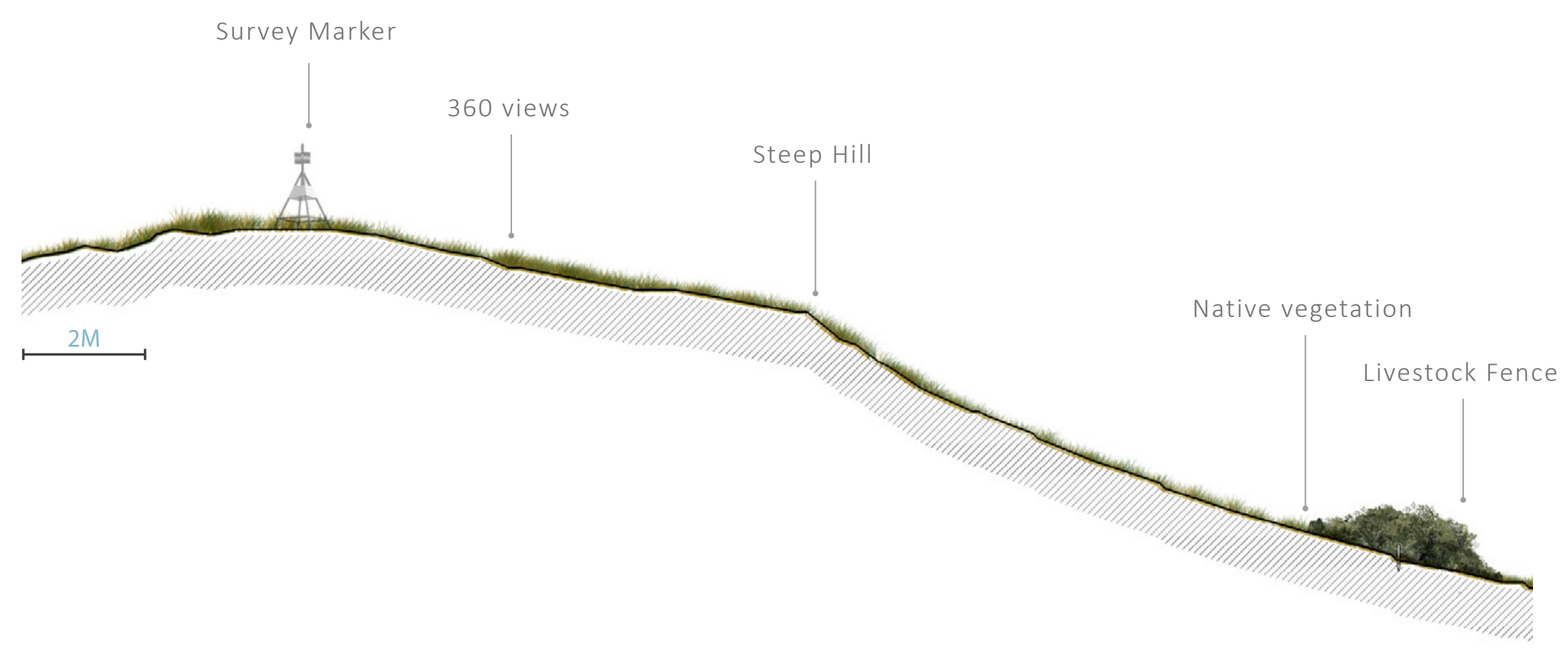

Section C: Main peak and Gun Emplacements

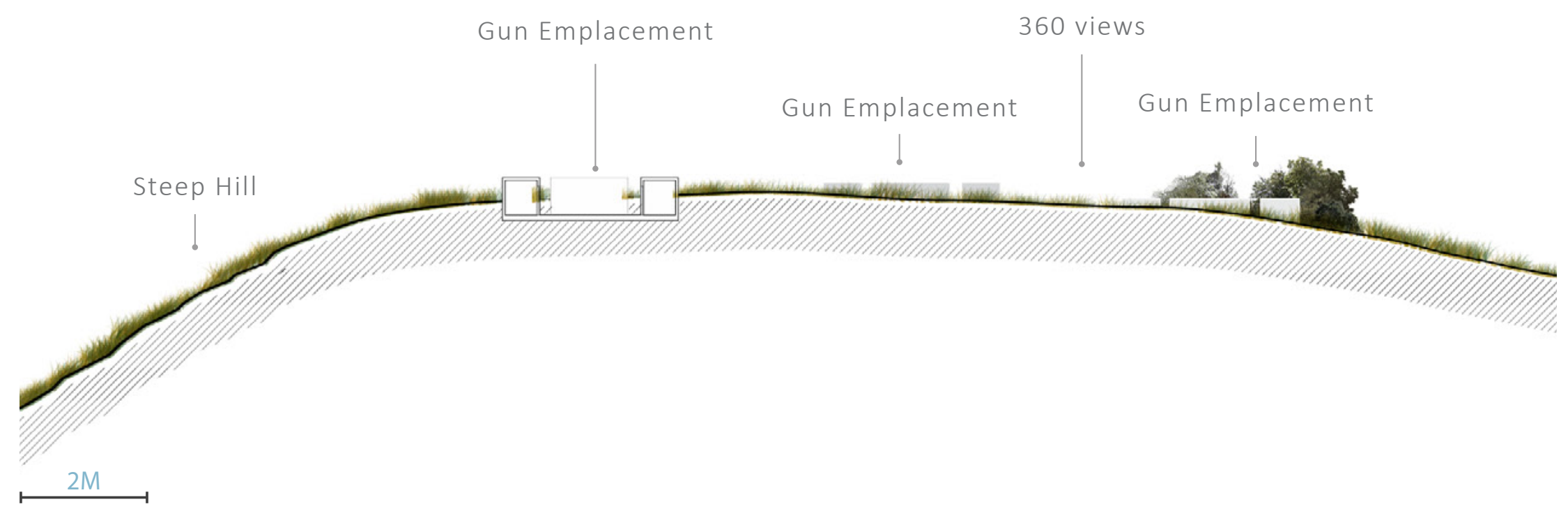

Fig. 32 Sections of the Islands peak 


\subsection{THE WALKWAYS}

The existing pathways on the island direct people from the entrance to a range of different sites. They showcase different ecosystems, wildlife and views out to Pōneke Wellington. They are a series of spaces that visitors spend a lot of their time in while they are on the island.

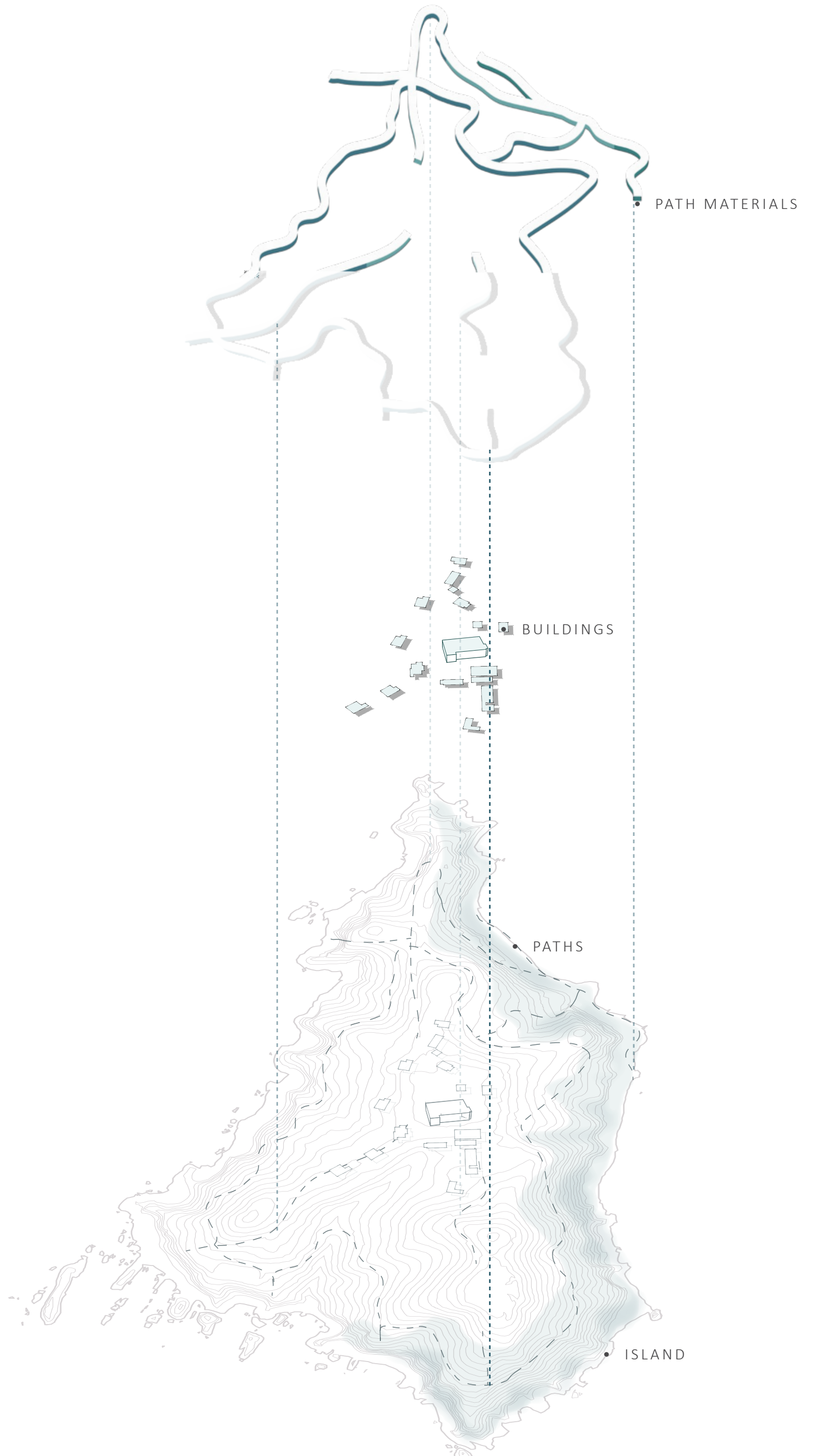

Fig. 33 Exploded diagram of the islands infastucture 


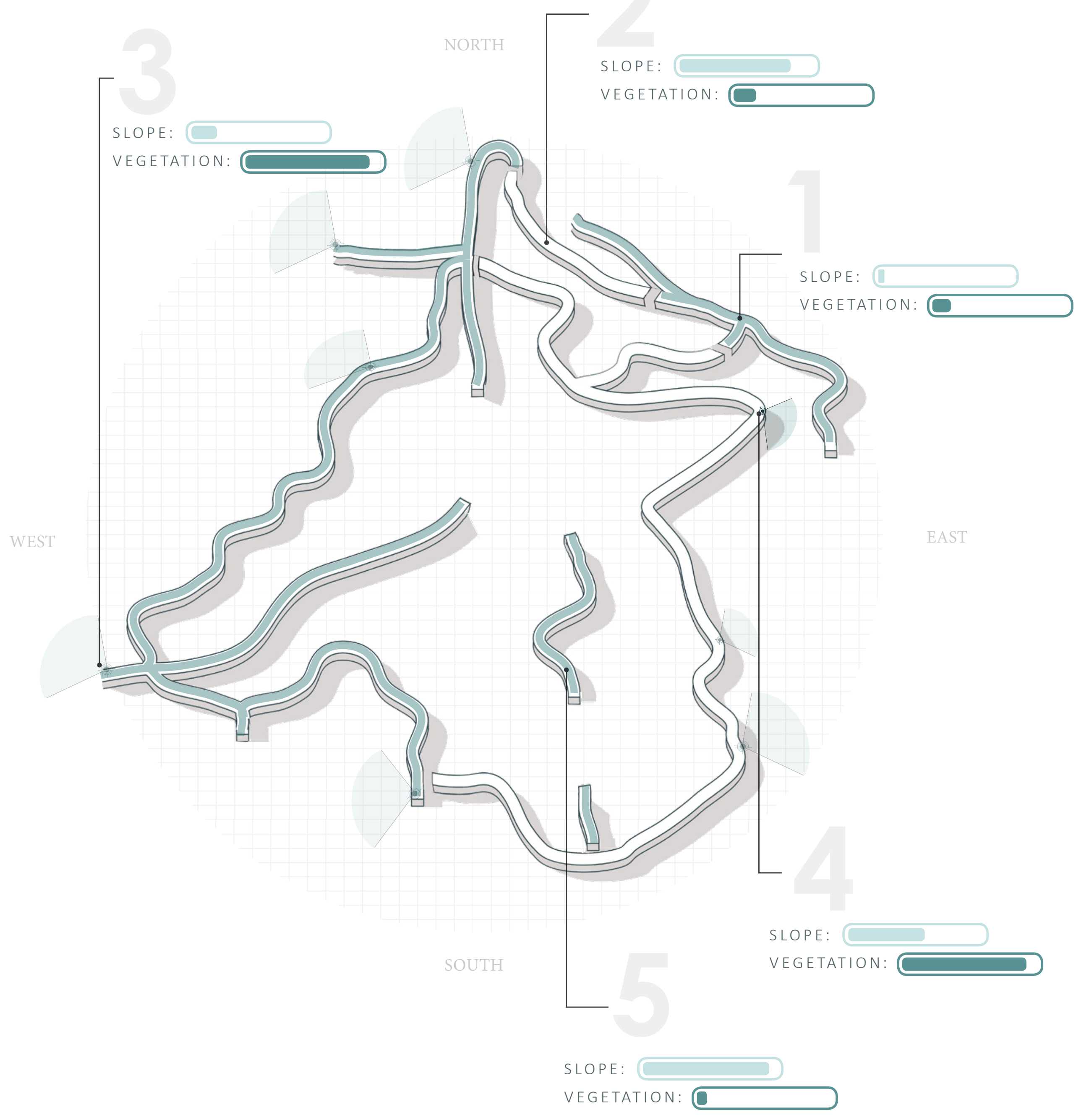


The islands walkways are diverse in ecology and dynamic in sensory experience. Some are lush and fully enclose visitors in vegetation while other are less restored, meaning plants are low lying and poorly maintained.

PATHWAY ZONE

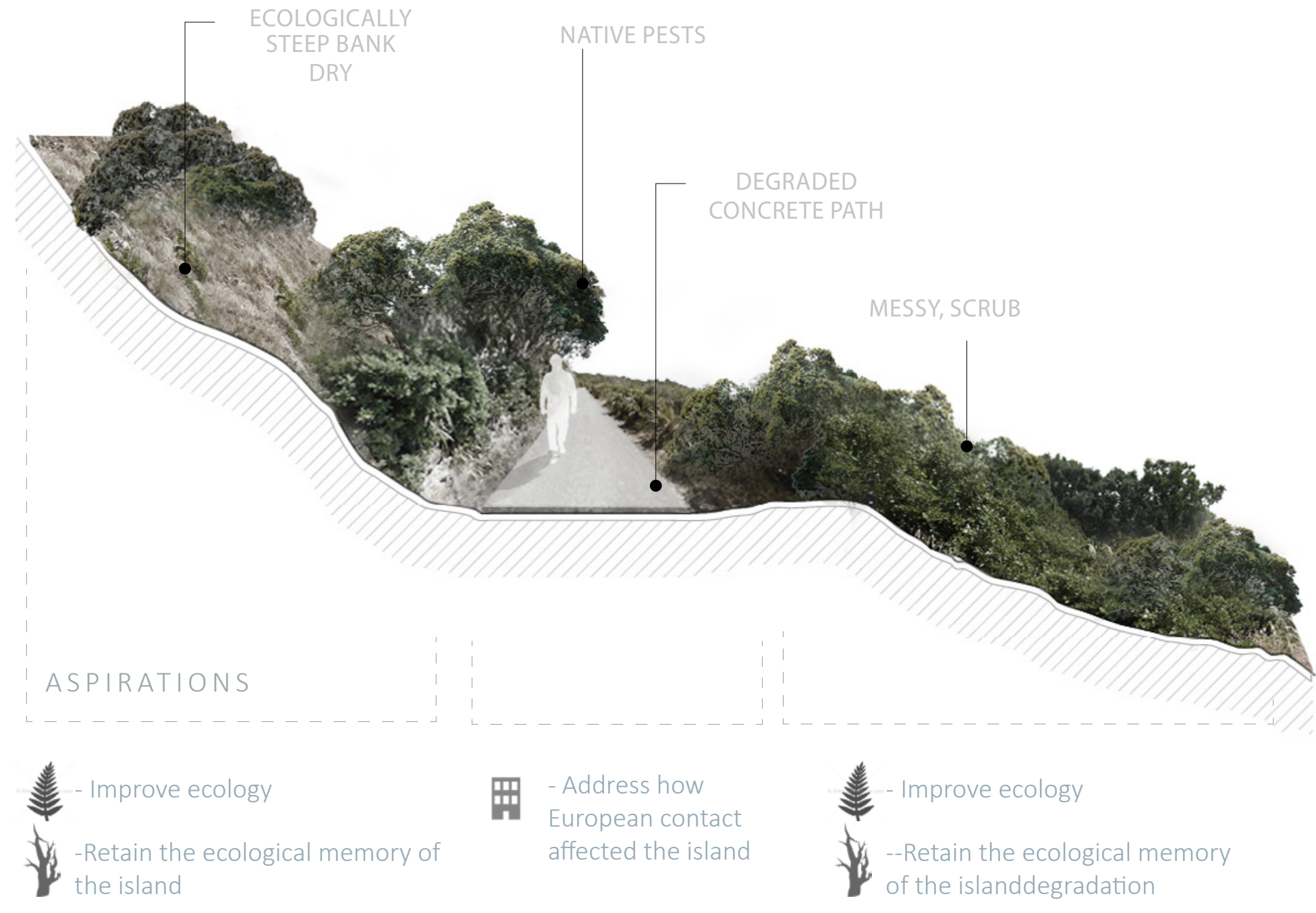

PATHWAY ZONE

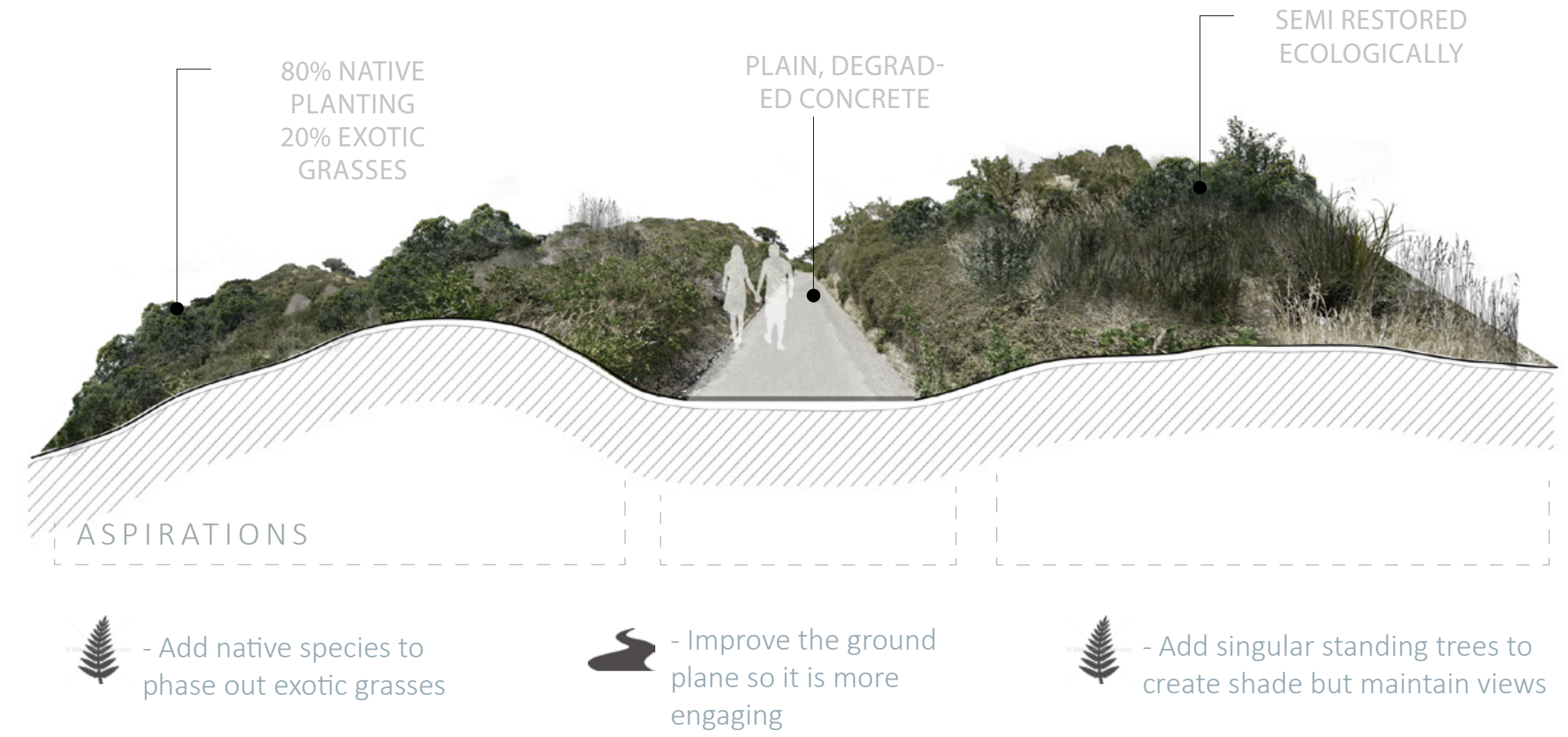




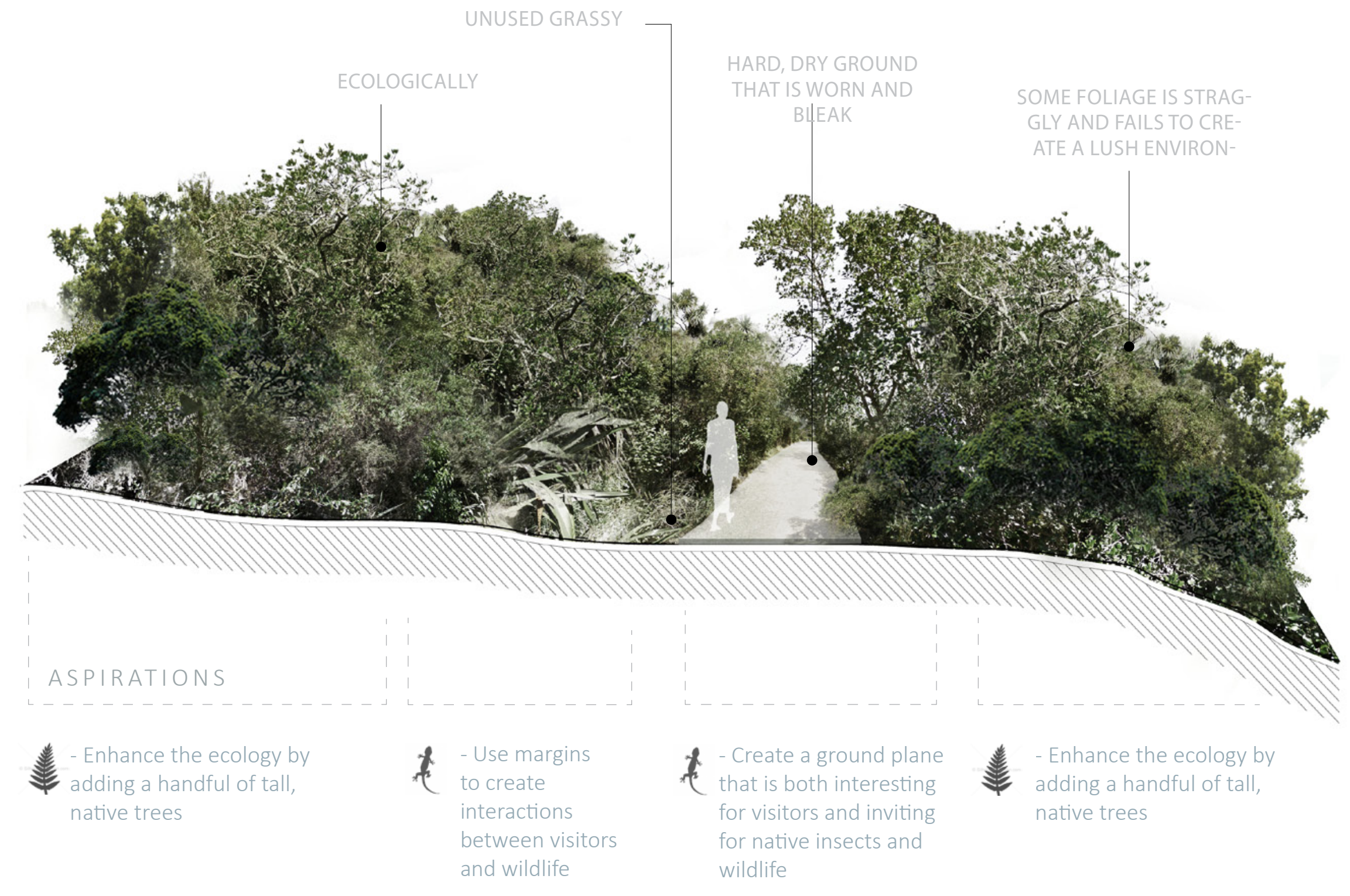

PATHWAY ZONE

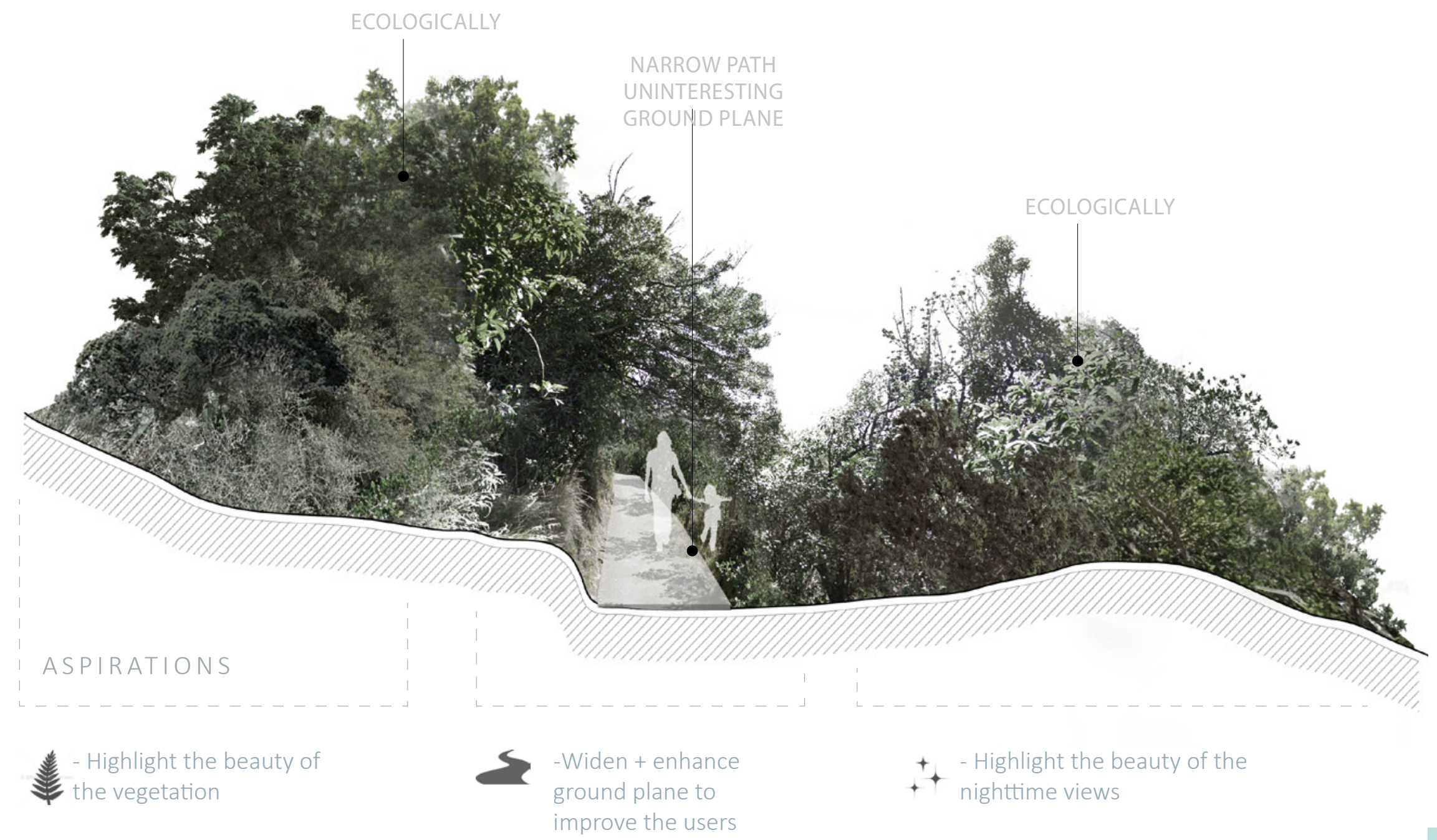




\subsection{FINDINGS}

Matiu Island is dominated by European landmarks due to its diverse utilisation throughout its time under the rule of the Crown. The absence of anything relating to the mana whenua ofnthe island has created a culturally imbalanced landscape that fails to be represent the mana whenua /Taranaki Whānui, their history and their Identity as a tribe.

The three key sites that attract visitors to the island, and that make up a core part of their experience, were the Wharf, the Quarantine building and the peak. However all of these sites were worn down, as seen in figure 36 , and failed to have engaging elements that allowed visitors to properly interact with each site. This creates an opportunity for each site to be developed to enhance its visual, interactive, and therefore experiential qualities, ultimatley improving the visitor experience.

These sites were also historically significant, Māori sites (a Pā, its lookout and a waka landing site) making them some of the richest cultural sites on the island. This indicates that these are potential sites where Māori values and traditions could be integrated back into the islands landscape. Not only would this expose the majority of visitors to the full cultural history of the site (both the European and Māori) but it would also create an educational and experiential opportunity for visitors to learn more about Māori culture and improve and diversify their experience on the island.

Through visually documenting the journey around the island it also became apparent that the pathways were a memorable and significant part of a visitors time on the island, suggesting these could also be redesigned to enhance the overall visitor experience.

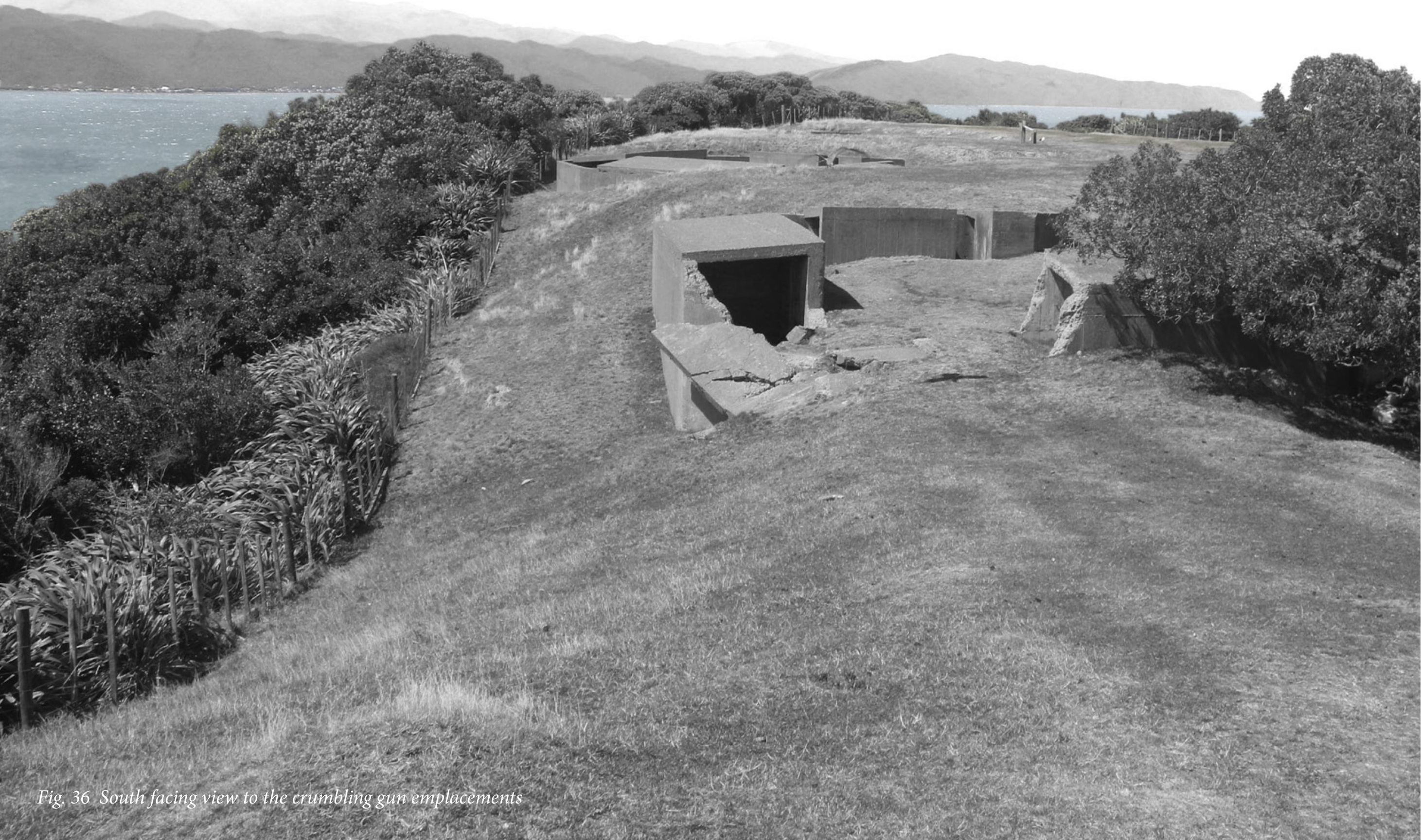




\section{THEORY + CASE STUDY}

RELEVANT LITERATURE AND CASE STUDIES

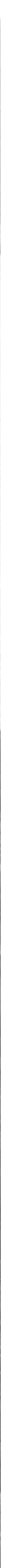




\subsection{INTRODUCTION}

With Māori now involved in the planning, management and future of Matiu island, its programmatic focus is no longer just on ecology and recreation, but it is equally about indigenous culture. This complicates the decision making process because there are a multitude of goals and visions from a range of different parties. Understanding what culture is, how it can be integrated into a site appropriately and harmoniously along with current and envisaged objectives is vital in order to create a multifunctional landscape that successfully satisfy the needs of Māori, locals, the existing ecosystem and its associated restoration efforts.

\subsection{CO-GOVERNANCE}

It is becoming more evident in today's world that environmental problems require collective responses. This ensures diversified and robust solutions are generated, increasing the resilience of a place. (Coombes, 2003). "Action to adapt and maintain resilience in the face of climate change requires adjustment by Governments, individuals acting as citizens"(Adger, 2004, P. 2) and indigenous people through collective action. It is for this reason that cogovernance has become a common solution for the management of land as it creates the opportunity "for dialogue and power sharing among land owners, resource users and managers" (Coombes, 2005, P. 136 ).

Co governance has become essential for native land to actively "incorporate Indigenous peoples into decision-making, and generate policies that reflect local ecology and culture" (Coombes, 2005, P. 135). Research in this field has found that co-management has the ability to reconcile conservation with social needs, which is fundamental when dealing with Māori land that is accessible to the public. This has been achieved through the sharing of power and decision making which enriches the resource management process, making it more responsive to a range of needs. Harmsworth also discusses the "great importance of understanding the characteristics and properties of whenua/Māori land, and the constraints of the land and its management, before embarking on future decisions and opportunities" (Harmsworth, 2017, P. 15).

In order to successfully align different groups incentives it is critical to explore innovative but realistic ways in which to create diversified and multi- functional landscapes, enabling the land to satisfy a range of needs within one space. (Harmsworth, 2017) Co-governance creates the opportunity to identify common motivations that many or all parties value as important, creating a synergy between multiple visions and shedding light on potential multifunctional capabilities of the land. 


\subsection{COMMON MOTIVATIONS}

The two main parties involved in the governance and management of protected land in Aotearoa New Zealand tend to be Māori and DOC representatives. In cases involving publicly accessible land, local community representatives are also involved to ensure the needs of these users are voiced. Research exploring successful models of co-governed land emphasise the importance of identifying the motivations of each party, group or individual to try and identify commonalties between them:

- Māori

Although their specific agenda depends on the characteristics of the land and the tribe, Māori generally want the Mauri of the land to be restored. This involves ensuring Māori culture and the identity of the tribe is represented on the site and the natural enviroment is protected and enhanced.

- The Department of Conservation DOC's main concern is the conservation and enhancement of the natural environment and its historical heritage, as well as educating the public on the work they do.

- The Local Community

Communities often utilise these sites for their diverse range of recreational activities and educational opportunities regarding native environment.

From examining the three parties general intentions it is apparent that there are three common motivations all parties can agree on (although these change from site to site and in hierarchy) are cultural experiences, human and environmental health, and education. These three topics are explored throughout the remainder of the literature review to provide an understanding of each topic and how it resonates or is viewed by Māori.

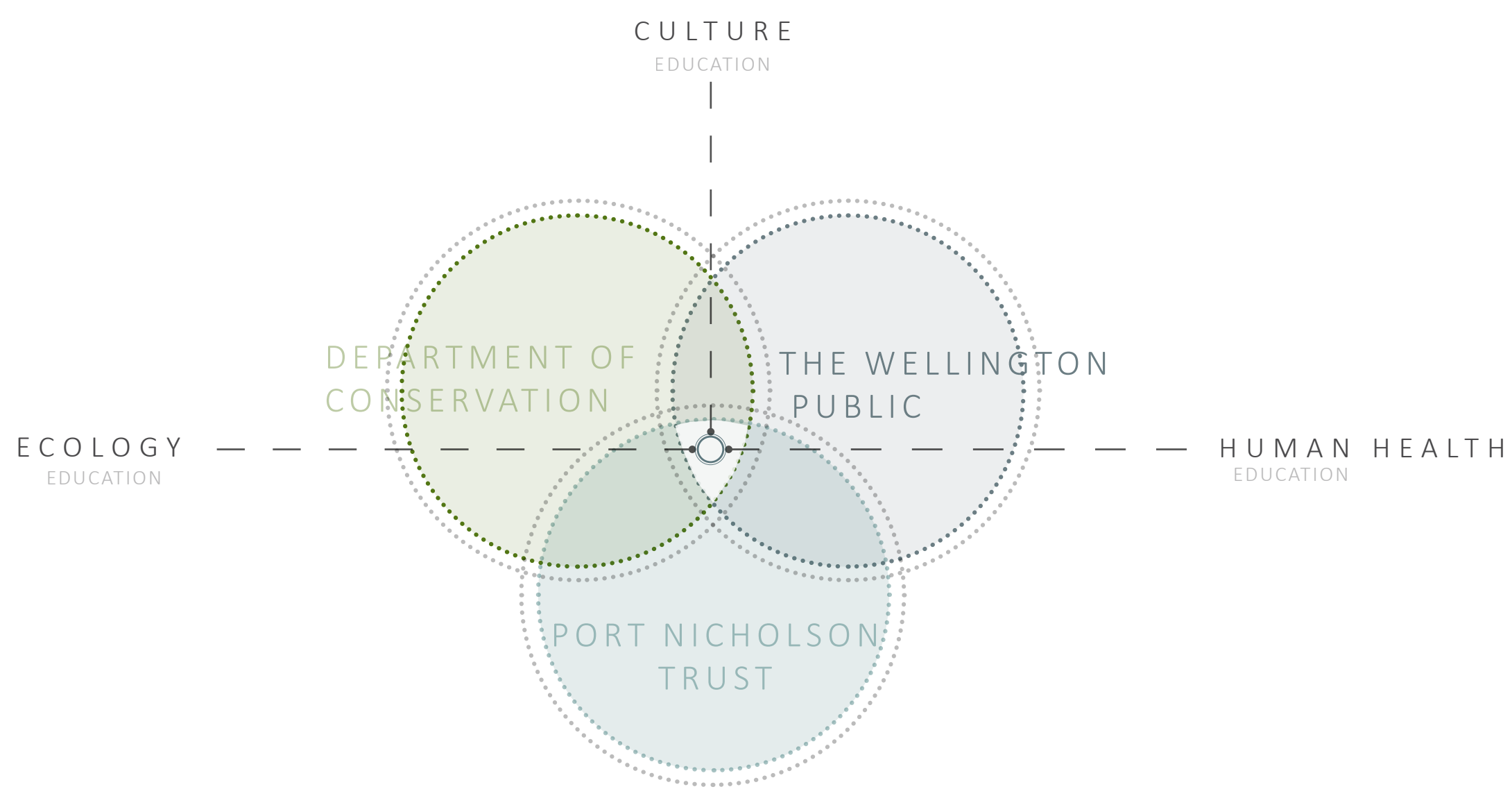

Fig. 38 The Kaitiaki Boards common motivations diagram 


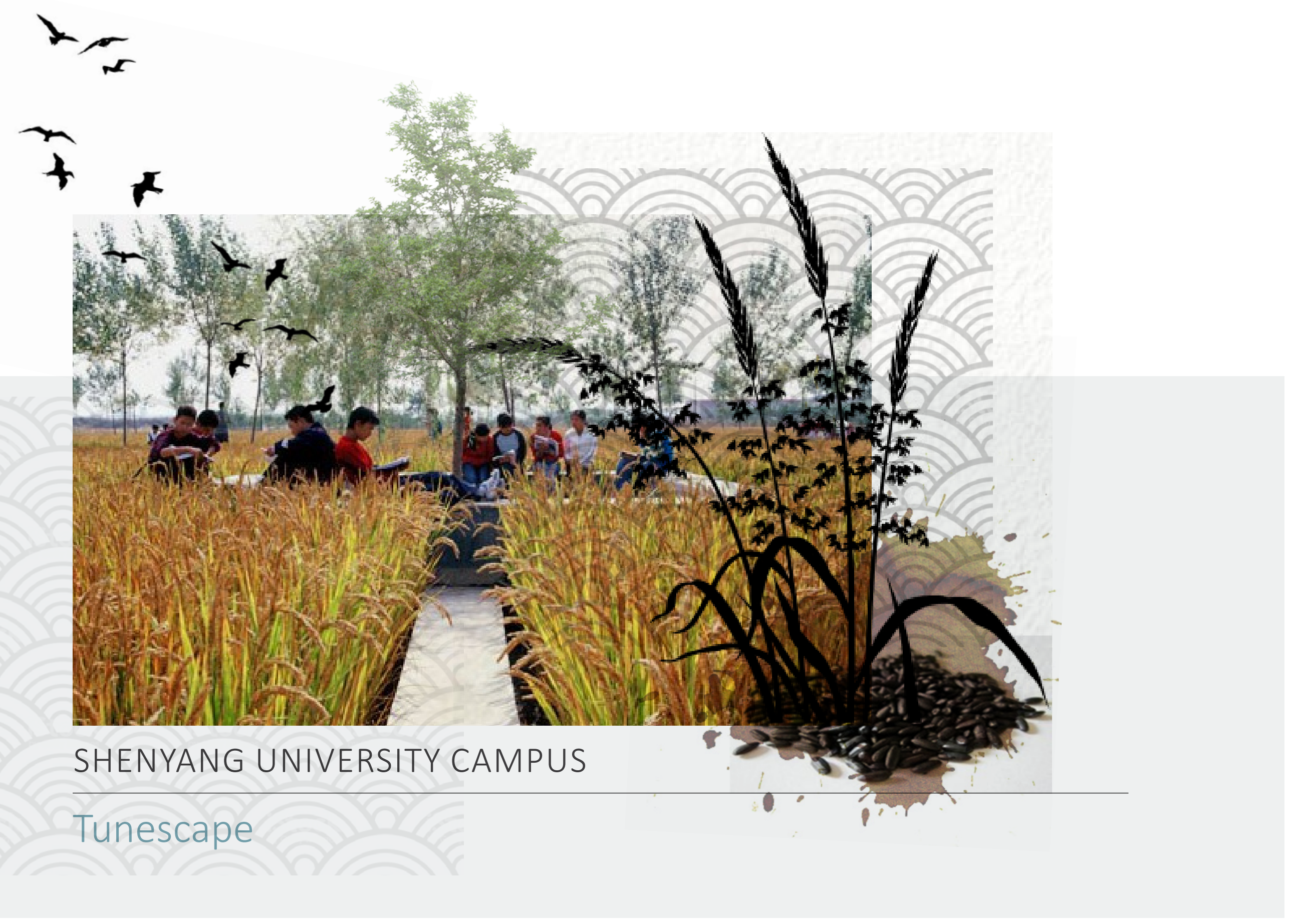

The Shenyang Architectural University Campus is an example of a multifunctional landscapes that satisfies the needs of a range of stakeholders and address a range of relevant and pressing environmental issues .

As China has a population of 1.3 billion people food production and sustainable land use are two of Chinas largest and pressing issues (Turenscape, 2014). In response to this issue, the campus's landscape was transformed into an educational and economic resource that drew on traditional references to produce a sustainable and efficient space. Turenscape identified that the cultivation of rice paddy fields was the regions most traditional and common use of land, which is also the region's main source of income, and fused it with the sites current needs for educational and social space. By doing this the landscape architects were able to create a social, productive and educational landscape that was economically rewarding. (O'Farrell ., 2015) modern thinking, can embrace cultural traditions and allow a specific group of people, as well as a city and region to benefit from one productive piece of land. The land, through the layering of different programmes on one horizontal plane, seen in figure 39 , can successfully provide local jobs, create learning opportunities, encompass social spaces, store its own water and generate food and income.

The Shenyang campus also unites students and farmers in one place is "to build a bridge across a widening gap in the fabric of Chinese society"(Turenscape, 2014, P.

1). This creates a unique chance for both parties to share their knowledge with one another which creates opportunties that have endless potential.

This multifaceted design, that unites two groups of very different, but important people, is a landscape that is of great precedential value to the development of Matiu Island, providing insight into how Maori and the local community could be united within one space.

The Shenyang Campus conveys how a small area of land, through the mixture of traditional methods and 


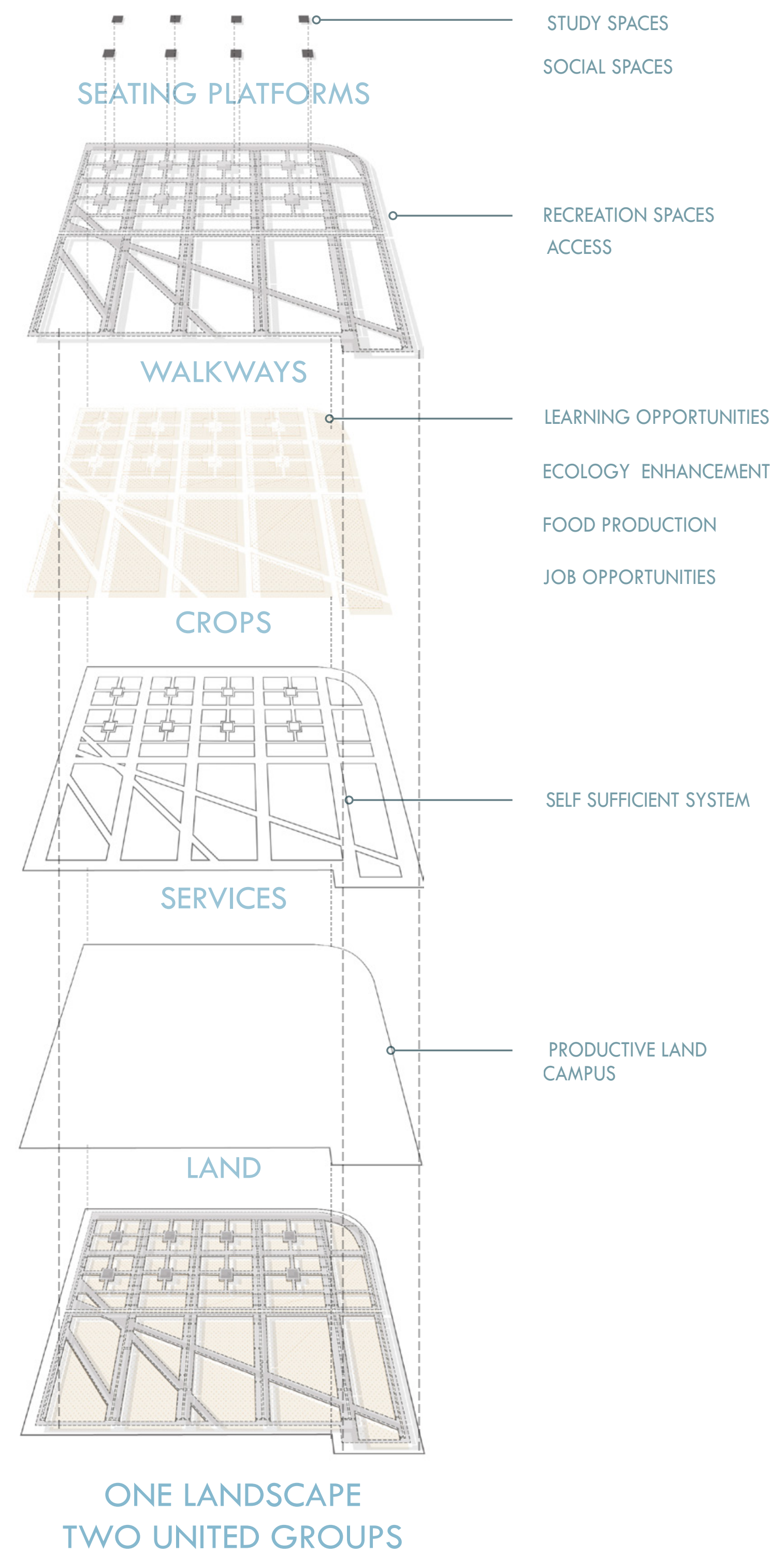

Fig. 39 Exploded diagram of the Shen Yang University campus 


\subsection{CULTURE}

Culture arises from the interactions between people and the landscape. Culture relies on the landscape to supply people with the tools and resources needed to survive and celebrate living, which inevitably leads to these resources becoming a part of everyday life and the development of customs and traditions that are unique to that environment. Culture is therefore the outcome of the spiritual, emotional and physical connection that we, as humans, have with the land we live upon. As each country, region or area differs in climate, vegetation, geology, topography, the way people have interacted with the land, throughout history, differs from place to place. These interactions have produced different customs, values and traditions highlighting what is valued within each place, making up what we consider to a culture. These differences, leading to adaptations in the way people live and behave, are what makes the world's cultures diverse and unique. As we have evolved, culture has become the way people identify themselves as individuals and as a collective. We are all people who live on this Earth, but it is each person's identity that derives from their culture, that sets them apart from the rest of the world. 
The distinctive identity of a particular place results from the interaction of many factors, including built form, people, activity and history. (Council, 2017)

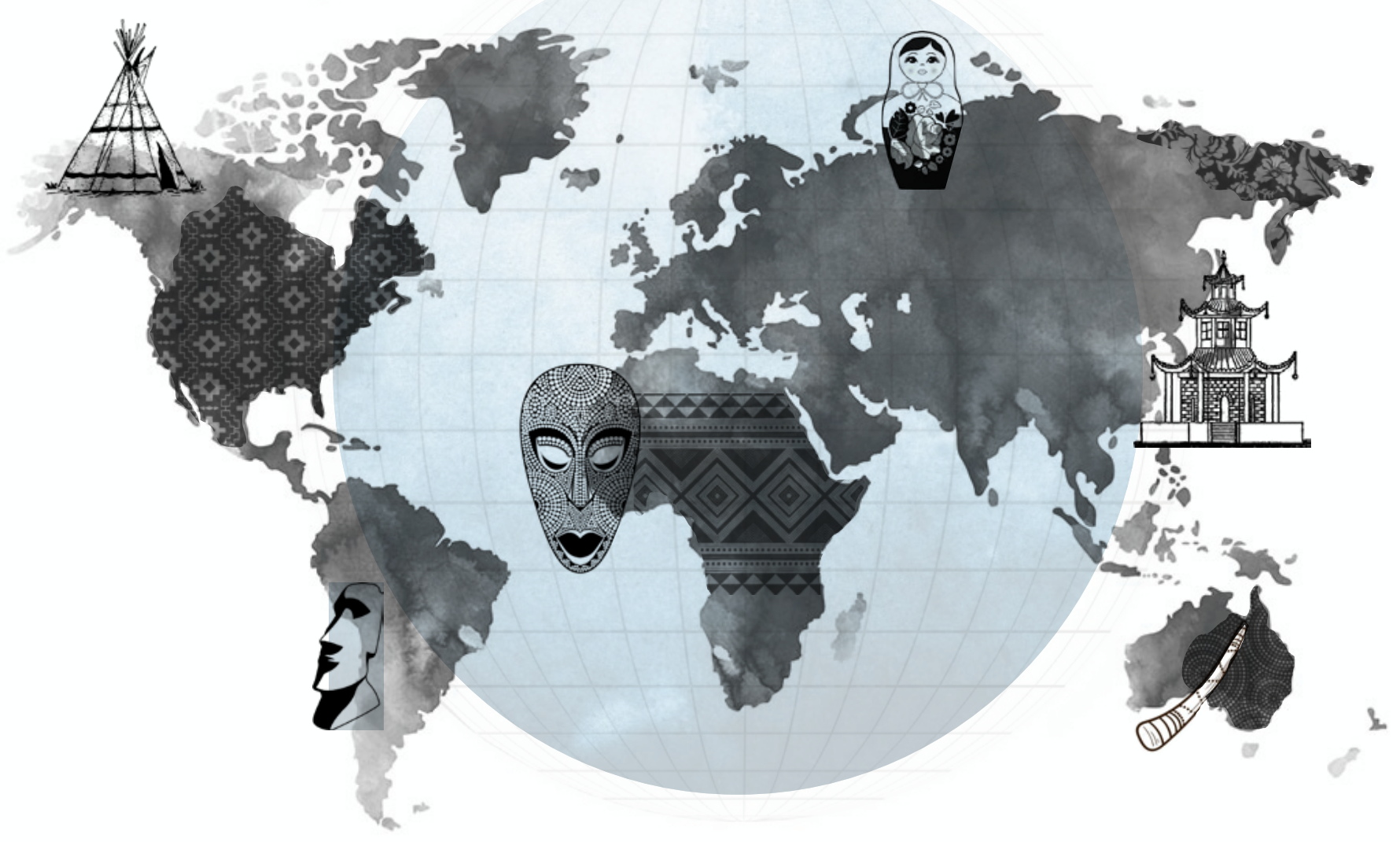

Fig. 40 World's Culture Collage 


\subsection{THE IMPORTANCE OF IDENTITY}

A sense of place is an important concept that allows people to connect to a space through an aesthetic, ancestral, cultural or spiritual relationship with land. One of the main issues with land that has been handed back to Māori is its degradation and loss of identity, which results in the loss of connection between the people and the land. Due to colonisation, the landscape of Aotearoa New Zealand has been exploited and now houses non-native flora and fauna species, irrelevant buildings and therefore fails to reference its cultural past. This means the "Mauri" or essence of the land is lost. Māori Identity is based on concepts that derive from traditional Māori ecology and emphasise the importance of traditional Māori values and social organisation (Houkamau, 2010). Relating to this are strong associations to Whanau (family), Hapu (extended family) and Iwi (tribe) which are key to Māori Identity. Wairuatanga (Māori Spirituality) is the awareness of ones Tipuna (ancestors), and their traditions and close relationship to the environment. "From a Māori perspective, identity, spirituality and the natural environment tend not to be conceptualised as separate entities" (Houkamau, 2010, P. 10). The traditional Māori understanding of the human existence is that one's self is intrinsically linked to the natural world through mind body and soul (Houkamau, 2010).

"The significance of a rooted sense of place is found in a cosmology that forges spiritual connections to nature and place, sustaining indigenous societies such as the Māori. This ideology recognises the relationship between rootedness, sustainability and the significance of a moral relationship with nature" (Hay, 1989, P. 246). "Māori remind us of the importance of community and ties to the land that continue over many generations, extending to ethical relationships with the nature that has supported them"(Hay, 1989 P. 247). The land should not only reflect its native origins, so that it has its own sense of identity, but it must reflect and foster Māori values, principles and beliefs in order for it to continue to be a reflection of their identity as well. For a degraded site to have its identity restored, all people involved in the restoration process need to be aware of the original native state of the land, its cultural history (including events and narratives) and the intrinsic values and principles of Māori, which reflects those of their ancestors who once inhabited the land. (Houkamau, 2010) 


\subsection{AOTEAROA NEW ZEALAND'S IDENTITY}

"The distinctive identity of a particular place results from the interaction of many factors, including built form, people, activity and history. Māori culture is what gives Aotearoa New Zealand a unique identity, setting it apart from any other country in the world" (Council, 2017, P. 1).This offers rich design opportunities that can have a positive impact on the built environment, its economy and the people within it. Mãori, the indigenous people of Aotearoa New Zealand, "evolved in important and significant ways as they encountered new environments and elements such as flora and fauna, they had not known or experienced before." (University, 2016) Māori had to adapt to the native Aotearoa New Zealand environment and develop a language, value system and a set of practises that appropriately responded to their surrounding context that evolved over time with the native environment. Their ideals and values relate to the landscape, respecting it and embracing it, resulting in a range of sustainable methods. These methods involve using the landscape to create a suitable living environment that simultaneously allowed the ecosystem (land, forest, water and air) to flourish. The values and knowledge associated with this way of life is the essence of Mātauranga Māori.

The arrival of Europeans into Aotearoa New Zealand in the mid 1700's saw a change in the culture of Aotearoa New Zealand. The introduction of new technology that exploited the land rather than respecting it, meant the focus of the people was no longer devoted to living harmoniously with the environment; instead it was about monetary gain and technological advancement. This lead to a period of rapid urban development which is evident today as "63 percent of Aotearoa New Zealand's land area has been converted for human-related activity"(Foundation, 2018, P.1). This has led to "the extinction of an estimated 32 percent of native land and freshwater birds and an additional 800 species of animals, plants and fungi that are threatened"(King, 2017,P.1). This high level of disruption and extinction is largely due to the harvesting of native species and the introduction of invasive species (Clarkson, 2007). As the European way of living completely opposed the indigenous one, Māori culture was discouraged and superseded. 

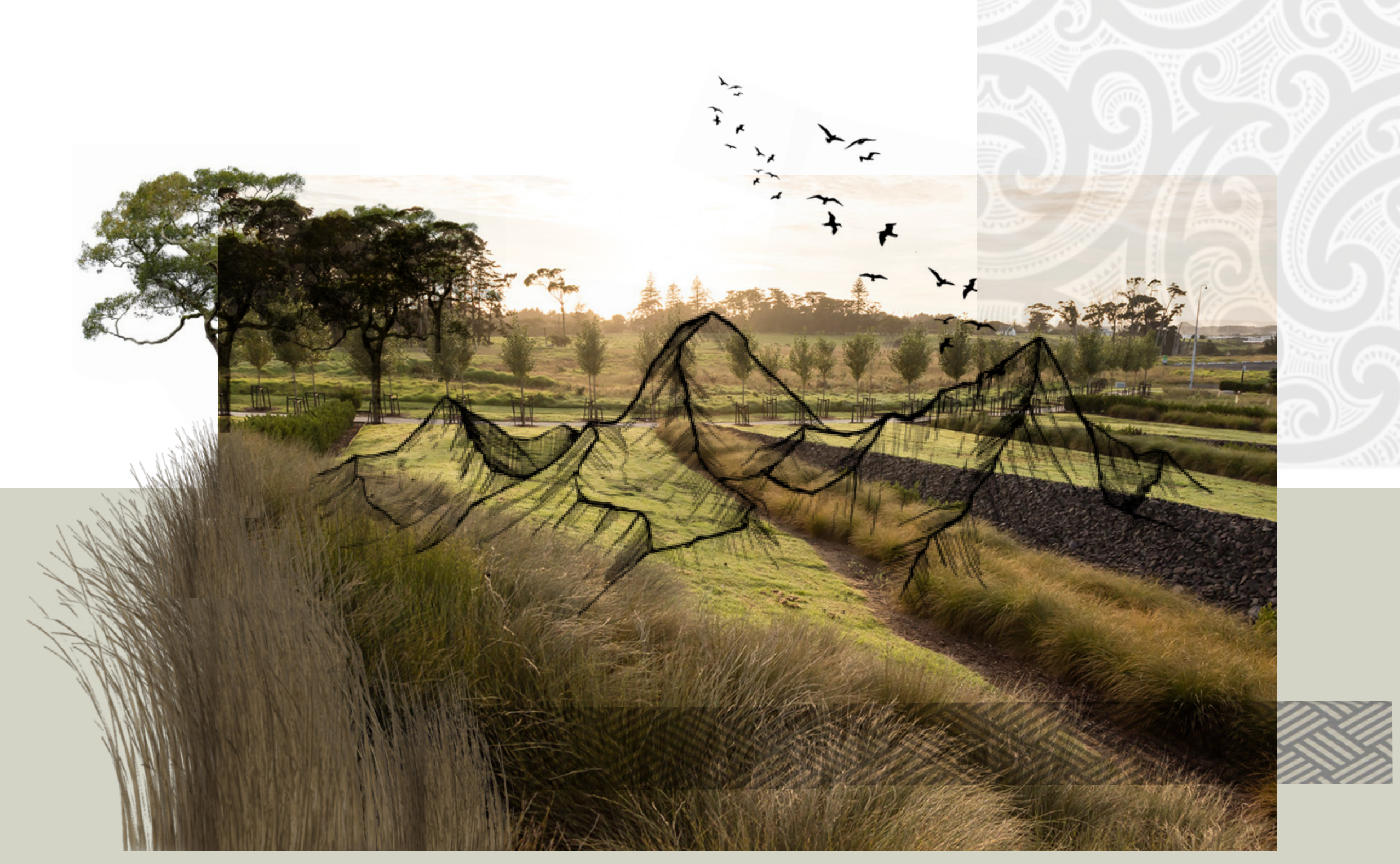

AUCKLAND AIRPORT LANDSCAPE, AUCKLAND

\section{Surface Design}

The design of the Auckland Airport is a clear example of how to restore a sense of place and the identity of a degraded site.

"Grounding is to do with orientation and rootedness"(Girot, 1999, P.62). The concept of landing and being grounded to a site, founded by Christophe Griot describes the impact of the arrival experience. It is about the relationship between the landscape that first welcomes a person on to a new site and the way the site presents itself, revealing the initial essence of the site.

The Auckland Airport is a prime example of a site within Aotearoa New Zealand, where people from all over the world become grounded within the country and the landscape surrounding the airport paints the first impression of New Zealand. James Lord, the designer of the new entrance way to the airport believes that this landscape has been wiped of its culture and traditions due to engineering standards and infrastructure that slowly creeps into the urban fabric, taking over before anyone has the chance to realise. (Barrett, 2014).

Lord went on to design the kilometres of land leading up to the airport with the emphasis on making the site an actual place not just a final destination using a "transect of New Zealand geography and ecology" (Barrett, 2014, P. 1) to do so. His design was driven by the "merging of cultures, and a fascination with first responses to this land; how when people came to New Zealand, they transformed the landscape"(Barrett, 2014). He acknowledges the land has been engaged with in two distinct ways, the Māori approach, where the earth was carved and lined for Kumera pits, and the European approach, which was more of manicured method using hedging and straight lines to grow and protect food crops and box in livestock.

The airport's landscape has been reshaped to reflect these two approaches. The massive earthwork mounds represent Kumera mounds, covered in volcanic stone on one side and visually textural plantings of Oioi and Carex on the other, showcasing native materials and dune land ecologies Māori worked with and lived amongst. Hedgerows surrounding the mounds create boulevards you can walk or cycle through, while Poplars recall the memory of the farms that were once operational in this site. Both the Māori and European elements work together to create a large silver fern and patterns, only visible from the sky. Lord believes this design "Orients your eye and makes cultural and physical connections happen"(Barrett, 2014), between yourself, the landscape and its past. 

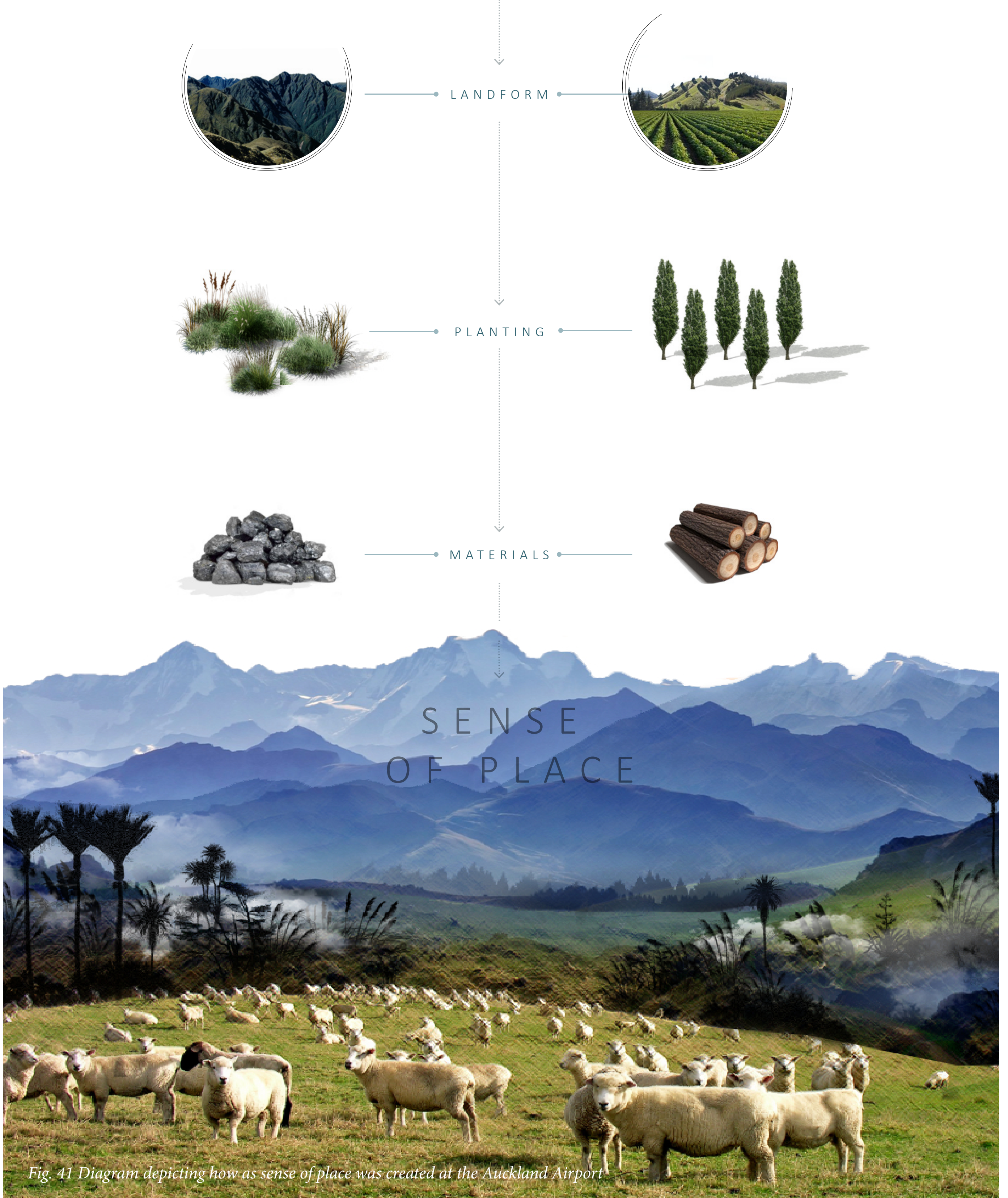


\subsection{INDIGENOUS NARRATIVES}

The relationship between indigenous peoples and land gives rise to Māori culture and it has generally "manifested in oral narratives, tales, songs, customs, and approaches to healing and birthing, as well as death rituals" (Marques et al. 2018, P. 2). Māori culture is deeply rooted in oral traditions including the passing on of narratives, and storytelling. These are used as a "transmission tool in passing down social, ecological, economic, and political constructs to the next generations" (Marques, 2018, P. 4). Oral narratives have the capacity to connect the past with the future, the land with the people, and the people with the story. (Marques et al. , 2018).

Māori values are deeply embedded in landscape but also in a spiritual, communal, and ecological construct, which are conveyed through narratives and myths (Marques et al., 2018). Representing these in the landscape is essential to ensure Māori can validate their culture, keeping it alive and evolving. By engaging with mana whenua to identify significant narratives and customs, they have the ability to gain a level of control in a design environment, rather than the designer, which is integral to the development of the site and its relationship with mana whenua. This creates a platform for stories to become both the method and meaning in the understanding of the values that create the identity of a place (Marques et al, 2018).

Harnessing significant narratives for the purpose of design enables these stories to become a representative and educational tool for the mana whenua of the site and the visitors, which enables Māori to have a presence while share their history and culture with others. It also allows the landscape to be repaired or enhanced, creating value for all parties involved. 

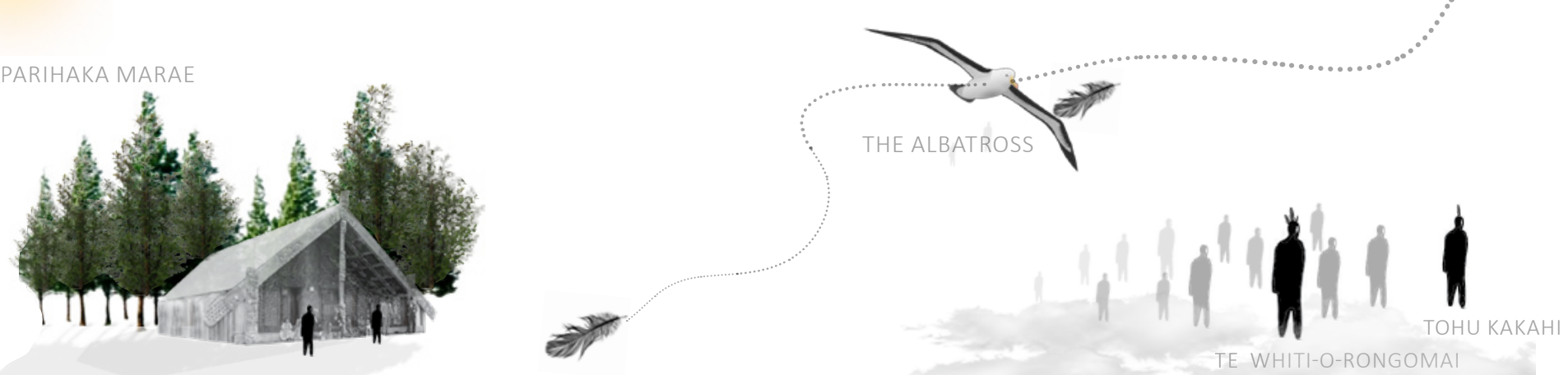

Fig. 42 The visual depiction of Te Raukura, an important Te Āti Awa narrative

\section{TE RA U KURA}

Te Raukura is the story of two honourable prophets

from Taranaki who taught their people to live in

harmony and unity. 


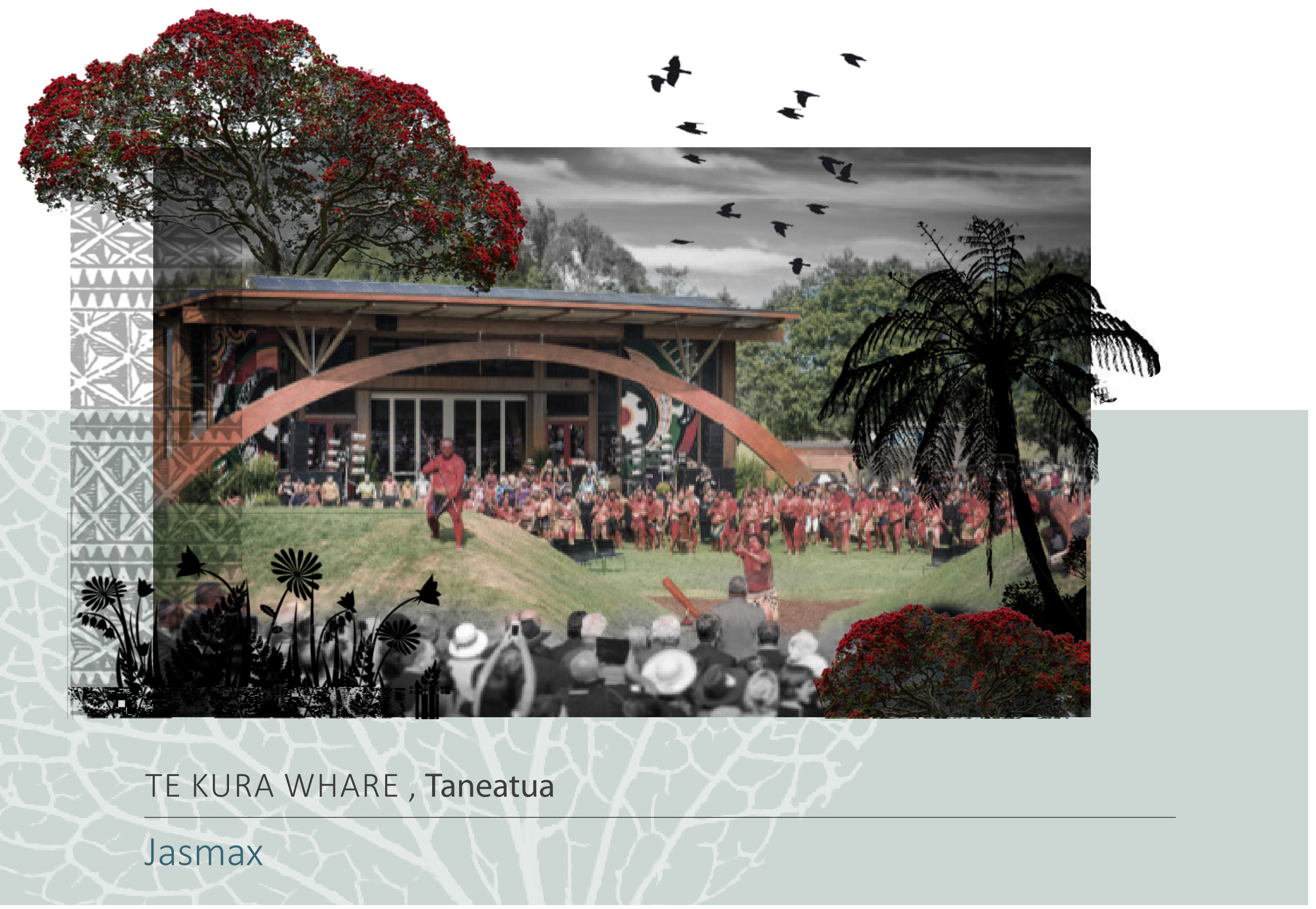

Te Kura Whare is a project that uses narratives and symbolism to reference the origins of the Iwi and their history. This is then used as an educational tool to enable them to share their culture with others.

Ngai Tūhoe are a large Māori tribe found in and around Te Urewera, a large national park in New Zealand. "Tūhoe Identity and culture is inseparable from place and from the land. When their land was taken away, it severed that vital connection and led to decades of disempowerment and despair" (Institute, 2018, P. 1 ). After receiving cultural and financial redress from the Waitang Treaty settlement tribunal, one of the first major investments Tūhoe made "as a regenerative symbol of their tribe, was the living systems, sustainable, design award winning building Te Kura Whare" (Menzies, 2018), with the intention of connecting Tūhoe people back to the land.

The building is designed to represent the Māori belief that people must restore the spaces they live in and live within their means. Te Kura Whare is the 15th certified Living Building in the world, and it is New Zealand's most advanced sustainable building (Waatea, 2017). It has achieved this by embracing the demands of the living building challenge to become net-zero energy and water, as well as zero waste and toxicity from the build. (Jasmax, 2014).

Te Kura Whare's most distinctive design feature is its large timber arch, "which simulates the flight path of Tama-nui-te-rā (sun) across the sky, from east to west." (Tuhoe, 2014, P. 1). The rising of the sun represents the potential of each day to bring forward opportunities and for progress to be made towards goals. This is of great importance as it "encourages Tūhoe to look forward, rather than backward at the bitter legacy of colonialism" (Institute, 2018,

P.1). The building uses natural logs as posts, beams and trusses "emulating the forest and reflecting the vital role trees play in the wellbeing of Tūhoe people"(Tuhoe, 2014). Relating to this concept, the architects played with the way light enters the building, creating the same effect of being in a forest where light streams through tree is creating pockets of warmth against the shadows. "Tūhoe who enter the building at once feel at home, surrounded by natural wood and natural light"(Institute, 2018). The front of the Whare has two design panels depicting important imagery such as animals that have meaning to the tribe such as a bird, relating to peace, quietness and the forest, as well as the use of circular symbols representing the continuation of life (Institute, P.1) and the passing on of important roles and knowledge. These panels tells stories of the past and what the tribe hopes for the future, provoking he retelling of stories to the upcoming generations and creating ways in which the people of the tribe feel connected to the building.

"Te Kura Whare is an exemplar of the Tūhoe connection with Te Urewera - nature. The disciplines and standards that emanate from nature to shape our people are brought to life in our Living Building"(ArchitectureNow, 2017, P.1). 

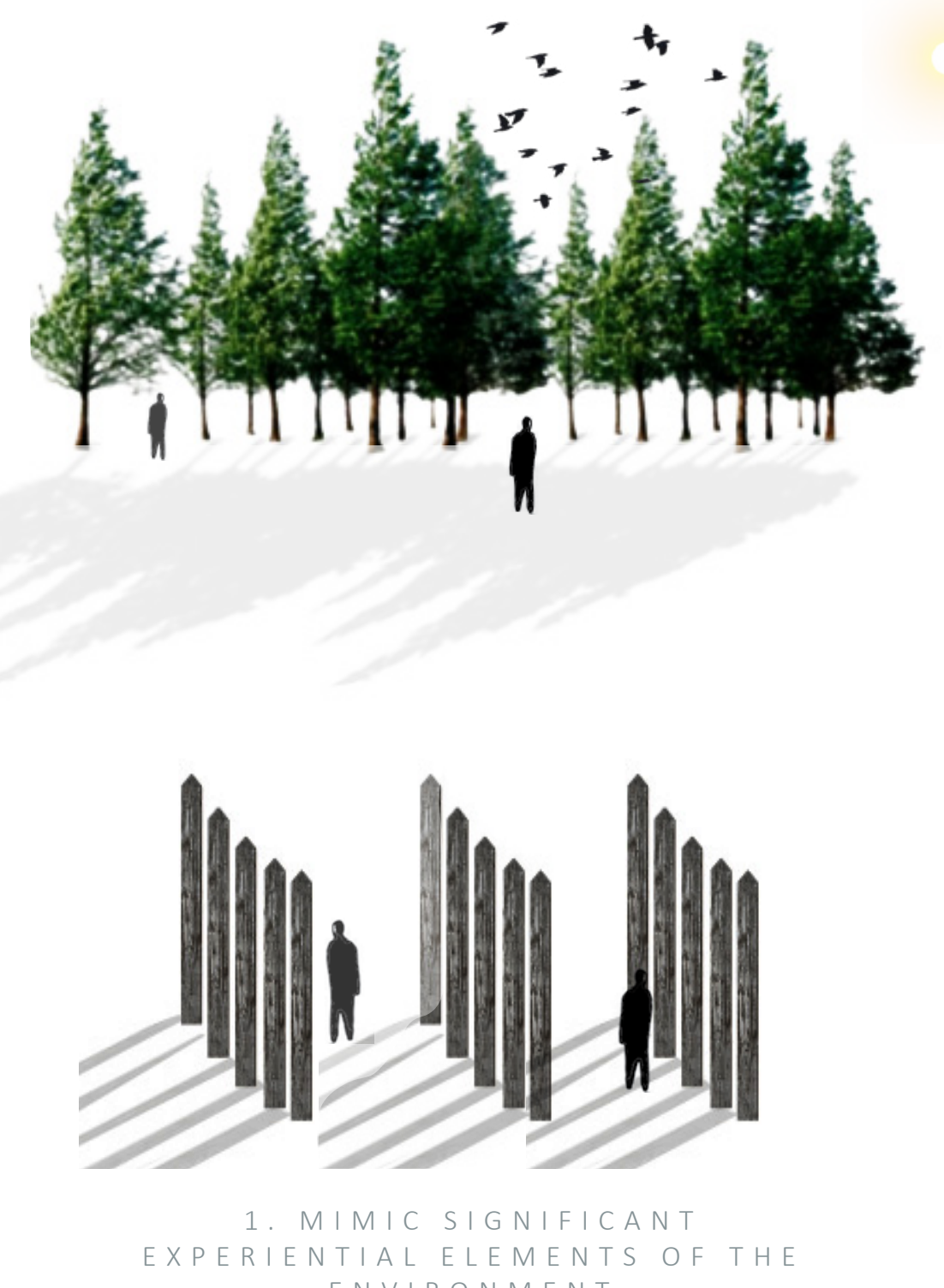

EN VIRONMEN T
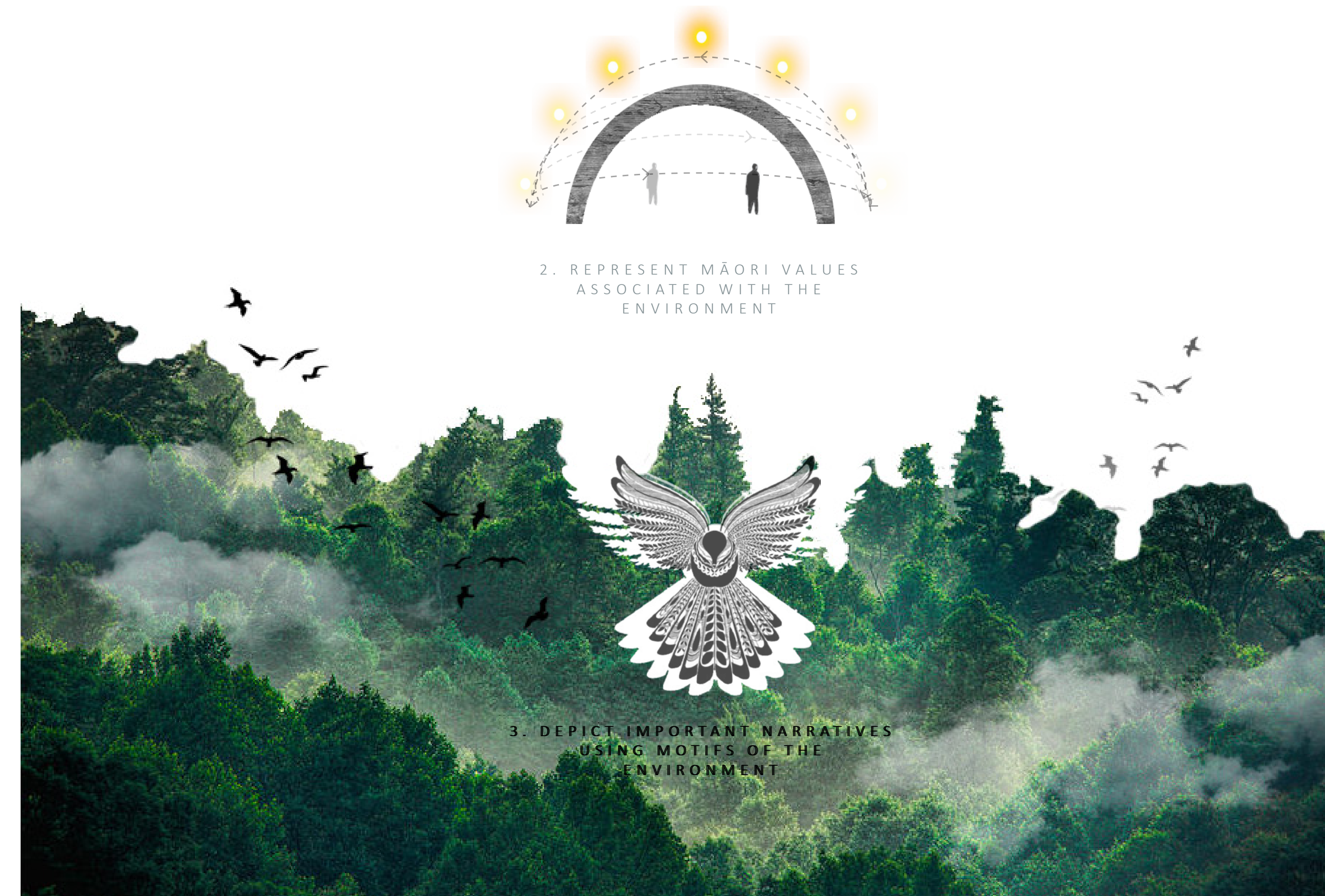

Fig. 43 A diagram of the influential narratives that were translated into space in the Te Kura Whare design 


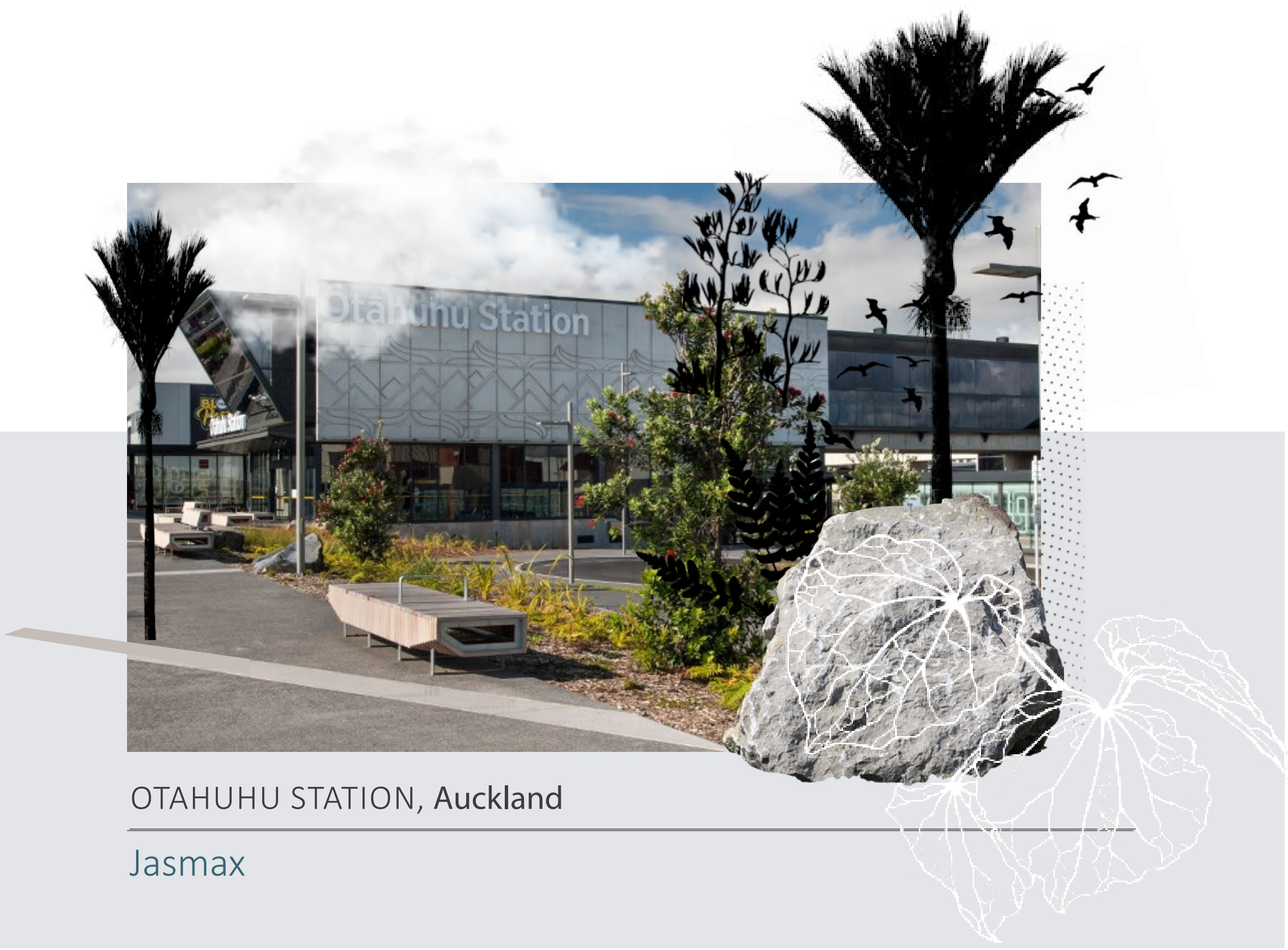

Otahuhu Station in Auckland successfully conveys how oral narratives can be transformed into physical design elements through the use of materials, planting, artwork and wayfinding.

The Otahuhu Station project used Iwi engagement as a tool to solidify and strengthen the significant narratives of the site. Iwi involvement was managed from the start of the design and "as a result of this engagement Mana Whenua kaitiaki were successfully able to convey creative concepts and narratives to the design team"(Council, 2018a, P.5).

The design team laid out three main themes for the design based off iwi engagement, based off the most significant narratives that were shared. These themes were Waka, Maunga (Mountains) and navigation. The team used narratives and the geographic location of the site to give the themes a form and place within the design. The orientation of buildings and landscaped elements referenced Waka, their arrival in the area and the marks they made when dragging the waka to the shore. Patterns and materiality were used to reference the navigation that helped direct
Māori to the site. The incorporation of Whetu/star design on the entry of the station symbolised a safe passage ahead. For the sculptural elements of the design, basalt rocks from the sorrounding area were printed with the Māori names of nearby mountains and faced in their associated direction. This acknowledging the role mountains played in the identity of the site and the wider Auckland region, and brought attention to their degradation due to quarrying.

The use of narratives which were shared and then expressed through landscape design, created a more robust, insightfu and meaningful design that speaks of its origins whilst looking forward. The site cleverly refers to old methods of transportation and navigation and uses it to create a modern sight for the same purpose. The beautiful grounds which are enriched with historic narratives clearly demonstrated the importance of Iwi engagement and their important role in creating a site with a unique identity. (Council, 2018a) 


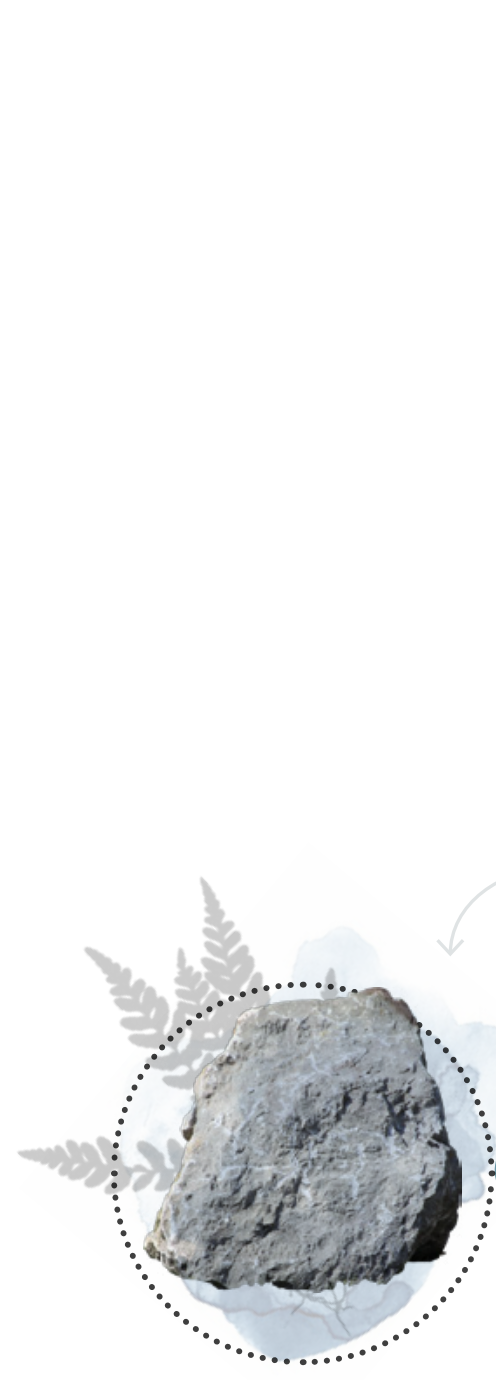

MATERIALS

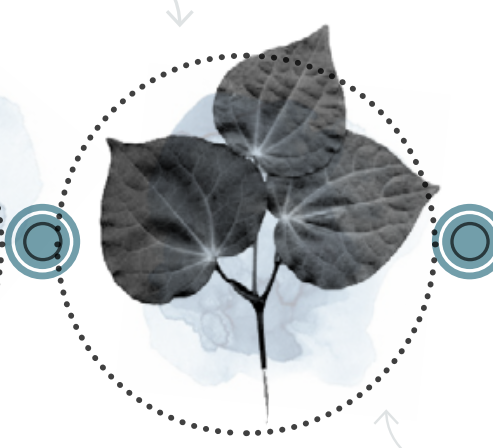

$P L A N T I N G$

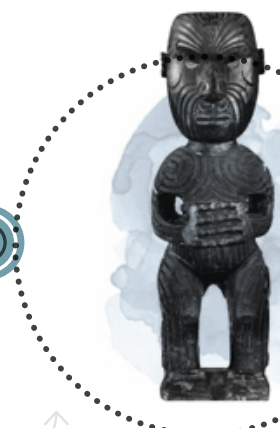

A R T W O R K

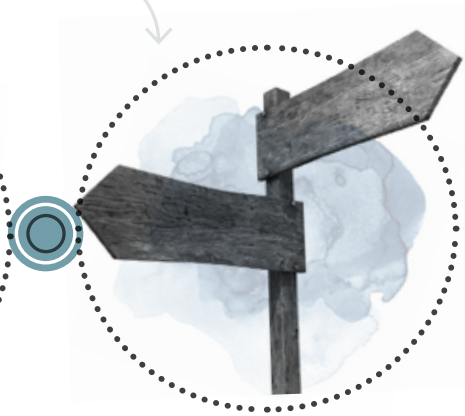

WAYFINDING

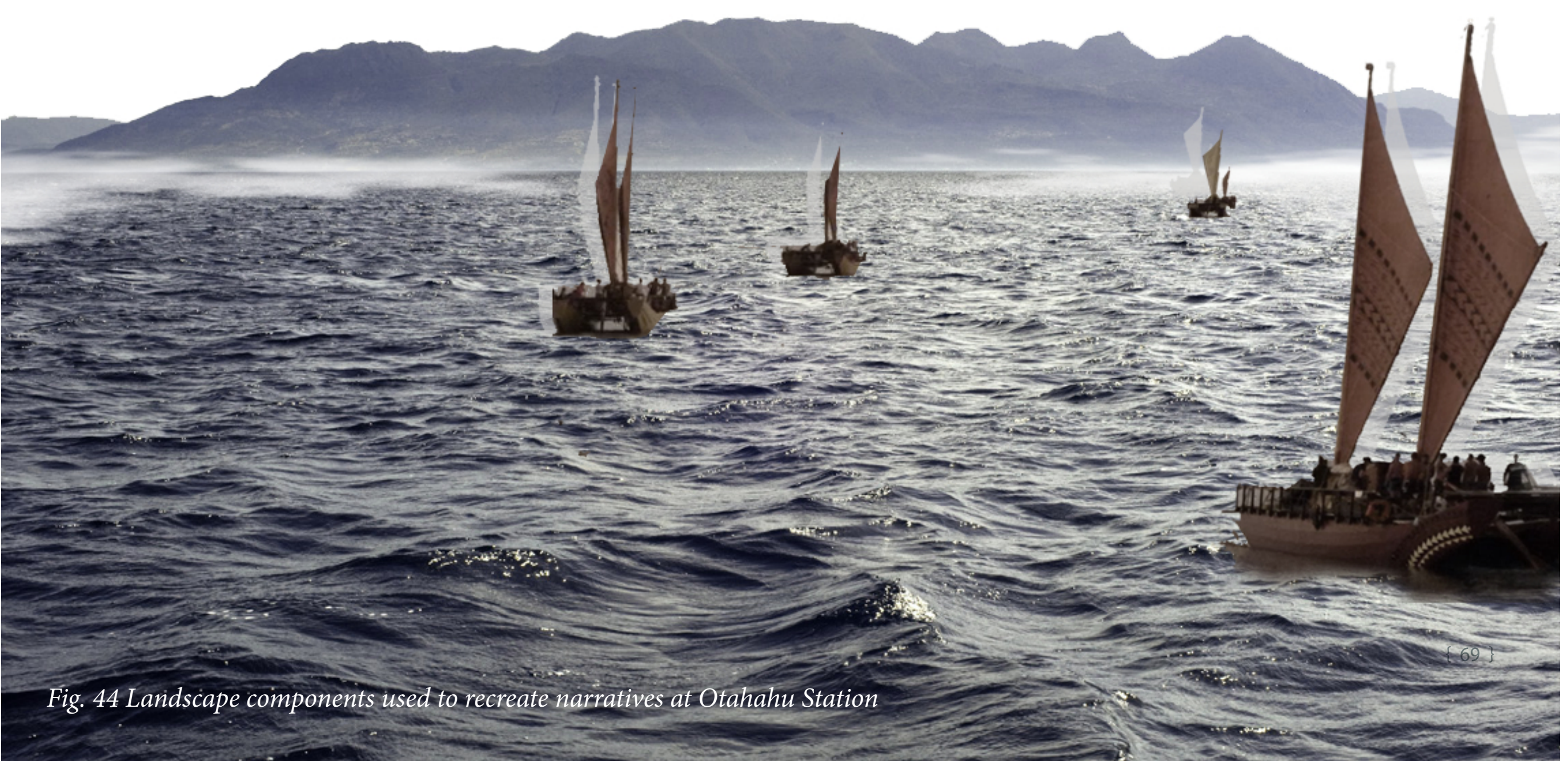




\subsection{MĀTAURANGA MĀORI}

Mātauranga Māori is at the core of Māori beliefs, and understanding the basic principles enables all parties involved with the decision making process of Māori land to have a general understanding of the fundamental concepts that underpin what Māori stand for. The term Mātauranga translates directly to the word knowledge, as it is the Māori understanding of everything visible and invisible in the world. It is present day, local, historic and traditional knowledge as well as the goals, aspirations and issues from an indigenous standpoint (Research, 2015). In the Māori world view, their ancestors relied on the land for their life, which led the understanding that "humans are connected physically and spiritually to land, water, air, forests; and therefore people are an integral part of ecosystems and ecosystems are an essential part of peoples heritage or whakapapa" (Research, 2015, P.1).

For this reason, Mātauranga Māori's holistic outlook is now recognised as a fundamental part of land use planning, ecosystem health and sustainable development. There is also growing urge from Māori to "develop frameworks that allow them to manage their own resources and ensure sustainable, customary harvesting of Toanga species (both animals and plants)" (Research, 2015, P.1). The success of these developing management frameworks comes from their reliance on a range of people to come together and merge traditional knowledge with modern day practises to support effective resource management (Research,2015).

Creating frameworks based on Mātauranga Māori, facilitates the development of the urban environment and creates the opportunity to produce more than just a culturally sensitive design. The framework process and its generated outcomes provides opportunities for shared learning, cultural appreciation, a greater understanding and therefore integration of Māori values and knowledge in research. This ultimately improves decision-making, producing a result that is of benefit to the whole community. 


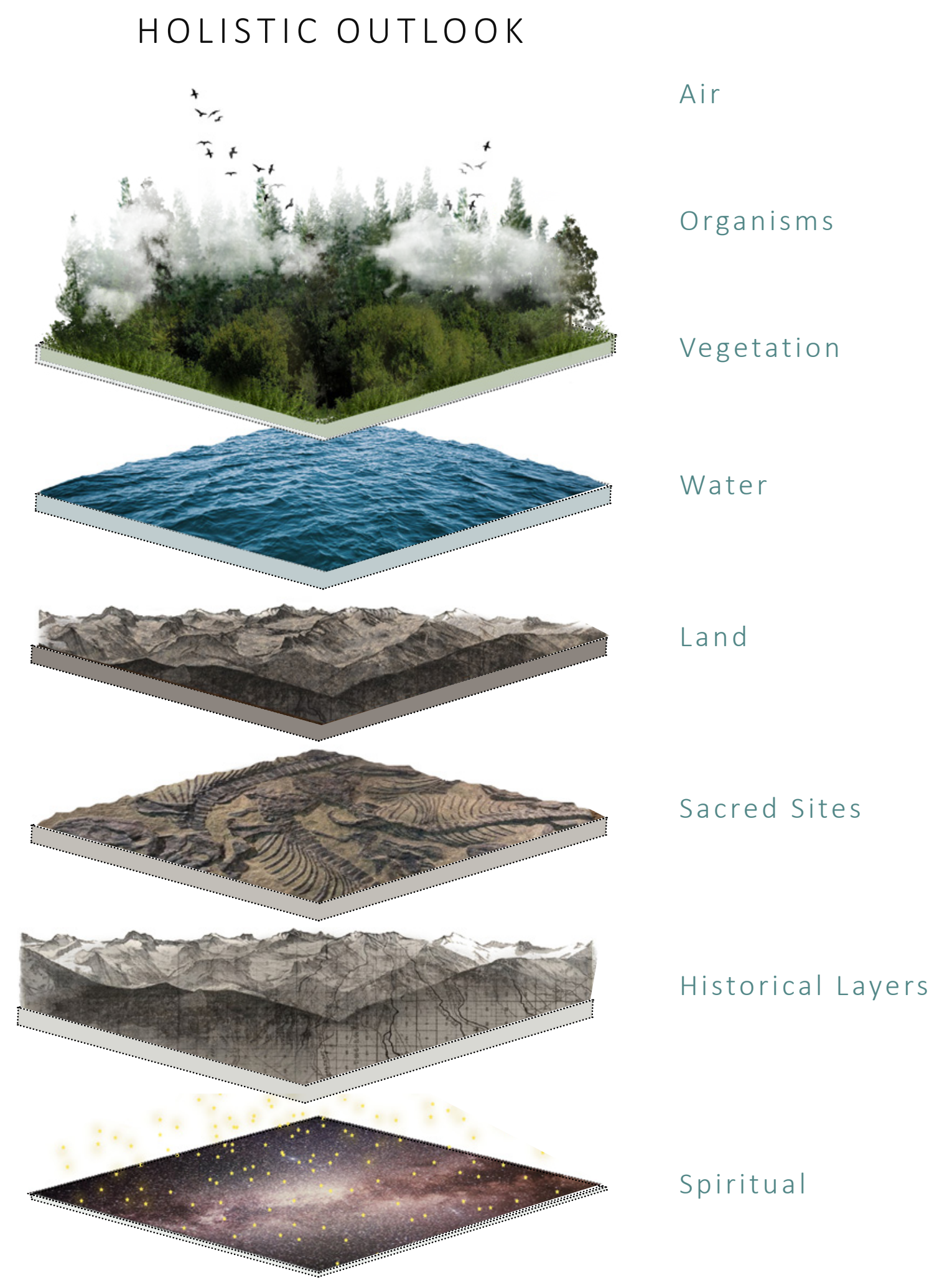

Fig. 45 The layers of Mātauranga Māori 


\subsection{ENVIRONMENTAL SUSTAINABILITY}

"Many indigenous cultures believe that Earth is a sacred environment and regard themselves as an integral part of a holistic and living landscape, relating to the landscape in ways that reflect their experiences"(Marques et al. 2018, P. 1). They see themselves as an extension of the land and therefore they believe they are intrinsically connected to the plants, animals and their ancestors spirits who also inhabit earth. It is therefore evident that concepts of contemporary sustainable design run parallel to indigenous values, such as Mātauranga Māori, when applied in the Aotearoa New Zealand context (Voyde, 2012).

Māori were initially reliant on a "balance between protection, conservation and use" (Voyde, 2012, P.220). Therefore, Māori have a "conservatory ethic "when it comes to the landscape. They understand the interrelated and united workings of it and everything that lives upon it. Māori also see the land as a source of identity, which is described through the words Tangata Whenua, meaning "people of the land". This reflects the Māori belief that living generations act as guardians of the land. This is another concept that resonates with modern day sustainability objectives. This individual and collective responsibility of the protection of the land is called Kaitiakitanga, which describes the act of maintaining and enhancing the Mauri of the land.

An example of the synergy between traditional Māori viewsand modern day sustainable objectives is recognised in the Aotearoa New Zealand Resource Management Act, Aotearoa New Zealand's main piece of environmental legislation. The RMA "acknowledges the traditional, holistic approach Māori take towards environmental management" (Voyde, 2012, P.220) and states that this outlook can positively contribute to modern day environmental management and urban design practise. (Voyde, 2012)

It is evident that ecological sustainability is at the heart of Māori values and a concept that is valued highly. This holistic approach to the sustainable development of concepts and protocol in Aotearoa New Zealand has already and will continue to produce ground-breaking solutions that are both culturally and ecologically rich. 


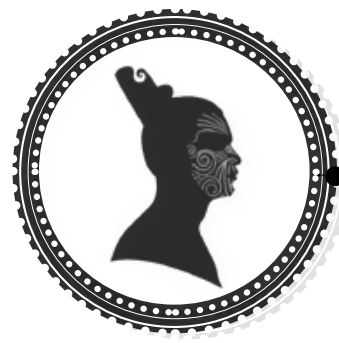

PRESERVATION

CONSERVATION

ENHANCEMENT

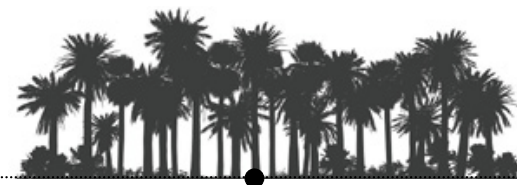

Evolution in the same environment
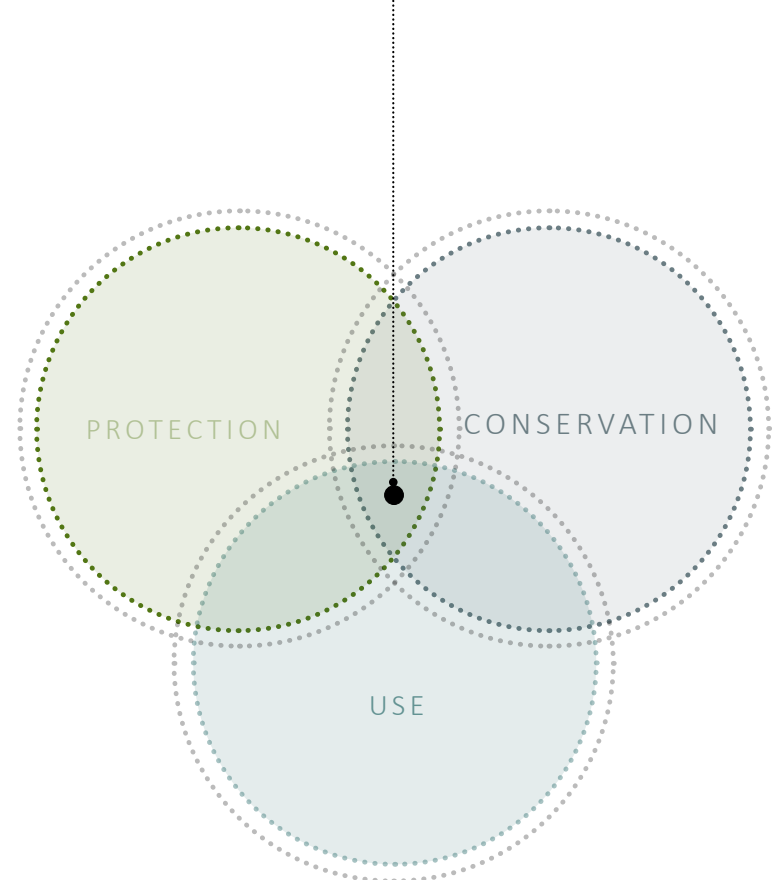

Fig. 46 A diagram of common values shared by Māori and DOC

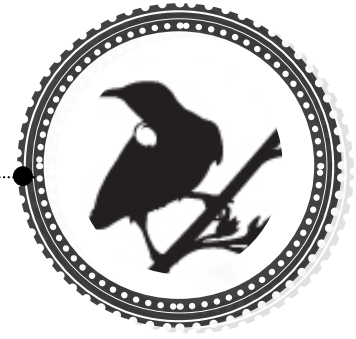

PRESERVATION

CONSERVATION

ENHANCEMENT 


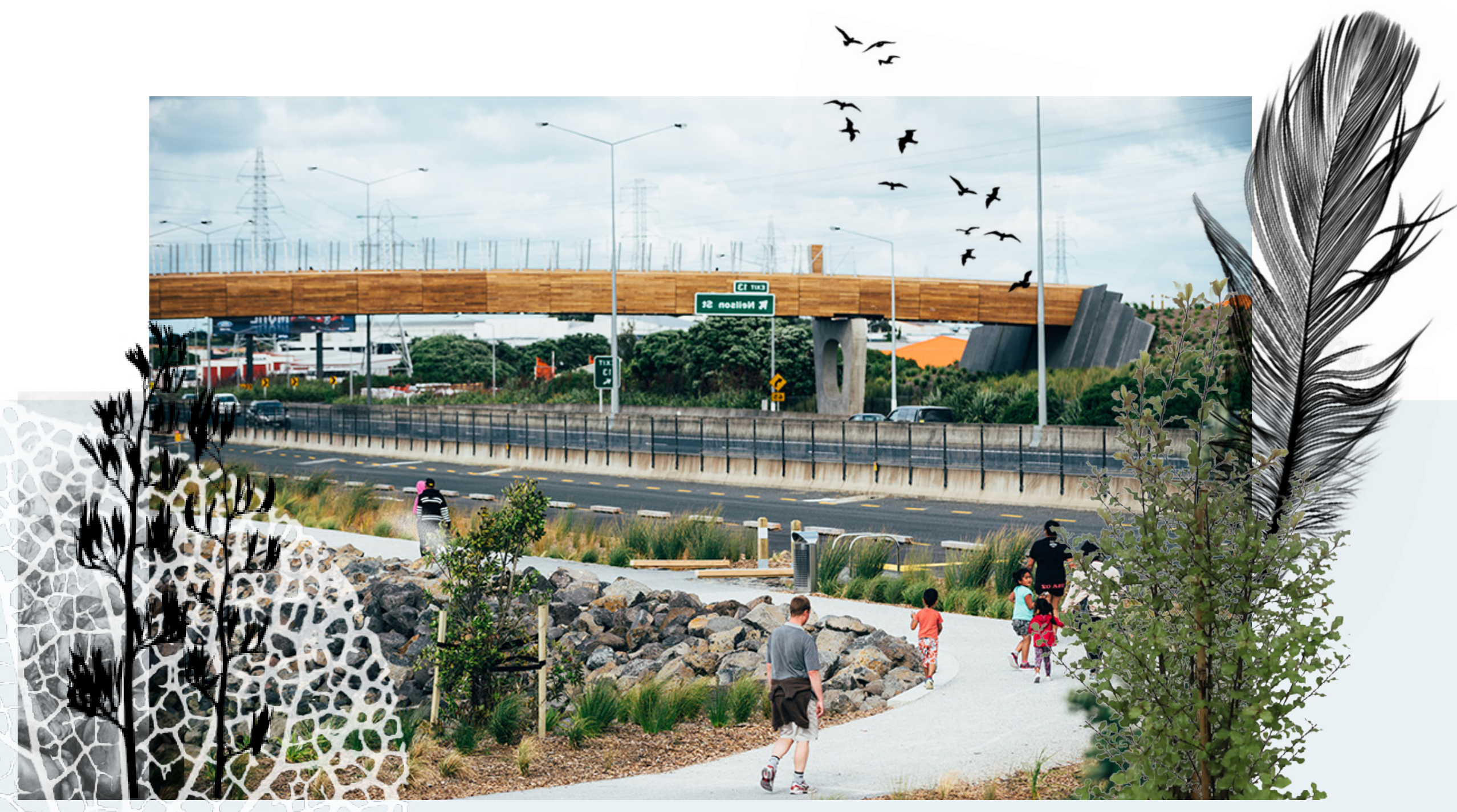

TAUMANU RESERVE, Auckland

Jasmax

The Taumanu Reserve project conveys how through working alongside Iwi and integrating concepts such as Mātauranga Māori, designers can begin to holistically understand the Mauri of a site. It is a key example of how people and therefore culture, cannot be separated from the environment and its health.

Restoring the true essence of the site was one of the most vital parts of the design. The coastline had been significantly impacted by the development of $\mathrm{SH} 2 \mathrm{O}$ and was continuously exposed to air and noise pollution. The new design developed a highly functional coastline with revitalised beaches and planting. The winning design team immediately enlisted the help of local mana whenua. This gave rise to "discussions, between designers and Mana Whenua, that proved fruitful in identifying local narratives and identifying the importance of the Manukau Harbour." (Council, 2018b, P.6) This highlighted important aspects of the harbours history and culture that needed to be expressed..

The landscape architects used the form of the original coastline and its natural character to influence the new design, creating a more resilient shoreline that functions in harmony with the current coastal processes. Extensive planting helped return the coastal environment to its natural state, using native species that are found in the area.
This planting, along with natural materials, such as rocky foreshores and large rocks, were used to create habitats for native species, enabling the local and wider ecosystem to flourish once again.

As the presence of humans is also a part of the life of a site, human interaction with a site is also a part of a places "mauri". For this reason, the coastal edge was developed to provide important facilities, creating a place of for people to relax as well as engaging in a range of recreational activities. (Council, 2018b)

The main narrative that became a driver for the projects was the historical role of the inlet. The Onehunga foreshore was once a strategic settlement point that provided access to the inlet, where waka landed. The area was home to at least 5 mana whenua groups and was a rich source of kaimoana and resources. The site lines of the site were also important in the development of the sites narrative as they showcase Managare and one tree hill mountain, which later became pa sites. These views were optimised by developing bridges that took advantage of these views, showcasing them to drivers and pedestrians and using the structure of the bridge to hint at their narratives and therefore significance 


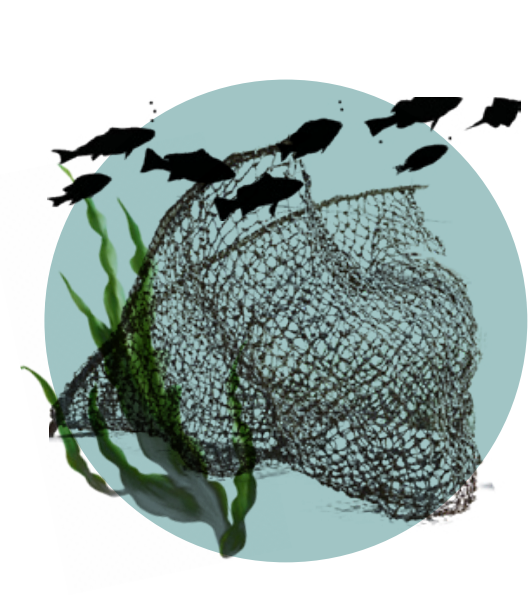

1. FOOD SOURCE

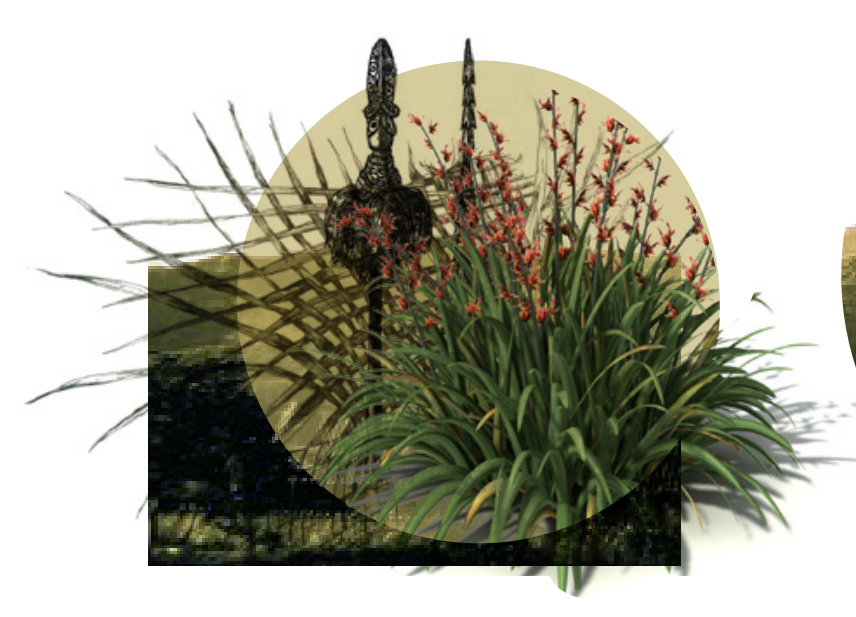

4. RESOURCE NODE

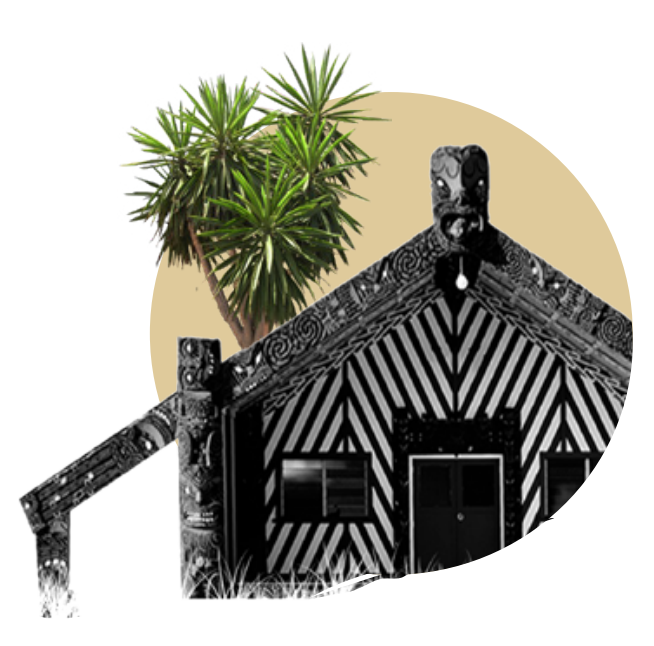

2. SETTLEMENT POINT

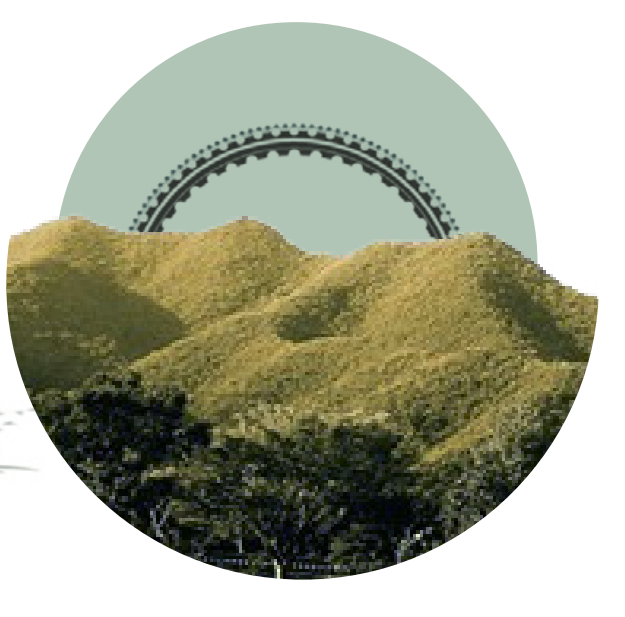

5. VISUAL ADVANTAGE POINT

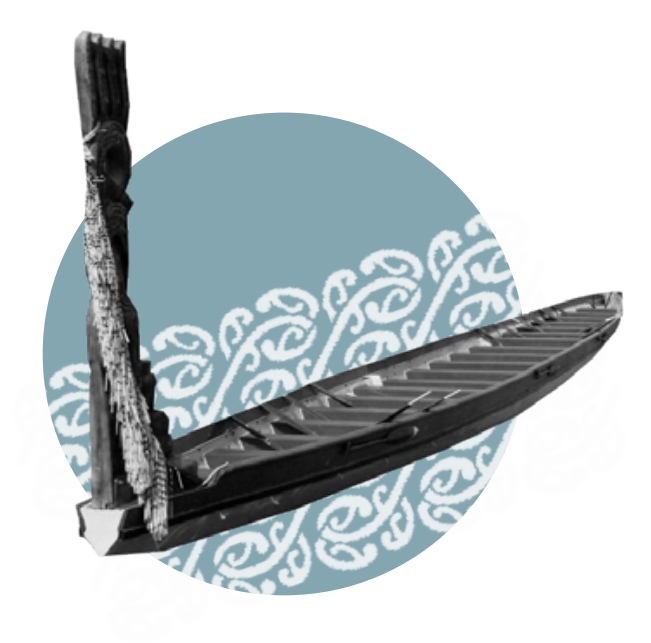

3. TRANSPORT NODE

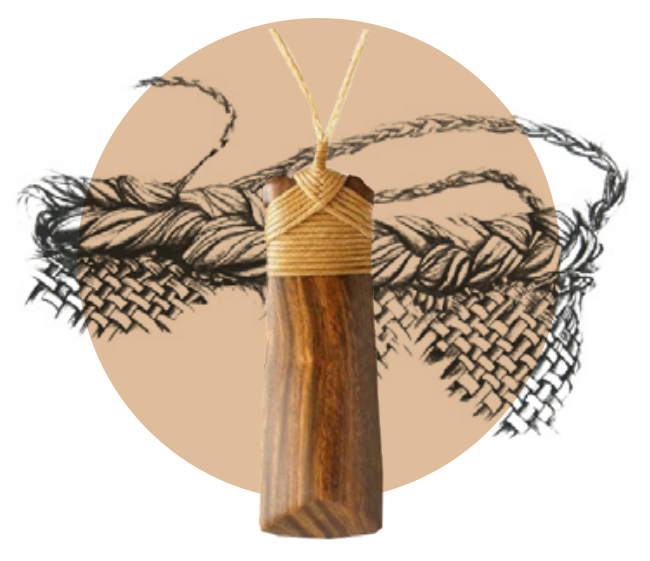

6. RECREATIONAL SPACE

ACKNOWLEDGEDTHROUGHRESTORATION

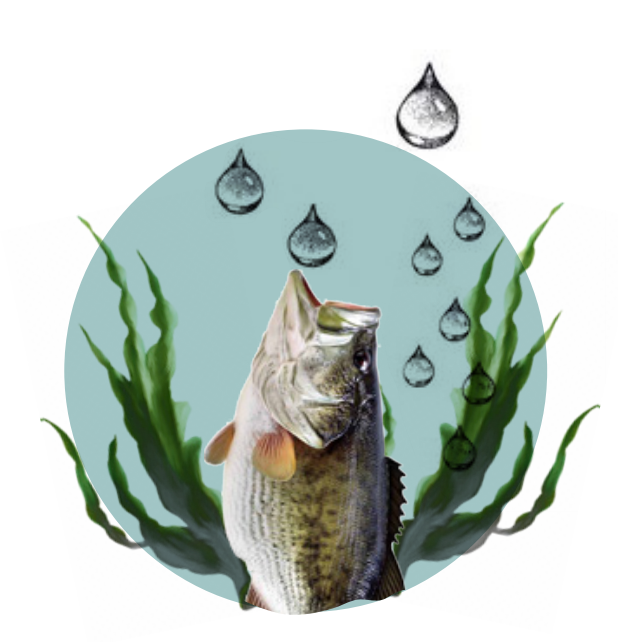

1. NATIVE HABITATS
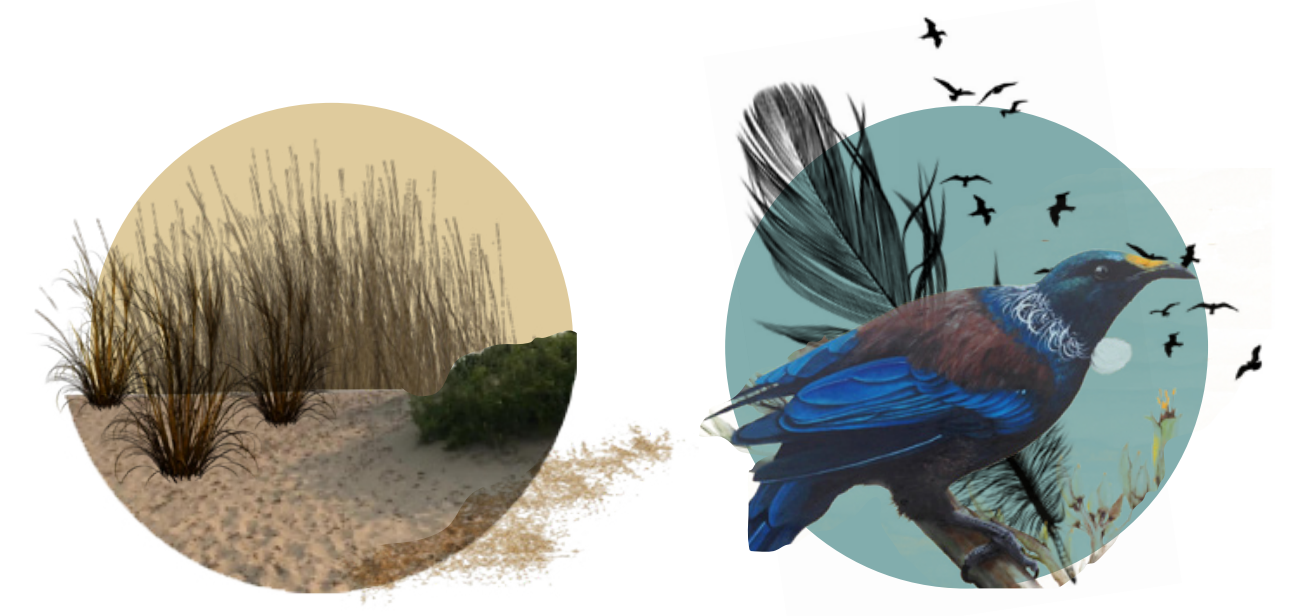

5. NATIVE SPECIES
- my y)

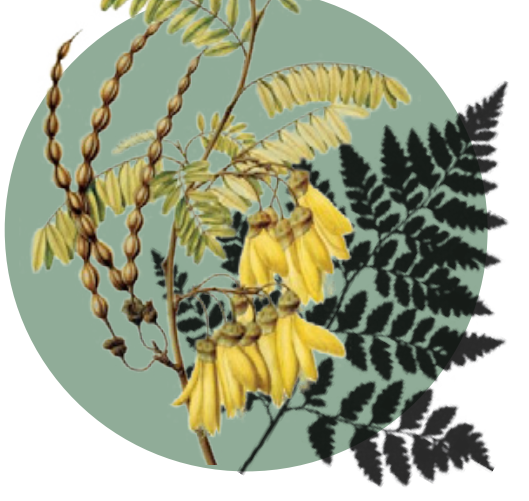

3. NATIVE PLANTING

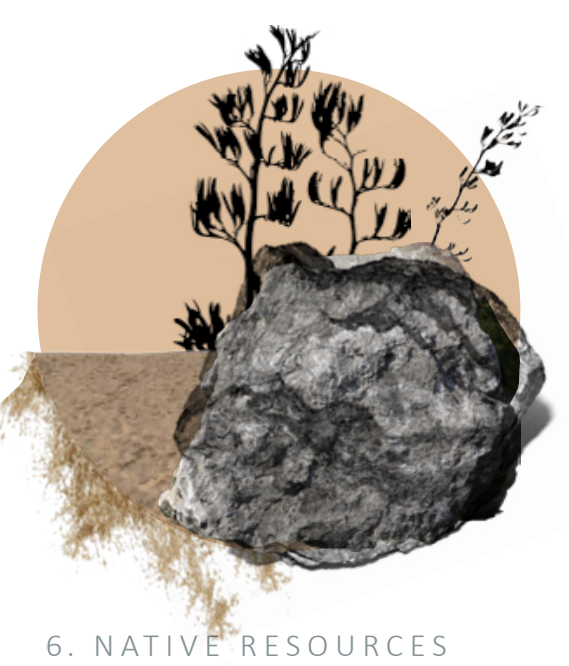




\subsection{RONGOĀ - HUMAN WELLBEING}

Māori's connection to the land and their holistic outlook is also evident in their medicinal customs and views. "The essence of rongoā is concerned with restoring health and wellbeing through a strong and impermeable connection to nature" (Kerridge, 2017, P.1). Encouraging Rongoā in urban settings gives Māori and other members of the community access to:

- Free or significantly cheaper medicine

- Resources to practise native traditions

- Education about Māori customs and traditions

- Education regarding an individual's personal health and wellbeing

- Education around the service's that native ecosystems have to offer for an individual, family and community

Rongoā is the name given to traditional Māori medicine that is historically passed on orally. It encompasses herbal medicine made from plants as well as spiritual healing, steaming and physical methods such as massages. "Plants such as Kawakawa, Harakeke (flax), Kōwhai and Mānuka were all important for healing, and so was a belief in the spiritual causes of illness" (Jones, 2007, P.1).

The practising of Rongoā became largely redundant after European settlement as the British brought many diseases with them that traditional healing methods could not cure, causing people to lose trust in their healing abilities. However, "there is scientific evidence recognising the detailed knowledge of anatomy, understanding of physiological principles, and recognition of the healing properties of various plants" (Jones, 2007, P.1)used by Māori. For this reason, Rongoā is becoming more prominent once again. 


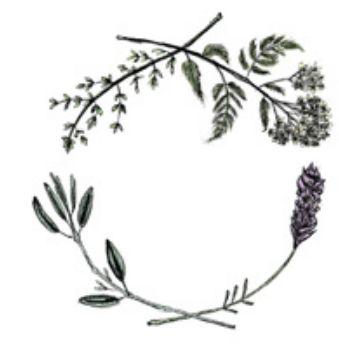

Herbal Remedies

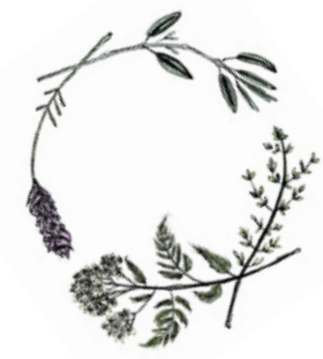

Spiritual Healing

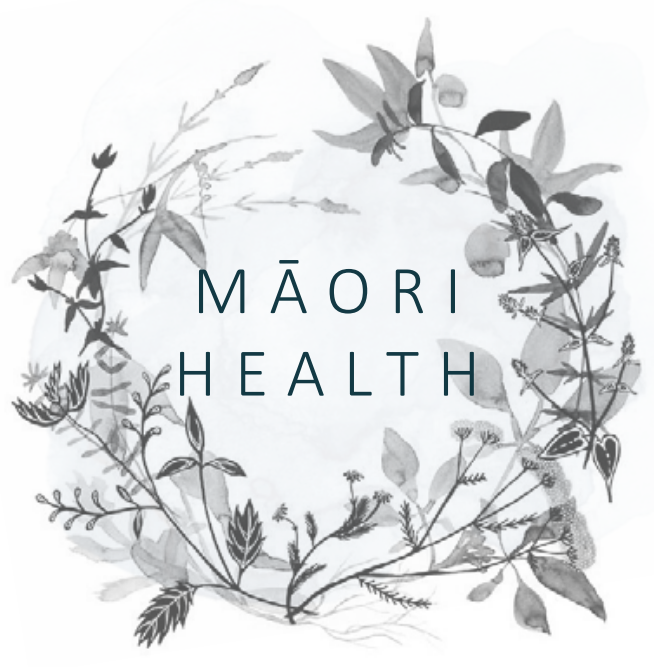

Fig. 48 Rongoā methods and outputs

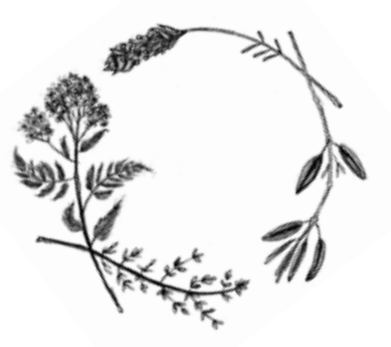

Steaming

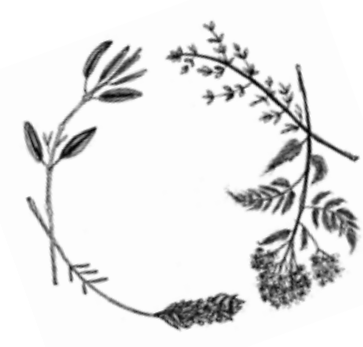

Massage

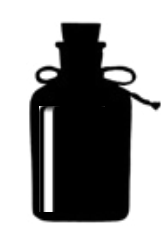

Access to Medicine

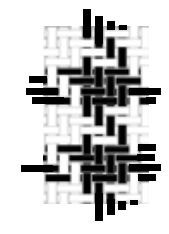

The practising of native traditions

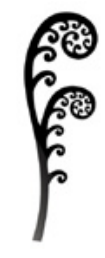

Māori Customs and traditions education

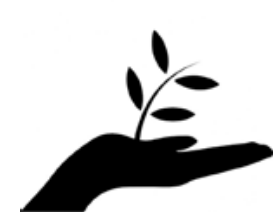

Health and wellbeing education
Ecosystem services

education 


\section{RONGOA PLANTING}

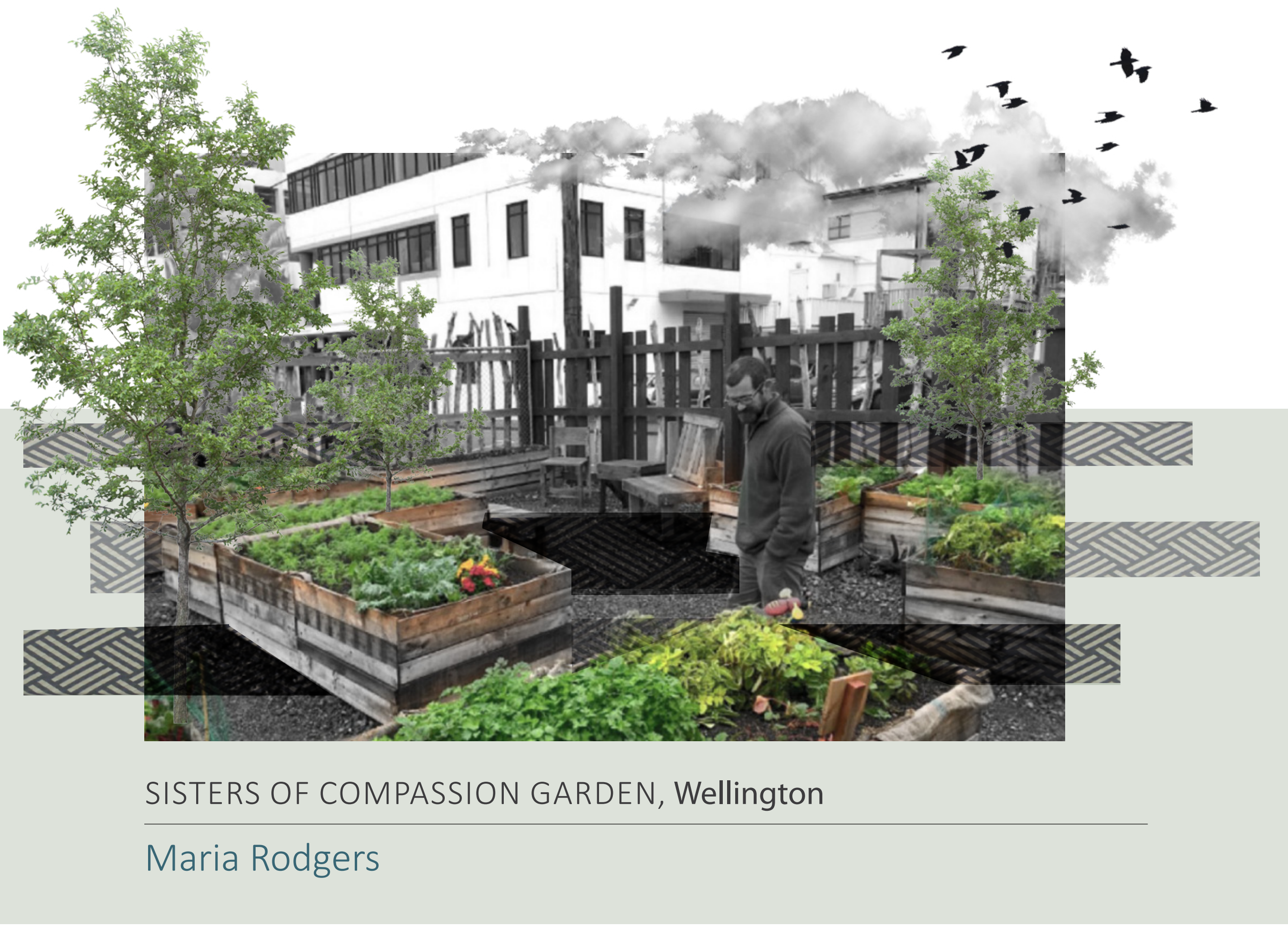

The Sisters of Compassion Garden is an example of how Rongoā can be used to unite a community, educate people about the practise and provide vulnerable groups with access to free food and medicine.

Centred in the middle of Wellington City is a soup kitchen for Wellington's homeless and a developing urban garden.

The garden includes:

- A Rongoā/ Māori herb garden

- A communal meeting area

- Raised garden boxes growing fruit, vegetables and flowers

The homeless people of Wellington line up everyday outside the tool shed waiting to work in the garden. "For many people who come here they experience poor mental health, loneliness, isolation and depression, but by working on the garden some of those feelings start being removed"(Richards, 2018, P.1). The urban garden has become a place of healing. It is also a place they can take ownership of and be proud of what they achieve, giving them control back to their lives, which builds up confidence and improves self-esteem. Matt Petrie, a Home of Compassion Social worker, says many of these people have extreme anxiety "and find it very challenging to be around people but when they are together in a group doing something meaningful that just melts away a bit. People start feeling more relaxed and calmer" (Richards, 2018, P.1).

The kitchen serves a minimum of 100 meals a day so growing and sharing kai is an important principle at the soup kitchen. The garden reinforces this concepts whilst giving homeless a sense of purpose.

One of the main ideas behind the design of the garden was Māori culture. "More than 60 percent of the Soup Kitchen's regulars are Māori so the garden will reflect this in many different ways from the driftwood fence to the planting, which is being done by the Māori lunar calendar with the first crop being potatoes to be harvested for Matariki" (Richards, 2018, P. 1). The Rongoa garden also creates a link to Māori culture, enabling people to grow and be educated about native plants and their healing properties. The communal space will also be developed to reflect Māori values and allow for traditional practises to take place through the implementation of seating where people can come in and give presentations, or where activities such as carving and music can occur. 


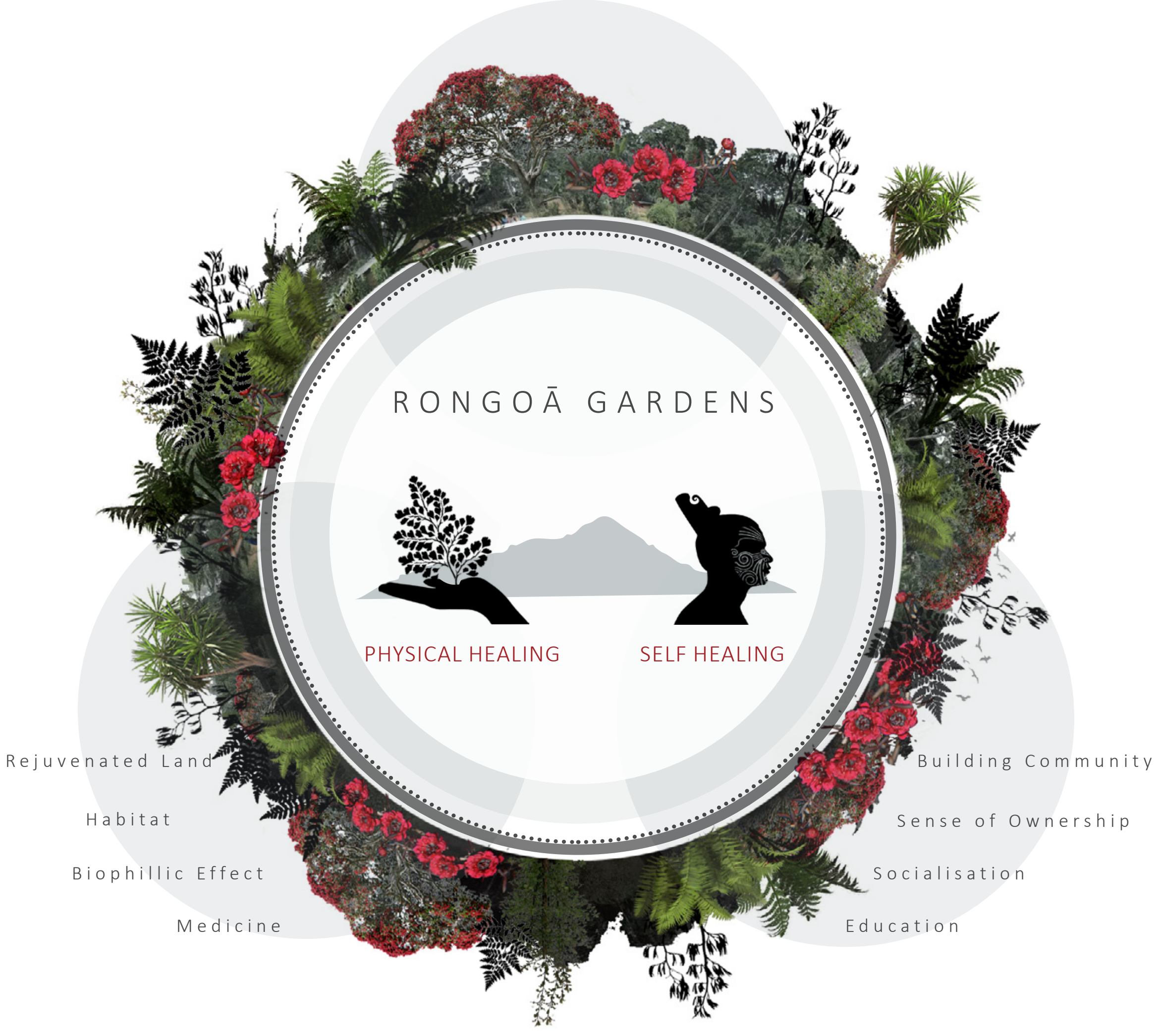

Healing of the land and the people can be achieved

through plant choice and the fundamental objective of the

Fig. 49 Benefit diagram of the implementation of an urban rongoa garden

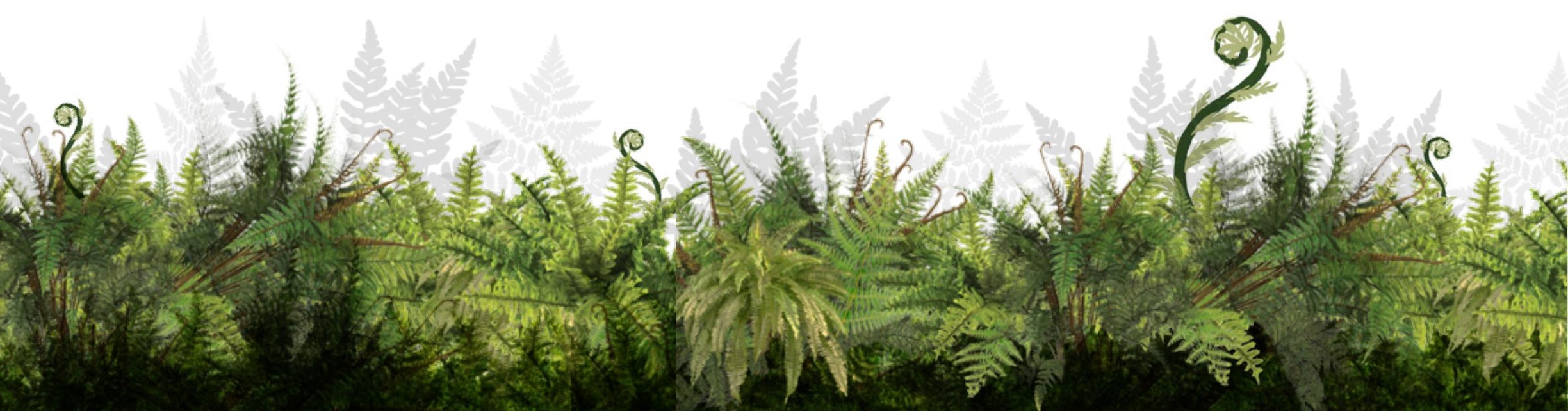




\subsection{THE TE ARANGA PRINCIPLES}

Understanding Māori values and narratives is simple; it is identifying the relevant ones and integrating them appropriately into the design of a site that is the challenge for modern day designers. The Te Aranga aim to provide design professionals with guidance for interacting with iwi and therefore enhancing outcomes in the design environment. (Paul, 2017)

The key objective of these principles is to enhance the protection, reinstatement, development and articulation of mana whenua cultural landscapes, enabling all Aotearoa New Zealanders connect to and deepen their 'sense of place'. The seven principles are as follows:

- MANA: The status of iwi as mana whenua is recognised and respected - WHAKAPAPA: Recognises and celebrates the Māori names

- TAIAO: The natural environment is protected, maintained and / or enhanced - MAURI TU: The natural environment is protected, restored and / or enhanced - MAHI TOI: Iwi narratives are captured and expressed creatively and appropriately - TOHU: Mana whenua significant sites and cultural landmarks are acknowledged - AHI KA: Iwi/hapū have a living and enduring presence (Council, 2017)

The effectiveness of the principles derives from their ability to cater to everyone involved in the design process:

For Māori, the Te Aranga principles ensures their identity and wellbeing is considered and enhanced and that their opinion is of value in the design process. This guarantees that their "spiritual connection and sense of belonging is preserved, and that there is reassertion of the Māori voice in the landscape, as well as many other beneficial outcomes" (Paul, 2017, P. 3).

For Designers, the Te Aranga principles are a useful tool that provide guidelines identifying the importance of "Māori cultural considerations and why they should be integrated into a site specific project. They also provide cultural perspective and therefore add value to a project" (Paul, 2017, P. 4).

The model provides designers with a framework to identify social, ecological, education and cultural opportunities that can be recognised or further developed through the sharing of narratives and/or knowledge of Iwi. The facilitated engagement, guided by the Te Aranga Principles between designers, Iwi and community (illustrated in figure 50), produces practical, relevant and realistic approaches. (Paul, 2017) 


\section{TE ARANGA PRINCIPLES}

Providing design professionals with guidance for interacting with iwi

\section{S I T E}

$\downarrow$

MAURI / ESSENCE OF A SITE

CULTURAL SIGNIFICANCE

NATIVE ENVIRONMENT

NARRATIVES

I W I INTERACTION

1118

CULTURALly APPBROPRIATE DESIGN RESPONSES

Seek interest
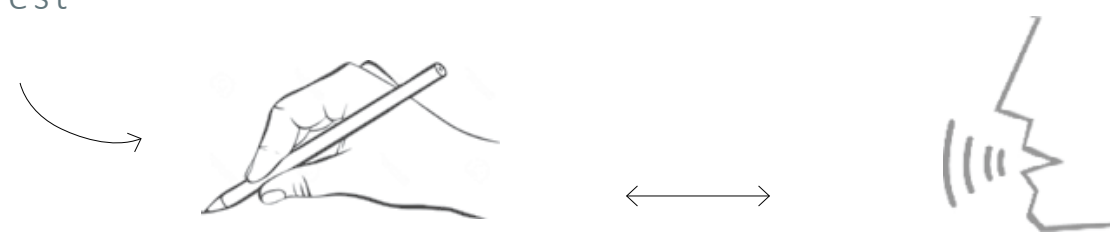

2 collect relevant

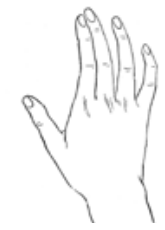

4 seek ongoing feedback

Co-design + collaborate 


\subsection{THEORY AND CASE STUDY FINDINGS}

With a selection of Aotearoa New Zealand islands entered in a co-governing agreement, Māori have begun working alongside groups such as the Department of Conservation and locals to manage and plan for the futures of these islands. This has identified the need to explore how reinstated public Māori land can be designed to cater for the needs of the public, the environment and Māori, as the owners of the land, ultimately finding a spatial synergy between all three significant parties in the form of physical spaces.

COMMON MOTIVATIONS: Through examining cases of co-governance and the development of Māori land, it became apparent that identifying the common motivations of each governing group was essential for this process. By reading the vision for the island stated in Kaitiaki Plan it is clear that all three parties are mutually interested in the development of culture, education and health (both human and environmental) within their site. Identifying these commonalities highlights areas the parties can work towards harmoniously, using their individual speciality to contribute to the group through a particular focus in culture, health or both, allowing everyone to work to their strengths.

ENVIRONMENTAL HEALTH AND IDENTITY: The degraded nature of many of the sites being handed back to Māori, like Matiu Island, stressed the need for cultural concepts relating to a range of modern and sustainable initiatives to be identified. Mātauranga Māori was highlighted as a key concept that had the potential to shed light on possible opportunities for spatial development on Māori owned land, as it encapsulates both the Māori perspective on identity, culture and a sense of place, as well as human and environmental health. Precedents also demonstrated how restoring the environment of a site helped to reinstate the identity and a sense of place within it.

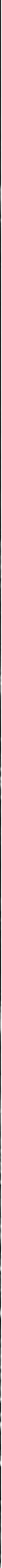


HUMAN AND ENVIRONMENTAL HEALTH: Case studies such as the Sisters of Compassion Garden conveyed how human health relies on environmental health. Rongoā is a practise that helps to restore the native environment while connecting people to it and to one another. This creates the opportunity to restore degraded areas, create a sense of community and provide a space for Māori to connect to their historic traditions and educate others.

NARRATIVES: Narratives and the use of symbolism were highlighted by literature and case studies as tools to create visually stimulating and educational spaces. They also provide Māori with a method for sharing how their identity and history could shape the landscape, enabling them to feel more connected with the land.

These oral narratives are generally converted from a spoken story to a spatial landscape configuration through the use of planting, artwork, way finding and materiality. The use of influential, cultural stories gives designers the tools to develop or allow a site to evolve whilst maintaining its identity and unique sense of place.

The Te Aranga principles were outlined in many of the case studies as a way in which designers can successfully work with Māori to identify these stories. This is essential as it ensures that Māori's"spiritual connection and sense of belonging is preserved, and there is reassertion of the Māori voice in the landscape " (Paul, 2017, P.3). This enhances the protection, reinstatement, development and articulation of mana whenua cultural landscapes, enabling everyone to connect to and deepen their 'sense of place'.

RECREATION AND SOCIAL SPACE: After examining precedents that successfully restored the mauri of a site, a common element that was identified between the projects was the presence of recreational or social spaces. Designers intentionally used incentives such as unique social spaces or recreational interventions to draw people to the site, allowing visitors to sometimes subconciously become immersed in Māori culture. This provides insight into how to draw people to a site and engage them.

RELEVANCE TO MATIU ISLAND: Matiu Island is a site that fails to resonate with the identity and history of the Iwi that own it. Through examining relevant literature and case studies, it become apparent that creating bicultural and environmental harmony upon the island, are not two separate tasks. Culture arises from the environment so both aspects need to be considered, togther, when developing the site. Precedents such as Te Kura Whare and Taumanu Reserve convey the capacity the narratives have to provide Māori with a platform to influence the design outcomes and therefore the land, while Rongoā gardens, environmental restoration and the implementation of recreational and social space are all physical mediums in which these narratives can take form. 



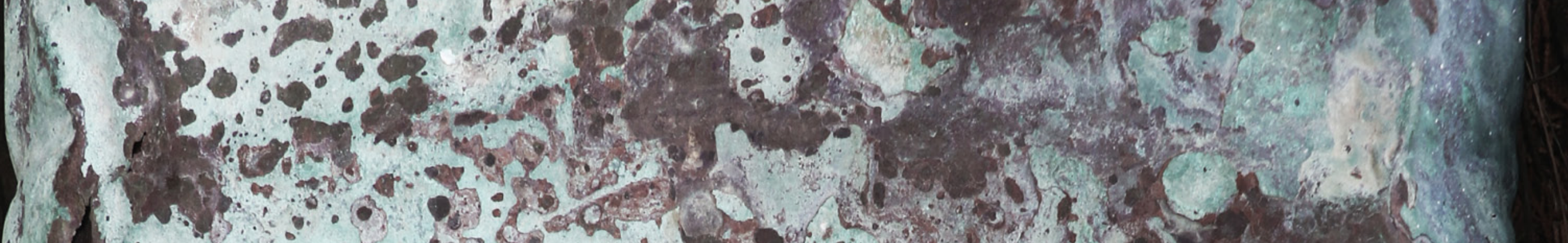

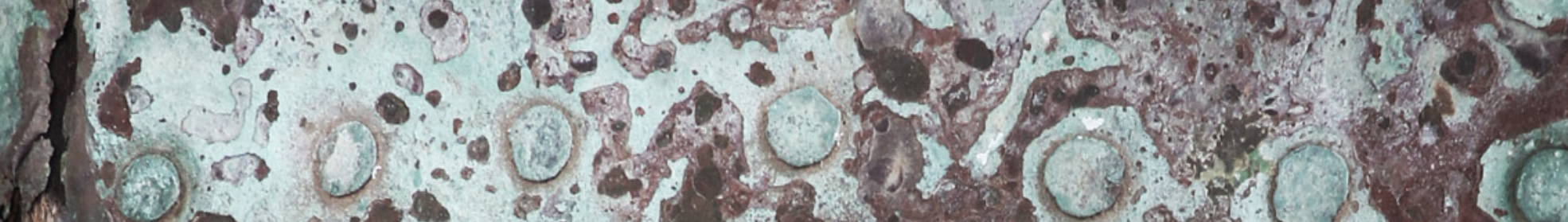

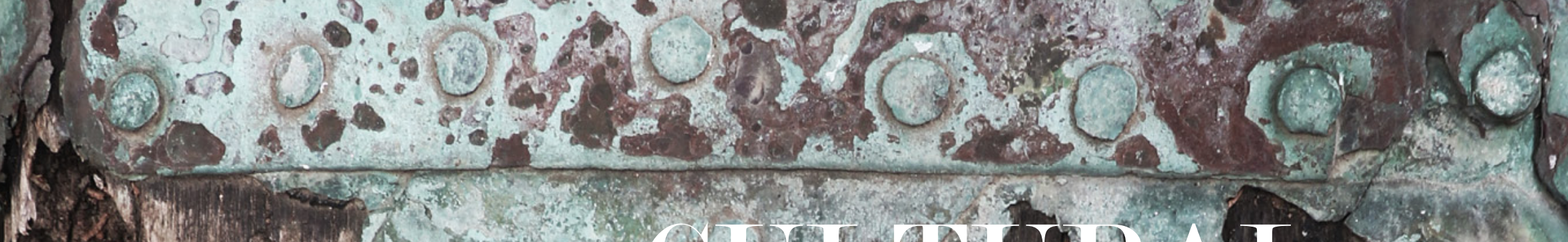

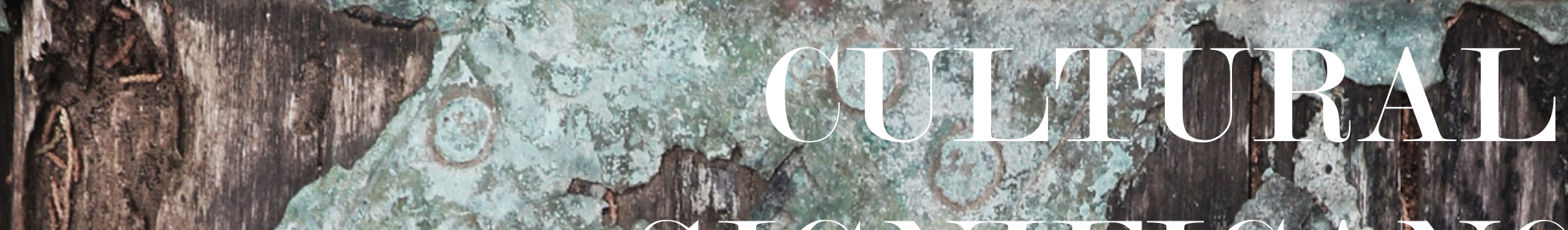
19) 10

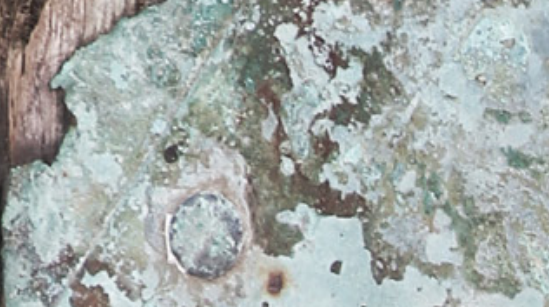
$\sqrt{1}-\rightarrow$

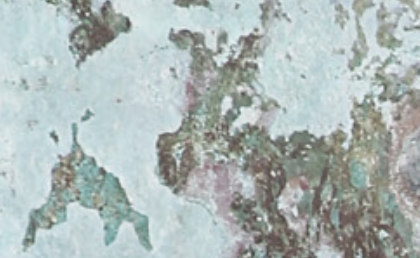

(1)

(6) STCNHCICNOF

as<smiles>[As]</smiles>

TARANAKI WHANUNHISTORY + NARRATIVES
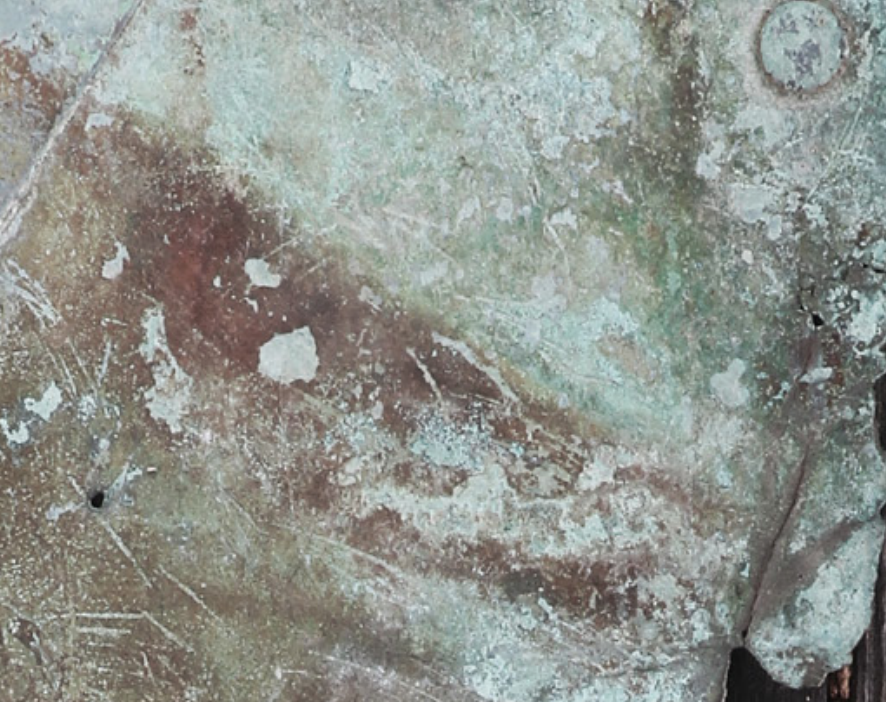
$4 .+2 x^{2}+3$
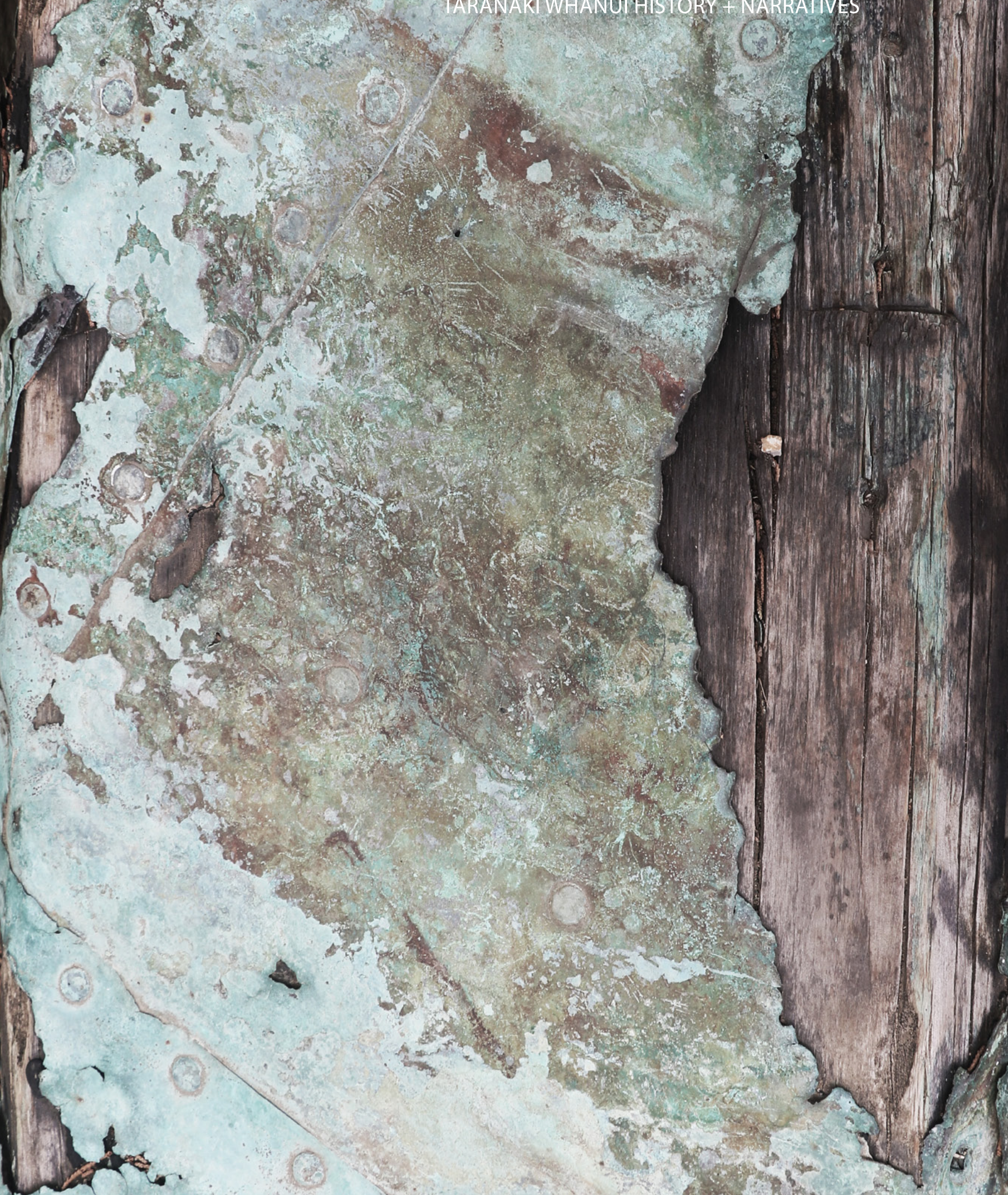


\section{NEW ZEALAND STORIES}
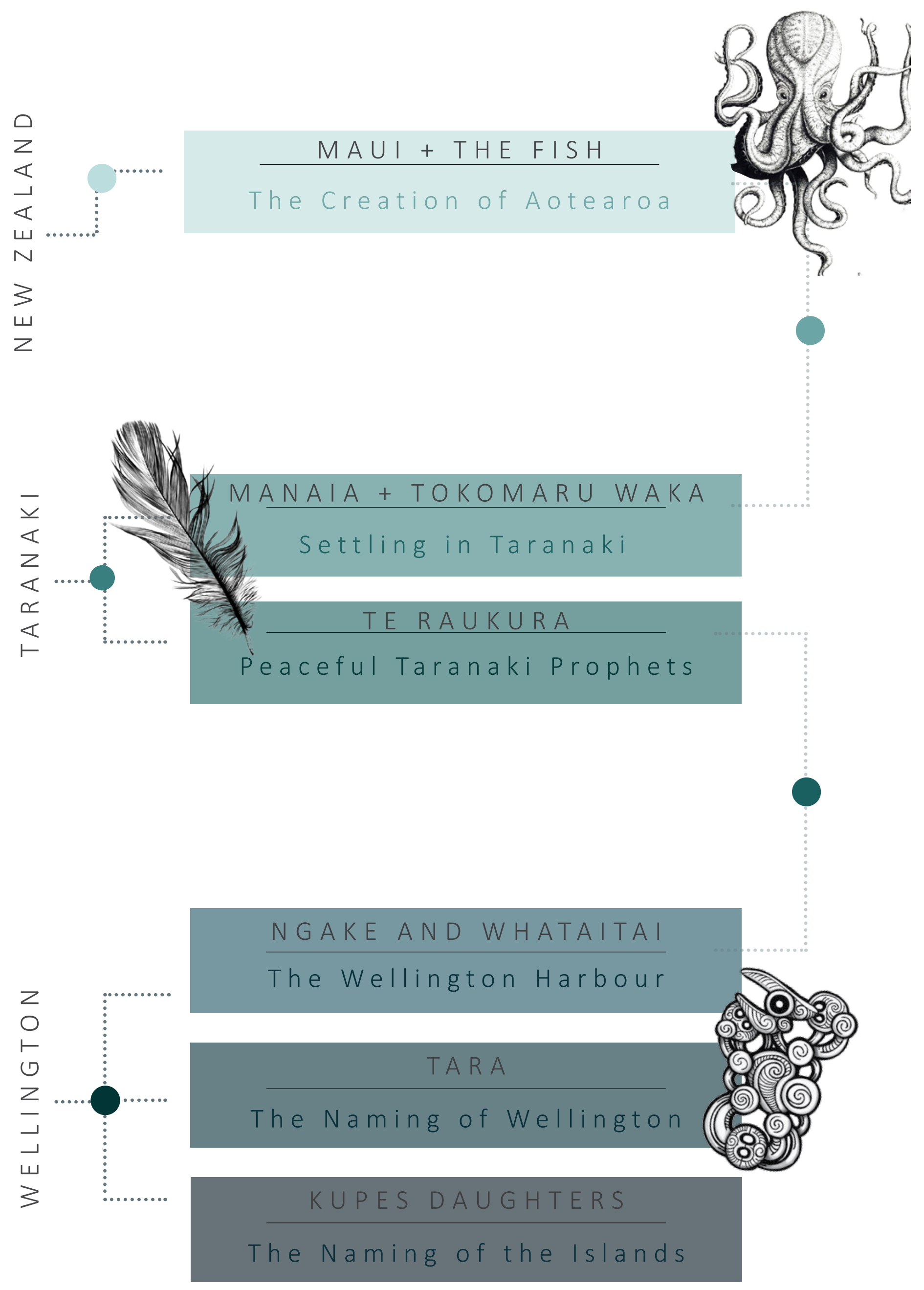

Fig. 53 New Zealand narratives significant to Wellington Mana Whenua 


\subsection{THE USE OF NARRATIVES}

As Māori culture is a foreign concept to many it is important that a Māori owned site initially introduces visitors to core Māori values and the founding stories of Aotearoa New Zealand, creating a strong foundation of understanding.

Site specific narratives should then be used to represent the history and identity of the lands associated to the Iwi. Narratives that have the capacity to do this will be brought forward by mana whenua. These narratives will often be a mixture of myths and historical events that talk about their ancestry, their relationship with the land, significant cultural values, principles and customs, ultimately using the landscape as a tool to share their history and intertwined relationship with the land.

Mana whenua generally have a hierarchy when it comes to narratives, where certain ones will be more appropriate or significant to the site than others. These significant narratives should therefore be the most predominate ones visually expressed in the landscape.

\subsection{TARANAKI WHĀNUI'S KEY NARRATIVES}

Engaging with Iwi from Taranaki Whānui to identify significant stories was an essential part of the design process. As seen in figure 20, Maui and the Fish is a legend that conveys how Māori believe New Zealand was created. This narrative was identified by members of Taranaki Whānui, as an important story to share with visitors throughout their time on Matiu island.

The Taranaki and Pōneke Wellington stories seen in figure 20 are contextual narratives that are greatly significant to the Taranaki Whānui. It was expressed by the Iwi that these were to be the key stories, used to inform the development of the landscape, as they are what best encapsulate their origins and identity as a tribe.

Examining case studies that used Māori narratives as a major influence in the design of the site conveyed that designers tend to break down a story, drawing out key messages or elements. They then recreate these within the landscape using symbolism, planting, materiality and structures to hint at or share these narratives. The narratives seen in figure 20 are described and depicted throughout the following pages, enabling their key messages and elements to be drawn out for potential translation into a spatial design. 


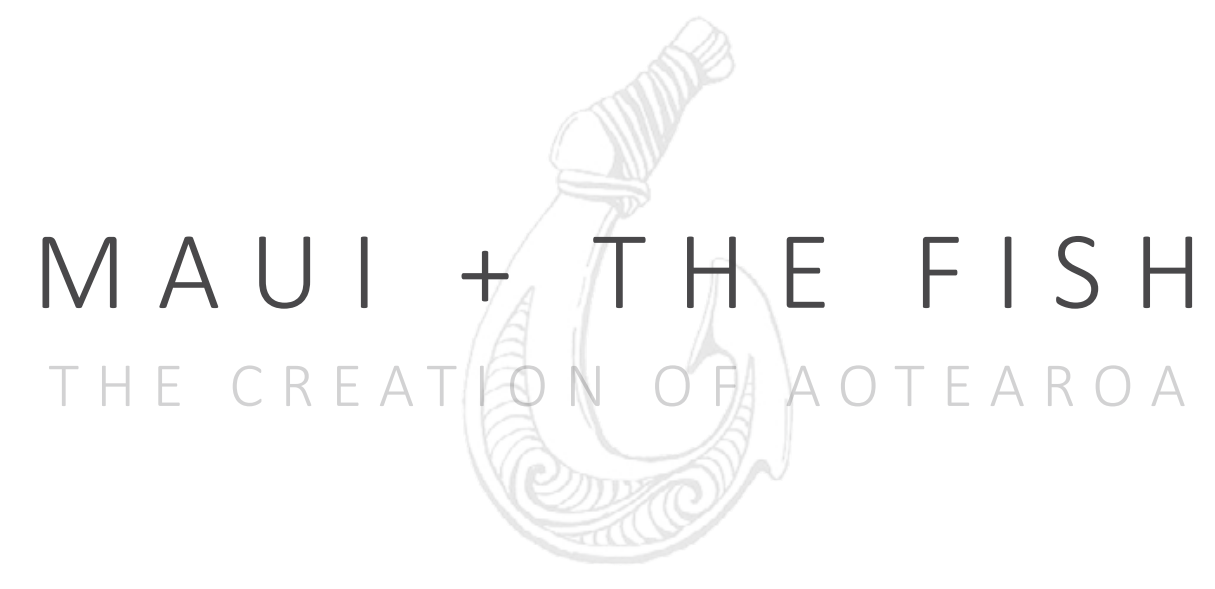

Maui wished he could go out fishing with his older brothers on the Hawaiki waters but they always had an excuse for why he was not allowed. Maui got tired of the excuses and hatched a plan to prove to his brothers he was a great fisherman.

One morning Maui hid in the hull of his brothers canoe. When he heard the anchor drop Maui got up from his hiding spot and said "I have come to fish because Murirangawhenua said I would be a great fisherman". Maui stood on the hull of the canoe and whirled his line out whilst reciting his karakia.

Maui's hook was taken and the waka began speeding across the ocean and slowly a giant fish rose to the surface, scaring the brothers. Maui said "Guard our fish, and I will soon return with our people." The brothers agreed to stay but as soon as Maui was gone the brothers began chopping at the fish, claiming pieces as their own.

Maui returned with his people and they stared at the great fish in amazement. "Maui is the best fisherman ever," they remarked. As they got closer they could see the brothers greedy brothers chopping the fish creating huge valleys and mountains.

Over thousands of years, these became part of Aotearoa's landscape. Species of birds, animals and the people of Hawaiki lived on the giant fish. The giant fish became known as the North Island whilst the South Island was Maui's canoe. (Grace, 2015) 


\title{
THE FLEET OF AOTEAROA
}

\author{
NEW ZEALAND WAKA \\ arif
}

“In $1350 \mathrm{AD}$ a 'great fleet' of seven canoes departed from the Tahitian region at the same time, bringing the people now known as Māori to Aotearoa New Zealand. These were advanced, warlike, agricultural tribes who destroyed the Moriori" (Howe, 2005, P.3).

The Tokomaru Waka is the ancestral Waka of the Taranaki Whānui. Referencing the Tokomaru in one of the first sites visitor's access will allow the island to speak of how the Taranaki Whānui came to New Zealand.

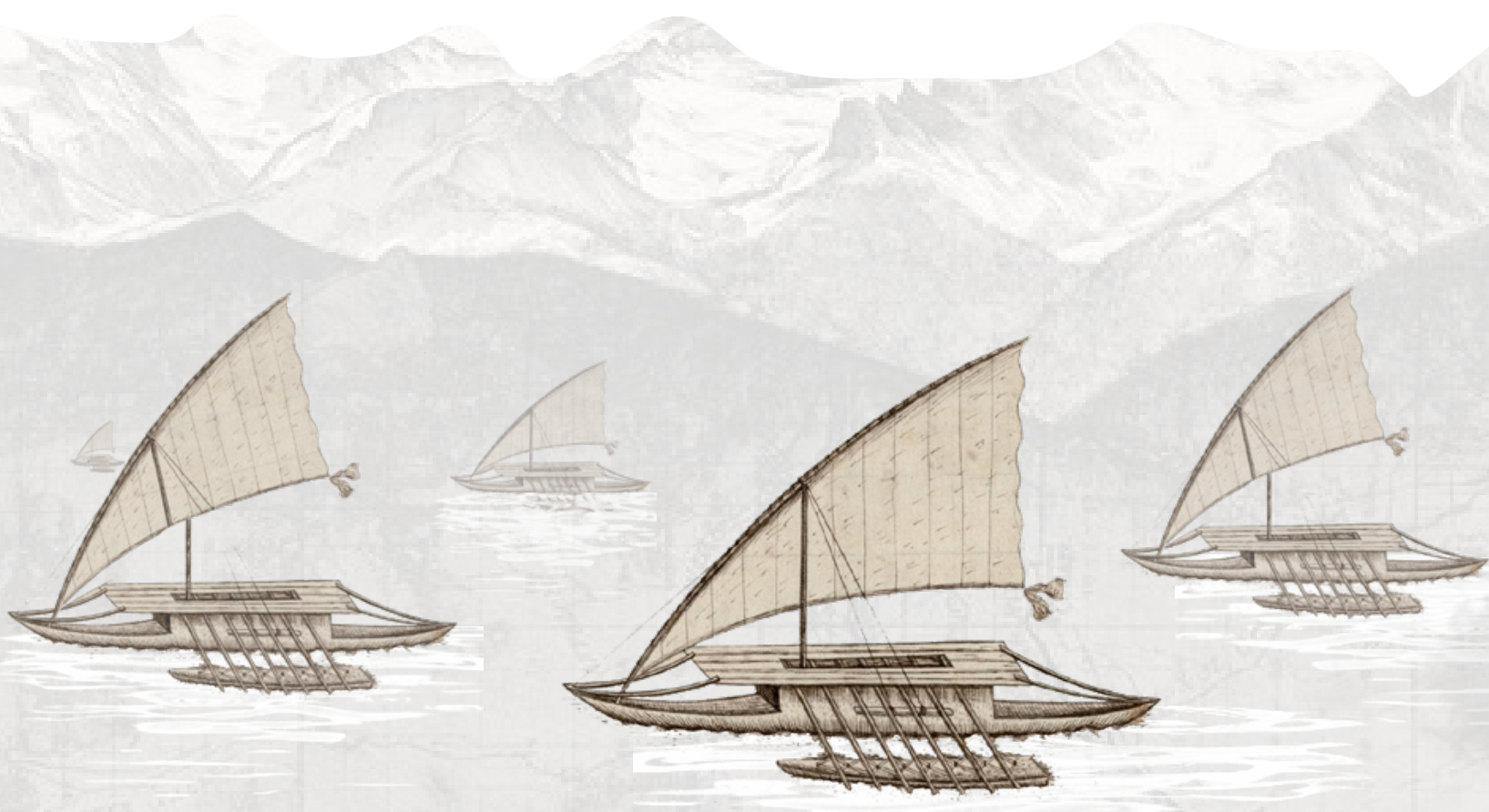

KURAHAUPO

MATAATUA

Bay of Plenty, North island TAKITIMU East Coast, North Island

TAINUI Central North Island

TOKOMARU

AOTEA

TE ARAWA

North + West Coast

Rotorua, North island

West Coast, North Island

West Coast, North Island 


\title{
MĀORI WAYFINDING
}

\author{
NAVIGATION TO AOTEAROA
}

Different methods of navigation were used by Māori in their voyages to and around Aotearoa New Zealand. The methods below were one's specifically used by the Taranaki Whānui in and around Aotearoa New Zealand.

\section{TAMANUITERA FLIGHT PATH}

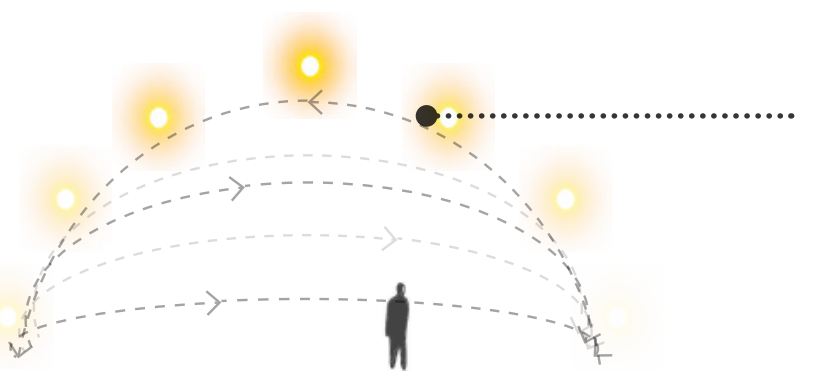

SUN HEIGHT:

Aronga mana/navigators knew that the arcs of the sun had differing heights depending on the time of year.

TE KAPEHU WHETU

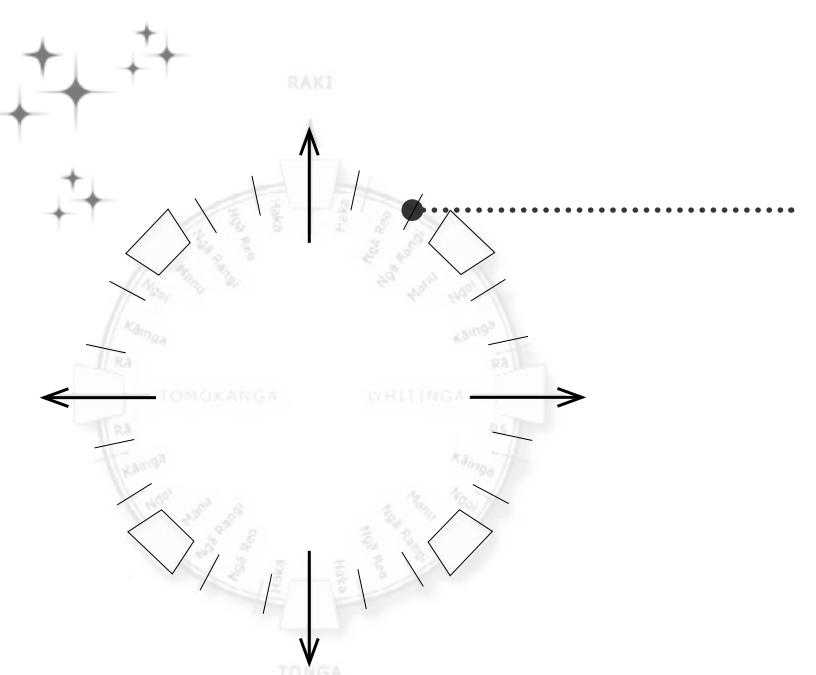

STAR NAVIGATION

Navigators used the direction and position of the stars and the horizon as a compass to aligning Waka in the directions of travel.

POLYNESIAN SHELL MAP

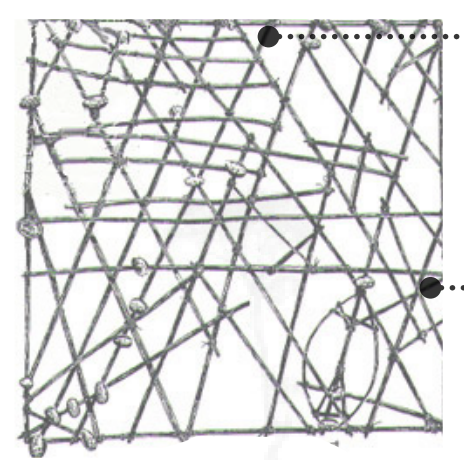

SHELLS

Indicate islands or groups of islands

\section{STICKS}

Showing ocean swells and their direction.

Fig. 56 Wayfinding methods diagram 


\subsection{THE IMPORTANCE OF WAKA AND WAYFINDING}

The majority of significant stories identified by members of the Taranaki Whānui spoke of the use of Waka and traditional wayfinding methods. This indicated that the waka in these narratives could be used as a way to create a unique identity for the mana whenua on Matiu Island. As Maui's Waka and the Tokomaru waka both grounded Māori to Aotearoa New Zealand, waka could symbolise the grounding of the Taranaki Whānui to the island, speaking of the islands time as a Pā.

The traditional wayfinding methods mentioned in these stories are an important part of Māori culture, for without them they may never have made it to Aotearoa New Zealand. There is potential for these methods to be represented in the landscape for use as an educational tool, sharing traditional wayfinding methods with visitors.

As all Māori have a relationship with waka, it is important that the way Waka and wayfinding is represented in the site, is unique to the Taranaki Whānui. Referencing locally significant waka in the site will allow it to take on its own unique sense of identity within the space. 


\section{TE ÁTI AWA WAKA \\ LOCALLY SIGNIFICANT WAKA

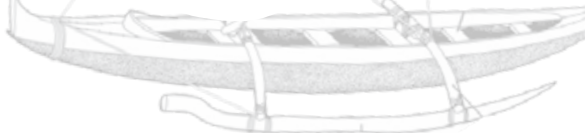

Te Rerenga Kotare is a waka taua, the

largest and most elaborate of the

single hull carved waka used by Māori

for ceremonial engagements and in

the past as war canoes. The waka

taua has an highly stylised prow from

Taranaki.

Te Hononga and Poutu are waka

that embody the hopes, dreams and

aspirations of the tribes ancestors.

As both men and women are welcome

on this waka it is envisaged that the

unification of people, the environment

communities and goodwill will elevate the

pride and prestige of Wellington.

Te Raukura and its sister waka,

Te Aniwaniwa are waka's that

were carved for the 1990

Waitangi celebrations.

TE HONONGA

Te Wharewaka, Wellington

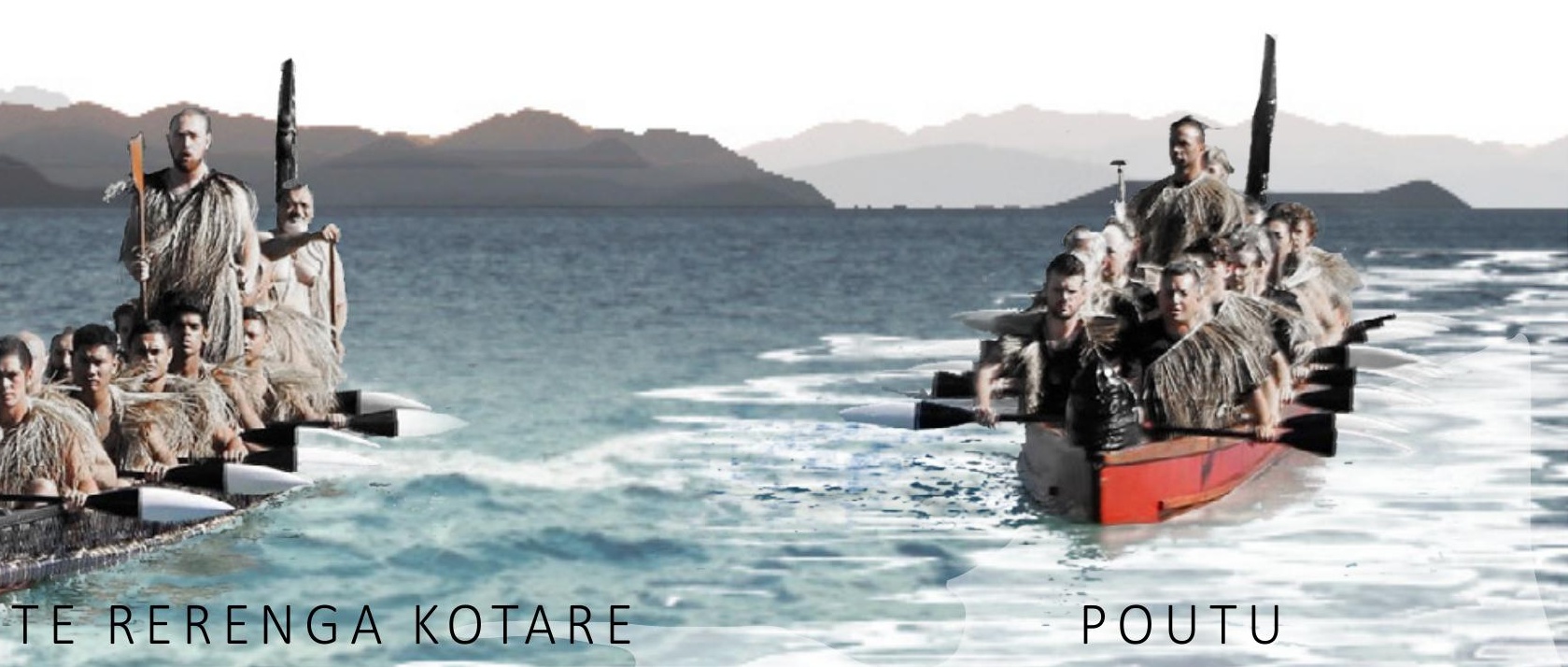

TE RERENGA KOTARE Te Wharewaka, Wellington
Te Wharewaka, Wellington
TE RAUKURA

Te Mãori, Lower Hutt

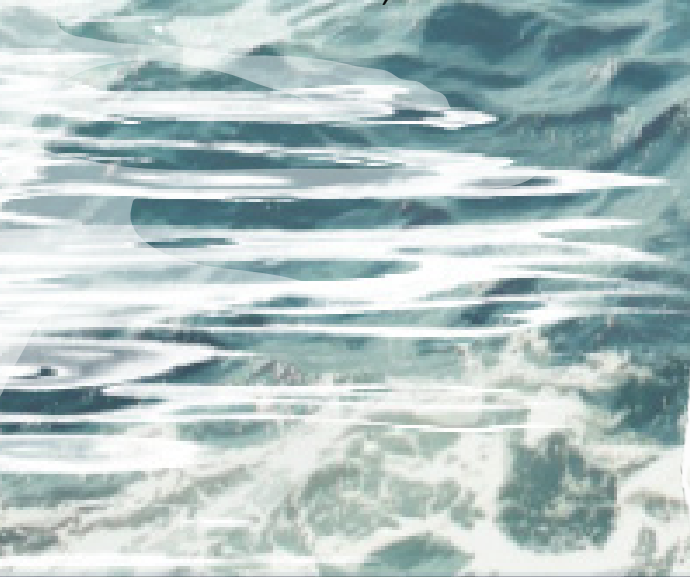

TE ANIWANIWA

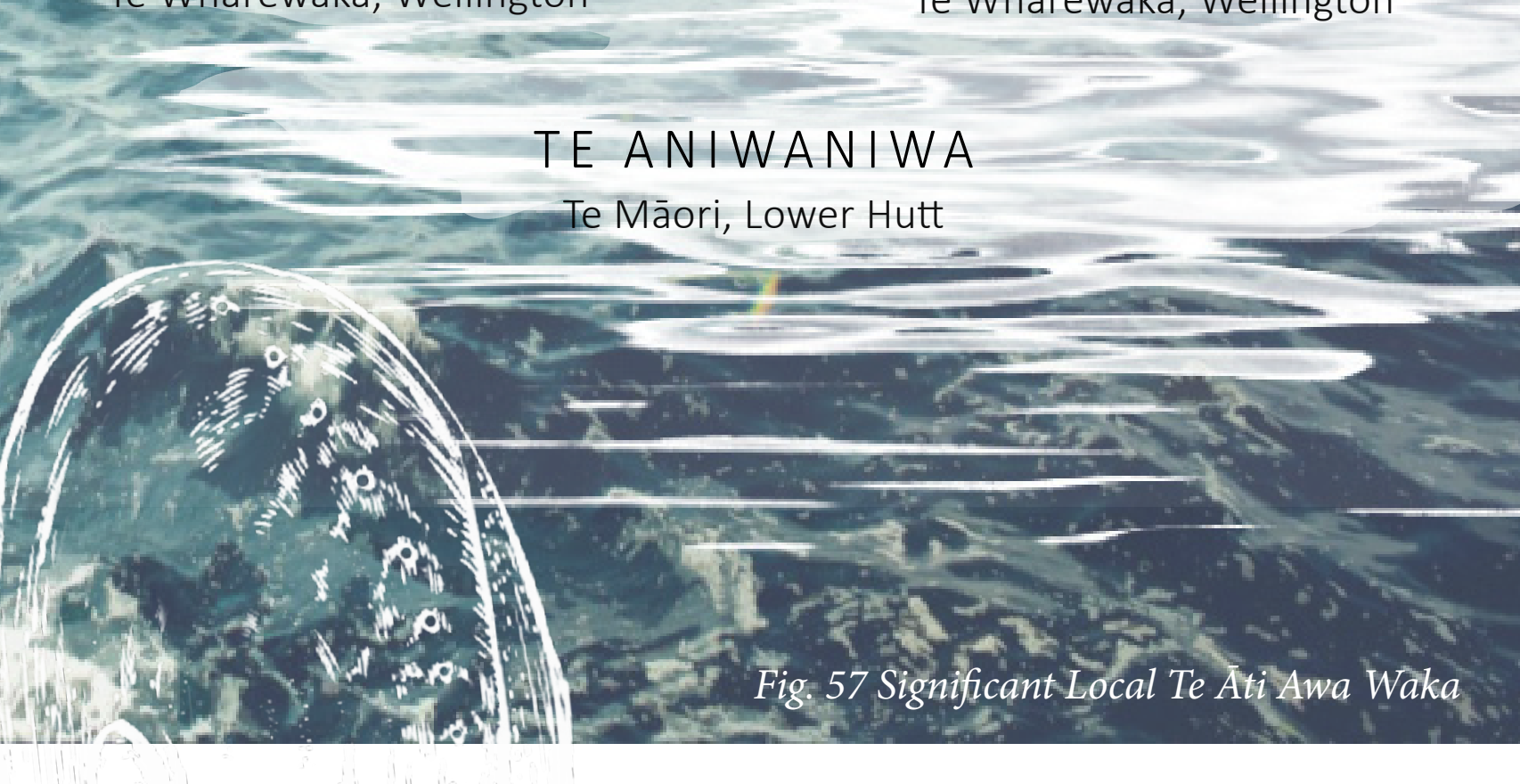

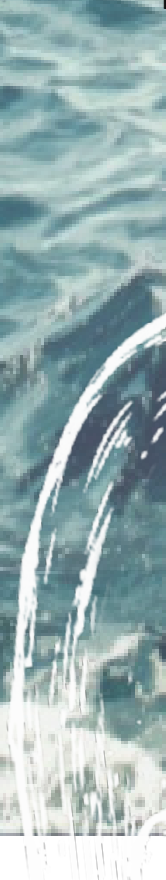




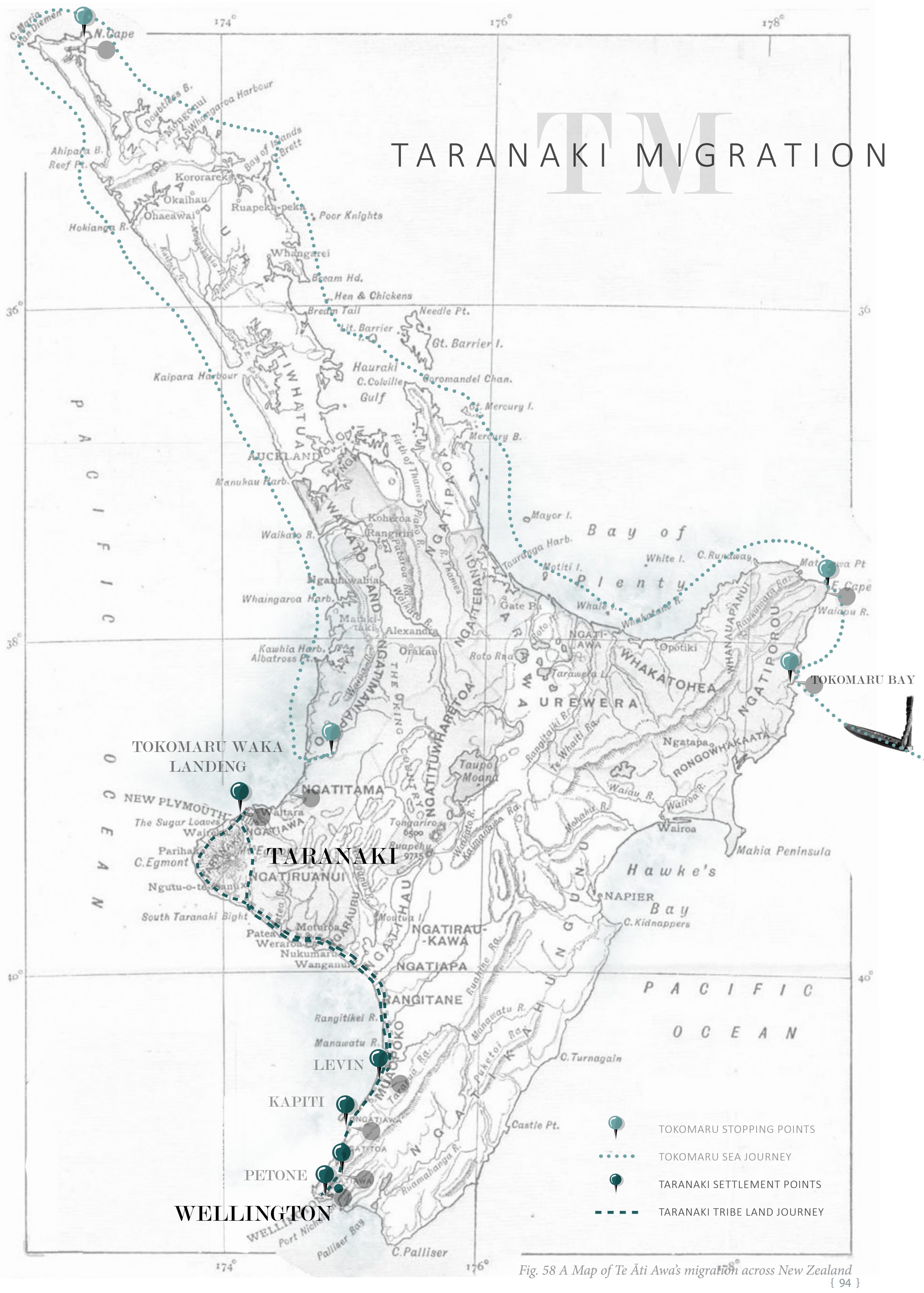




\subsection{NARRATIVES OF MIGRATION IN NEW ZEALAND}

The migration of the Taranaki Whānui's ancestors, not only from Hawaiki to New Zealand, but around New Zealand, is a significant part of their history. It is therefore important that the tribe's origins, which began in Taranaki, are shared with visitors.

The case study, Otahahu Station, drew on narratives of land migration and sea voyages as these resonated with the projects envisaged programme of the site, a core transport link for the people of Tämaki Makaurau Auckland. Using the pathways around Matiu Island could be a successful way to share Taranaki Whānui's migration from Taranaki and their movement around the Wellington harbour. This would resonate with the programmatic function of the paths, which enable visitors to embark on their own journey within the site. 


\section{NGAKE AND WHATAITAI}

WELLINGTON HARBOUR

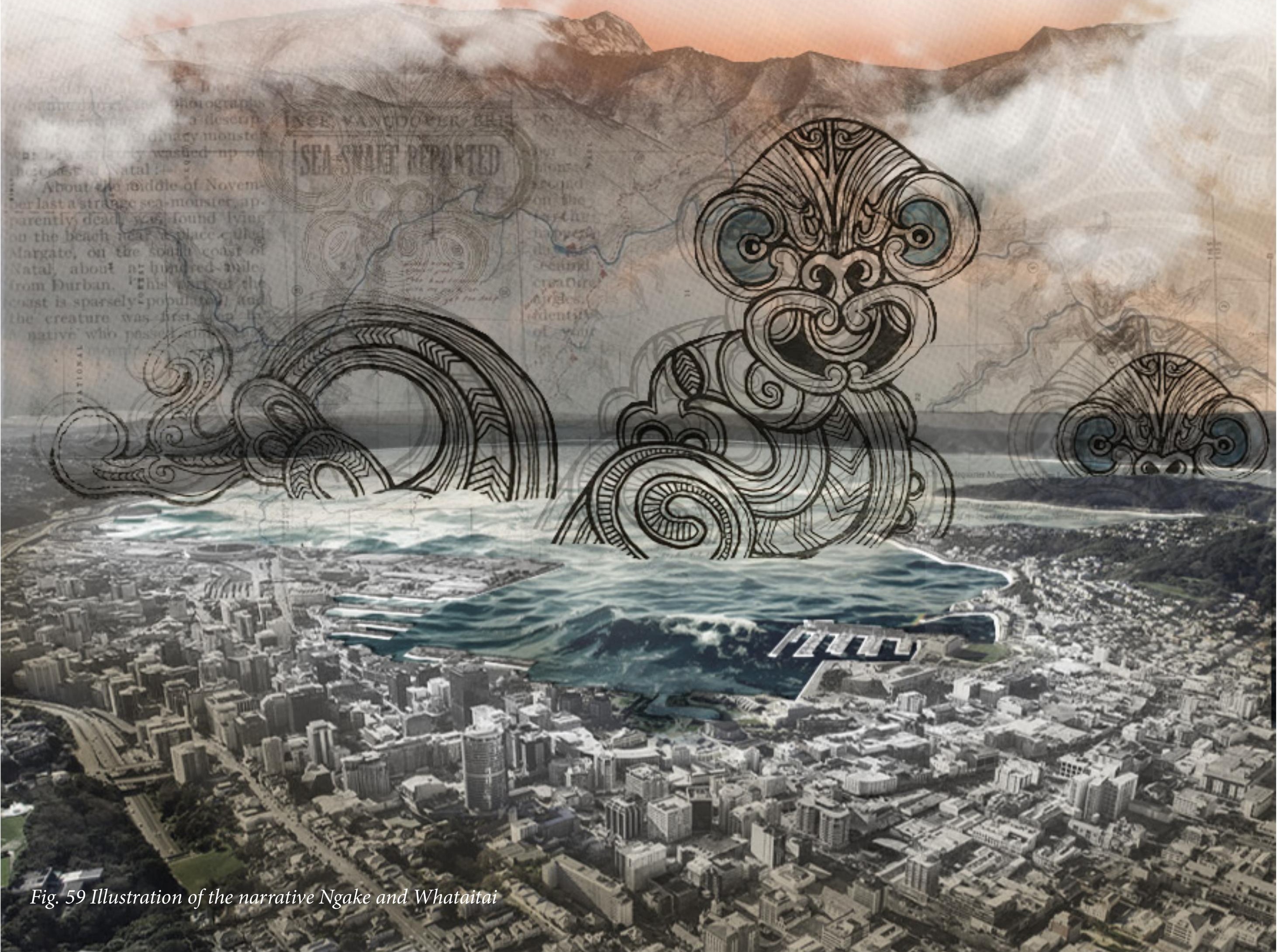




\section{LONGAGO...}

Before Kupe's time, there were two taniwha, Ngake and Whataitai, wholived in a lake that is now the Wellington Harbour. As the years passed, the taniwha grew bigger and the lake seemed to get smaller and smaller. Ngake was tired of being stuck in the lake and he convinced Whataitai they needed to break free.

Ngake swam to the north side of the lake where he hatched his plan to escape. He coiled his tail tightly and with an almighty roar he sprung out of the water. Ngake flew across the lake slamming into the cliffs behind the shore with such force he shattered the cliff, creating a path to Te Moana o Raukawa The Cook Straight. His tail had also slashed the land forming what we now call the Hutt River.

Whataitai, wanting to follow her brother tried with all her might to coil her tail up and jump out of the lake but she was not as strong as Ngake. Whataitai sprung out of entered the gap made by Ngake and came to a stop, she had not been fast enough to push hers over the land. Whataitai was stranded

between the sea and the lake. She began to lash her tail violently, trying to escape but all hope was lost. As the years passed the incoming tides kept her scales wet and provided Whataitai with food but she did not move.

One morning there was a large shake from under the ocean floor, an earthquake was erupting. Whataitai was lifted from the shallow waters, high above sea level, stranding her. With no tide to bring her food or keep her wet, she was doomed. As Whataitai died, her spirit transformed into a bird, Te Keo, and

flew to the nearest mountain, Matairangi / Mount Victoria.

Over the years, Whataitai's body turned into rock and earth, forming what is now known as Haitaitai. Although Ngake was never seen again people believe he lives in the turbulent waters of Te Moana o Raukawa - The Cook Straight.(Grace, 2015c)

\subsection{THE CREATION OF THE WELLINGTON HARBOUR}

The story of Ngake and Whataitai is significant to the mana whenua of the Harbour as it is a Māori legend describing how the Pōneke Wellington Harbour was formed. As the story references Mount Victoria, Petone and the Cook Straight, providing views to these sites, from the Island, could simply acknowledge the importance of these sites within the founding of the harbour. 


\section{TAR A}

THE NAMING OF WELLINGTON

Whatonga, was a Māori navigator and son of a

Polynesian explorer. Once he had settled on the Mahaia Peninsula Watonga married Hotuwaipara and they had their first son Tara, who was named after the spine of a fish that had pricked his mother's finger just before his birth.

Whatonga had a restless personality continuing to travel across Aotearoa. When Whatonga and his family reached Wellington, they initially settled on Matiu Island but then moved to the largest Island in the Harbour Motukairangi, which is now Miramar Peninsula.

Wellington was originally named Te Whanganui a Tara in honour of Tara, translating to "The Great Harbour of Tara". This refers to Tara's time as a chief in Wellington in the 12th century. (Reid, 2005)

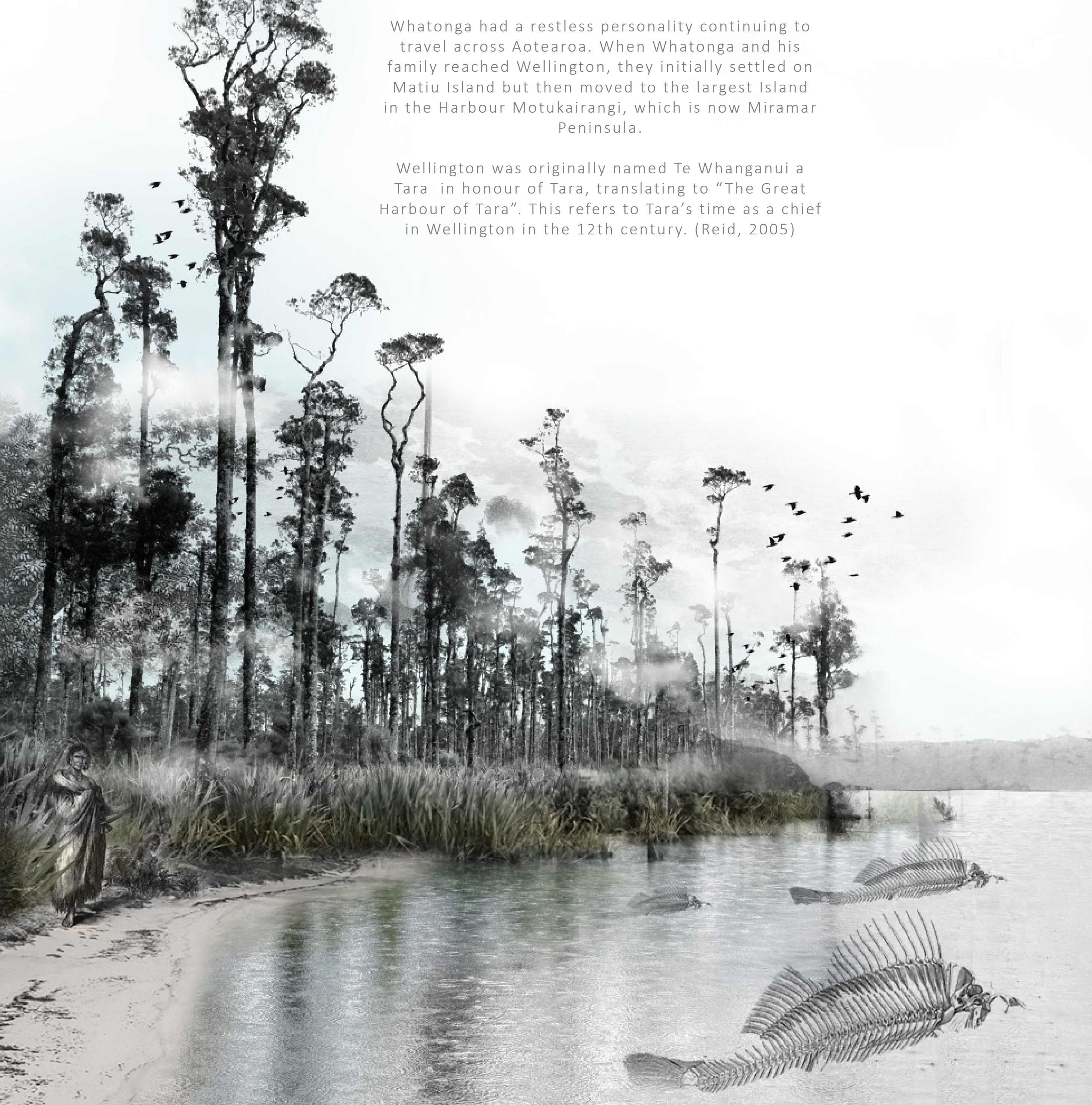




\title{
KUPES DAUGHTERS
}

\author{
THE NAMING OF THE ISLANDS \\ Kupe, a great Hawaiki chief who chased an Octopus \\ to New Zealand with his family. In his absence \\ fighting the giant Wheke (octopus), his wife and two \\ Mokopuna, Matiu and Makaro, who were living in \\ Wellington at the time, were worried Kupe had been \\ slain so they slashed their breasts, staining rocks \\ on the Wellington coast, giving them the name Red \\ Rocks.
}

When Kupe returned he named the three Wellington harbour islands Matiu and Makaro in their honour.

(Grace, 2015a)

\subsection{MĀORI IN WELLINGTON}

These stories are two of the most historic Māori narratives describing important events in the Pōneke Wellington region. Ensuring visitors know the narratives that gave Pōneke Wellington and Matiu Island their name's is of great importance to the mana whenua.

These stories also speak of the important relationship Māori have with the marine environment, physically and symbolically. Acknowledging this important relationship, on the island, will allow visitors to appreciate and respect Pōneke Wellington marine life. Case studies such as Taumanu Reserve convey how providing visitors with access to significant environments, used by Māori, can be a subtle way of acknowledging their significance. Creating ways in which visitors can interact with the islands coastline and sea, like the great explorers, could be a way of paying tribute to them. 


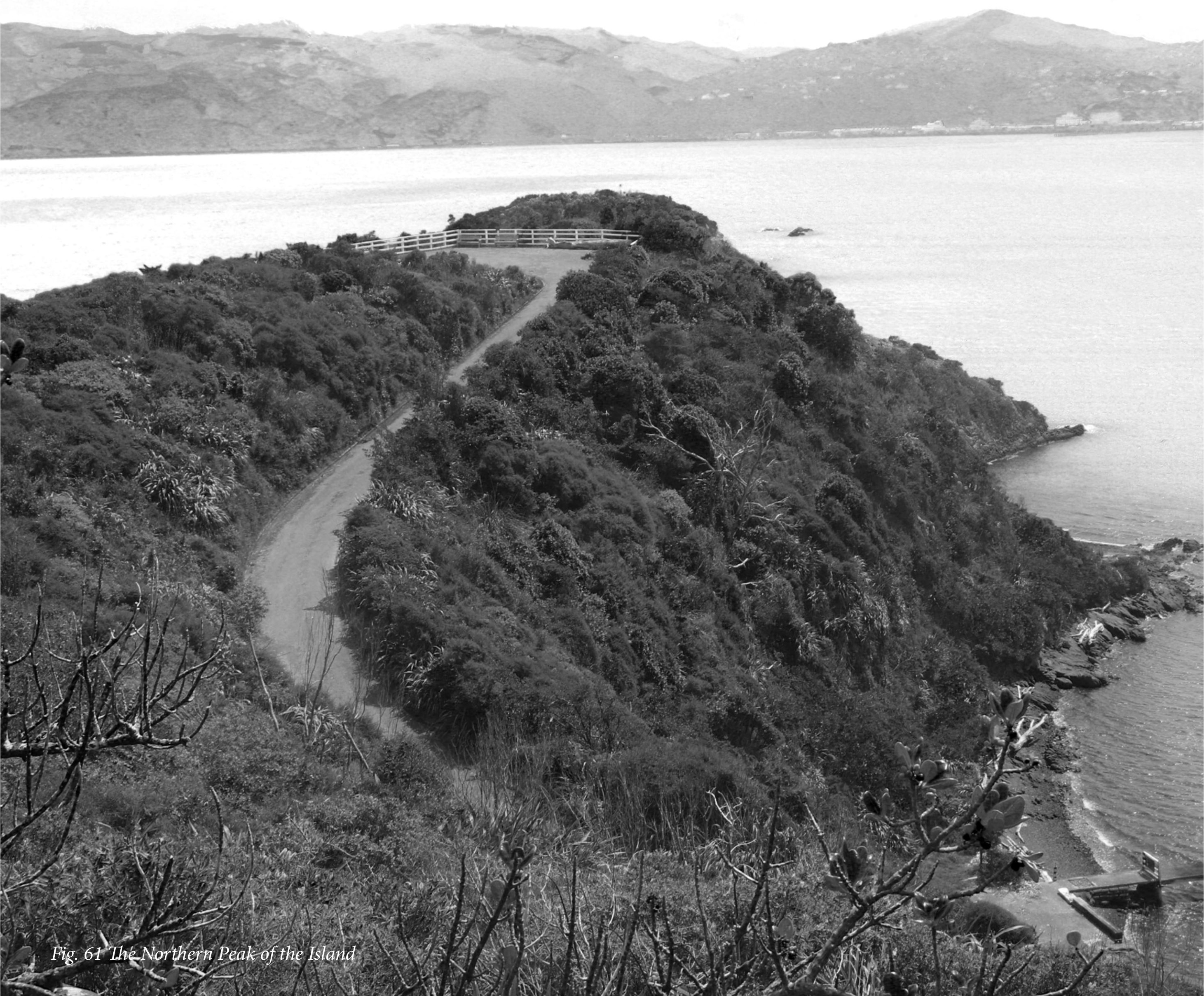




\subsection{CULTURAL SIGNIFICANCE FINDINGS}

SELECTING THE NARRATIVES Through consultation with members of Taranaki Whānui, narratives that were significant to the mana whenua were selected as a medium to create a landscape that connected to its people. A selection of general, contextual and site-specific stories were highlighted as narrarives that had the ability to set the scene, conveying Taranaki Whānui's origins as well as describing the essence and the historical events of the site.

THE INTRODUCTION When visitors arrive at the Island they should be introduced to key Māori concepts and narratives, setting them up with a basic understanding of Māori views and their background. The founding story, Maui and The Fish, will be the first visual narrative visitors interact with when they arrive on the island. This will provide visitors with insight into where Māori came from, the famous pacific explorers and their Waka voyages and the legend of how New Zealand came to exist. The theme of waka will be carried throughout the rest of the design of the island, through wayfinding and navigation themes, due to their presence in most of the Taranaki Whānui 's significant narratives.

CONTEXTUAL INSIGHT Migration across New Zealand is an important aspect of Taranaki Whānui's history as it explains where the Iwi came from (Taranaki) and how they ended up in Pōneke Wellington. Telling these stories of migration, along pathways in the site, can educate visitors on the movement of the tribe from Taranaki, Kapiti and through to Pōneke Wellington, while they embark on their own journey across the island.

SITE HISTORY Stories such as Kupe and his daughters and Tara have the capacity to give visitors insight into the history of the Wellington harbour and the island itself. They also emphasize the special relationship between the mana whenua and the marine environment, placing importance on people's ability to access and interact with the marine environment themselves.

The story of Tara also indicates that Māori used Matiu island as a Pā and a visual vantage point, where they relied solely on the surrounding environment to feed and protect them. This is something that is not currently, but should be, celebrated on the Island. These are the core stories of the island and therefore, they should be incorporated onto the islands destinations spaces so they can be shared with visitors and resonate with Māori. 



\section{DESIGN APPROACH}

THE DESIGN PROPOSAL

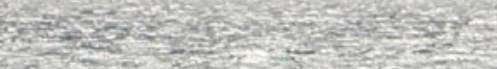

Ci.

W.

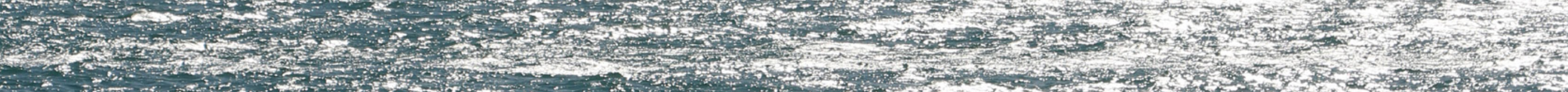

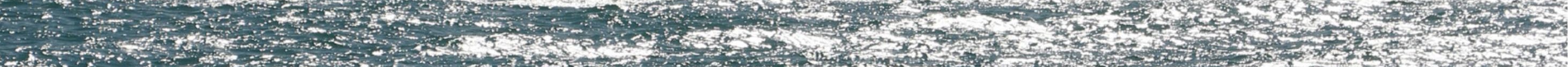

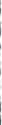

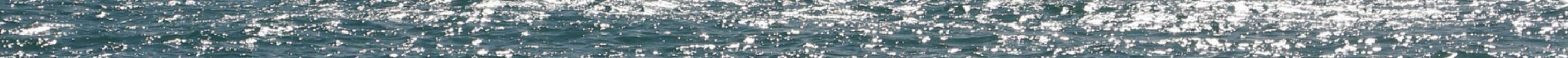

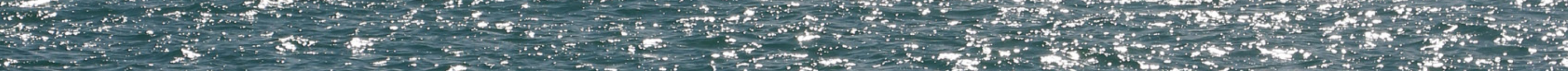

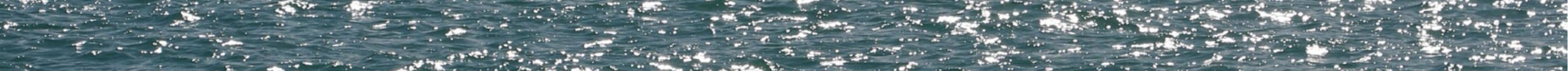

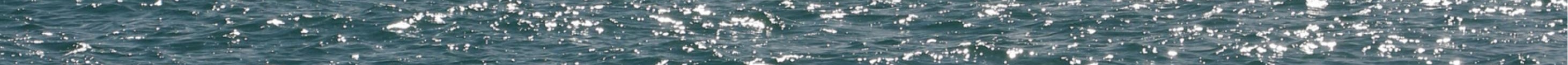

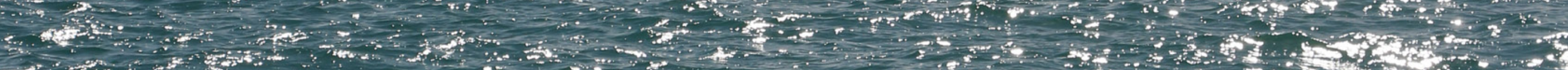

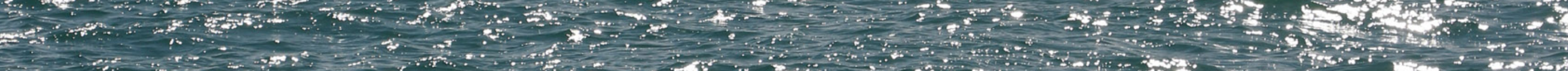

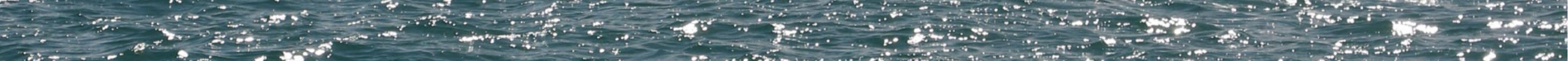

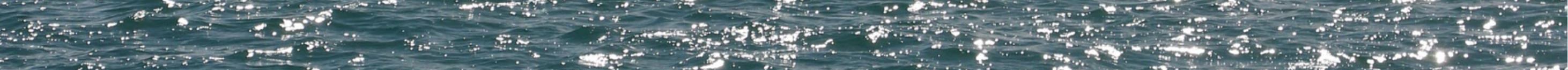

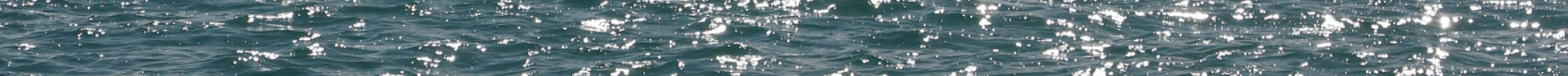

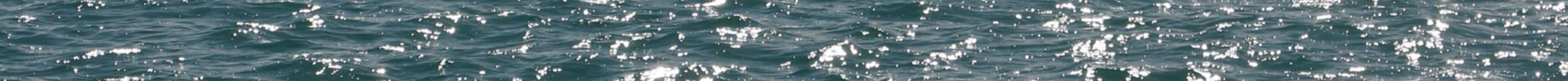

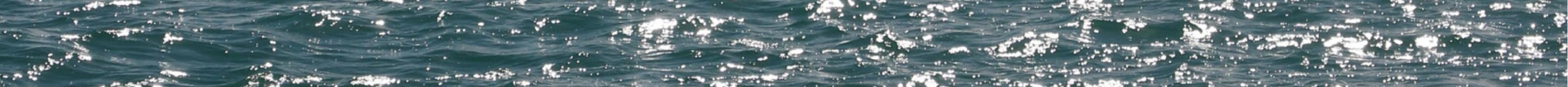

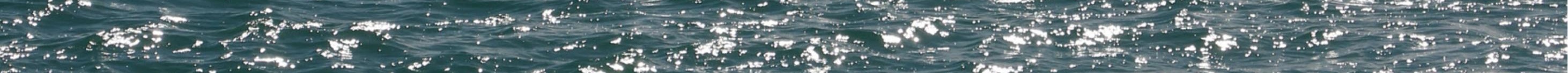

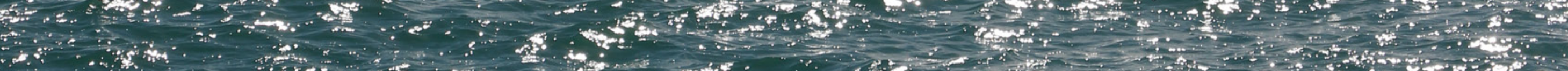

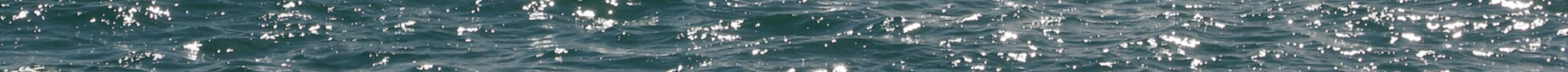

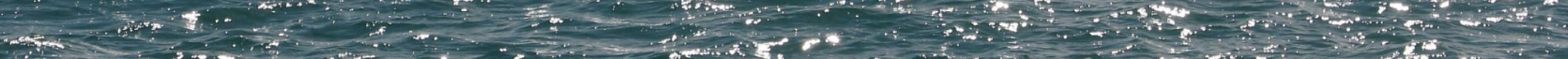

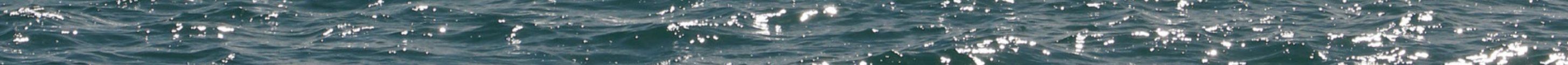

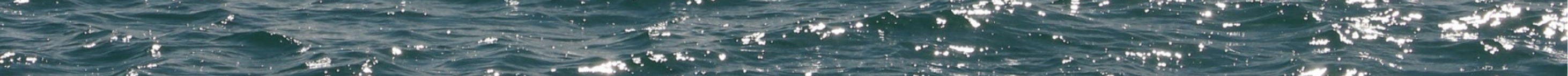

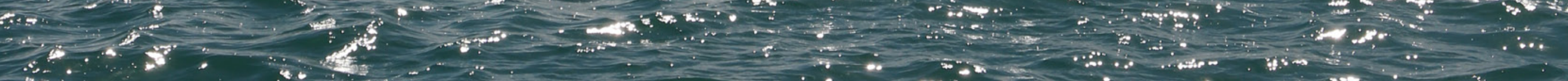

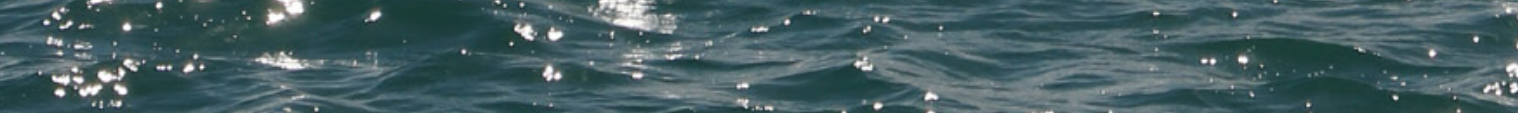




\subsection{PROJECT OVERVIEW}

The project proposes a new scheme for the development of Matiu Island. It looks to re-introduce the presence of Māori heritage and culture on the island, while enhancing the existing social and environmental aspects. It will do this through spatialising key contextualised and significant narratives and concepts, associated to mana whenua, through a range of cultural destinations and journeys.

The design will focus on four areas on the island, The Wharf, The Quarantine Building, The Peak and the existing pathways. These sites were selected based on the role they play in a visitor's experience on the island and the significant role they have played in Māori History. These sites will celebrate their culturally historic past by showcasing cultural practises, native ecologies and engage and educate visitors through a range of recreational and social spaces. 


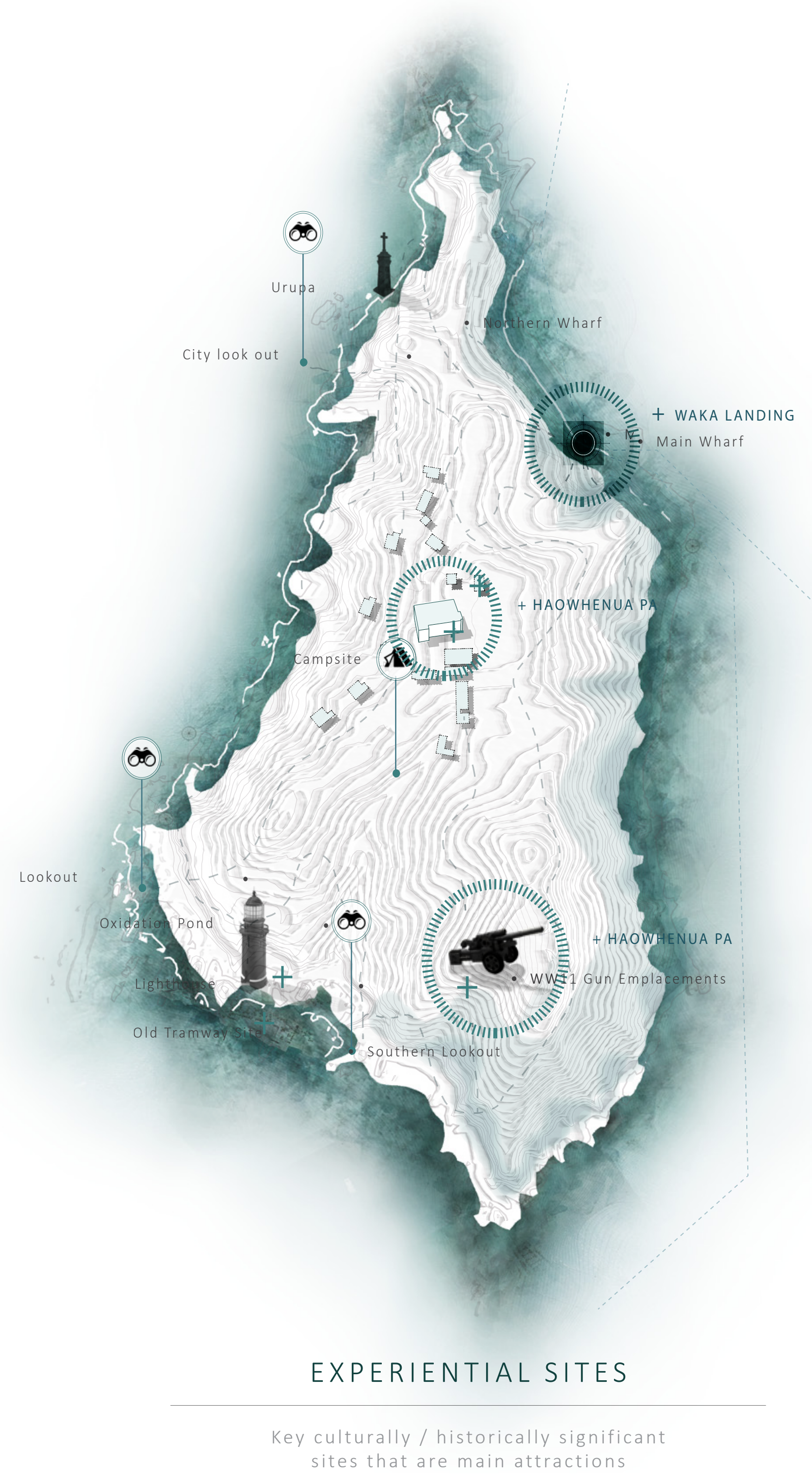

Fig. 62 Matiu Islands Key Attraction Sites 


\subsection{FRAMEWORK STRATEGY}

The design framework was created to recognise and celebrate culturally significant sites on Matiu Island. The framework focuses on a Waka landing area, one of the main Pā sites on the island, its lookout and the walkways around the island. The main cultural sites, which are already well established destination spaces on the island, will be designed to become culturally focused zones. The cultural zones that are ecologically degraded will integrate Rongōa planting. This involves the integration of species that will help to restore the native environment, creating educational spaces for Māori to teach and share Rongoā with others. The island's pathways will use planting, materiality, wayfinding interventions and artwork to share stories of the Iwi's migration and showcase the native ecologies during the day and night. 
CULTURAL HISTORY

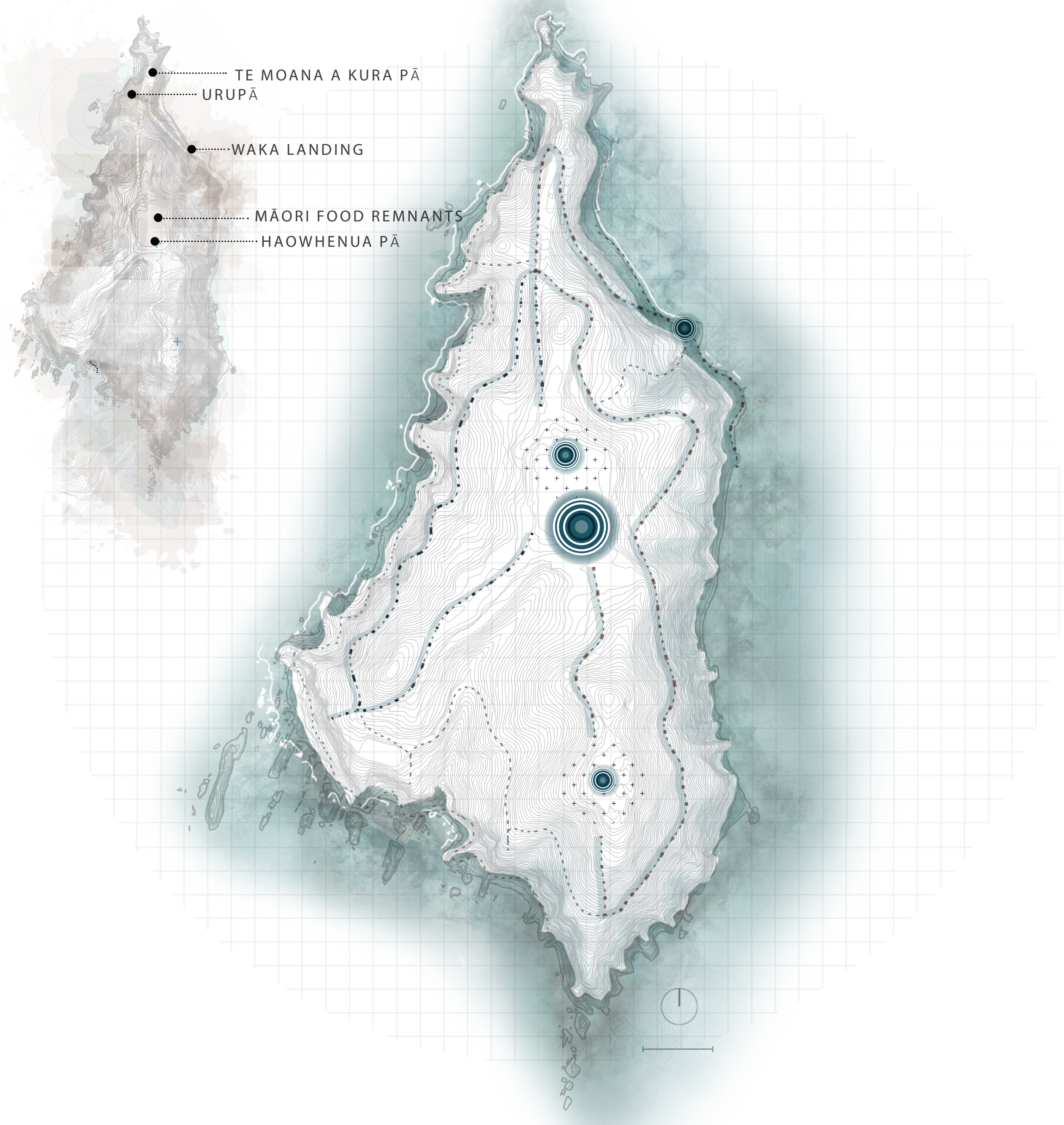

FOCAL CULTURAL ZONES

(2)
Showcasing traditional practises
RONGŌ̄A PLANTING

$+_{+}^{+}++$Growing medicinal plants

${ }^{+}+{ }^{+}+{ }^{+}+$Practising Rongoā
ISLAND JOURNEYS

Night experience enhancement Ecology showcase 


\subsection{PROGRAMMATIC STRATEGY}

In order to celebrate the cultural history of the island and create bicultural harmony, the development of the selected key sites did not drastically move away from the current or historic programmatic program of the sites. For this reason, each site was examined to identifying what the sites were historically, or currently, used for. This enabled new ideas to develop that integrate aspects of Māori culture, building upon the historic Māori or European use of the site.

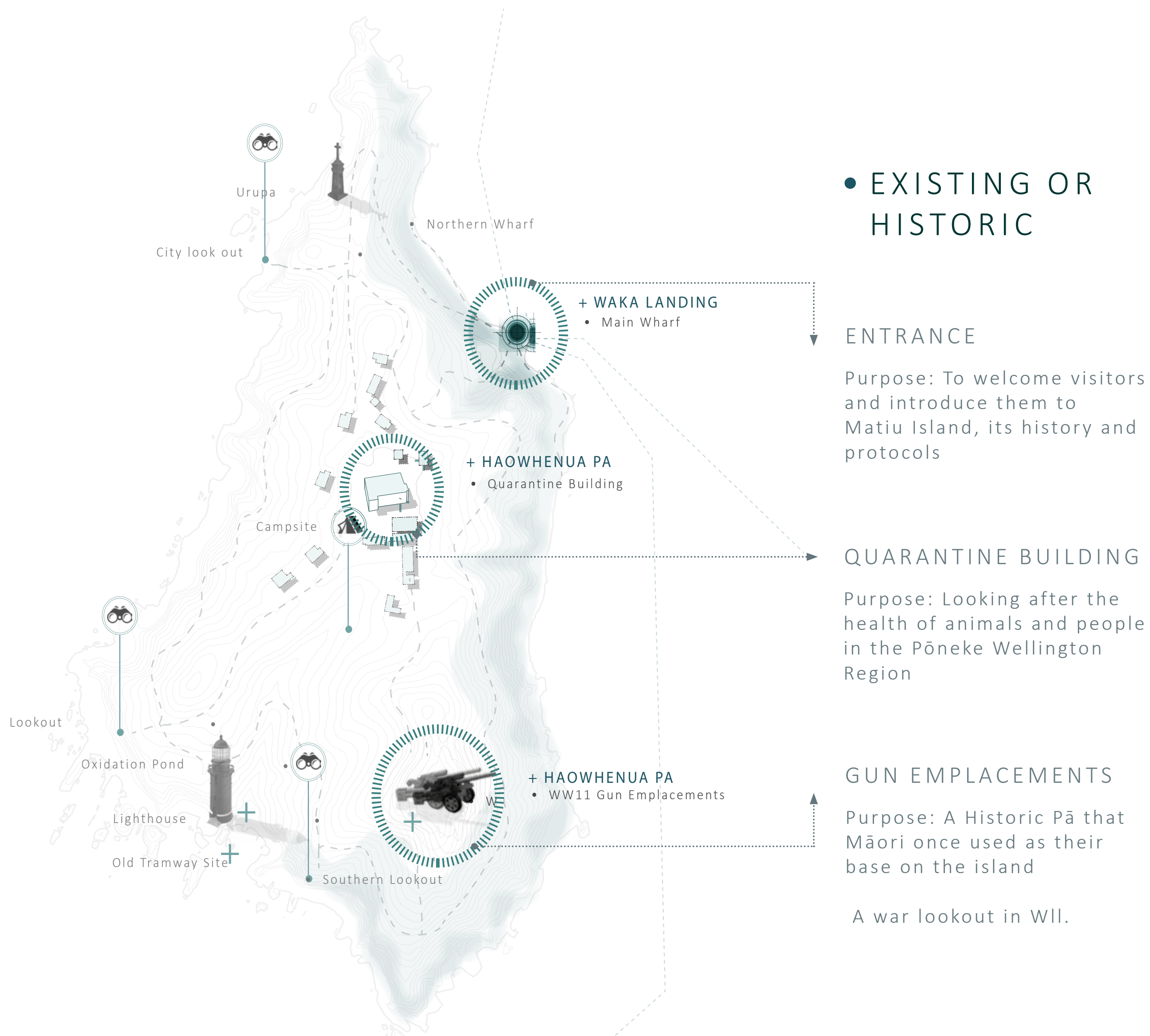

Fig. 64 Matiu Islands programmatic diagram 
- NEW IDEAS

\author{
ENTRANCE \\ - Introduce visitors to Māori \\ concepts and narratives \\ - Allow visitors to interact \\ with the marine environment
}

QUARANTINE BUILDING

-Create a functioning building that continues to look after the health of animals and people in the Pōneke Wellington Region through introducing Rongoā practises.

GUN EMPLACEMENTS

- Create a modern day base for Māorion the island, a place where they can celebrate certain occasions and stay on the island temporarily.

- Create a unique lookout space where people can continue to use the peak as a way to observe the surrounding area 


\subsection{DESIGN CRITERIA}

The design criteria were created based of the amalgamation of the findings from the site analysis, literature review, case studies and Taranaki Whānui's significant narratives.

ENTRANCE: Through analysis, it became clear that the Wharf site was underwhelming and failed to appropriately introduce visitors to the island. Readings about a sense of place and the Auckland Airport case study conveyed the importance of the entrance of a site, grounding people to a place through instantly conveying some of its essence and identity. Further research into narratives and values important to mana whenua found that this is where Mātauranga Māori and the story of Maui and the fish should first be introduced to visitors, providing them with a basic understanding of Māori values and Māori History.

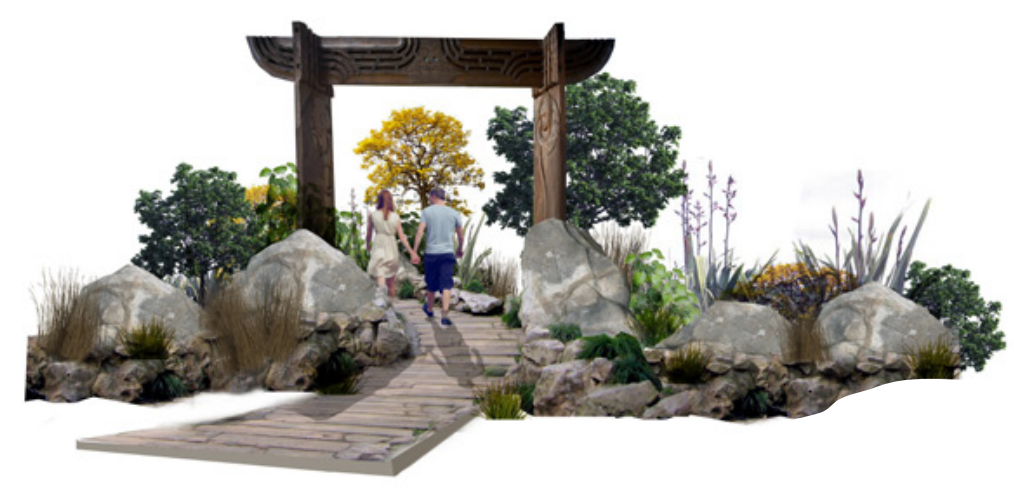

Fig. 65 The Entrance icon

ISLAND PATHWAYS: The pathways provide a way for visitors to explore the island and observe the abundant wildlife species present on the island. Through discussing significant narratives with mana whenua and analysing case studies that developed cultural pathways, it became apparent that these paths could also be used to share important migration stories of Taranaki Whānui's ancestors, who travelled across Aotearoa New Zealand. Planting and materiality, as seen at Otahahu station could be used to reference these narratives while enhancing visitors interactions with native wildlife.

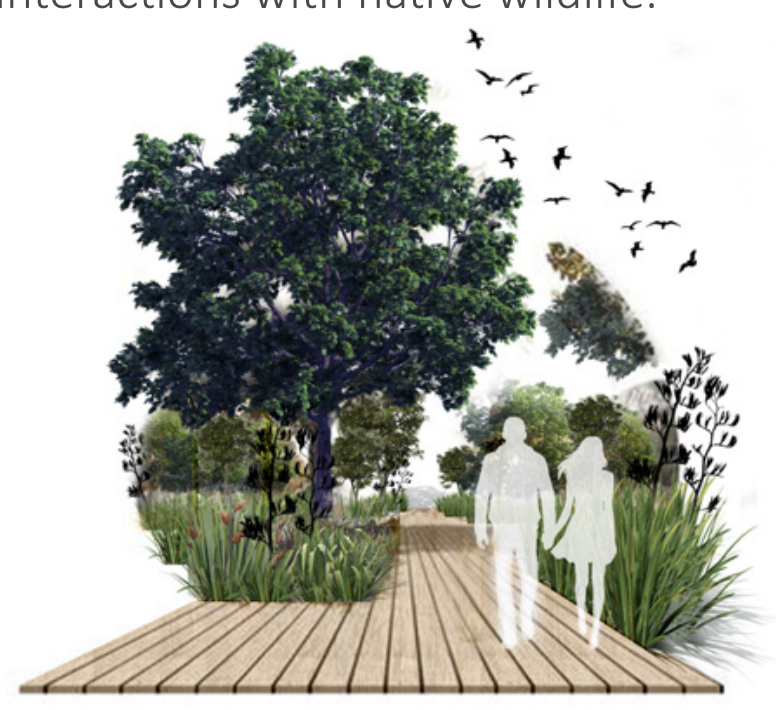

Fig. 66 Pathway icon 
QUARANTINE BUILDING: The Quarantine building was established to monitor the health of animals and people in the region, however the building is now abandoned and poorly maintained. After examining the practise of Rongoā and looking at the Sisters of Compassion Case Study, it became apparent that implementing Rongoā plants in and around the building could restore its role as a health facility within Pōneke Wellington. Introducing Rongoā planting would also enable it to become a cultural and educational space for Māori to share this practise with others.

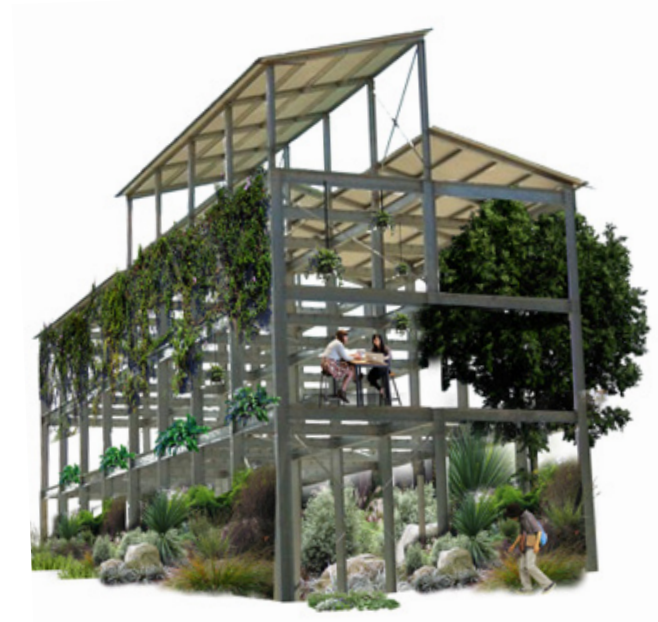

Fig.67 Quarantine Building icon

THE PEAK: The flat space located in front of the Quarantine building is a culturally significant site as it was once the Haowhenua Pā, one of two Pā's on the island. The site provides views out to the harbour, although it is still semi sheltered from the wind due to the vegetation that surrounds it. Case studies regarding the development of important Māori land, like Te Kura Whare, illustrate that these sites are often converted into a base for Māori to gather and celebrate their land, culture and the place their anecstors once settled. Using the ancestral story of the Tokomaru waka and site-specific narratives, such as the story of Tara, this site will ground Māori to the place that their ancestors were connected to, while representing their past and identity.

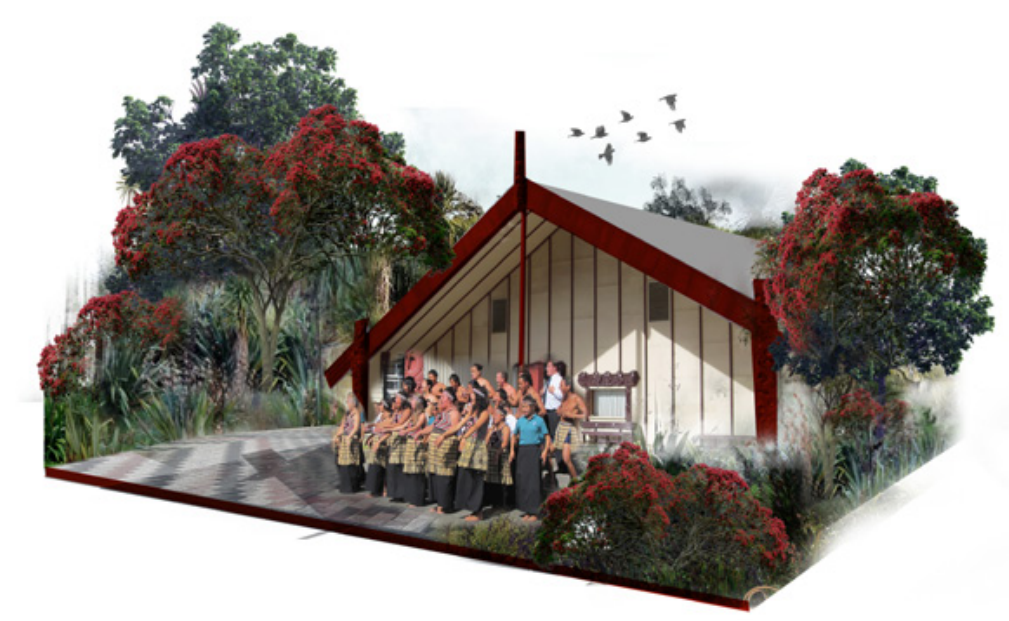

Fig. 68 The Peak icon 


\section{DESIGN CRITERIA}

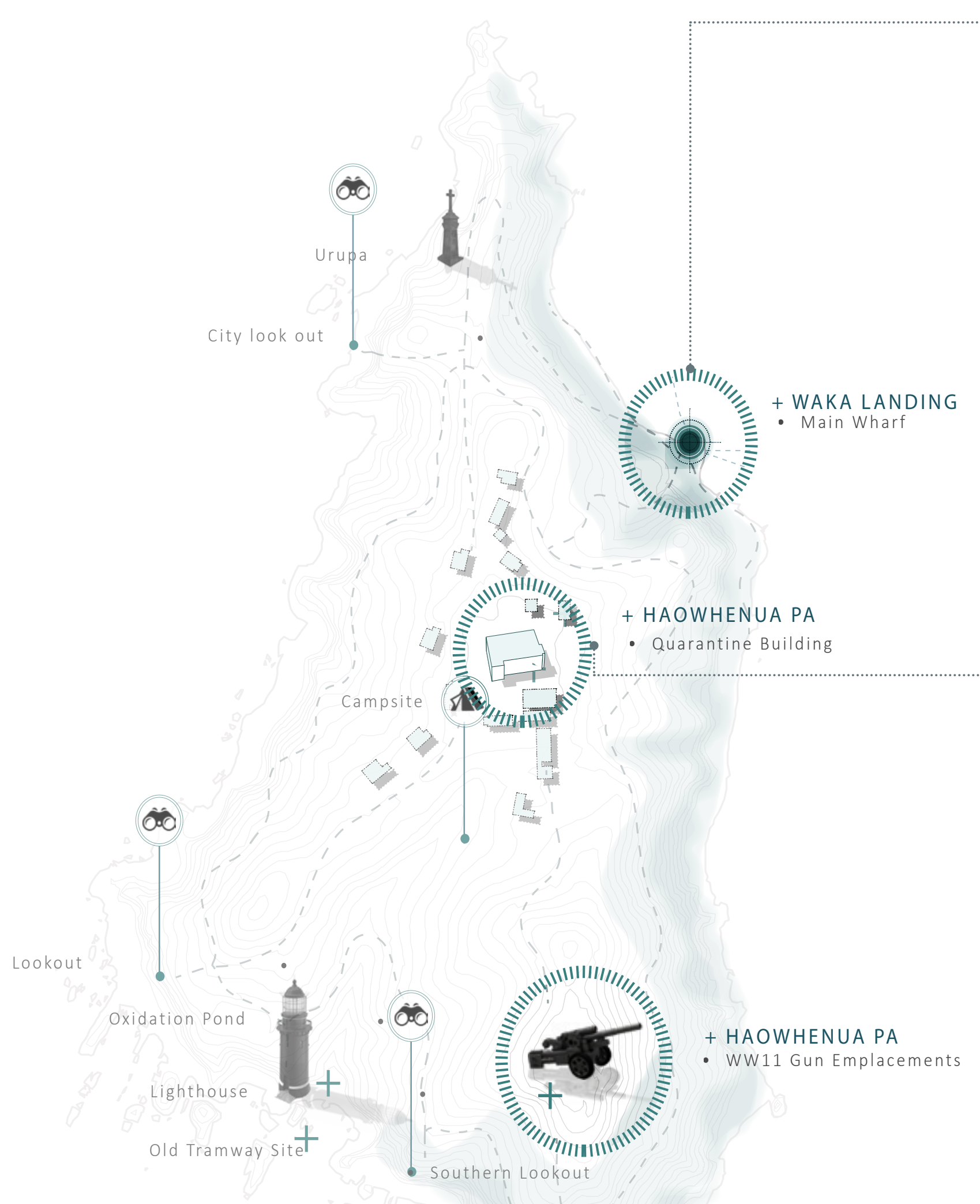




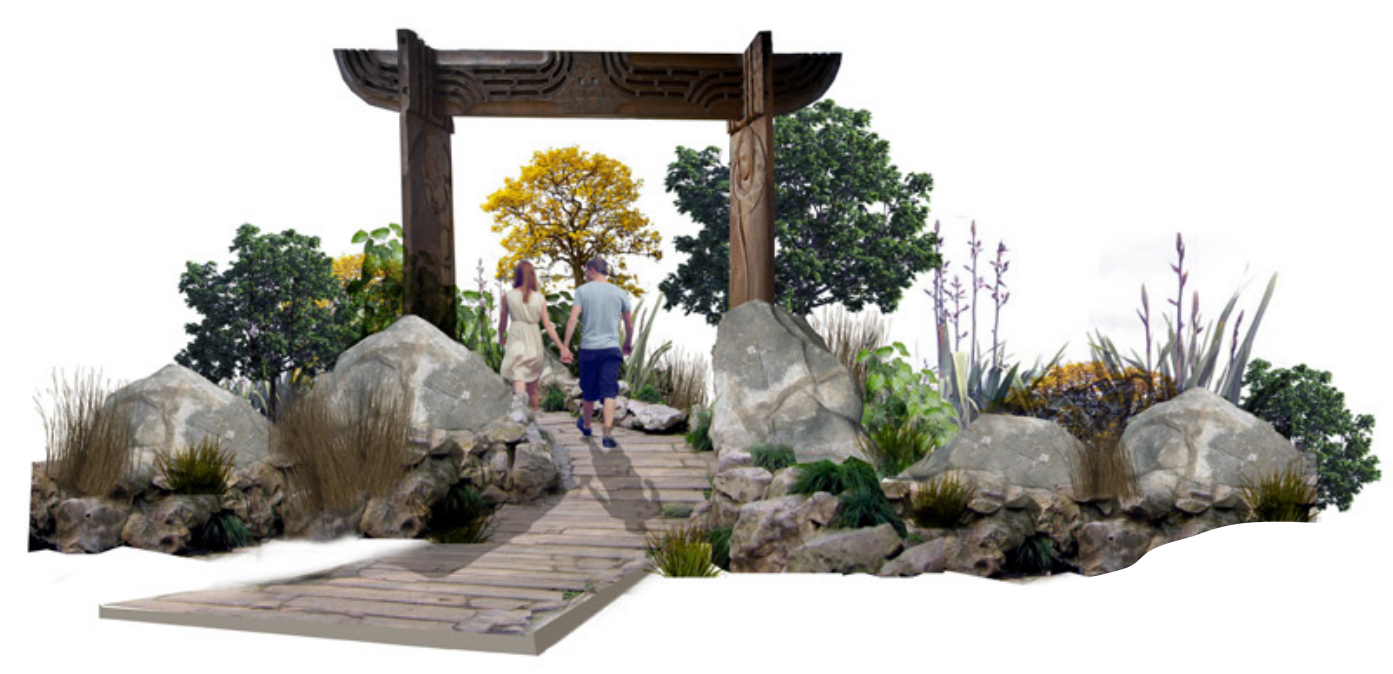

MEMORABLE ENTRANCE

Create a memorable entrance for visitors that shares key Māori narratives and values, speaks of the Islands maritime history and allows for cultural activities on water and land.

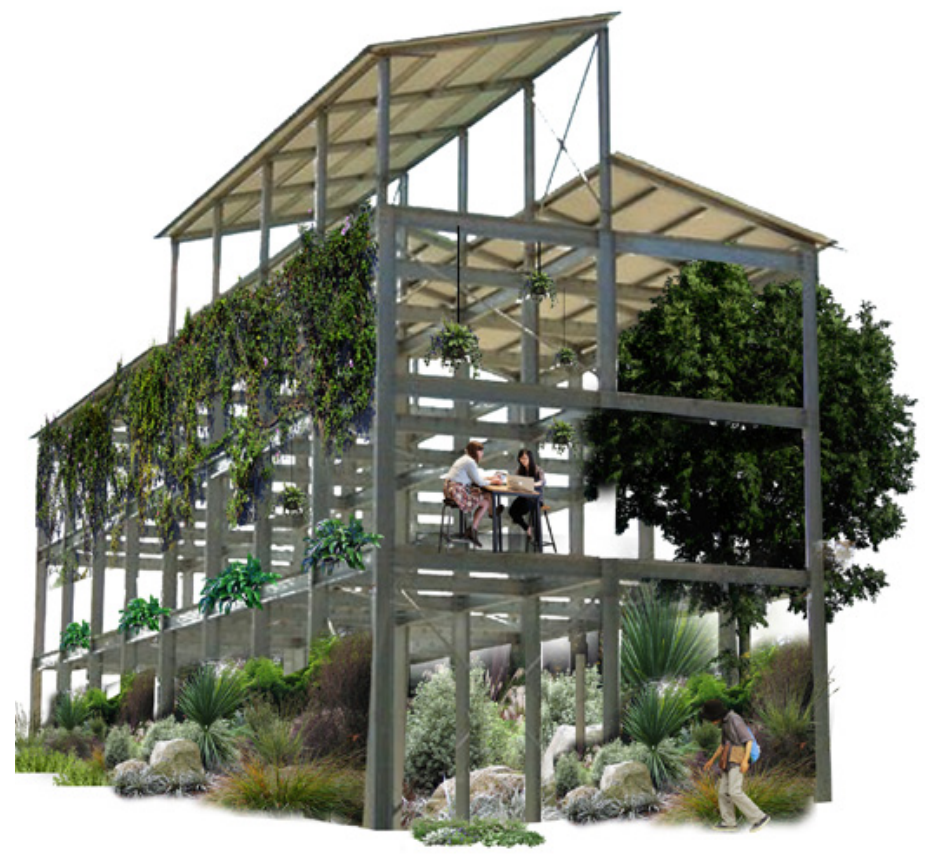

RE-PURPOSED QUARANTINE

Transform the old Quarantine into a conservatory type building that grows Rongoā plants and has a relationship with the Marae.

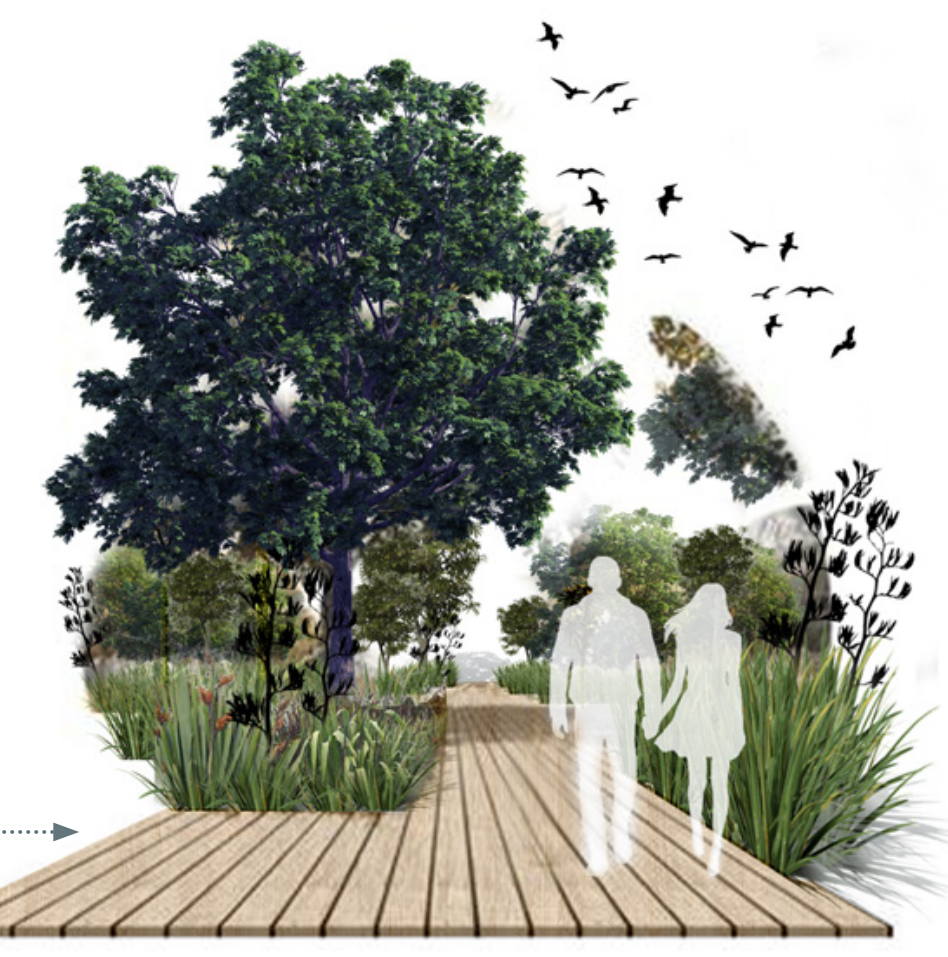

ISLAND JOURNEYS

Produce a series of interesting journeys across the island that retell important narratives and showcase the islands different micro climates and wildlife

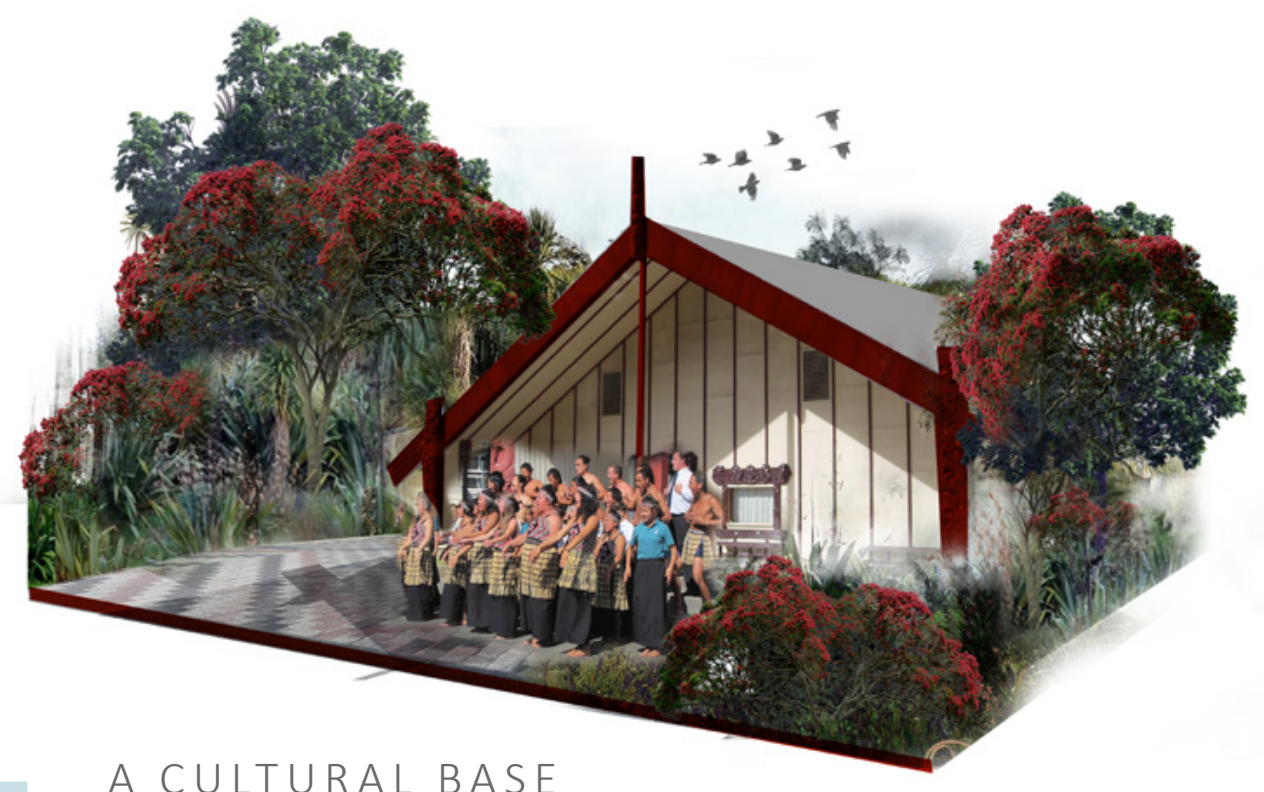

Implement a Pā that acts as a cultural base for Māori in Pōneke Wellington and an educational tool visitors and locals. 


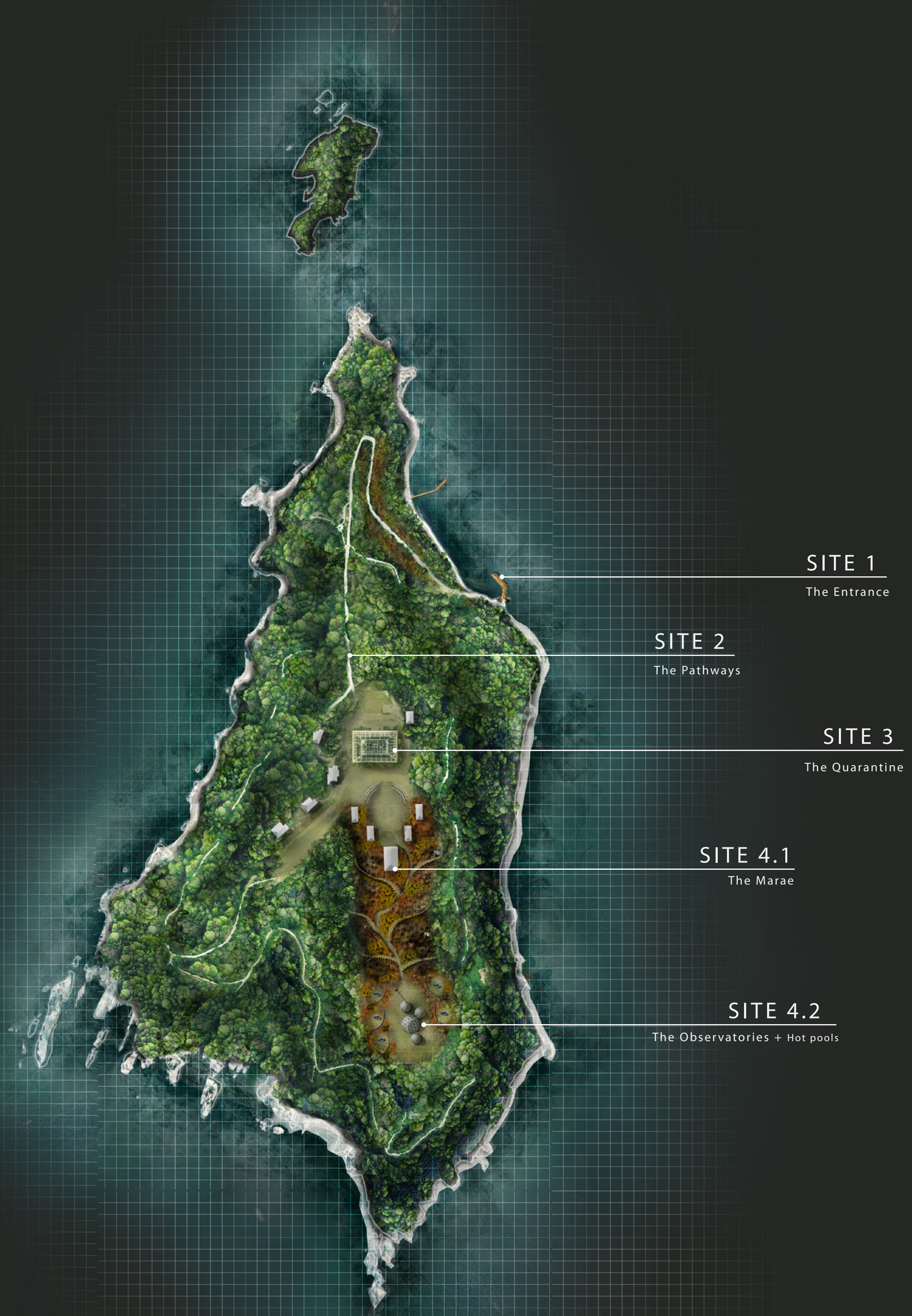






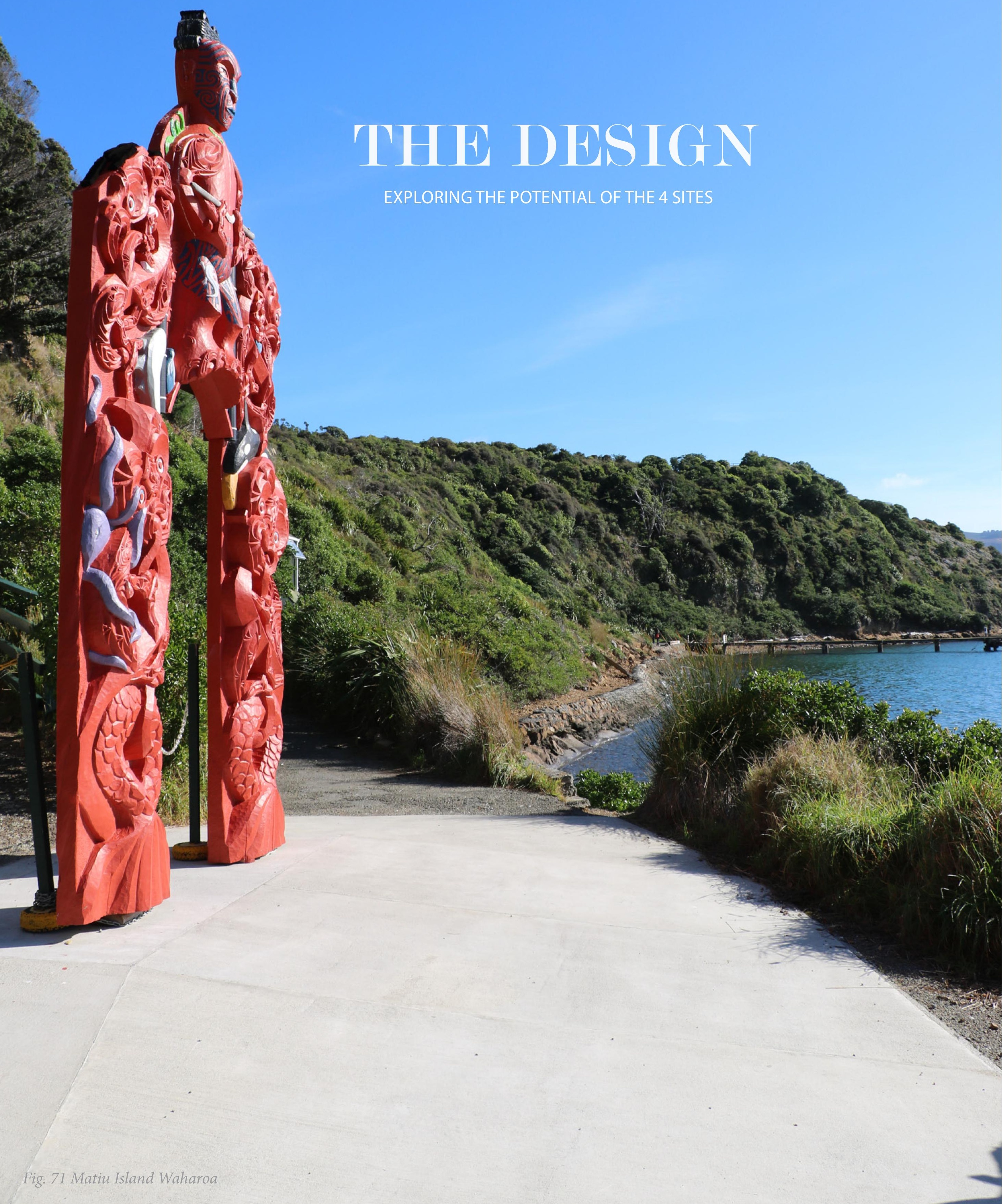




\section{SITE ONE}

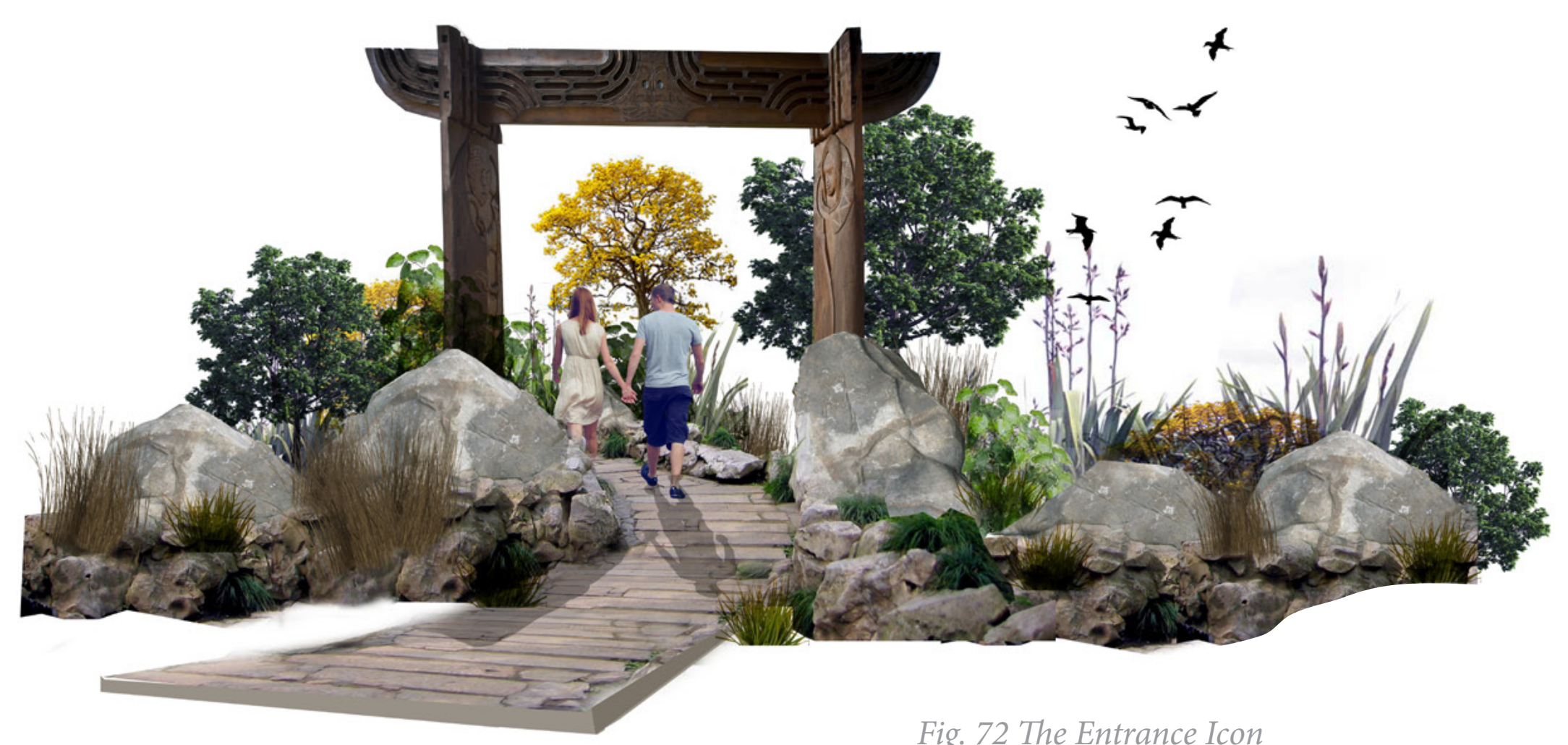

\subsection{THE ENTRANCE}

Upon arrival, visitors first contact with the island is the Wharf. This site is historically significant as it was where the first Māori waka landed. The Wharf area should be a space that represents the holistic essence of the island, introducing people to the core values of the mana whenua and their founding stories. However, the experience of arriving there is currently underwhelming due to the worn and neglected nature of the site, its materials and the vegetation.

Through examining and applying concepts from the case studies to create engaging entrances, the space will work to share core Māori values with visitors and the spiritual connection Māori have with the environment.

The Wharf is also one of the few places where visitors can interact with the water's edge. The design exploration of the site will focus on enhancing the coastal edge as well as providing better and diversified access to the water for Māori, locals and visitors. This will create an engaging space that educates people about Aotearoa New Zealand's marine environment and how Māori interact with it. 


\section{OBJECTIVES}

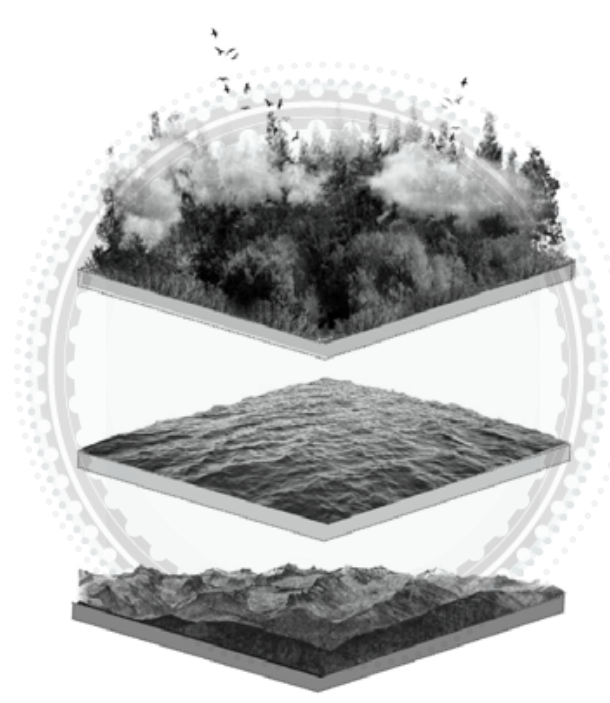

Introduce visitors to Māori values/concepts and traditional practises

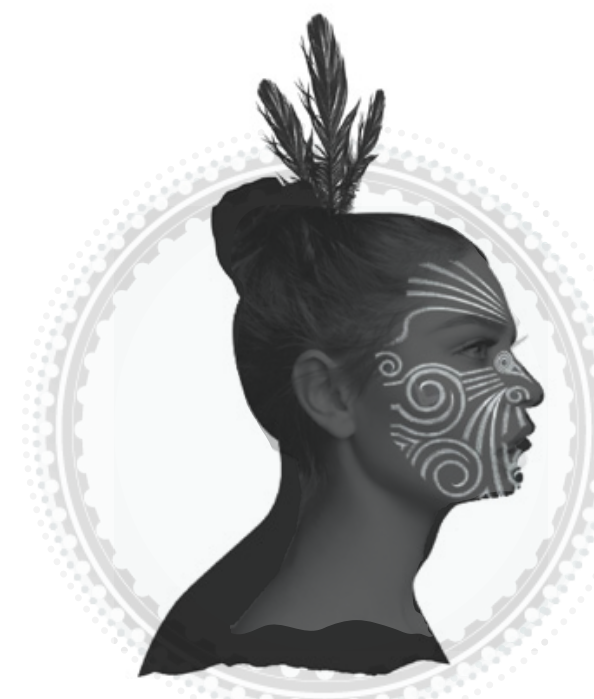

Create a space for Māori to use Waka.

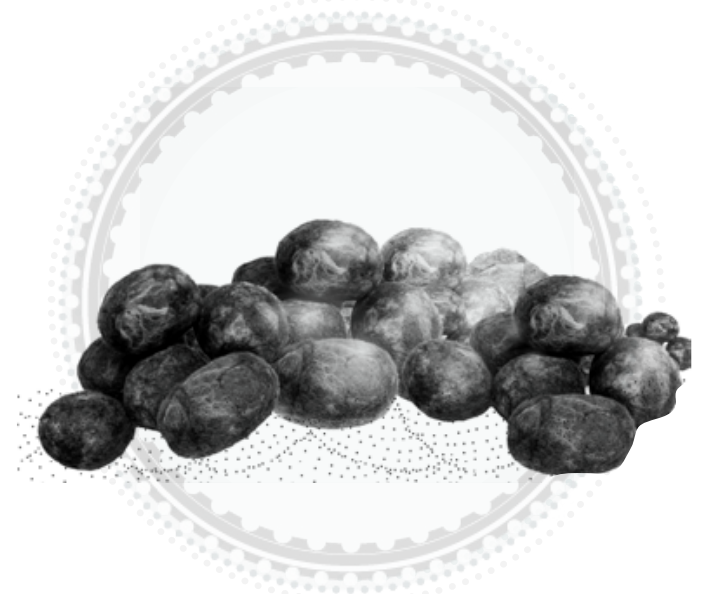

Create recreational and social spaces that provide people with access to the marine environment 


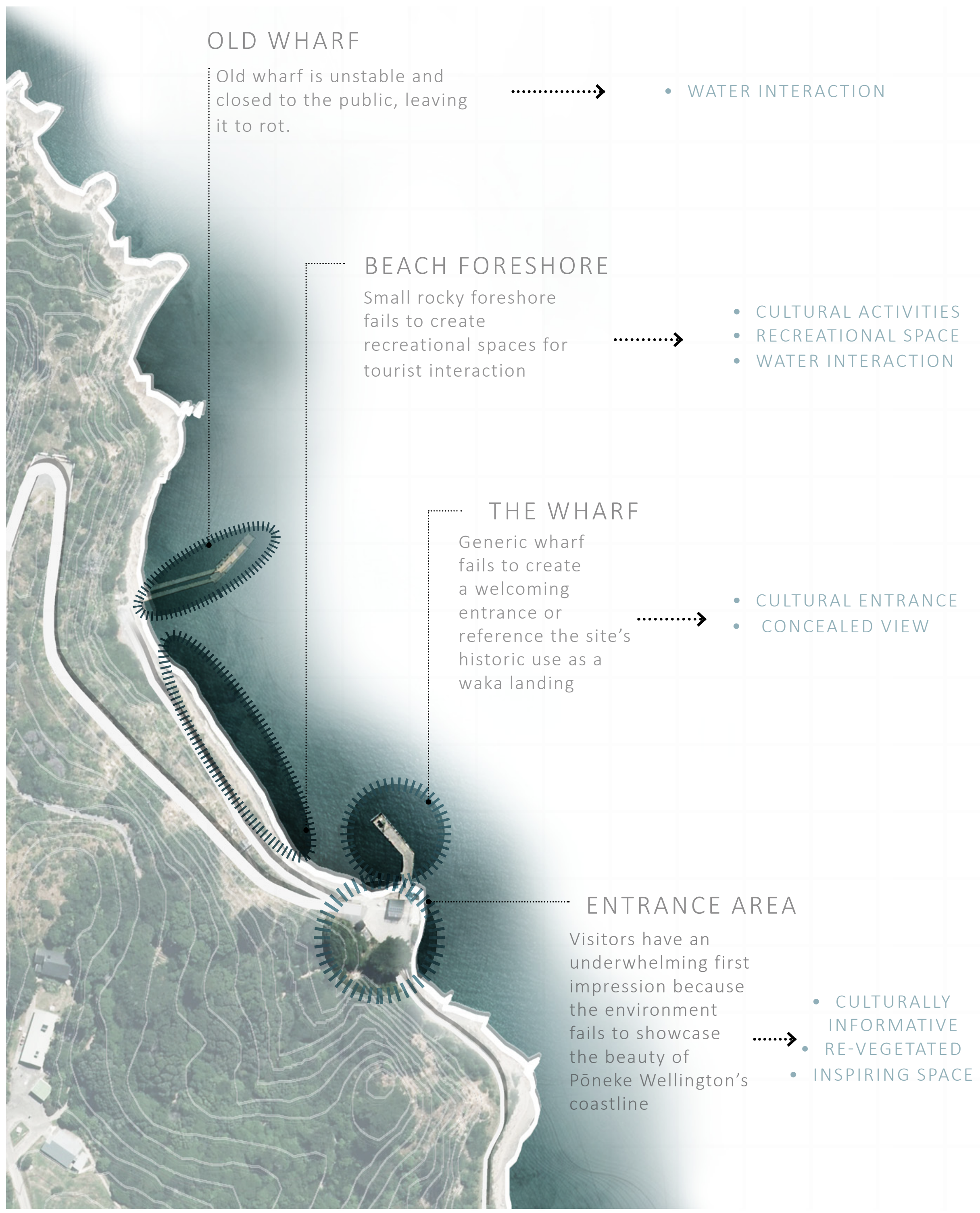

Fig. 74 Entrance Site Map 


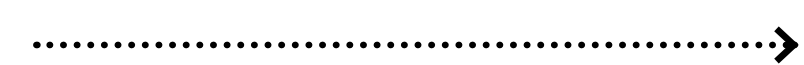

Kupe + The Wheke
- THE OLD WHARF

Re-purpose the wharf to create a platform for interaction with the water as well as an educational tool about the surrounding marine life.

\section{- BEACH FORESHORE}

Develop the foreshore to allow cultural activities to take place.

- THE WHARF

Improve the experience of wharf through transforming its structure into something unique and visually limiting, creating a greater sense of suspense and curiosity.

- ENTRANCE AREA

Ground people to the island and introducing them to Māori concepts such as Mātauranga Māori.

Ecological 


\section{CONCEPT ITERATIONS}

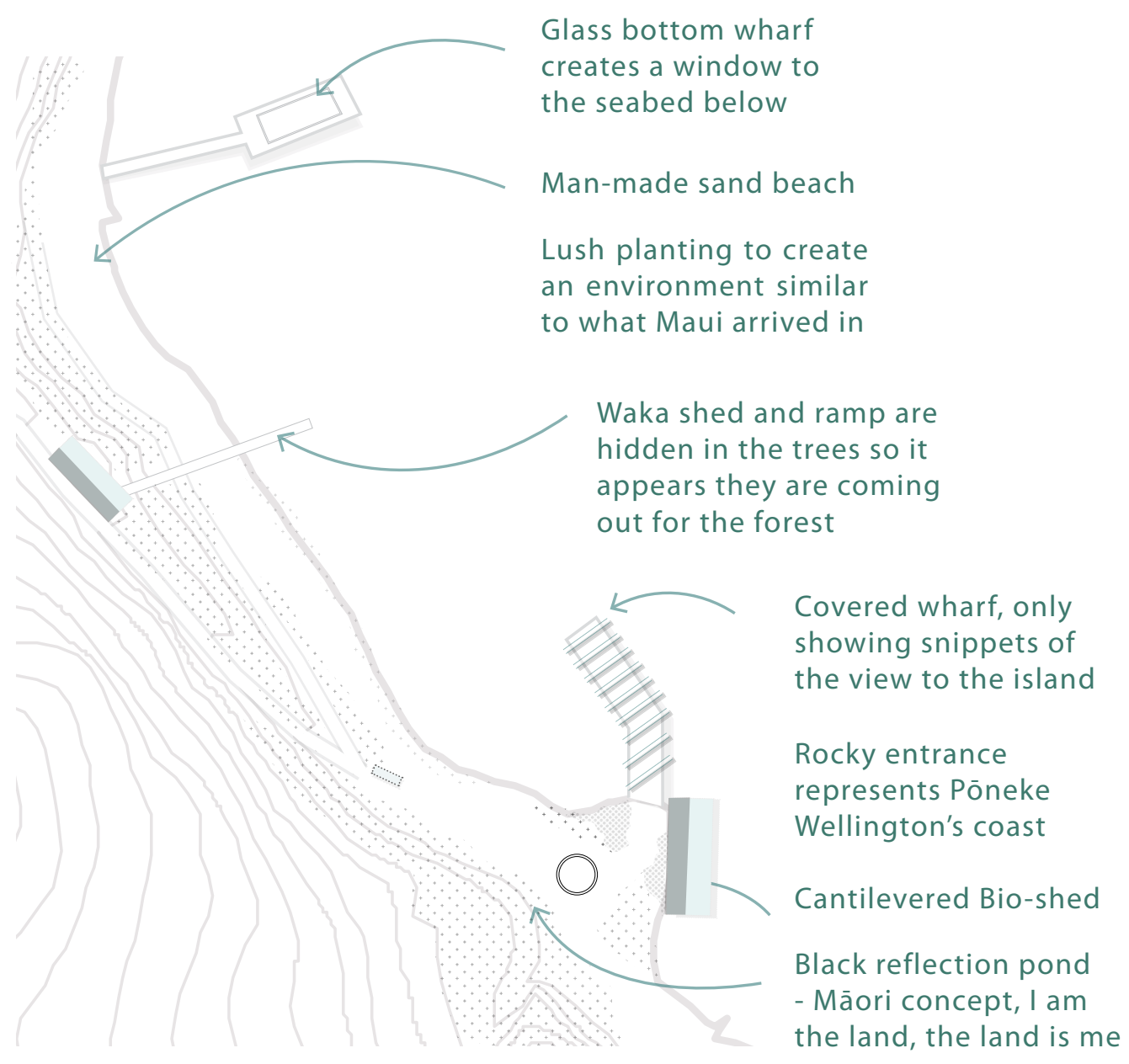

LANDSCAPE ELEMENTS:

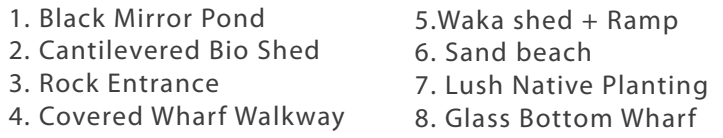

$\begin{array}{ll}\text { 3. Rock Entrance } & \text { 7. Lush Native Planting } \\ \text { 4. Covered Wharf Walkway } & \text { 8. Glass Bottom Wharf }\end{array}$

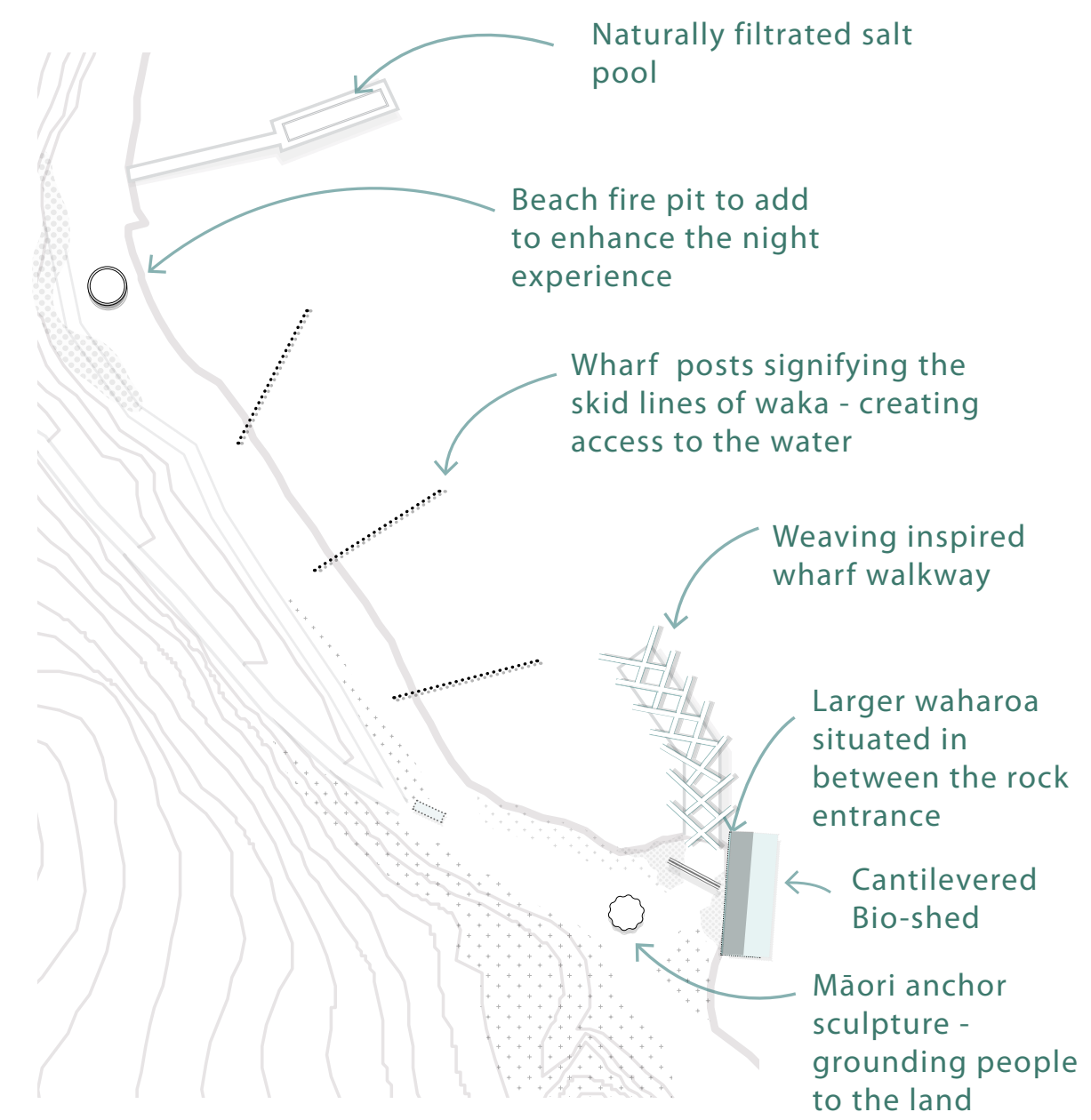

LANDSCAPE ELEMENTS:

1. Native Anchor Sculpture 5. Wharf Post Trail

2. Cantilevered Bio Shed 6. Fire pit

3. Waharoa + Rock entrance 7. Open salt pool

4. Sculptural Wharf Walkway

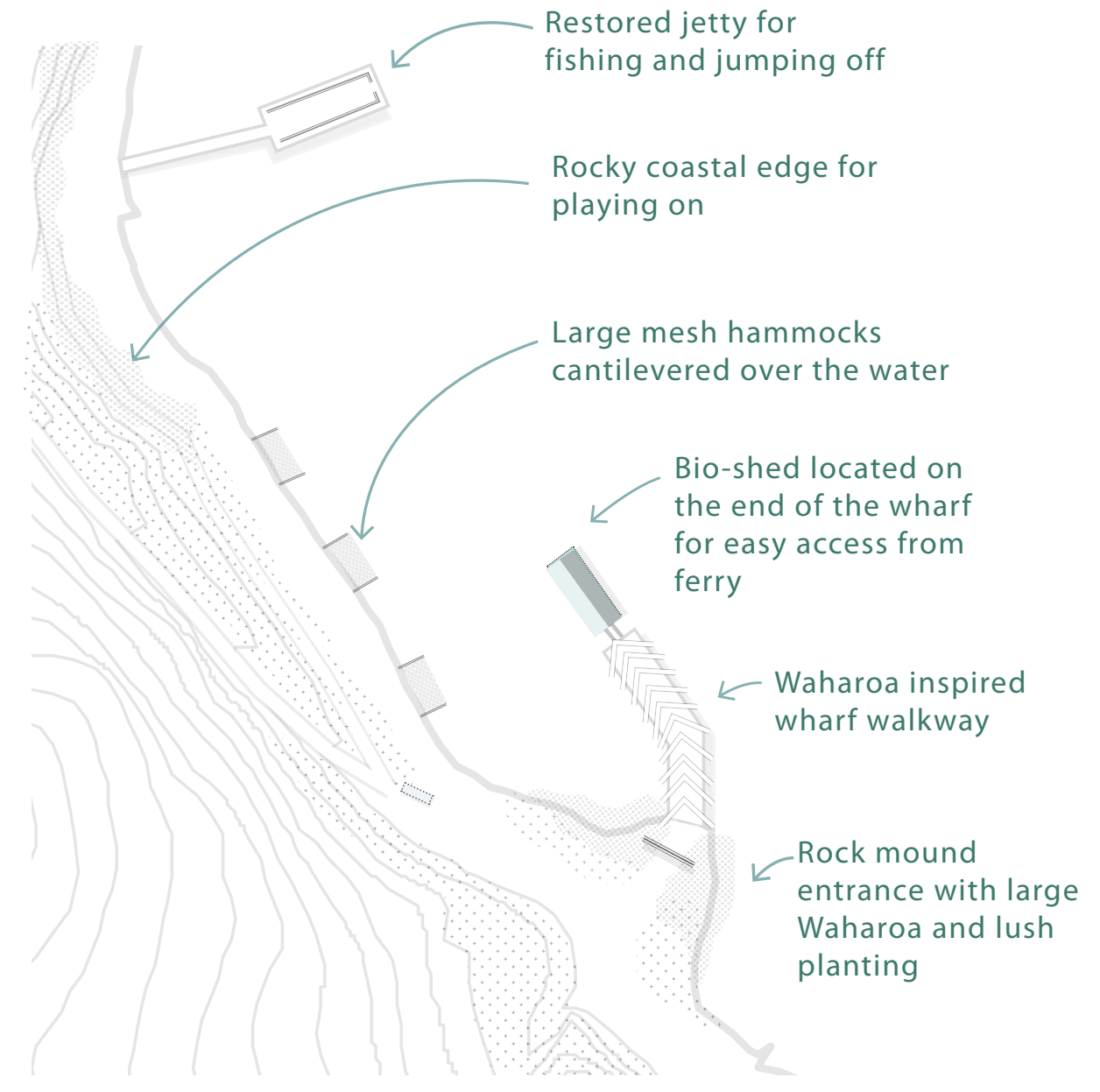

LANDSCAPE ELEMENTS

$\begin{array}{ll}\text { 1. Rock Mound Entrance } & \text { 5. Rock and Sand Beach } \\ \text { 2. Entrance Walkway } & \text { 6. Restored Wharf }\end{array}$

3. Floating Bio Shed (n)

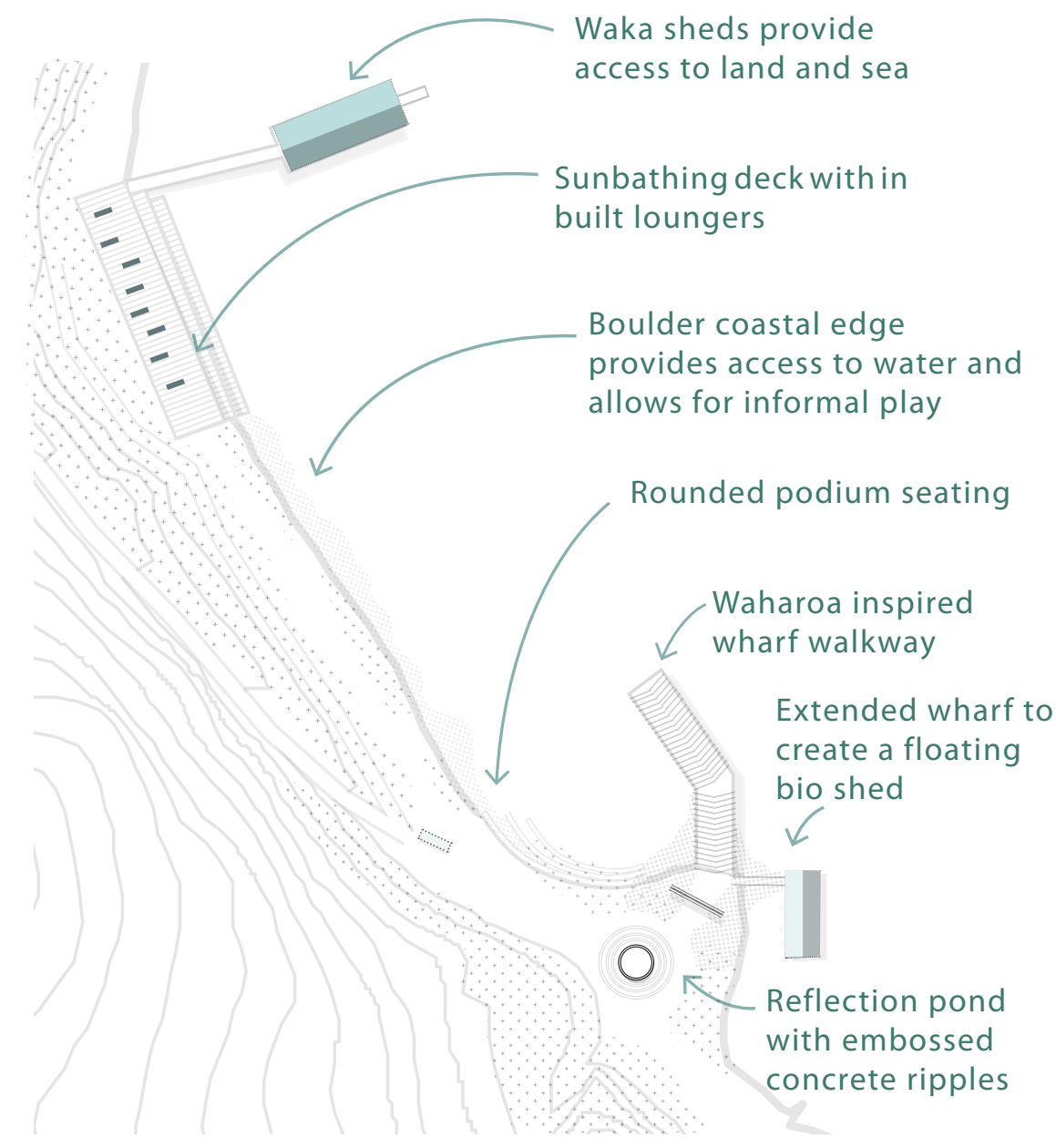

LANDSCAPE ELEMENTS:

1. Reflection pond 5 5. Wharf seating

$\begin{array}{ll}\text { 3. Rocky entrance } & \text { 7. Sunbathing deck }\end{array}$

4. Covered Wharf Walkway 8. Waka Shed 


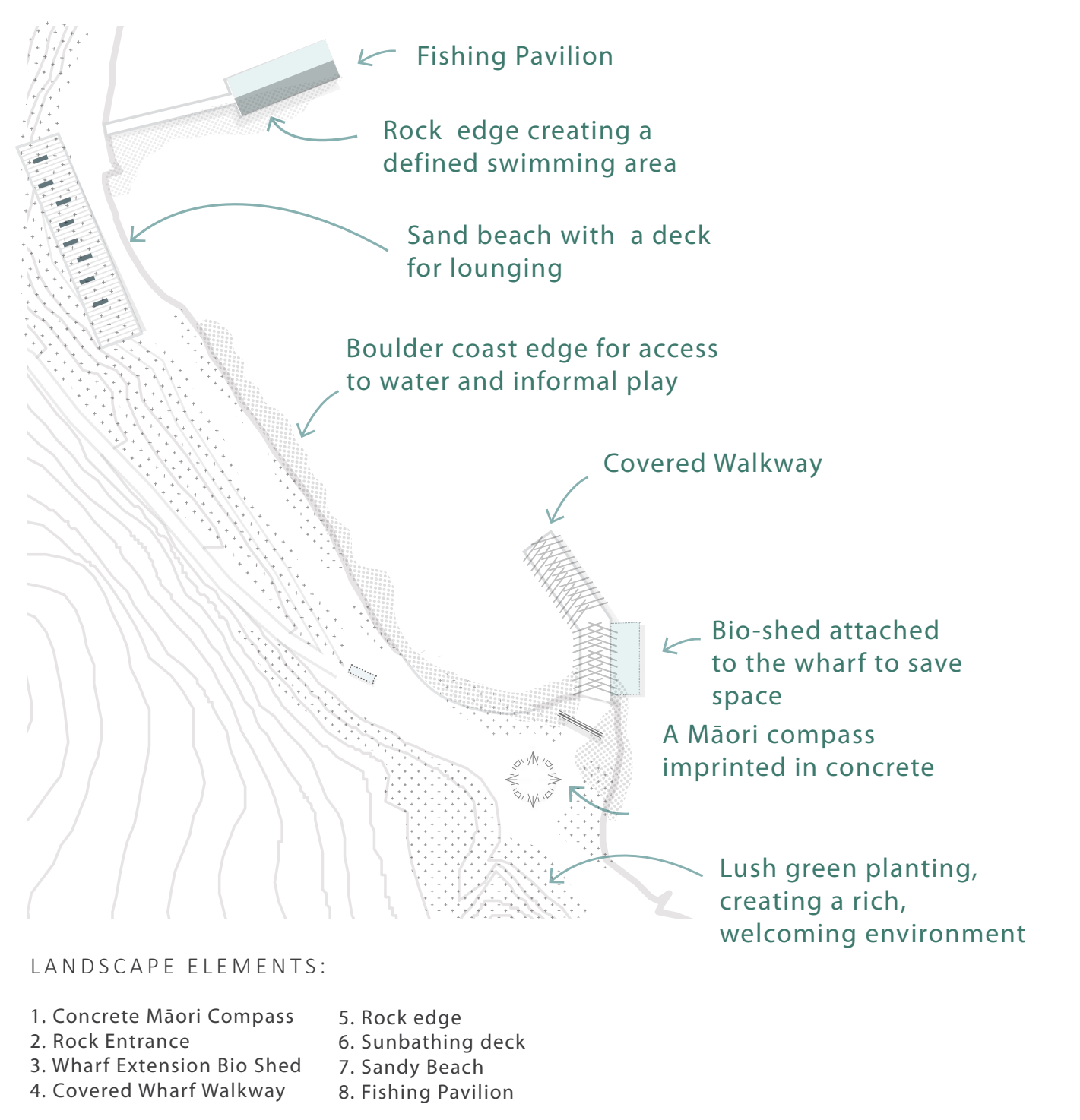

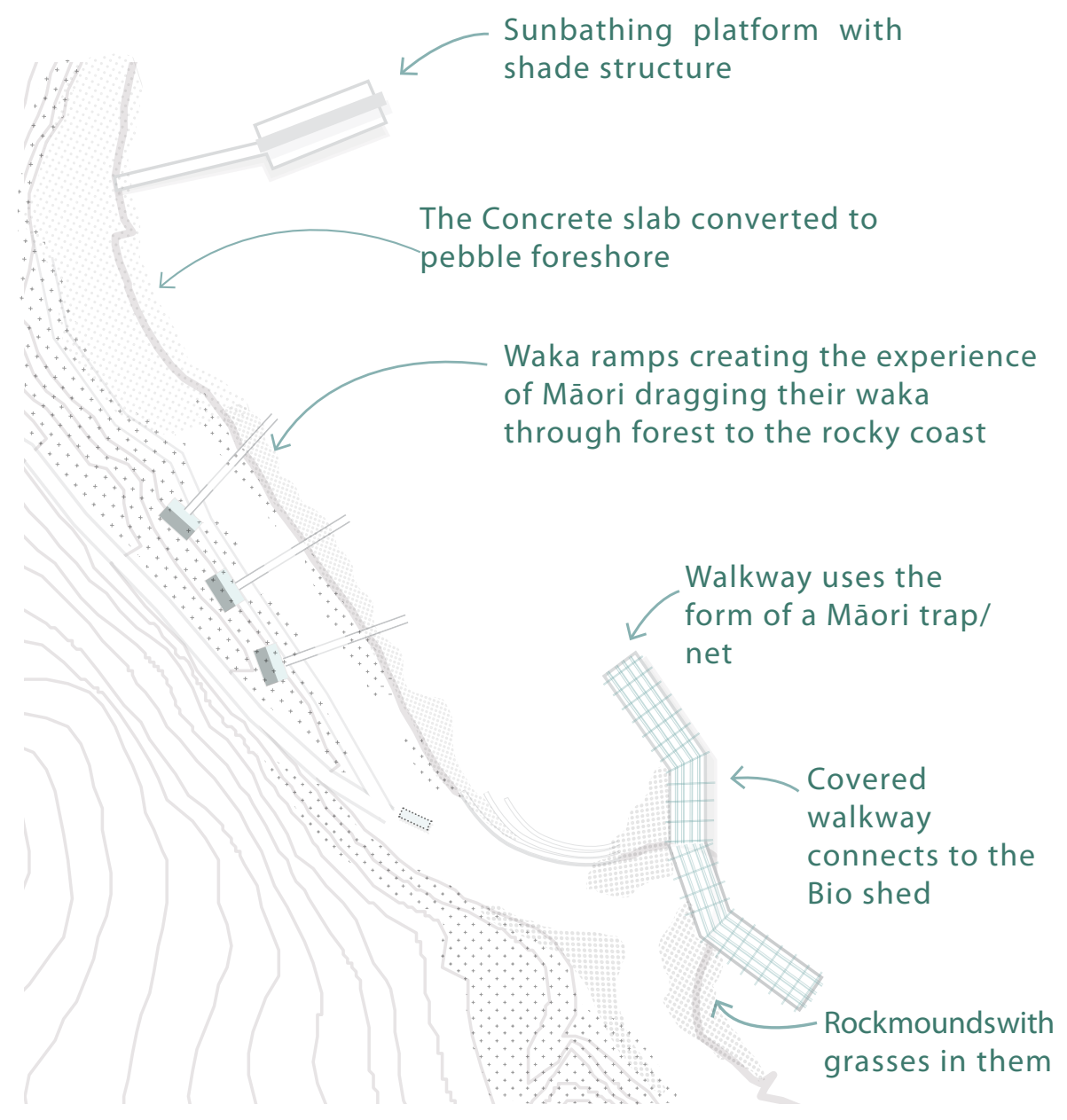

LANDSCAPE ELEMENTS:

$\begin{array}{ll}\text { 1. Reflection pond } & \text { 5. Wharf seating } \\ \text { 2. Wharf Extension Bio Shed } & \text { 6. Boulder walkway } \\ \text { 3. Rocky entrance } & \text { 7. Sunbathing deck } \\ \text { 4. Covered Wharf Walkway } & \text { 8. Waka Shed }\end{array}$

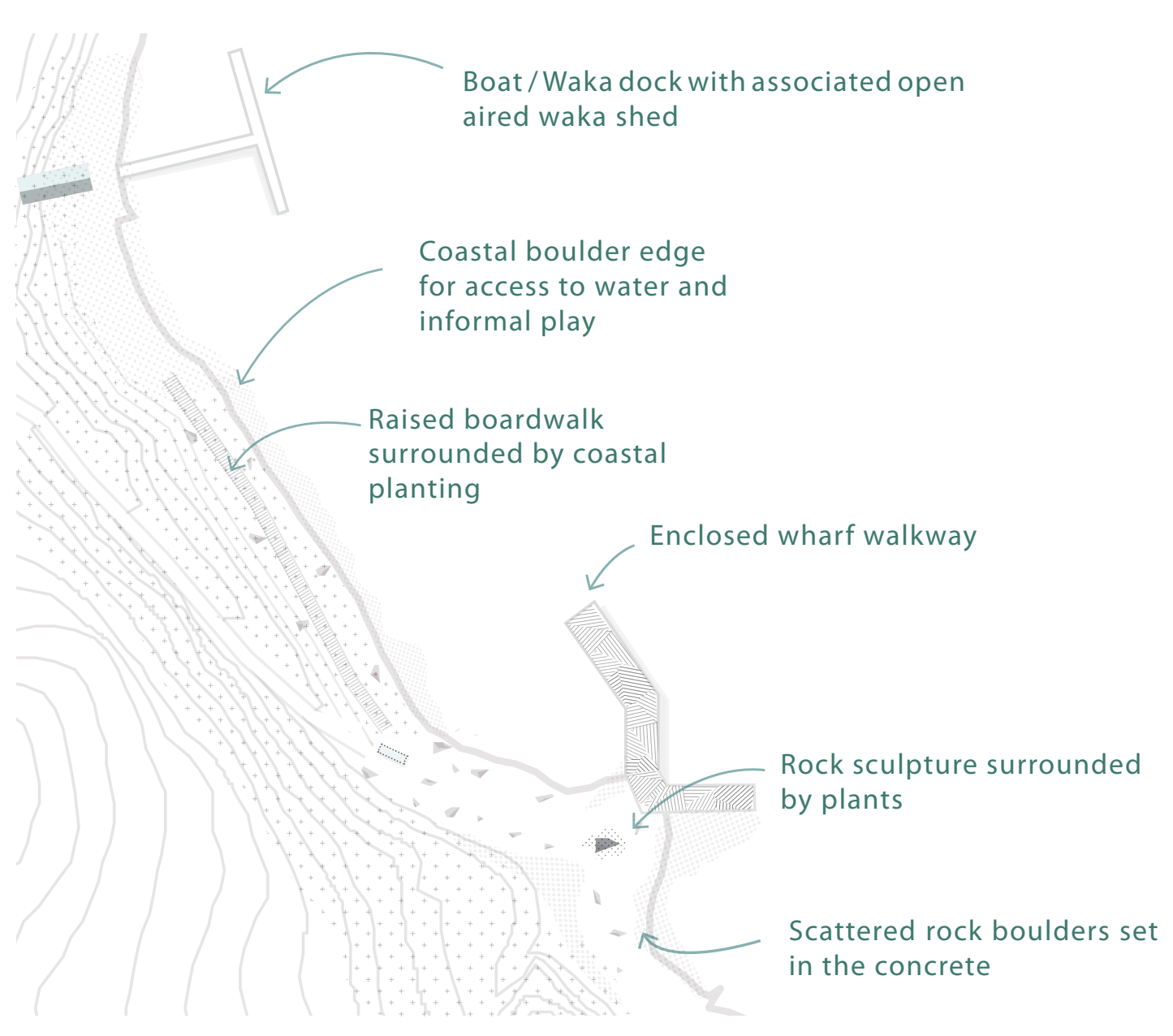

LANDSCAPE ELEMENTS:

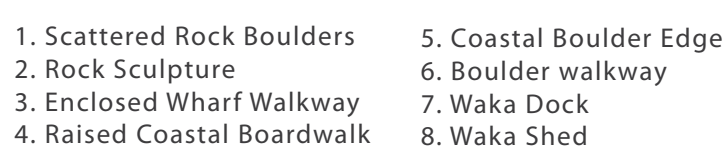

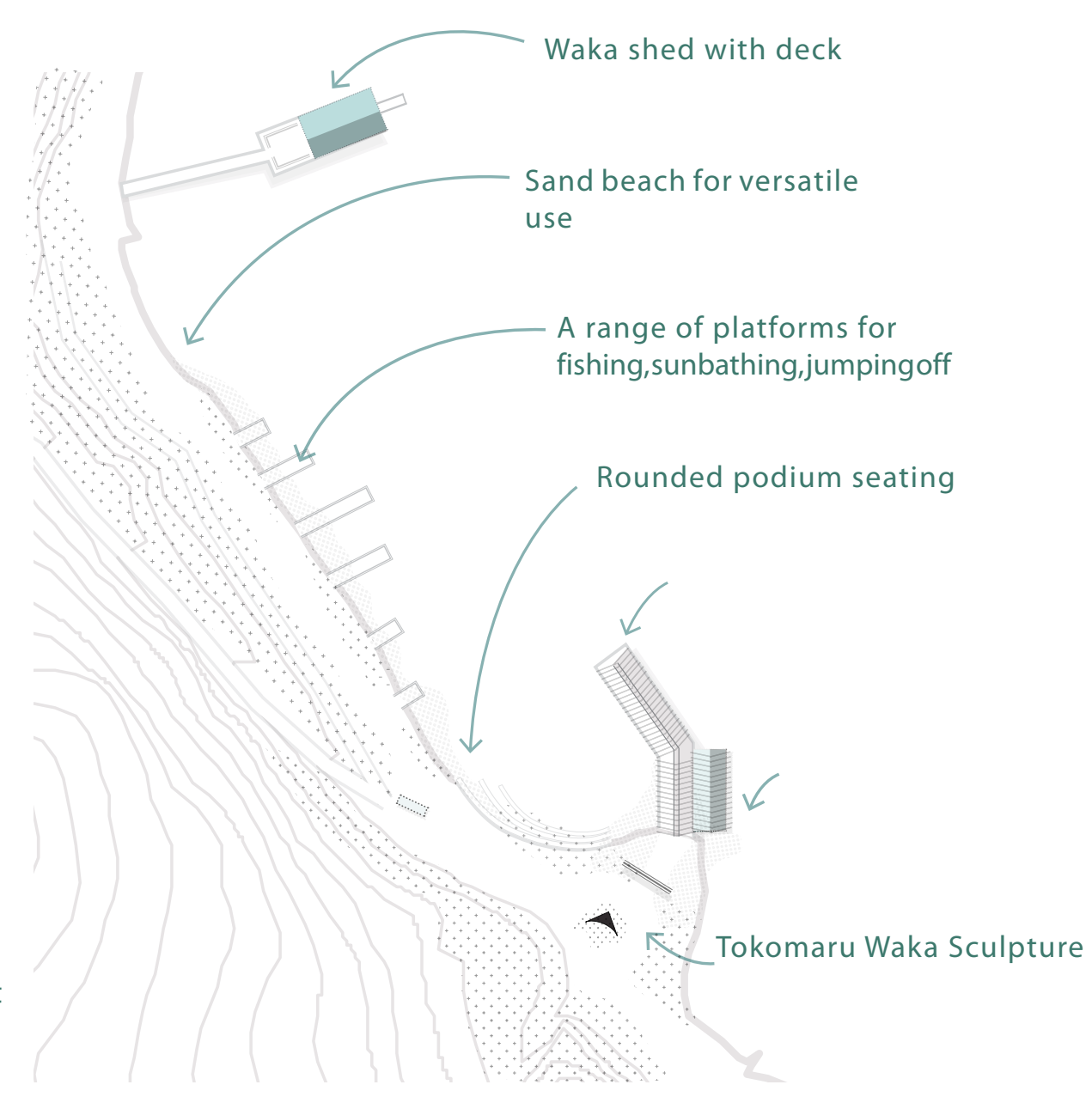

LANDSCAPE ELEMENTS:

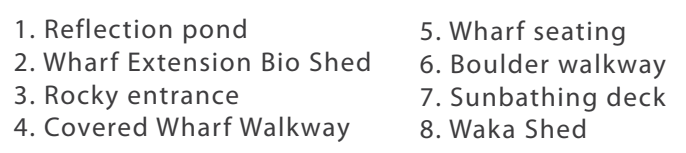

3. Rocky entrance 7. Sunbathing deck

4. Covered Wharf Walkway 8. Waka Shed 


\section{REFLECTION}

THE WHARF: Through iterative testing, it became apparent that the wharf and the flat space visitors first enter needs to be experientially rich to create a strong impression when visitors first arrive, as this is what will set up a first and potentially lasting impression. The iterations explored different types of wharf designs, mostly playing with covered structures that sheltered visitors. The ones that were most effective were simple designs that did not take away from the visual impact of the surrounding environment.

ENTRANCE SPACE: Many iterations explored what could be placed centrally in the middle of the flat concrete space, from large sculptures of ancestors and waka to imprinted concrete writing and symbols. The use of large rocks or a waka helm seemed too cliché and common as similar installations can be found in other areas of Pōneke Wellington. This was not appropriate as the design of the entrance needed to be a unique and an identifiable feature of Matiu Island. The concept of a subtle dark reflection pond was explored to allow people to see themselves in the ground, communicating the key Māori belief "I am the land, the Land is me". This is effective as it is a subtle intervention that does not draw away from the beauty of the restored environment that represents what Maui would have first experienced when he arrived in Aotearoa New Zealand.

THE BEACH FORESHORE: Along the shore, it was important to retain the existing walkway but create a coastal edge that created places for recreational activities and interaction with the water to take place. A range of recreational concepts were explored from jumping platforms, to sun beds, public hammocks and Waka sheds. The sun beds and public hammocks seemed too touristy for the naturalised site, where as the viewing platforms were a more subtle way of integrating social space along the water's edge.

The Waka sheds were culturally appropriate, due the sites past as a waka landing space for Māori. The iterations explored situating the sheds on the coastal edge for ease of access, however the iterations that hid the sheds in vegetation were most succesful due to the showcase they create. This composition creates a showcase that shares with visitors how Māori would have once pulled waka from the forest to the coast. 


\section{FINAL CONCEPT}

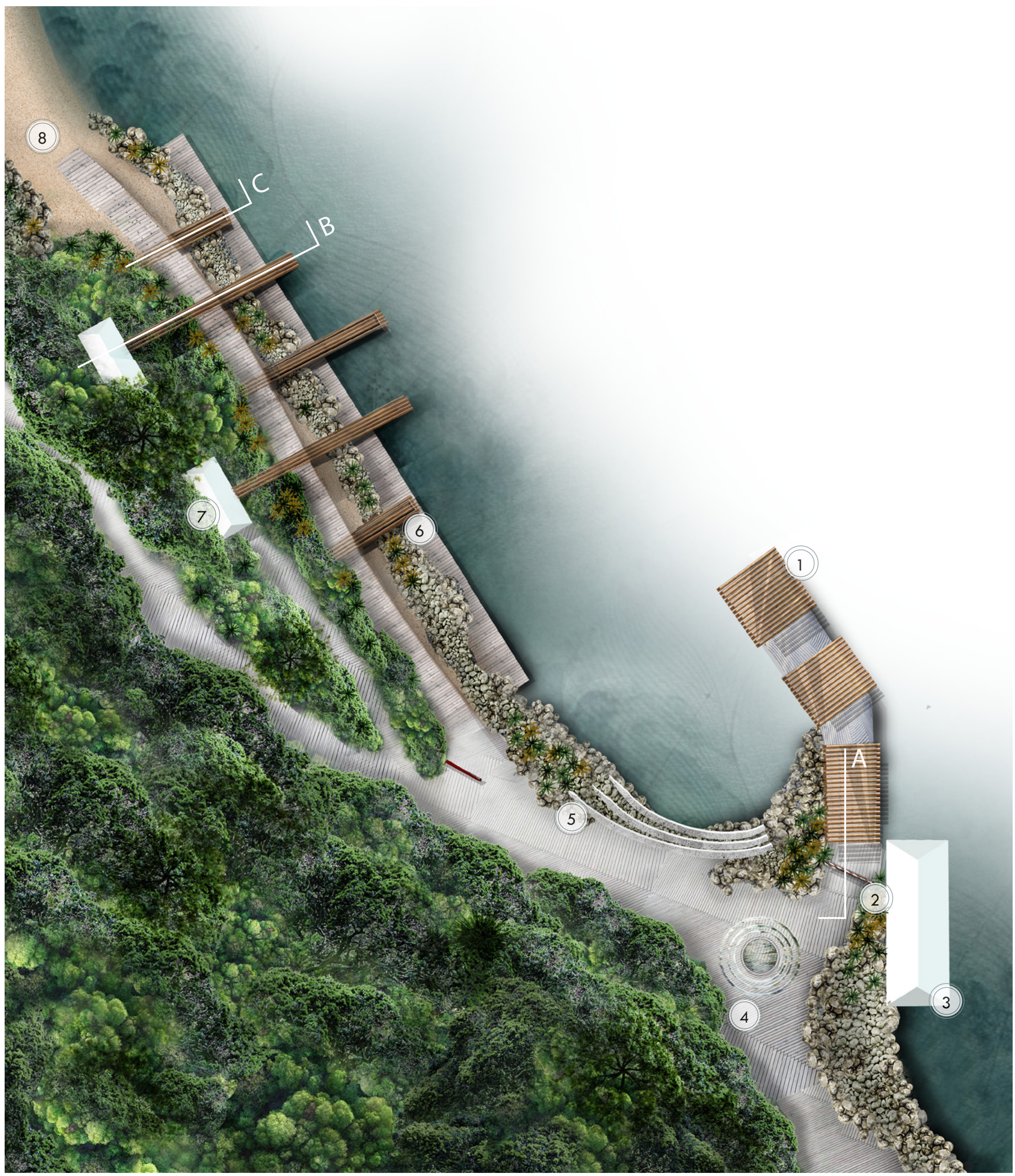

LANDSCAPE ELEMENTS:

Fig. 75 Rendered Site Plan

1. Covered Wharf Walkway

2. 2nd Waharoa

3. Wharf Bio-Shed

4. Black Mirror Pond
5. Seaside Amphitheatre

6. Sea platforms and Hammocks

7. Waka sheds + Ramp

8. Sand beach 
THE FINAL DESIGN:

THE WHARF: The final design reconceptualises the Wharf so it represents Maui's Waka, sheltering visitors from the conditions while they wait for the ferry. The surrounding area revitalises the immediate coastal environment to reflect the lush, untouched Aotearoa New Zealand coastline that Maui would have first experienced when arriving on the land. Large stones around the Wharf are used to contextualise the site within Pōneke Wellington.

ENTRANCE SPACE: The entrance area uses a simple black reflection pond, set in the ground, to share the integral Māori belief that people are a reflection of the land and the land is a reflection of the people. From here the focus shifts from Māori values and ancestral narratives to showcasing the marine coastline and how Māori once utilised it.

THE BEACH FORESHORE: The waka sheds and observing platforms along the coastal walkway create a spectacle and share live demonstrations of the use of waka with visitors. The sheds are designed to be hidden from sight so when the Waka are being dragged out they appear as if they are coming out of the forest, creating a showcase for all. Housing waka on the island allows Māori to practise their rowing while visitors can observe the tradition happening first hand.

CONCLUSION: Ultimately this site and its core elements set up an understanding of Māori culture and Aotearoa New Zealand's environment. The site also provides visitors with unique ways to experience the Pōneke Wellington coast and interact with the marine life environment. It creates a welcoming and exciting introduction for visitors that is a cultural, recreational and educational experience all in one. 
SECTION A-A : Wharf Entrance
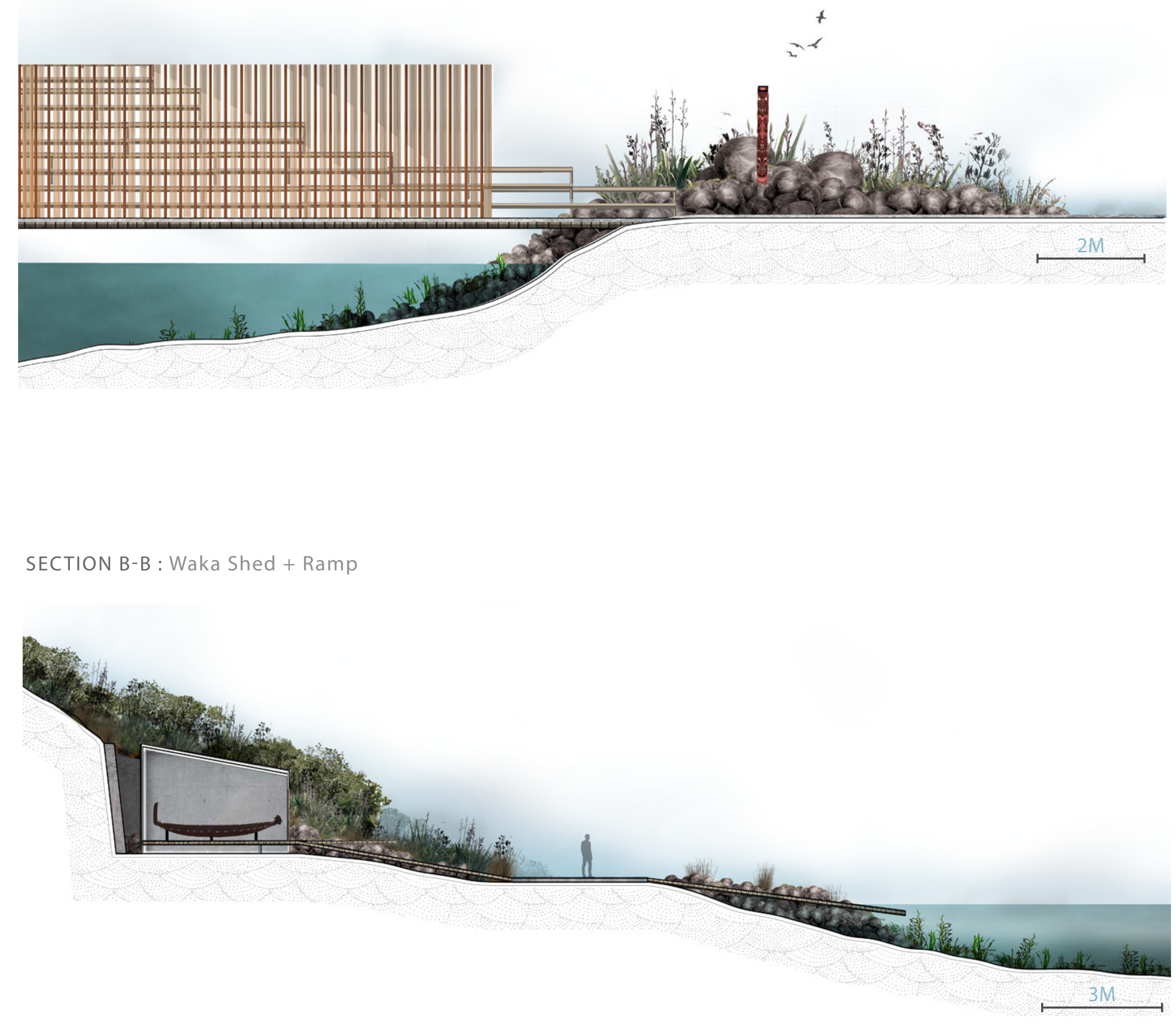

SECTION C-C : Sea Platform and Hammock

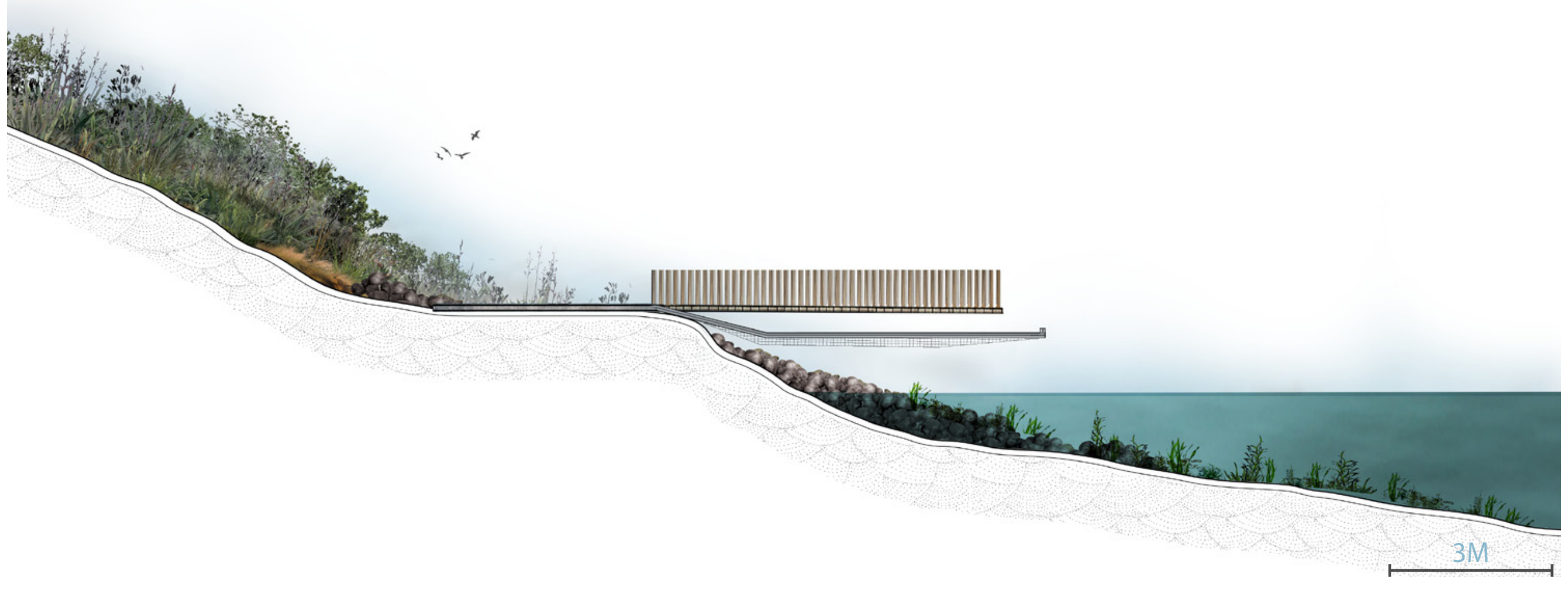



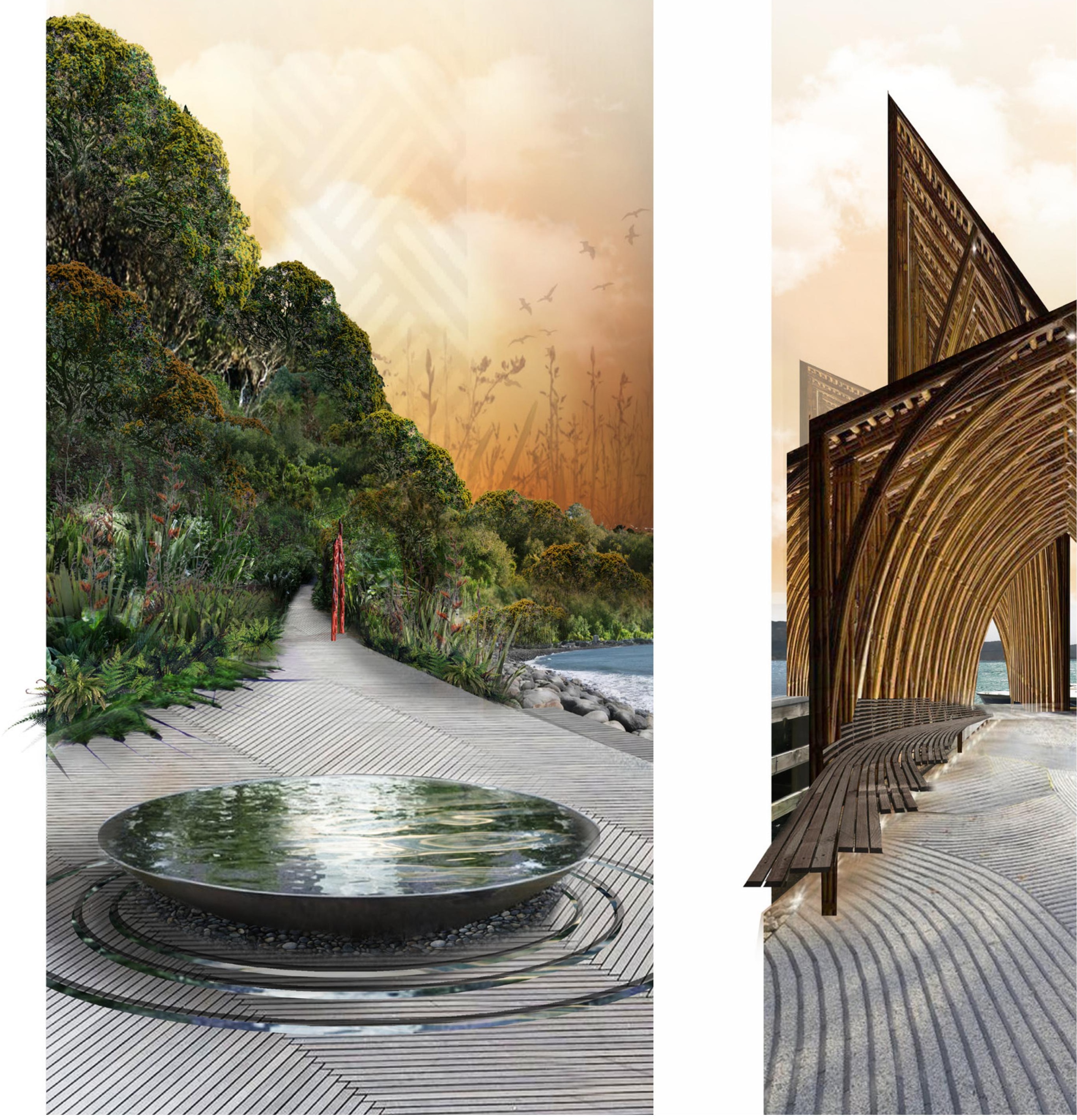

Fig. 77 Black Reflection Pond Render

Fig. 76 Covered Wharf Render 

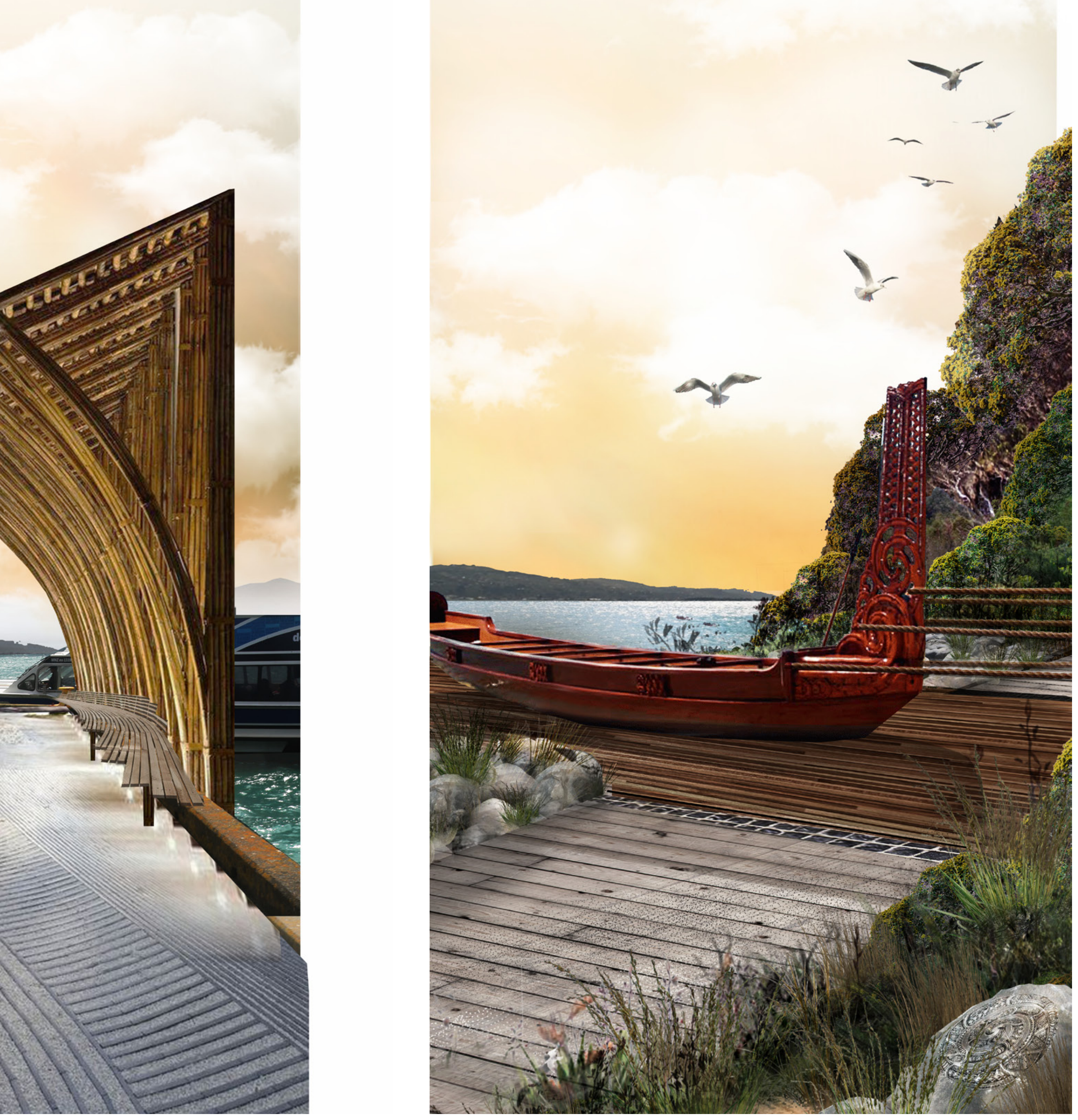


\section{SITE TWO}

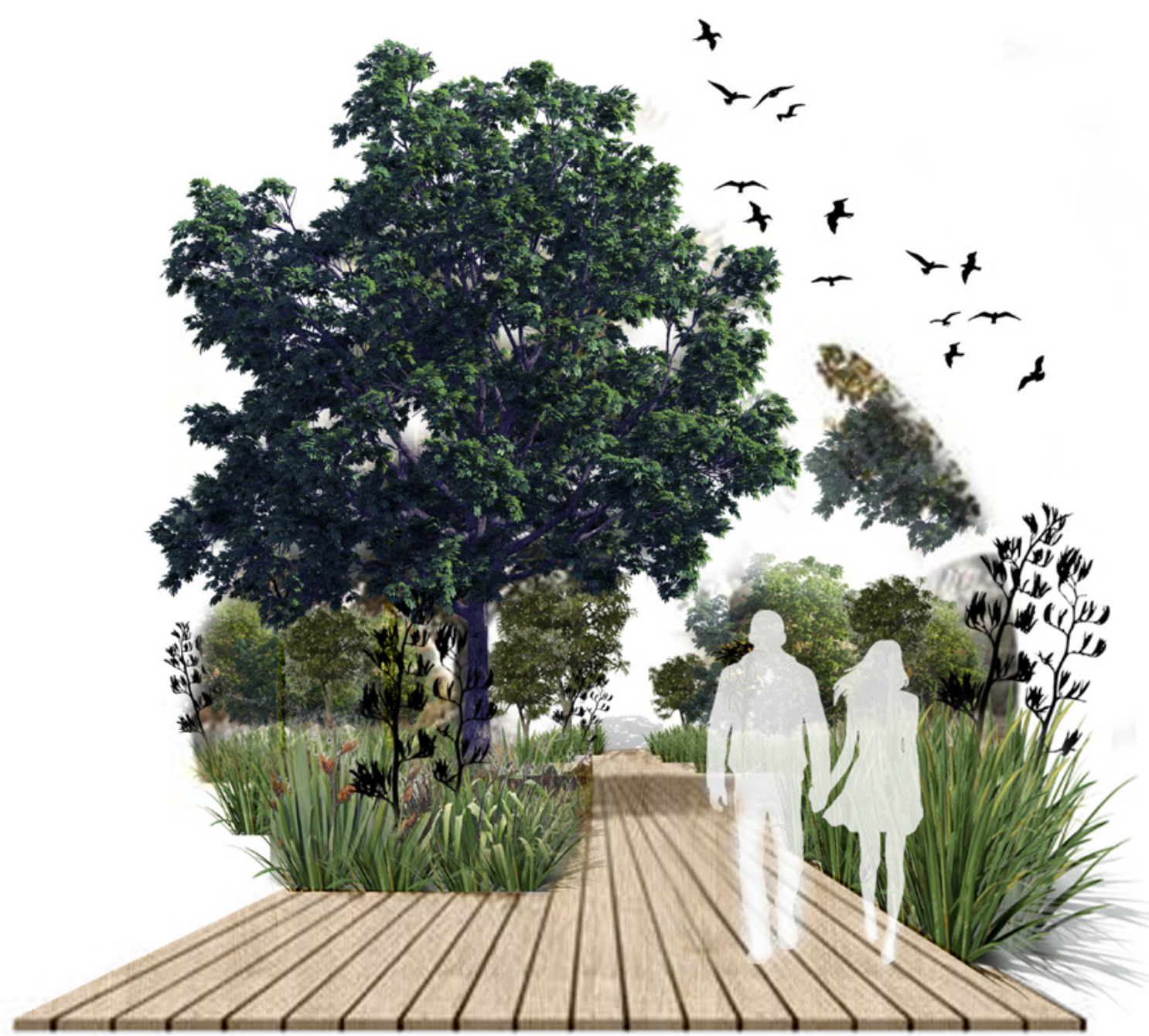

Fig. 79 Pathways Icon

\subsection{THE PATHWAYS}

The existing pathways on the island direct people from the entrance to a range of different sites. To create a series of cohesive spaces, it is important that the pathways build upon the role of the entrance by continuing to educate people about the history of mana whenua and the island. Based on precedents such as the Taumanu Reserve, it was apparent that giving each pathway a theme would be the most effective way to communicate certain narratives. Pathways that wound through restored native areas would showcase the efforts of DOC, pathways that took visitors through poorly degarded sites would talk of the destruction caused by European settlers on the island, while others would talk of Taranaki Whānui's ancestors migration from Taranaki to Pōneke Wellington. 


\section{OBJECTIVES}

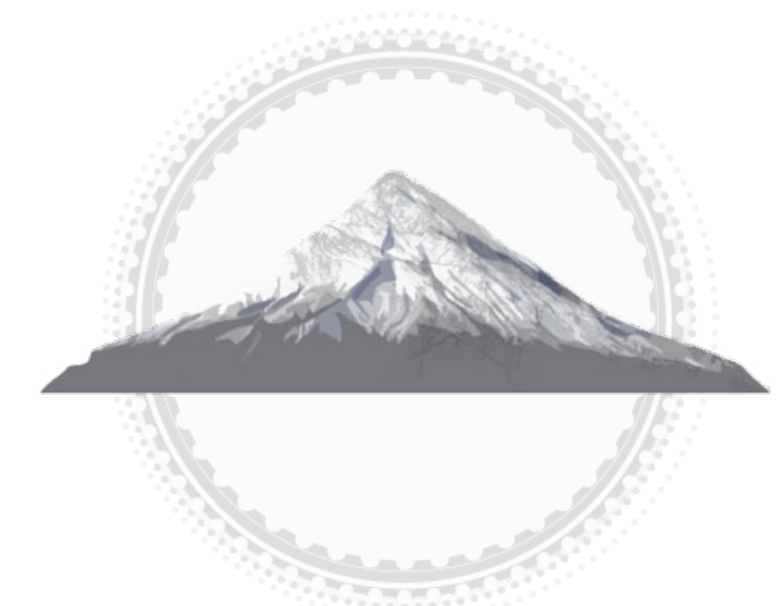

Retell stories regarding the migration of Taranaki Whānui's ancestors

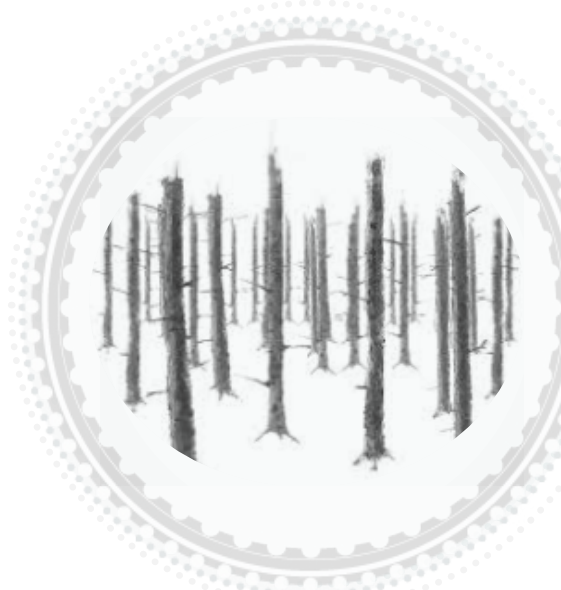

Showcase native wildlife and the ecological restoration efforts of DOC on the island

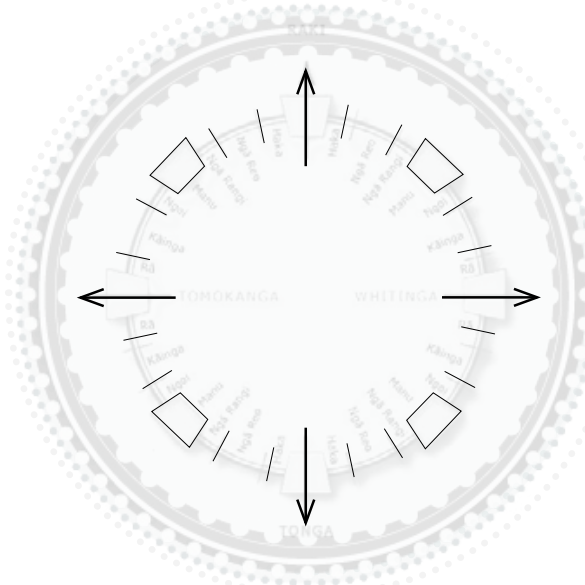

Retell stories of the European impact on Pōneke Wellington and Matiu Island 


\section{PATHWAY ZONING:}

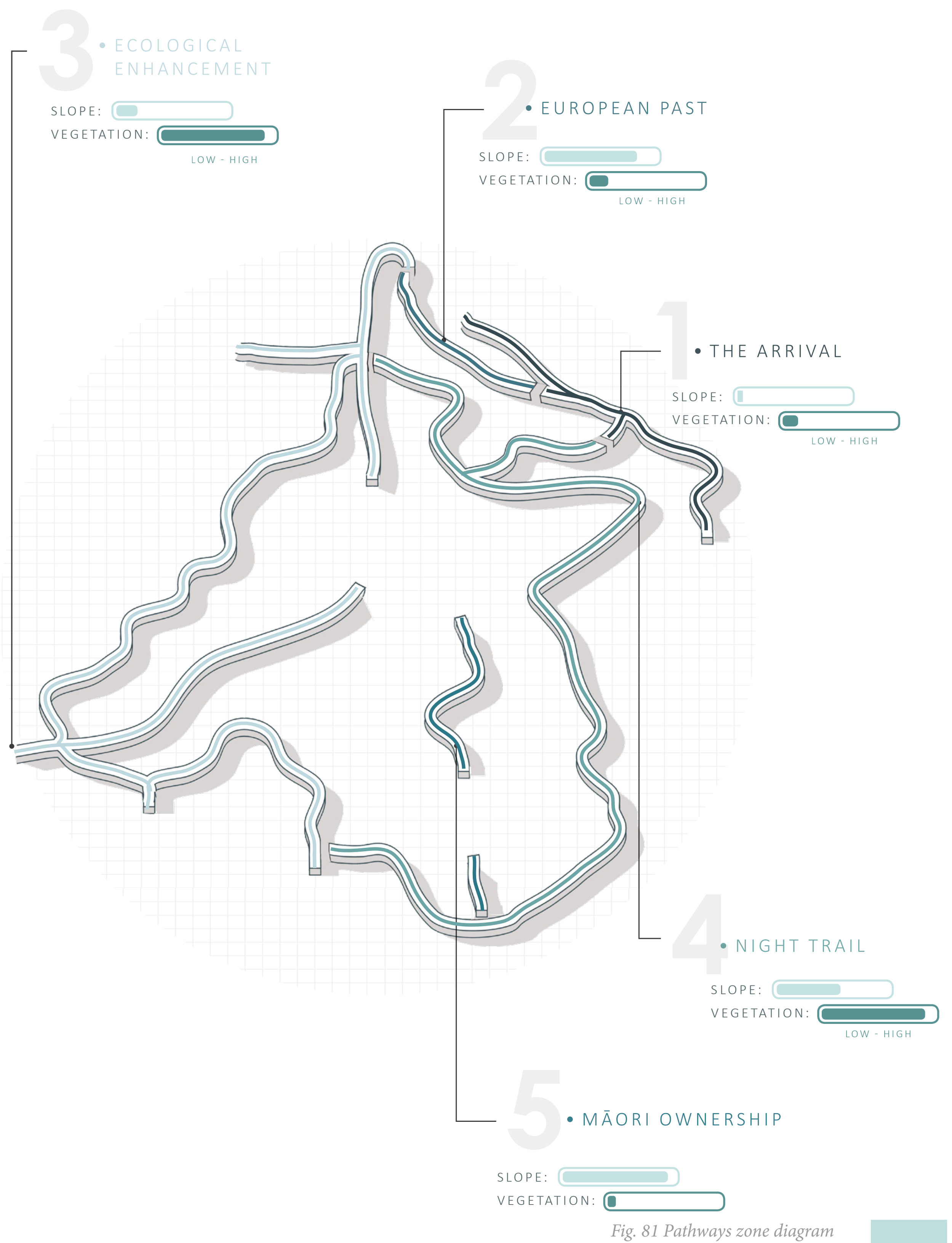


- THE ARRIVAL

- Concept: Creating a strong first impression Tara + Kupes Daughters by using this space as a reflection of the once pristine Pōneke Wellington coastline that explorers first met with.

\section{- EUROPEAN PAST}

- Concept: Using the degraded enviroment in this site to talk about the impact European settlers had on Matiu Island. This will be achieved through introducing low lying brown shrubs and flaxs with sculptural elements to talk to people about the destruction caused on the island, conveying how far it has come

\section{- ECOLOGICALENHANCEMENT}

- Concept: Acknowledging the efforts of Forest and Bird, upon the island, through Tara + Kupes Daughters enhancing the native habitats that have been restored or established.

- Concept: Increasing the utilisation of the island at night by creating a permanent light Tara + Kupes Daughters sculpture showcase that references star and night navigation.

Taranaki

- MĀORI OWNERSHIP

- Concept: Acknowledging the Mana Whenua of the Island while improving the ecological integrity of this barren area.

Iwi Ownership 


\title{
EUROPEAN PAST
}

\author{
GROUND PLANE
}

The European path talks of the ecological devastation caused across the island in the 1900's

(Chronis, 2009). The design concepts explore the role brown and black coloured natives can play in conveying what the degraded landscape would have looked like following this devastation. This path is strategically developed to talk about the island's destruction directly beside the lush and restored environment of the entrance way. Having these two sites side by side highlights the strong contrast between the natural state of the island and the island 50 years go. The corten steel structures in the site are used to reference the other ways in which the island was impacted by European settlement, mainly as a prison or place or keep people in.

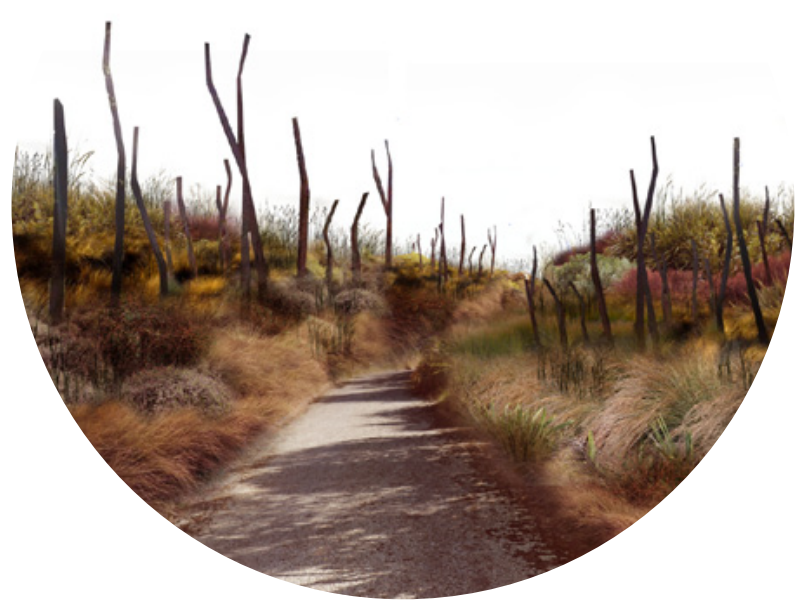

TRUNK SCULPTURES

Dead tree sculptures reference the
devastation caused by the Europeans

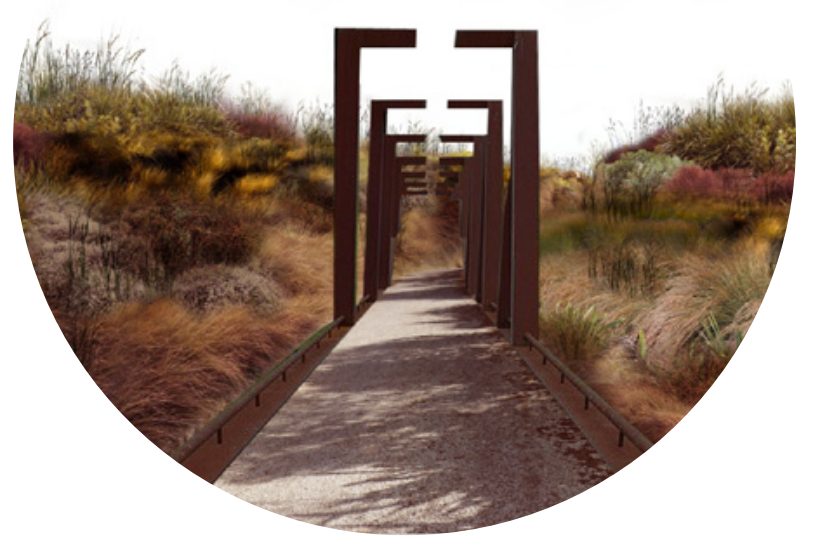

CORRIDOR COVERING

Referencing the quarantine building by recreating its riddle of corridors

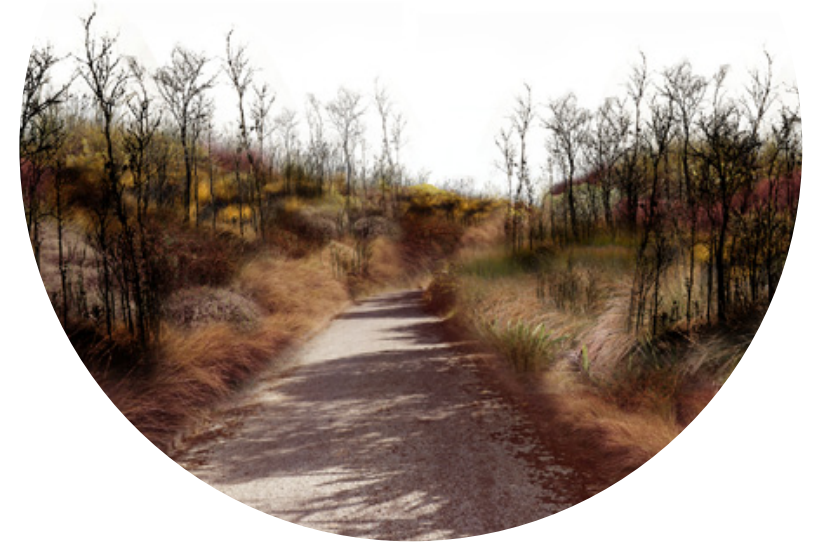

PRESERVED BRANCHES

Branches create the sense of dead forest that can simultaneously house Wetas

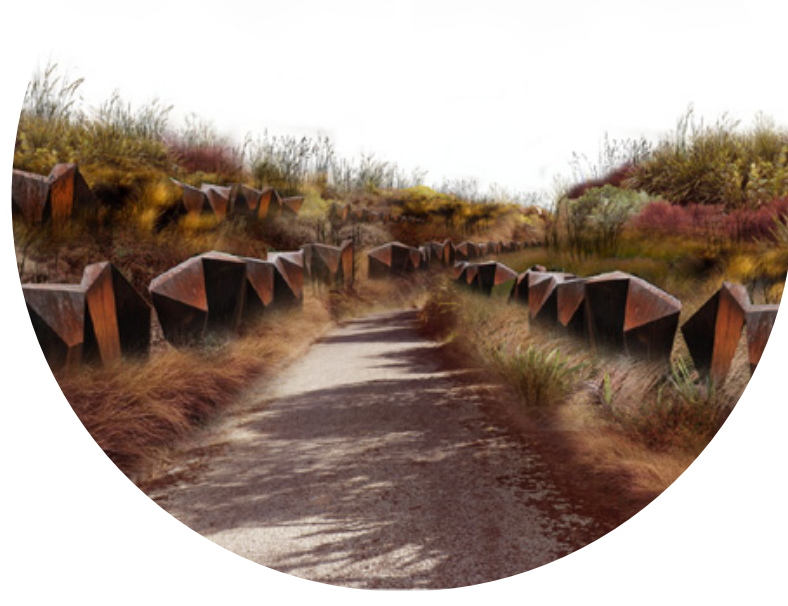

RETAINING WALL

history of containment and prisoners

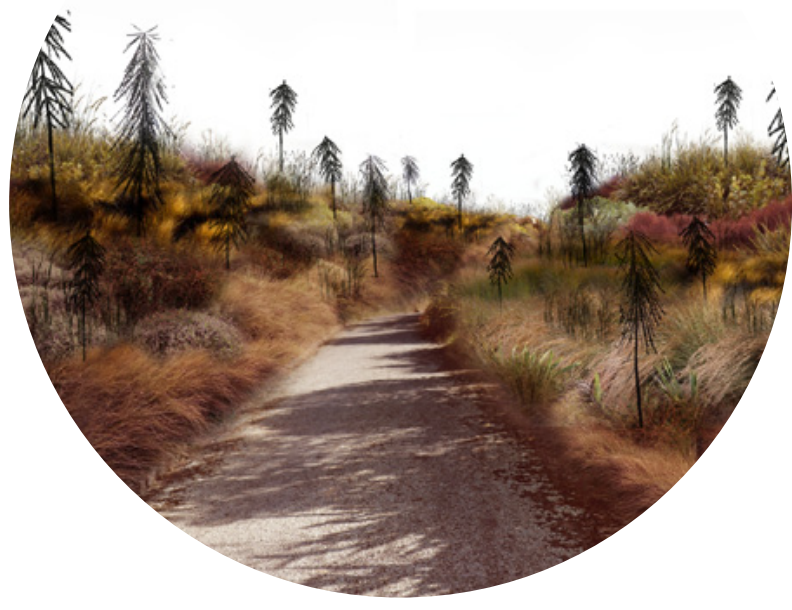

LANCEWOODS

i. Stand alone lancewoods create the appearance of a dying forest

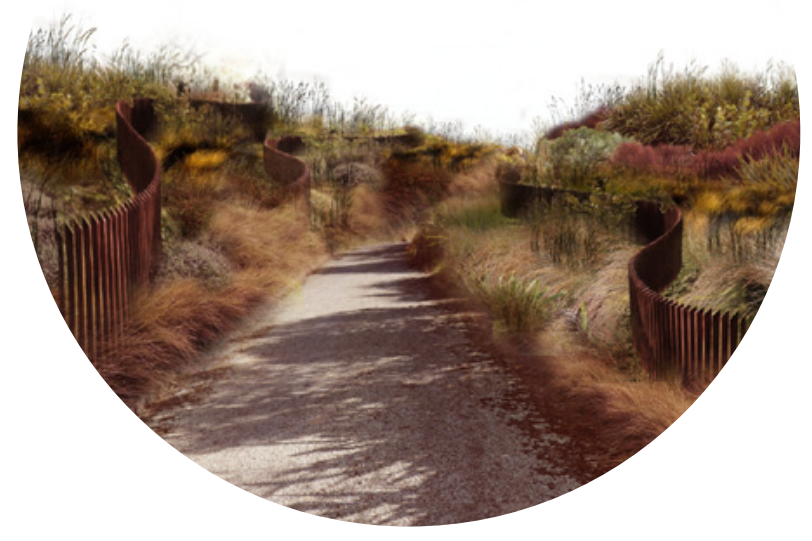

"RESTRICTED"FENCE

A winding fence references not only people kept on the island but people who were excluded 


\section{ECOLOGICAL}

\section{GROUND PLANE}

As the materiality of the paths across the island consists of plain concrete, they fail to add any experiential value to the site. For this reason the ground plane and associated vegetation is explored throughout these concepts to showcase some of the cultural patterns associated to the island and the iwi.

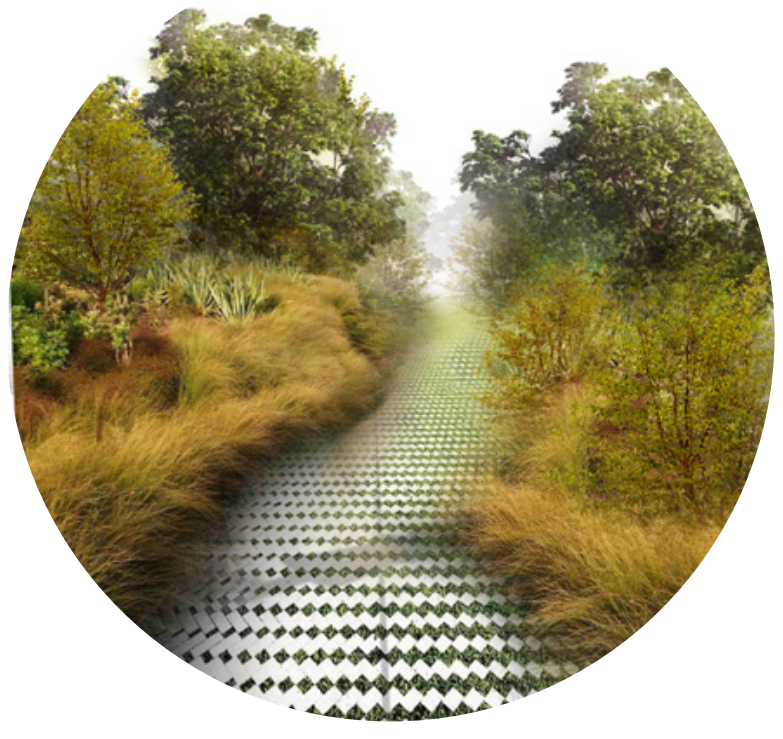

CULTURAL PATTERNING

Using Polynesian patterning referencing the origins of Māori

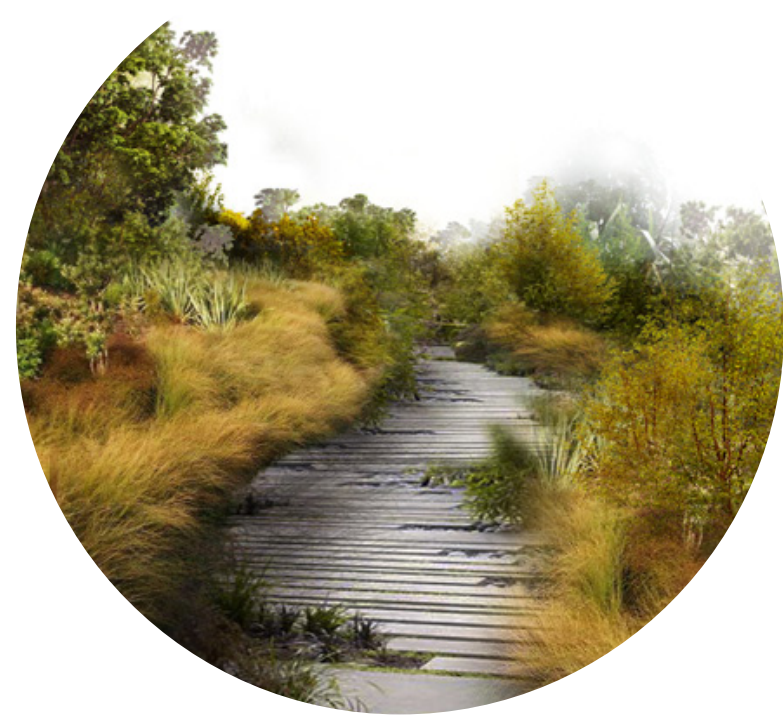

HYBRID LANDSCAPE

Playing with the paving to express the battle between the organic and the built form

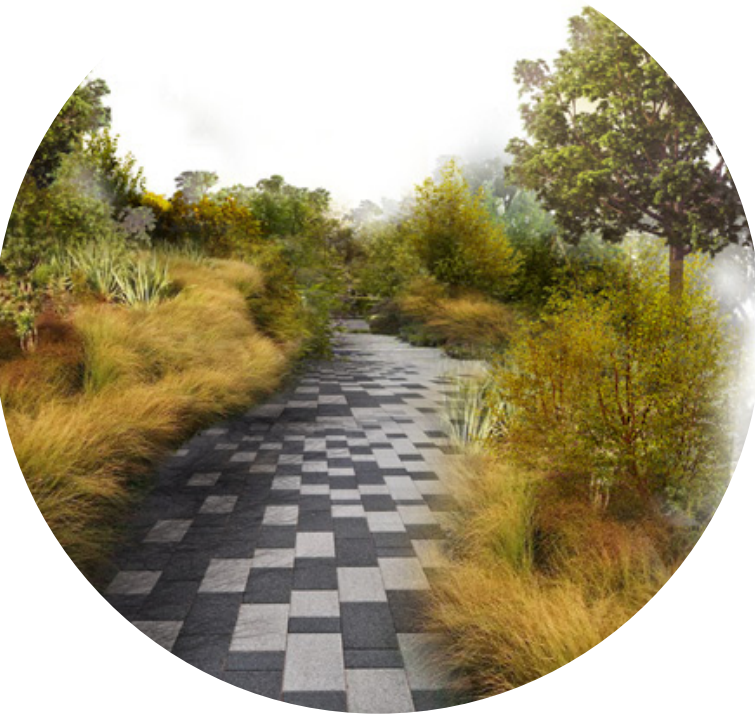

Weaving PATTERN

Speaking of the weaving of both Māori and European culture on one land s

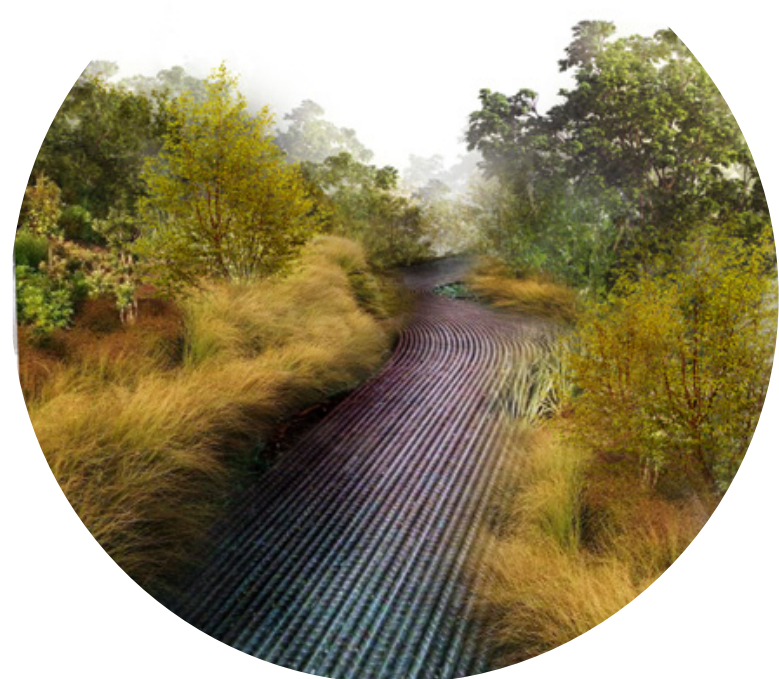

FLOWING WATER

$\mathrm{m}$ Mimicking the flowing of water over and around rocks

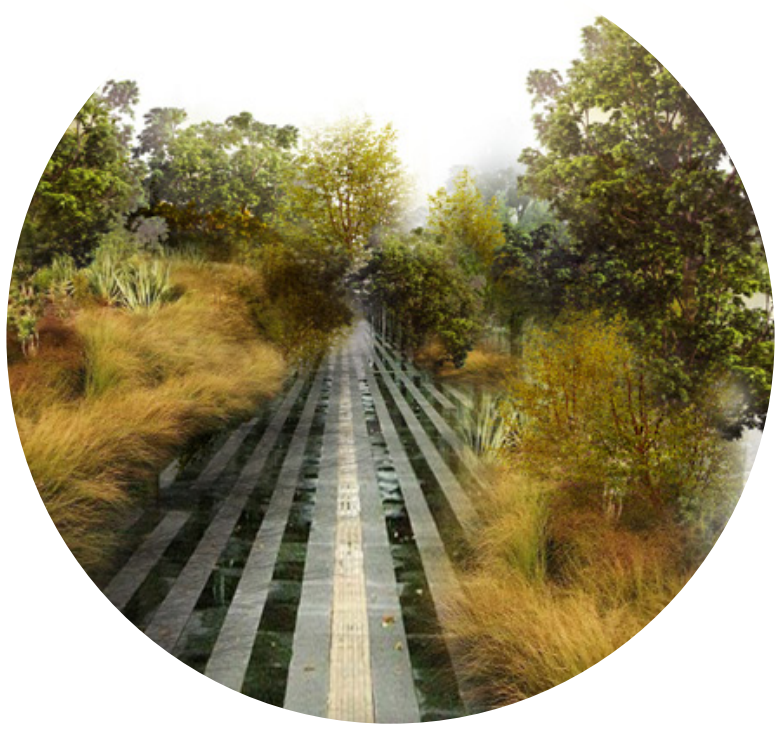

WATER STREAMS $\ldots$ Using different surface finishes on stone
to get a wet vs matte look.

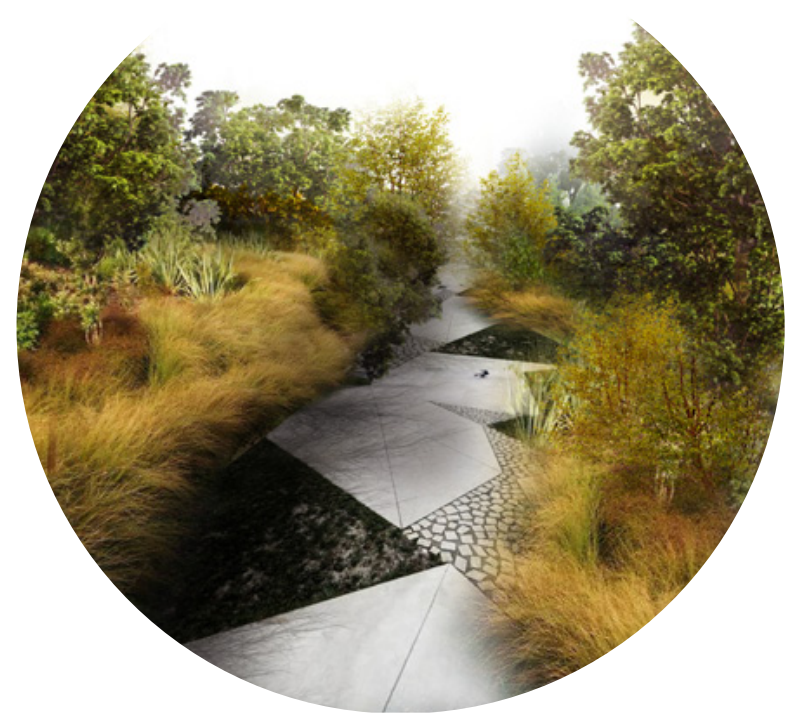

FRAGMENTED LAND

Acknowledging the different environments Māori coexisted in 


\section{ECOLOGICAL}

\section{NATURALISATION}

These path concepts highlight the restoration efforts of DOC. They do this by focusing on more subtle techniques of path development through playing with the softening of the ground plane and the establishment of walkways that allow ecosystems to continue to operate below them.

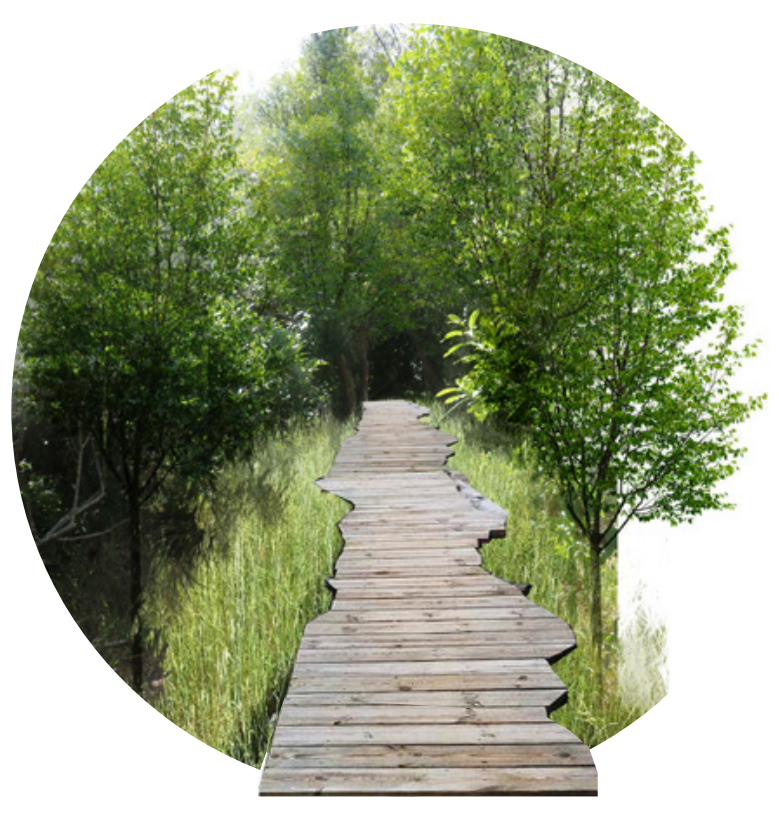

\section{ORGANICTIMBER}

Rippled edging for organic look and raised to create micro-habitats below

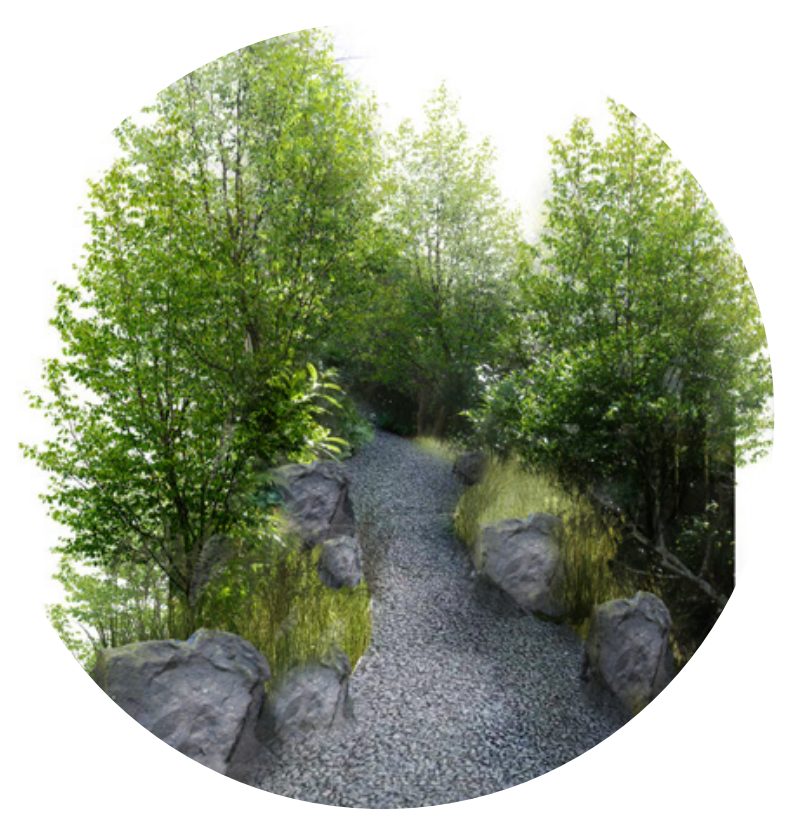

STONE + ROCK

Using natural materials that recreate the

Pōneke Wellington Coastline environment

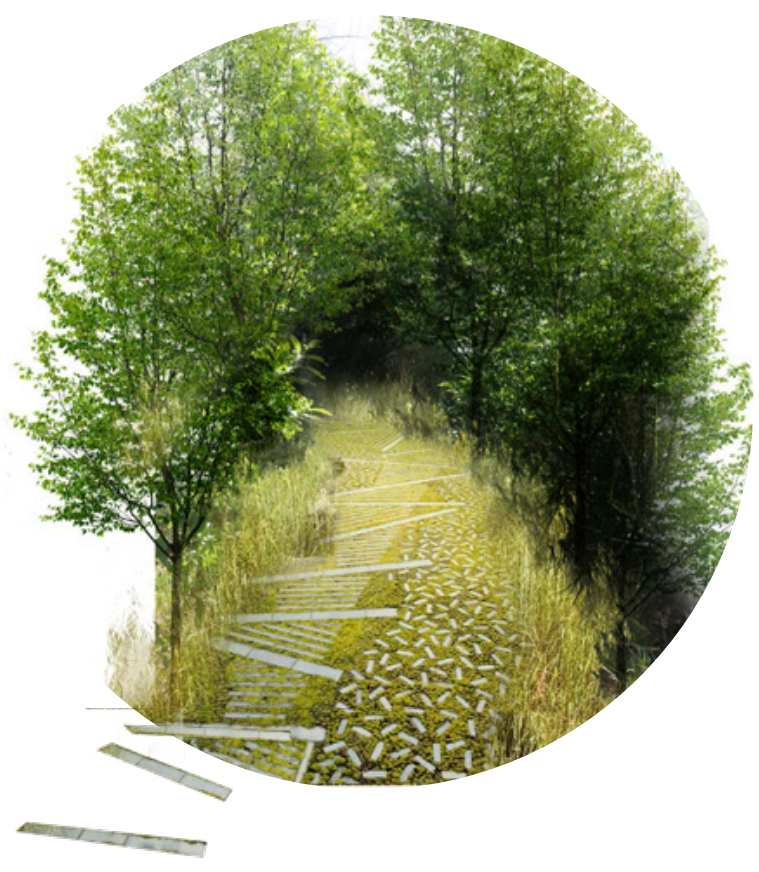

Embedded PAVING

Using paving to highlight the path whilst
allowing ground cover to grow

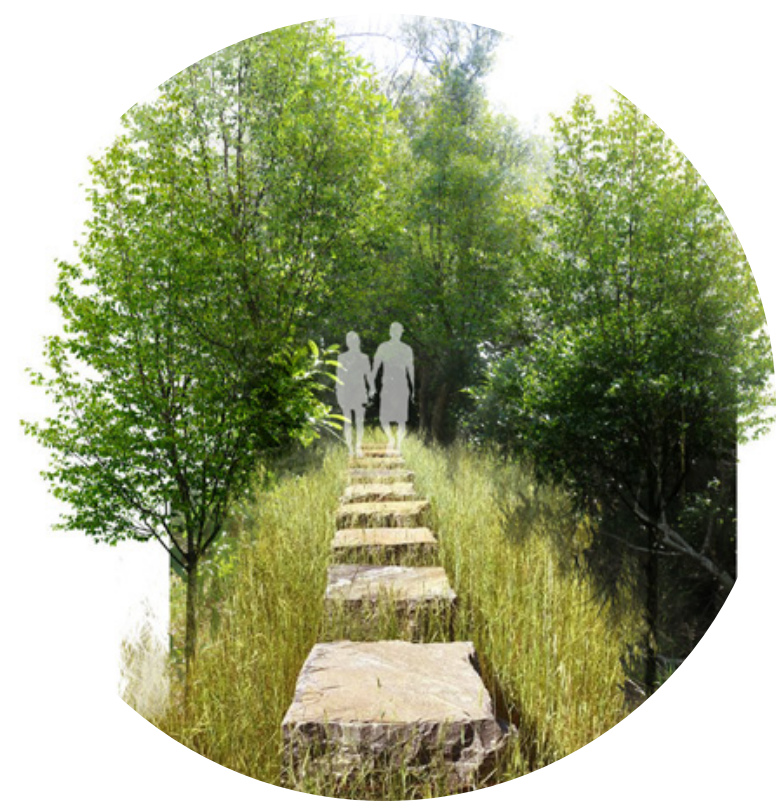

ROCKSTEPS

Spaced to allow for grass to grow between them giving them a more nature look

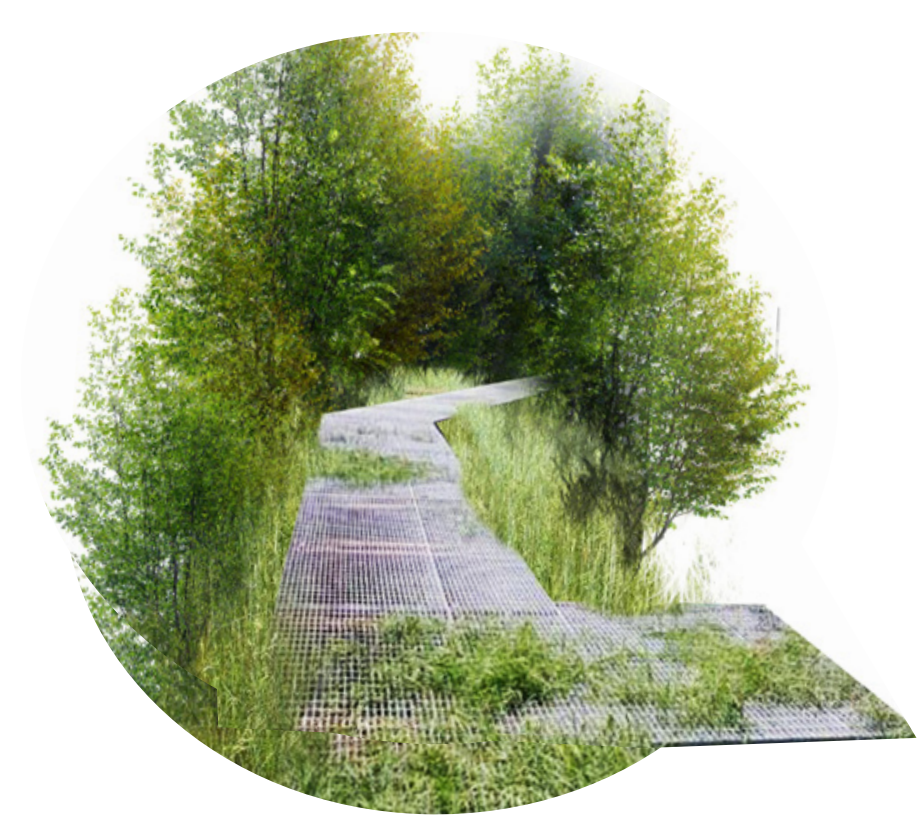

\section{GRATED METAL}

Raised with large perforations to allow for habitats to form below and grow up

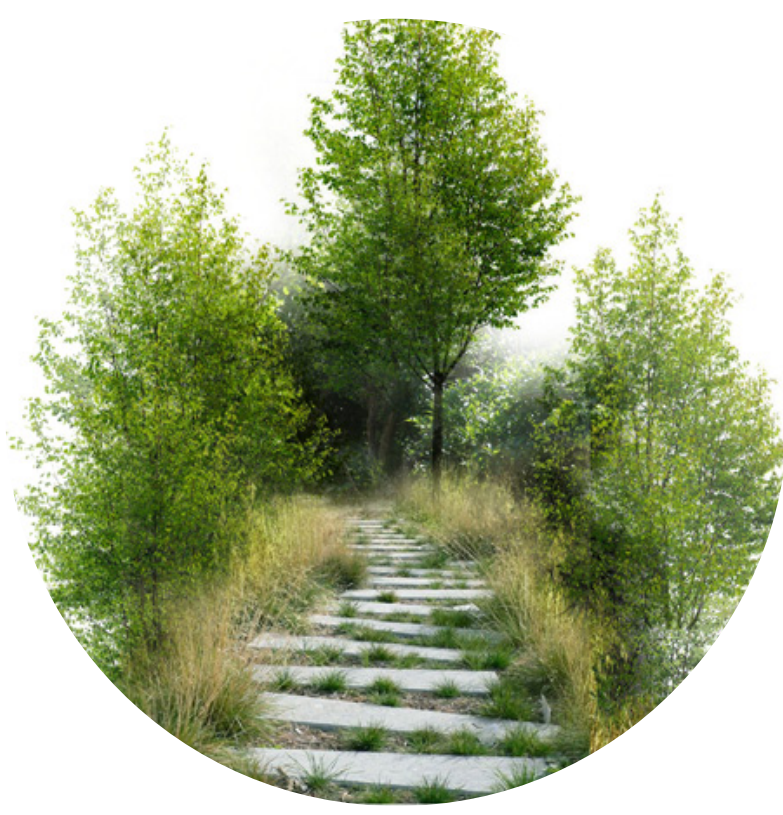

SPACIOUS PAVERS

\# 


\title{
ECOLOGICAL
}

\author{
NATIVE HABITATS
}

The exploration then shifted into looking at creating

habitats for key species, such as Penguins, Weta, Tuatara

and native birds, to increase sightings of them by visitors.

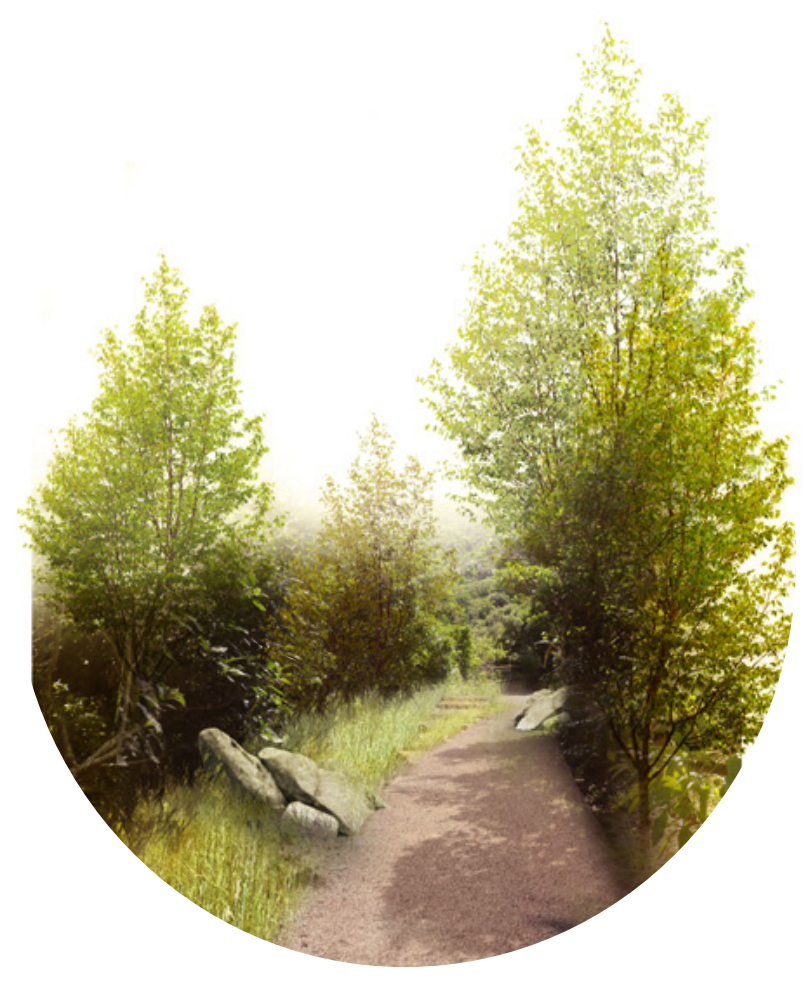

f. Placing rock piles in the sun to attract native

( lizards which can be watched by walkers

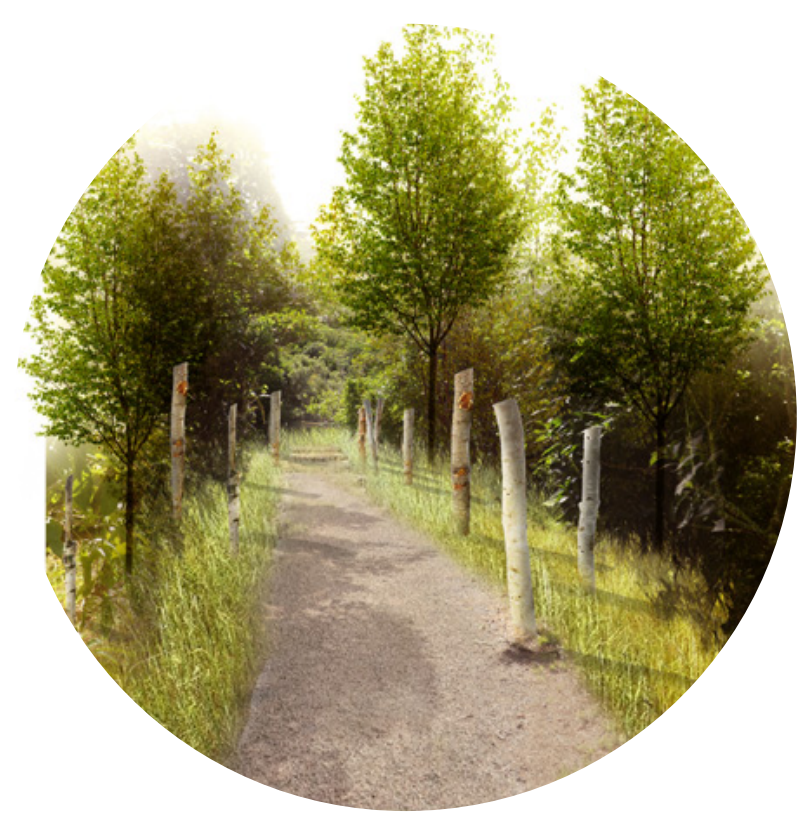

WETA MOTELS

$=$ Replicating the weta motels currently on the island along pathways for easier access

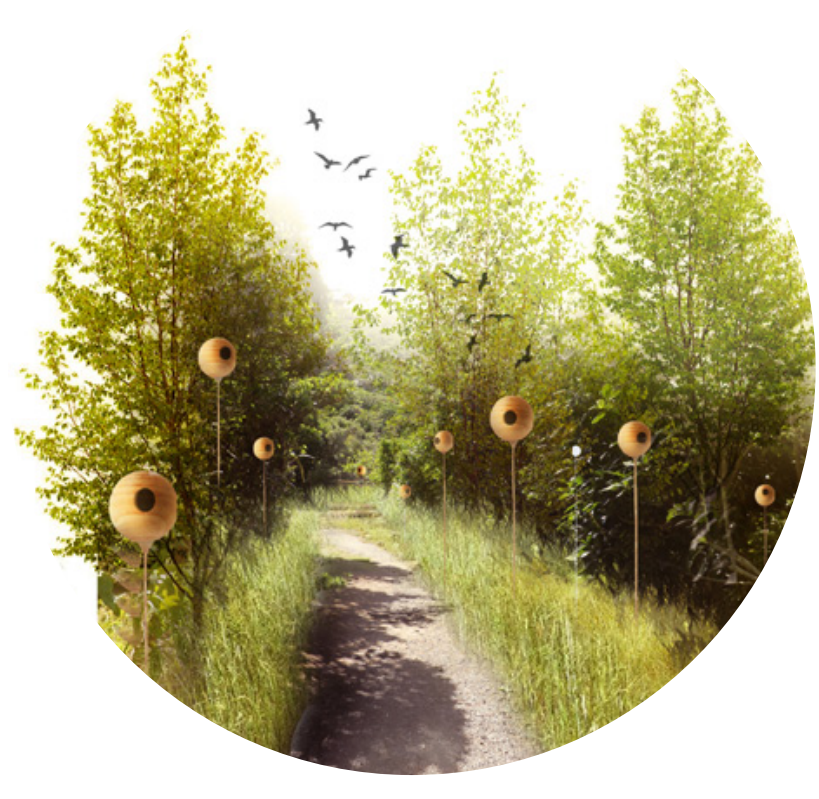

BIRD HOUSES

- Encouraging birds to engage more with visitors through hubs of bird houses

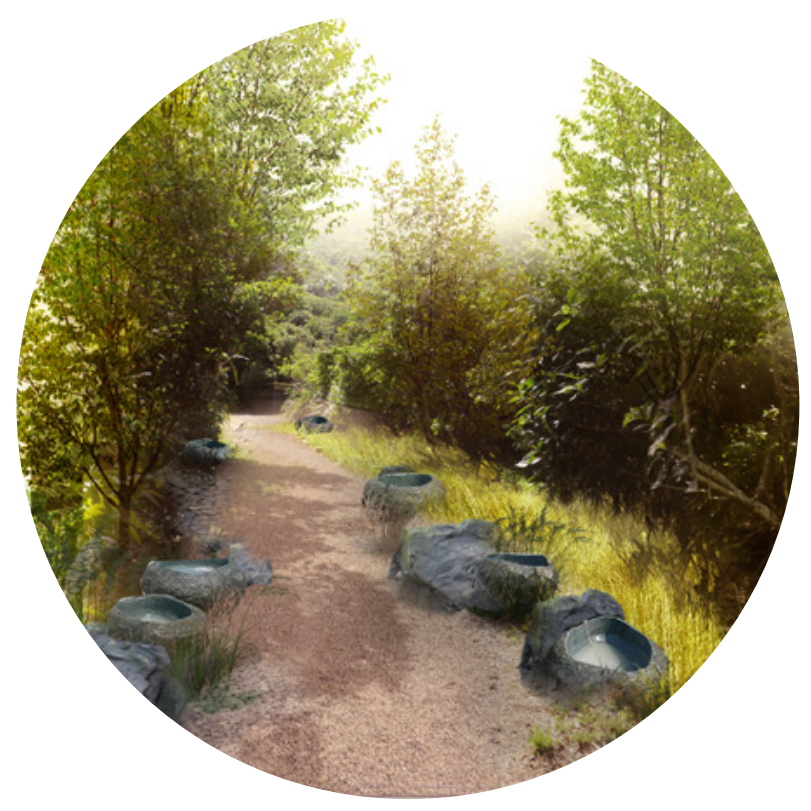

BIRD BATHS

Using carved rocks to create bird baths for native species on the island to frolic in

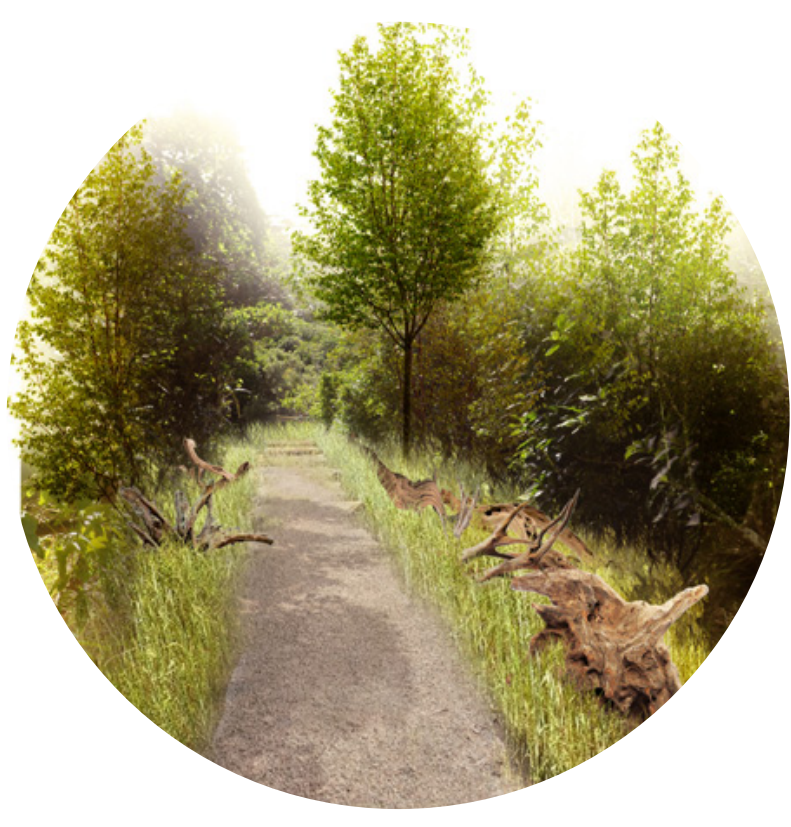

PENGUIN SAFE ZONE

- Using large drift wood pieces alongside the path to encourage penguins to venture inland

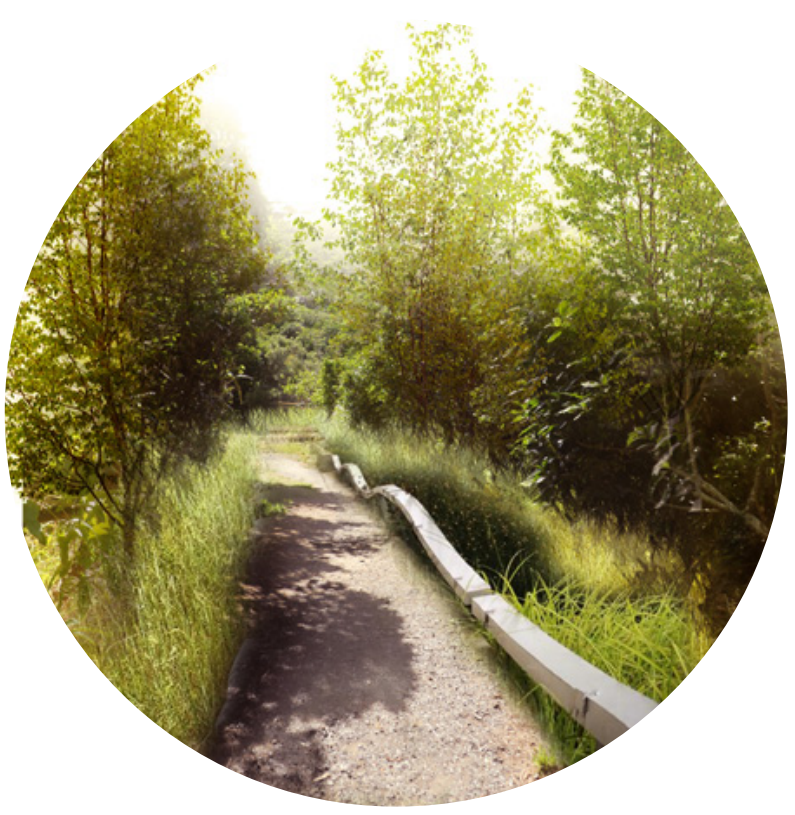

SIDE SWALE

Creating depressions that produce lush patches (with a barrier) to attract species 


\title{
NIGHT TRAIL
}

\author{
GROUND PLANE
}

The island also has the potential to be utilised more at night, however the lack of things to see or do means people rarely visit for the nightime experience. The exploration of a sculptural night path looked to solve this issue, providing visitors with a unique experience within the Pōneke Wellington region. The iterations begin by simply playing with the ground plane and how lights can be used to hint at narratives associated Taranaki Whānui.

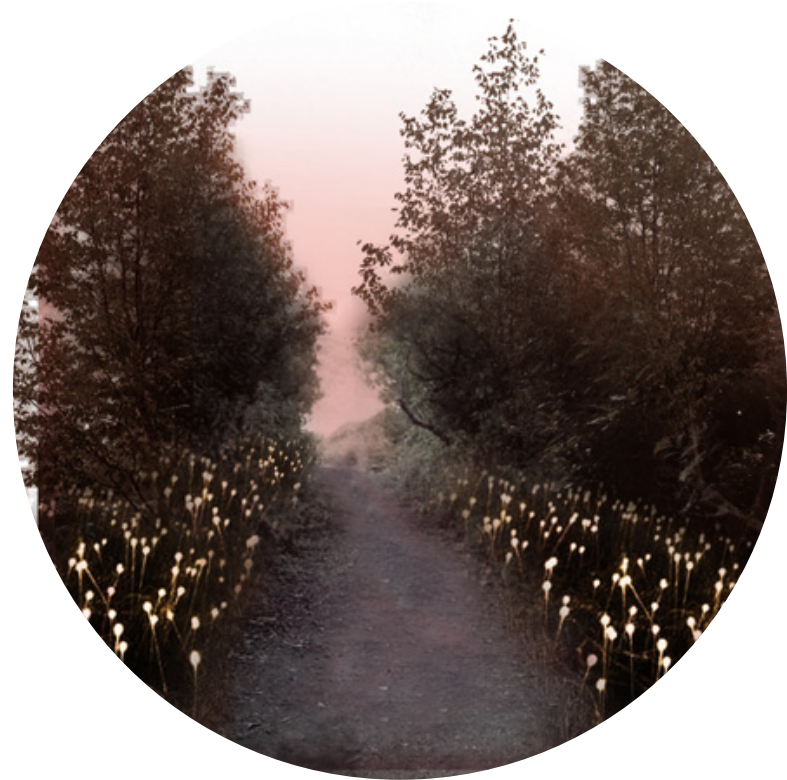

NIGHT SKY ADAPTION

+ Representing the constellations, creating

+ a sculptural piece

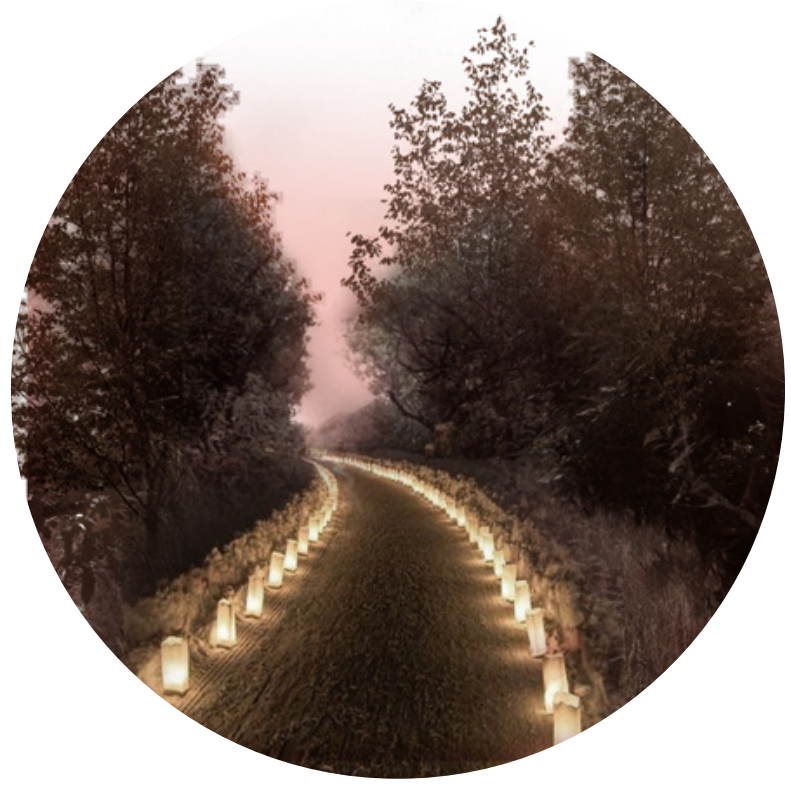

GUIDING THEWAY Lighting along a defined path acknowledges the importance of light for navigation

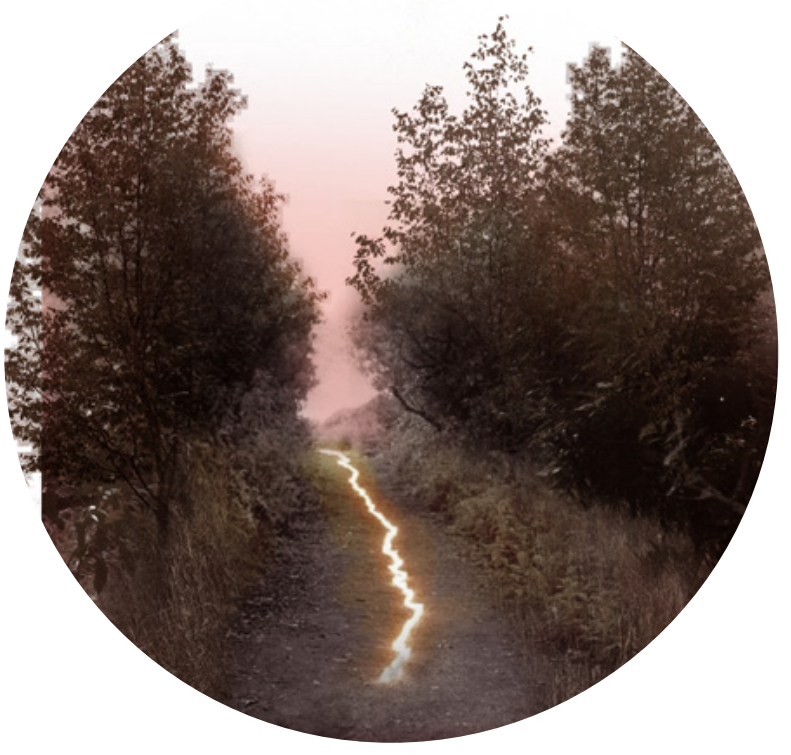

JOURNEYTRAIL

Using a singular light trail to acknowledge the path from Taranaki to Pōneke

Wellington

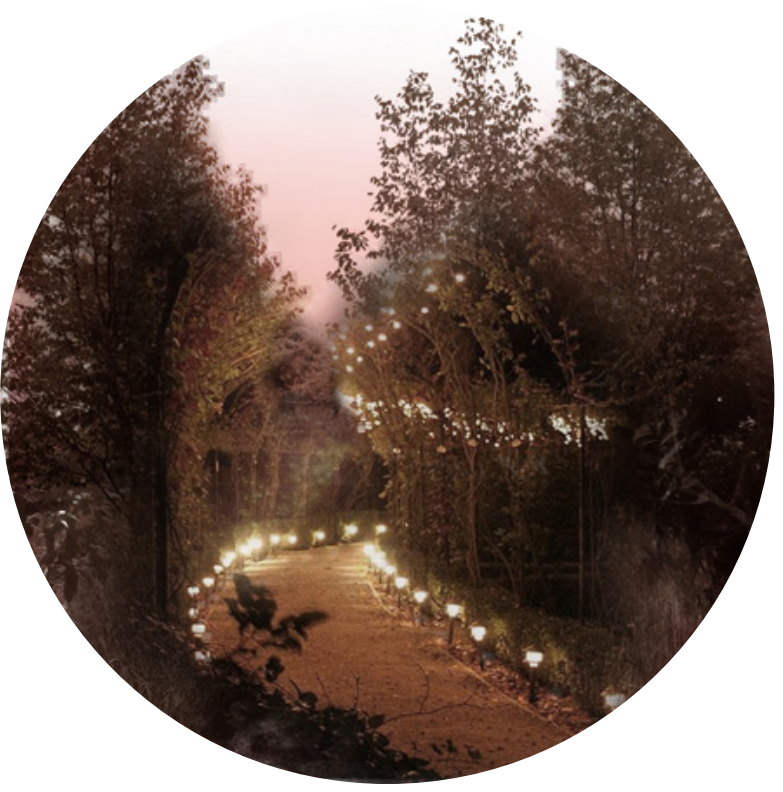

PITCH BLACK PATH LIGHTING

t. Using both low and high lighting to lead

$+{ }_{+}^{+}$people through pitch black paths

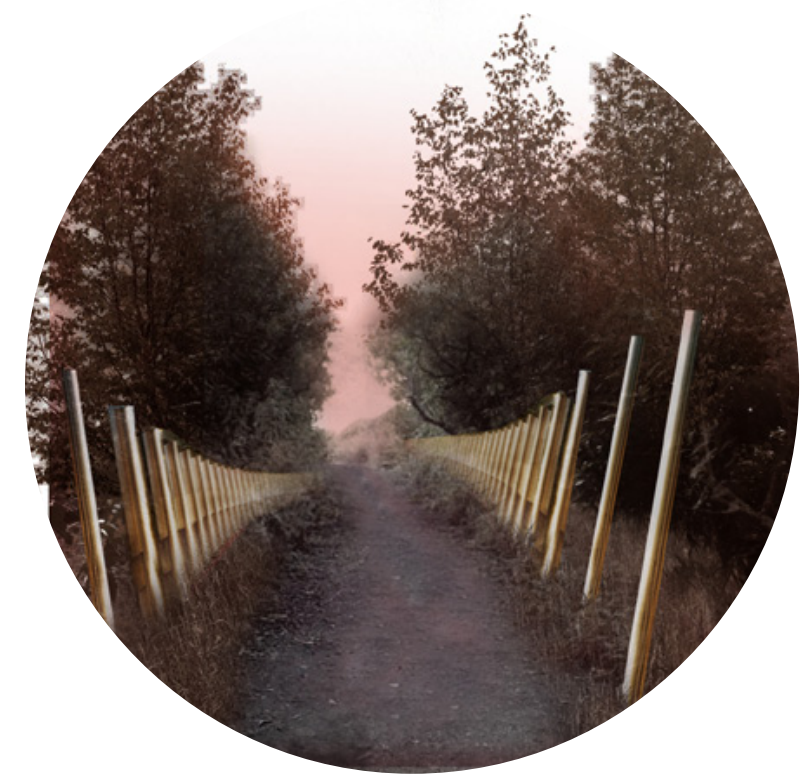

WAKA OARS

Recreating the form of waka oars over the

side of a waka

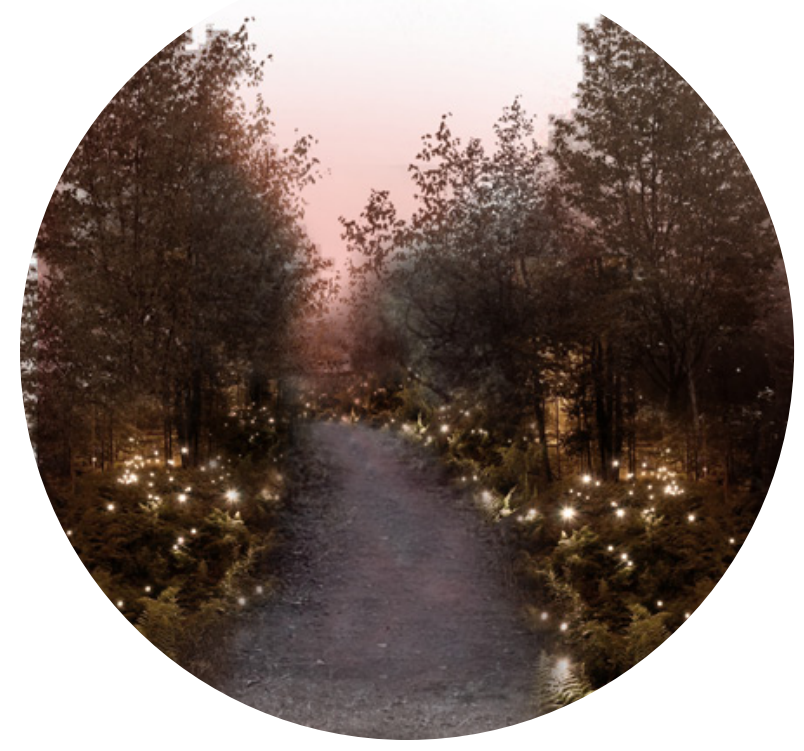

LIGHTS IN A FERN GROVE

Sprinkling lights through fern groves to

highlight the beauty of the species 


\section{NIGHT TRAIL}

\section{VEGETATION}

The iterations then shifted into introducing lights above and around the vegetation for interventions that completely sorrounded visitors. The

concepts explored recreating migration paths by hinting at Māori's use of star navigation to travel around the pacific.

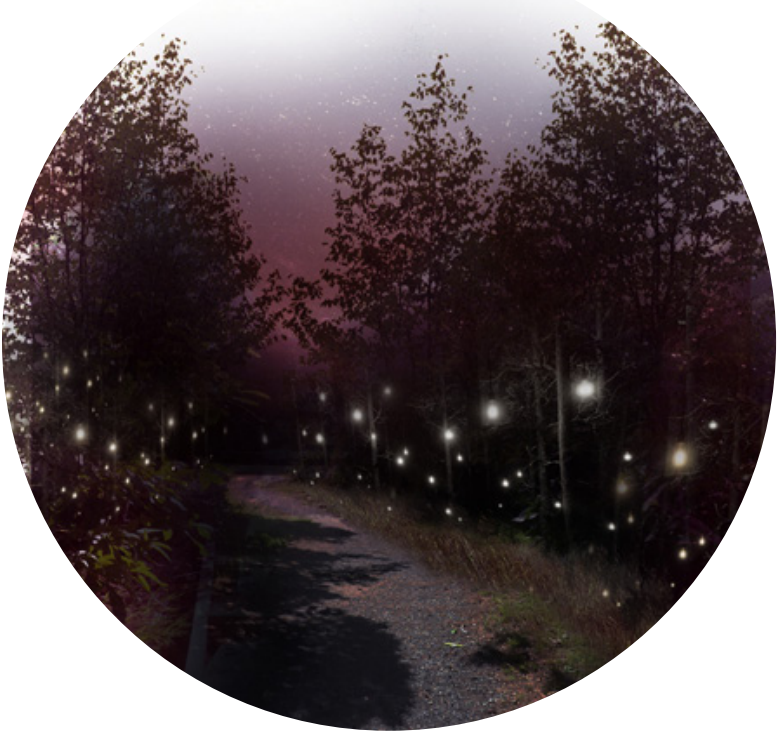

HANGING LIGHTS

$+\quad$ Hanging lights dangling at different

+ heights and depths creating a night sky

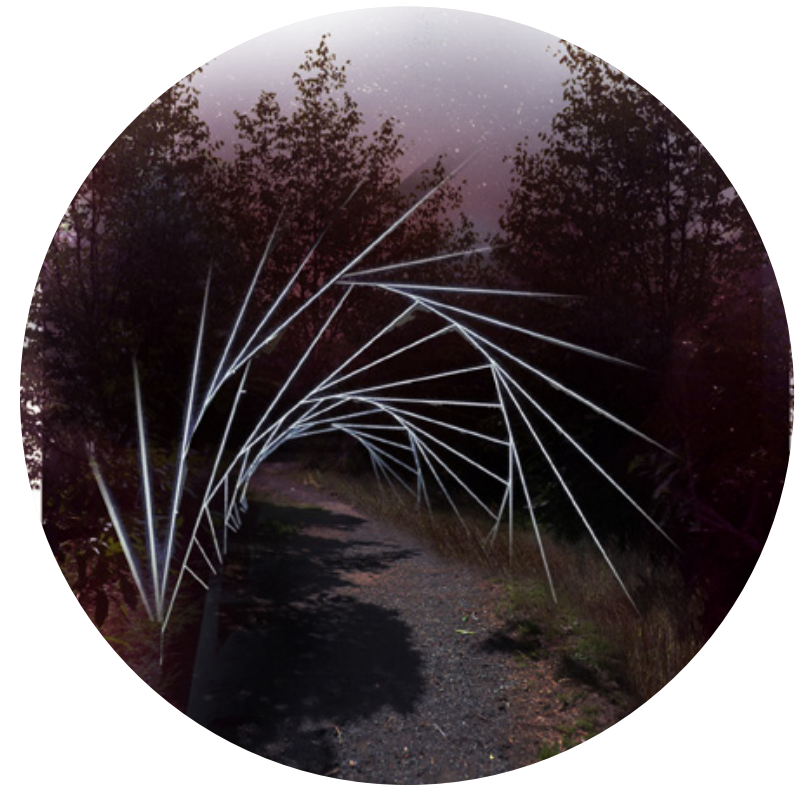

SHELLTUNNEL

1. Lighting along a defined path acknowledges the importance of light for navigation

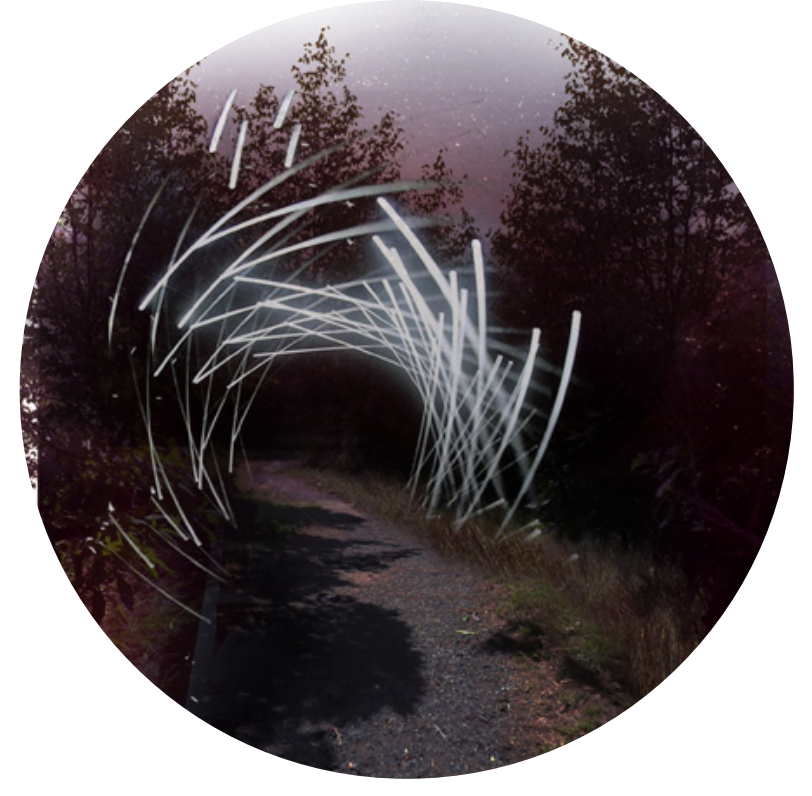

TE KINA

Representing forms found in the surrounding ocean that are a food source

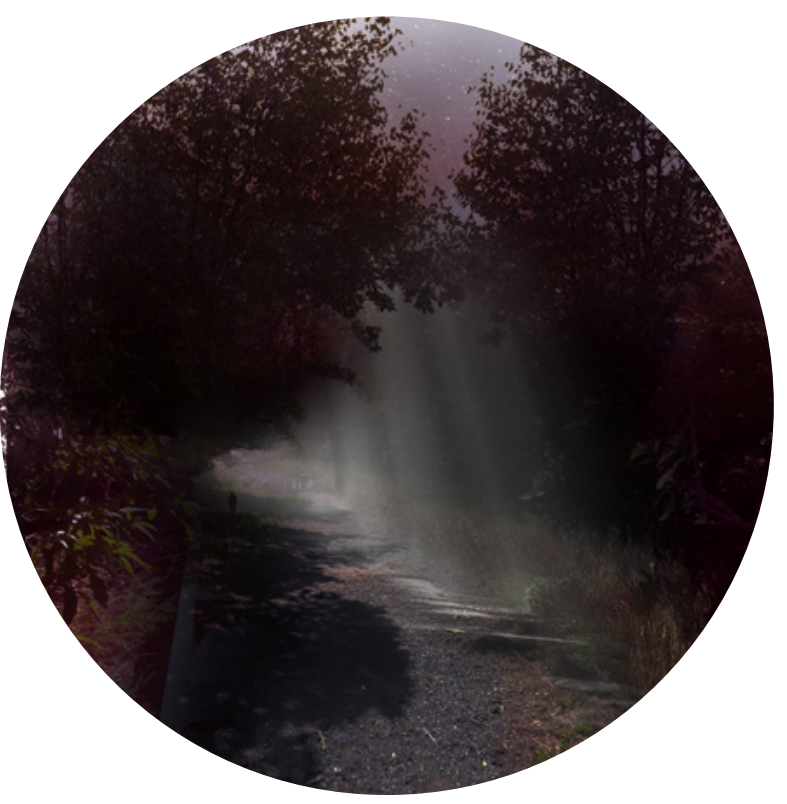

SOFT FALLING LIGHT

$+\quad$ Using soft light to represent the moonlight

+ that Te Ati Awa would have followed

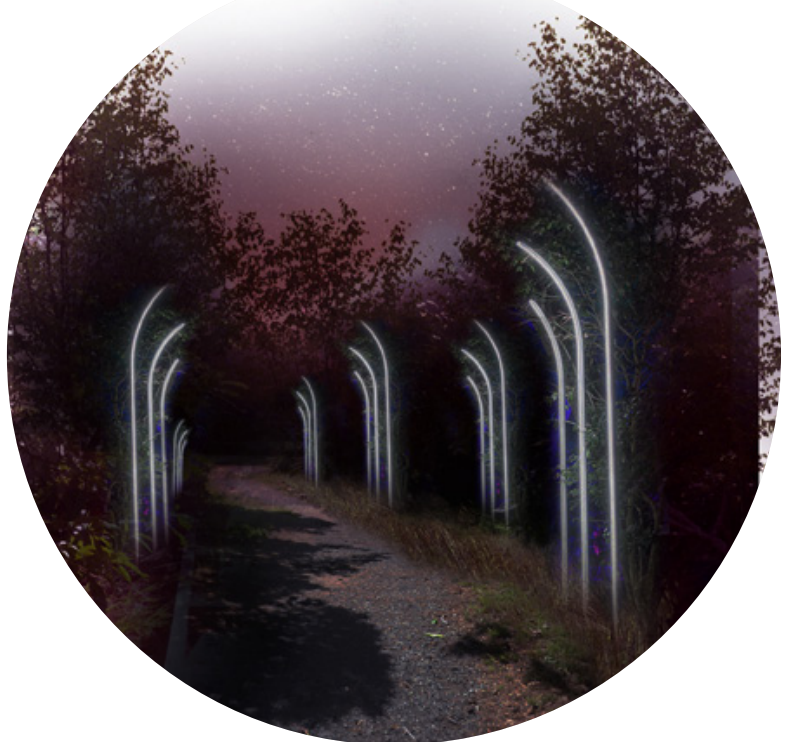

SILENT SAILING

Abstract forms represent wakas silently moving through the night

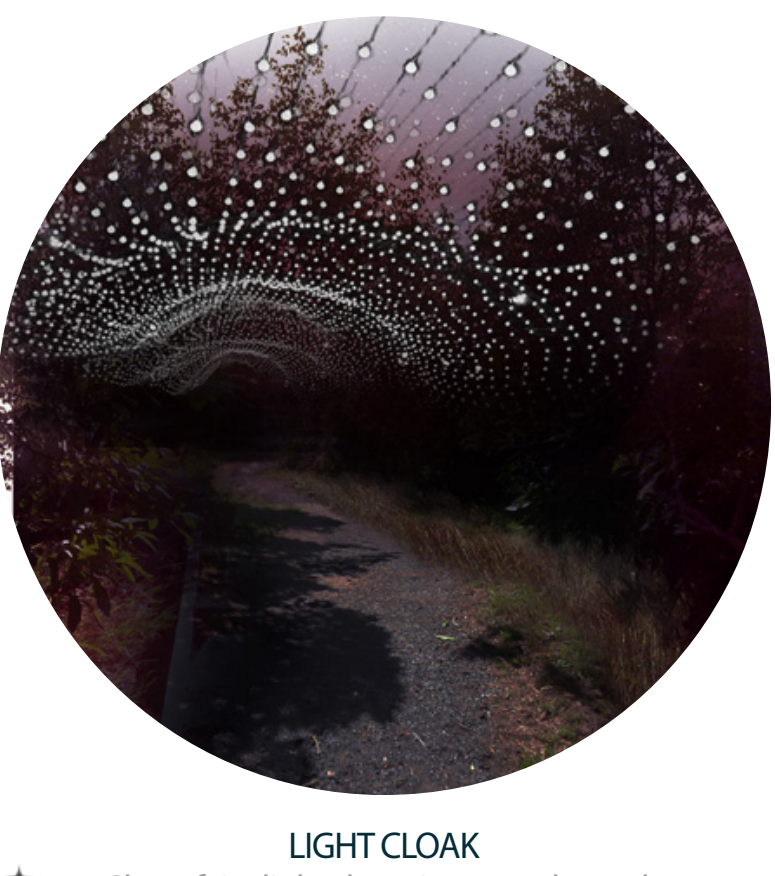

+ Sheet fairy lights hanging over the path recreate the night sky 

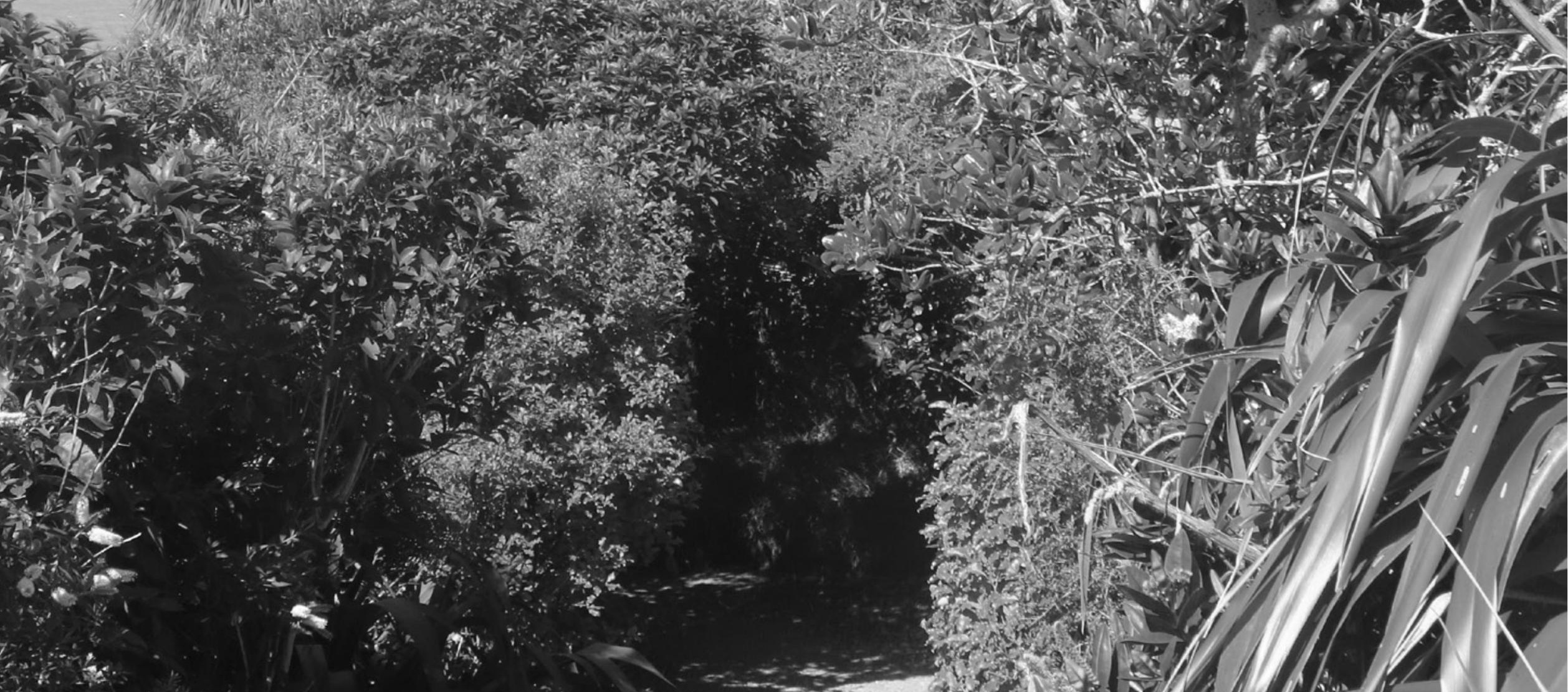

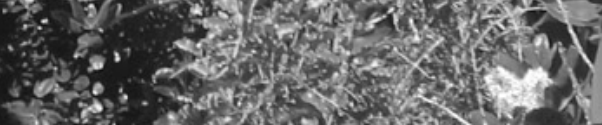

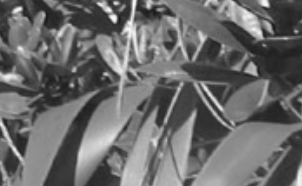

7

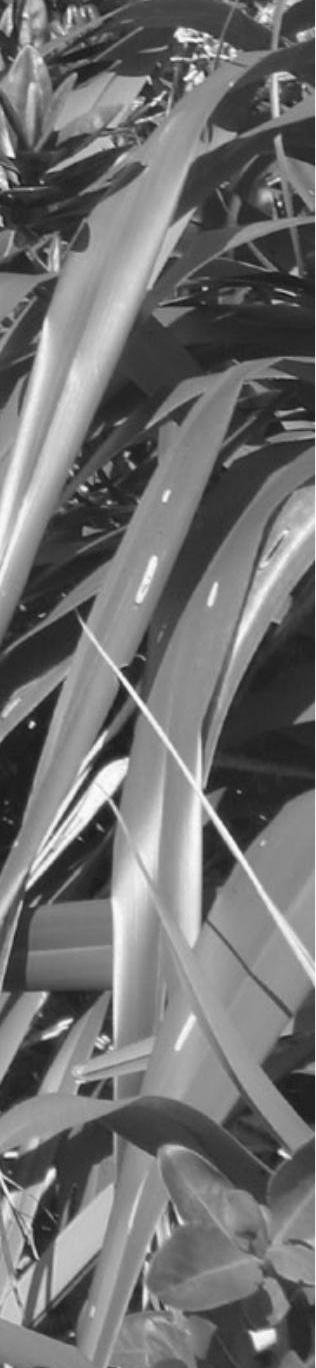

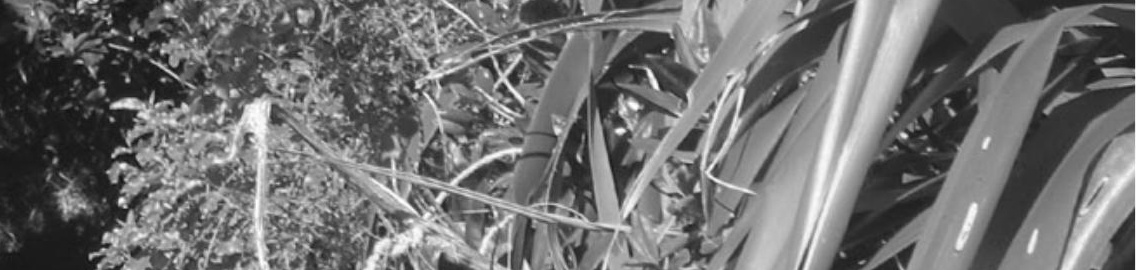
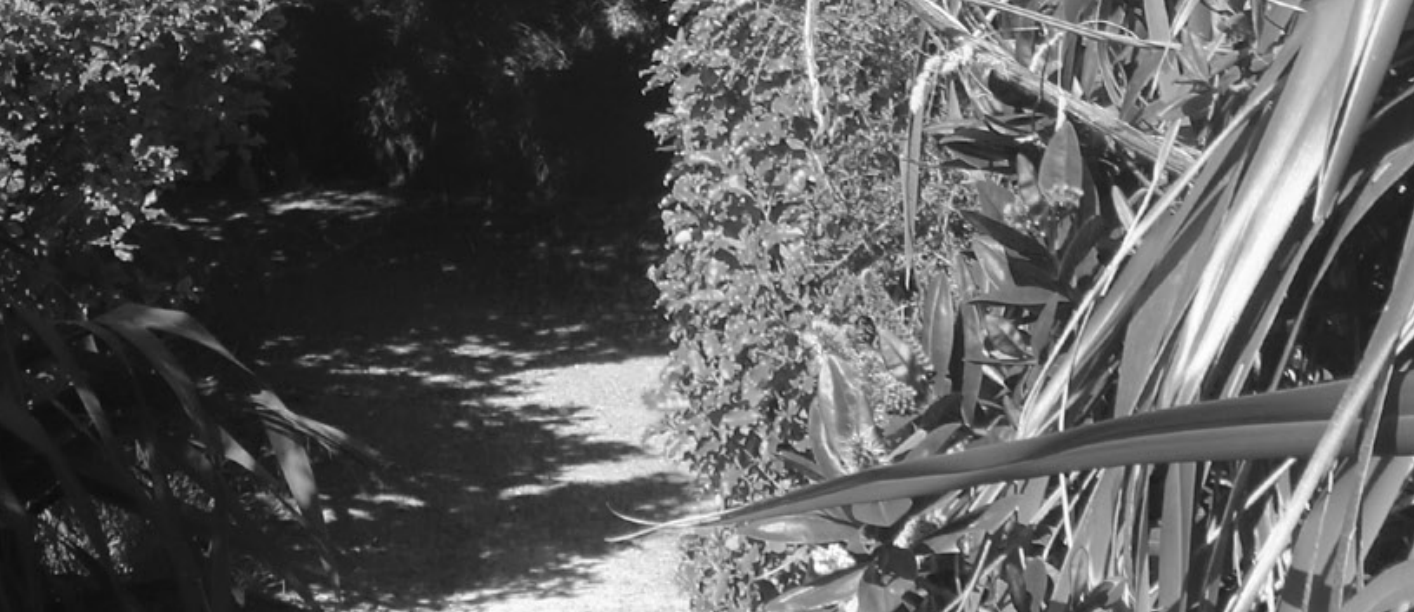

Fig. 82 Southern Pathways Image

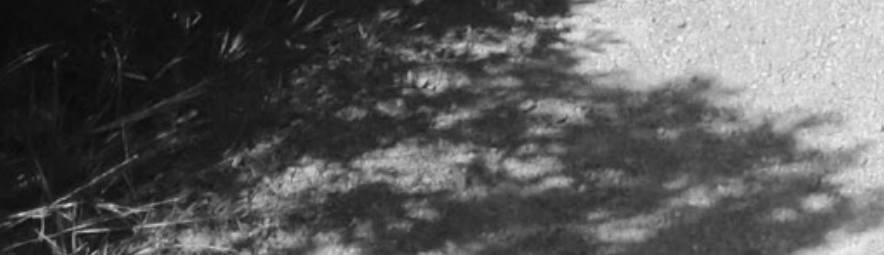

trets 


\section{REFLECTION}

Breaking up the paths into themes was effective as it allowed a multitude of experiences to be explored to convey a narrative or historical event.

EUROPEAN PAST: The iterations explored the role brown and black coloured natives could play in conveying the visually degraded state of the landscape after the devastation caused by Europeans. The use of corten steel structures in some of the iterations referenced the quarantine building bars to create a structural contrast against the soft native plants. However, these iterations were too harsh and visually dominant. The more natural iterations were more effective and did not compete with the view lines when visitors looked up at the island from the Wharf.

ECOLOGICAL ENHANCEMENT: The iterations exploring the development of the ground plane were most effective when the pattern drew the user up the path and had a variance in colour and material, drawing visitors attention to the ground plane.

The paths that were designed to showcase the restoration efforts of DOC looked at increasing the interaction between wildlife species and visitors. Some of these concepts, such as the bird baths and log walkways, were not as effective as they appeared too clunky and were not practical in terms of a walking surface for visitors. Concepts that had minimal impact on the existing environment or that subtly enhanced it, like the pole bird houses,swales and the drift wood piles were more successful due to their ability to bring one or more species closer to the path without impacting the safety and the walkability of paths for visitors.

NIGHT PATHS: The exploration of a sculptural night path began by simply playing with the ground plane and how lights can be use to hint at significant narratives relating to ancestral of the iwi and the use of star navigation to travel around the pacific. The subtle iterations that played with lighting on the ground plane were under whelming due to the small area of space that was lit up. The concepts that were most effective were the ones that used structural light elements all around the path, fully enclosing the visitor in the display for maximum experiential impact. 


\section{JOURNEY MASTERPLAN}

It became apparent that the pathways were most effective when they changed throughout people; journeys. This suggested that selecting the most effective iterations and allowing one to bleed into the other would create a dynamic and changing path that would keep people engaged while sharing multiple narratives. With the development of the night and the ecological path, it seemed appropriate that the path starts off simply, through a slight change in the materiality of the ground plane or a simple light intervention, and overtime become grander and more engaging, building suspense to create an unforgettable experience.

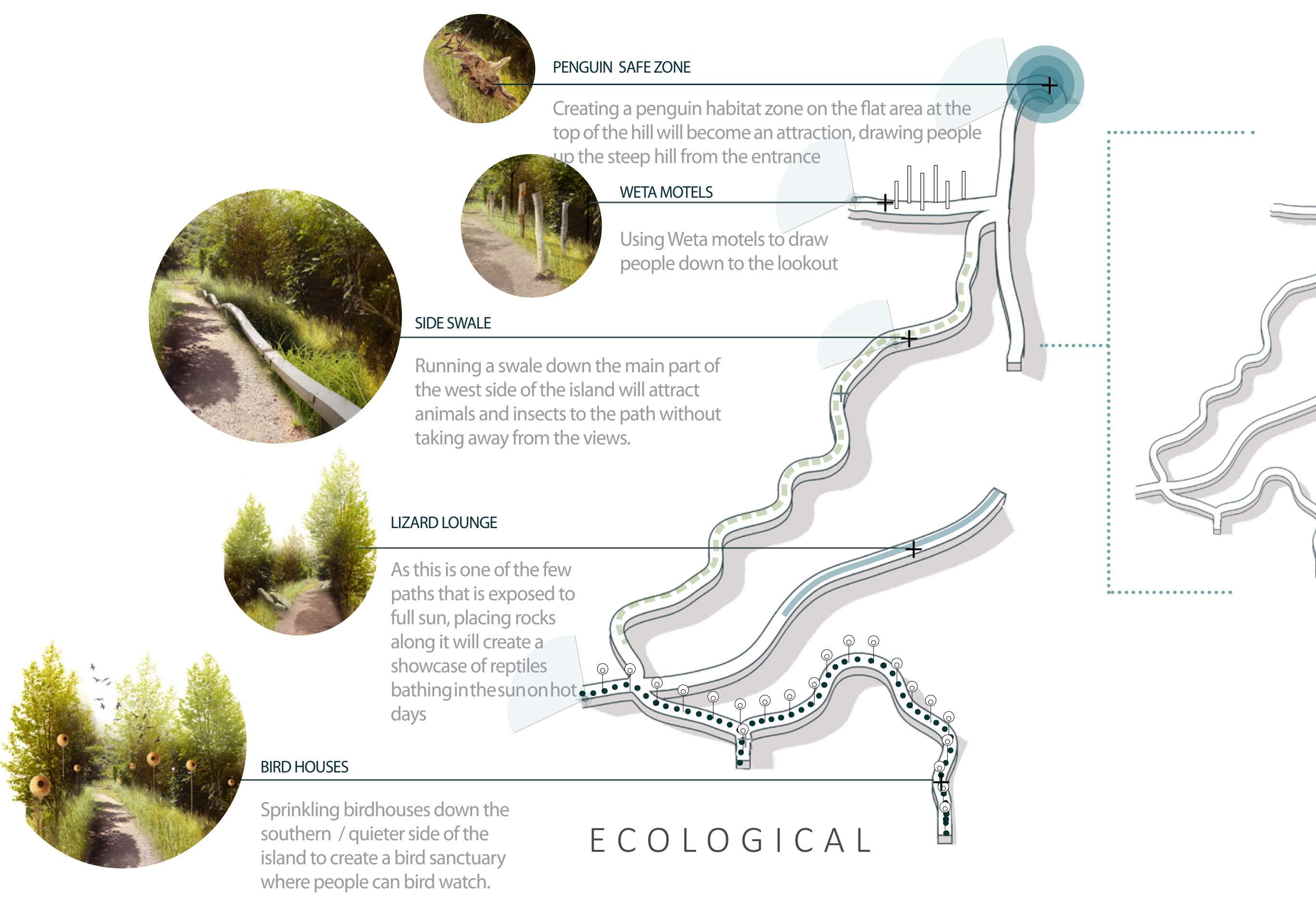




\section{TRUNK SCULPTURES}

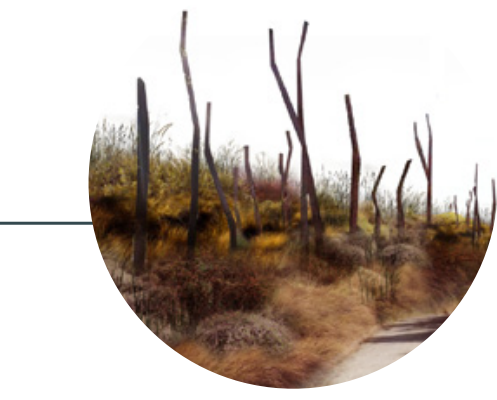

Dead tree sculptures are sprinkled hroughout the brown and black natives

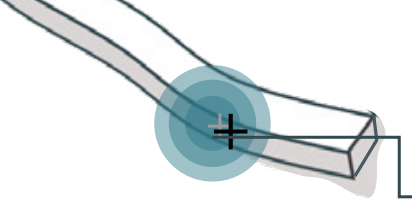

QUARANTINE COVER

The archway is located halfway up the path so it does not visually detract from the sculptural features found at the wharf or the beautiful views at the top, whilst breaking up the steep

journey.

\section{EUROPEAN PAST}
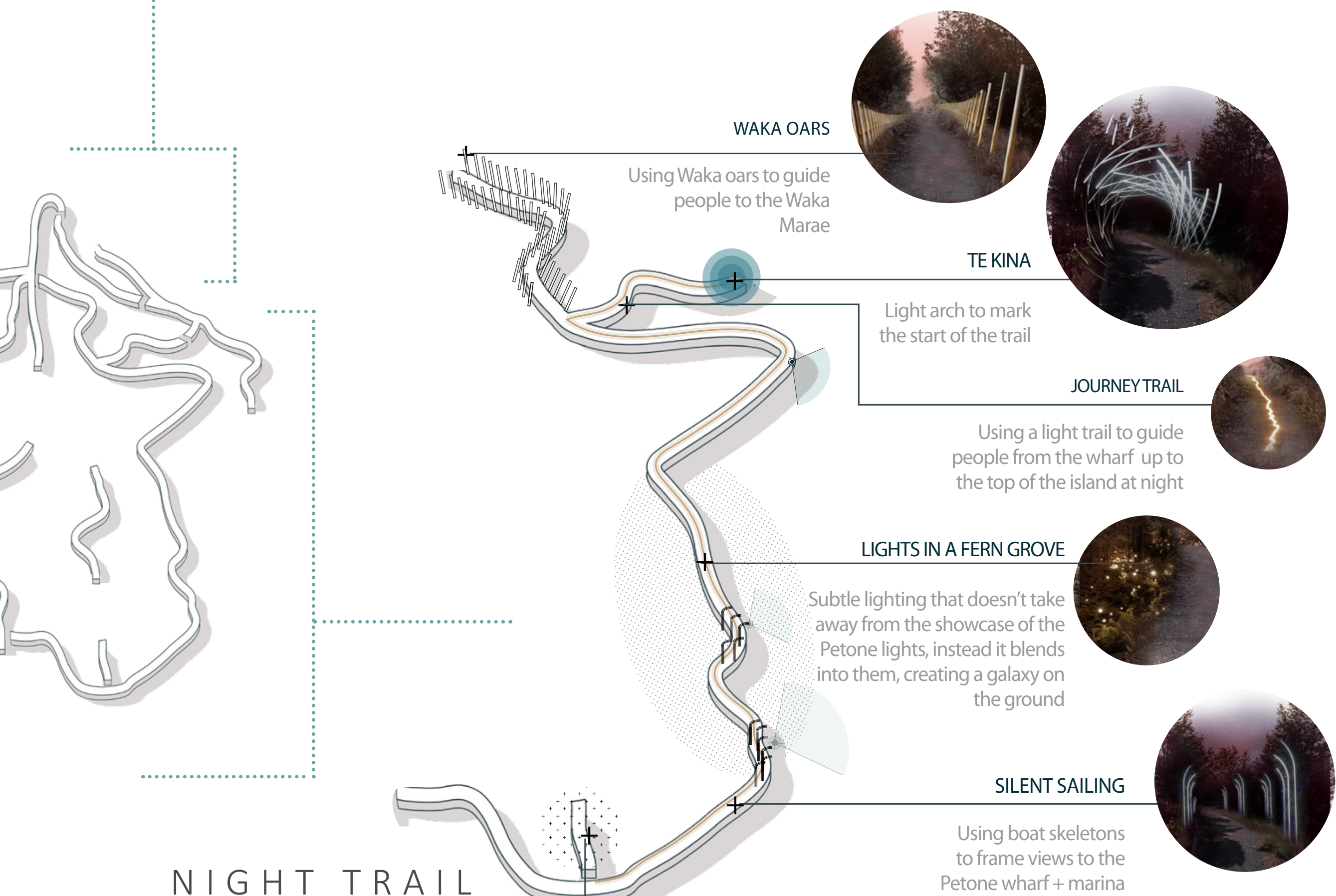

NIGHT TRA I L

Petone wharf + marina

LIGHT CLOAK

A recreation of the night sky to lead people up to the star

observatories 


\section{SITE THREE}

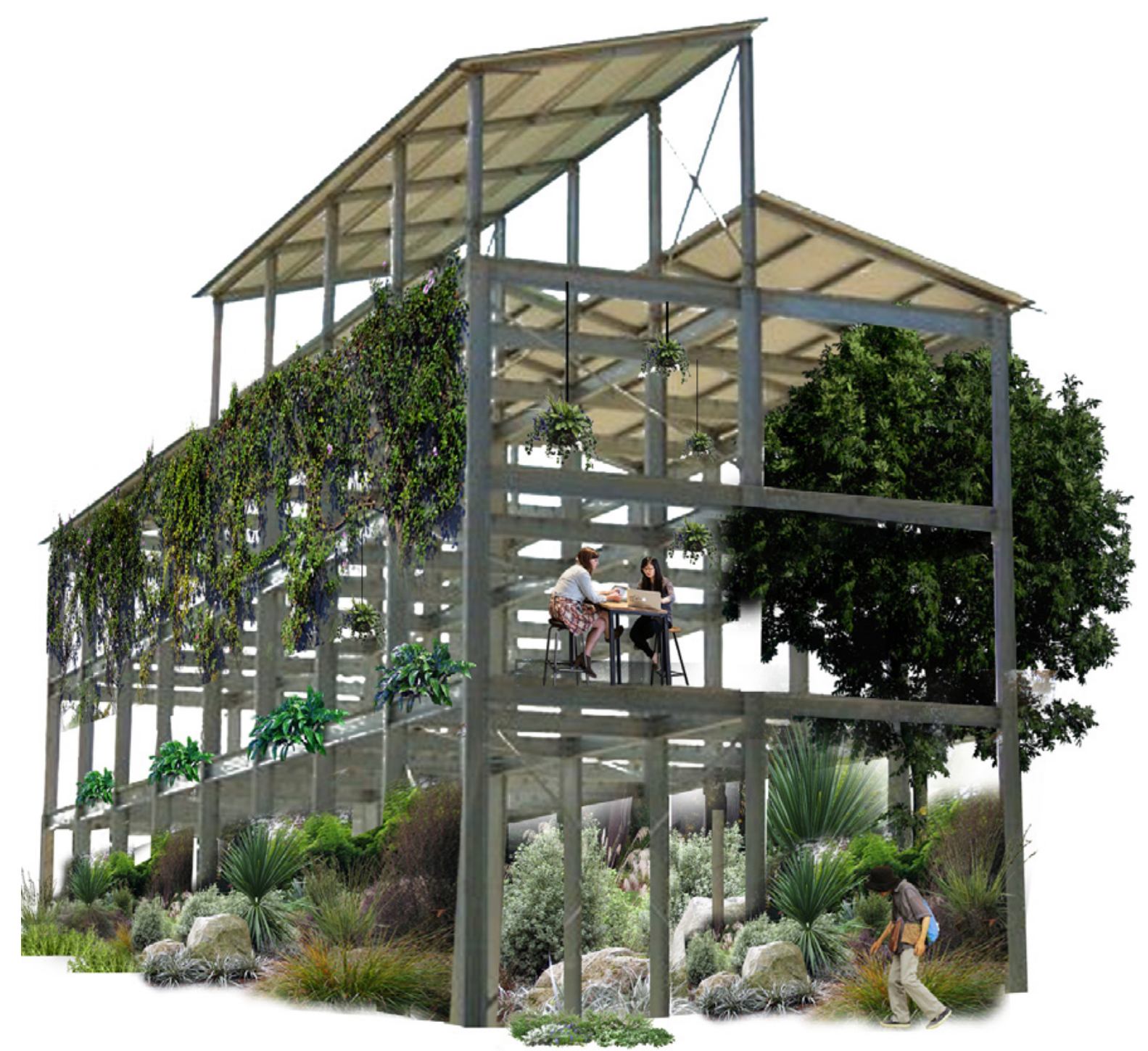

Fig.84 Quarantine Building Icon

\subsection{THE QUARANTINE}

The Quarantine Building located at the top of the island is an unused and empty building that was previously used to monitor the health of both animals and humans in the Pōneke Wellington's region. The building provides the island with a structure that has water and electricity, creating the opportunity to repurpose it. Leveraging on its role as a health facility, the design explores how the building can again aid in the maintenance and enhancement of both human and environmental health in Pōneke Wellington. The design iterations play with re-using and re-configuring the current internal structure to create a range of different spaces for Rongoā plants to be grown in an indoor, greenhouse setting. 


\section{OBJECTIVES}

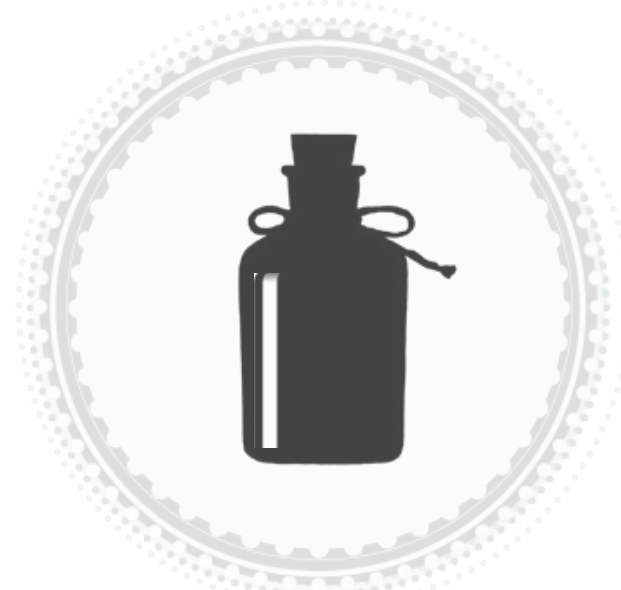

Create a Rongoā garden that shares traditional medicinal methods with visitor

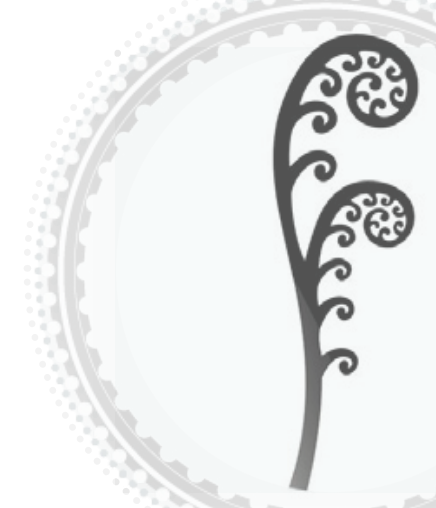

Establish a Whare Kai that feeds the Marae

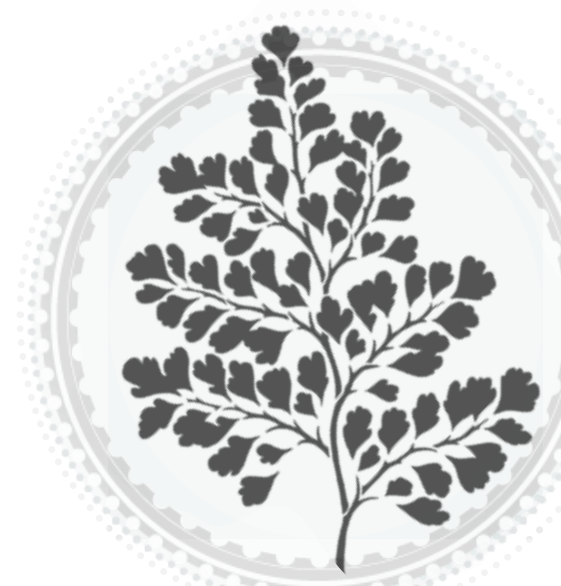

Create a collection of important native species to share with locals and visitors 


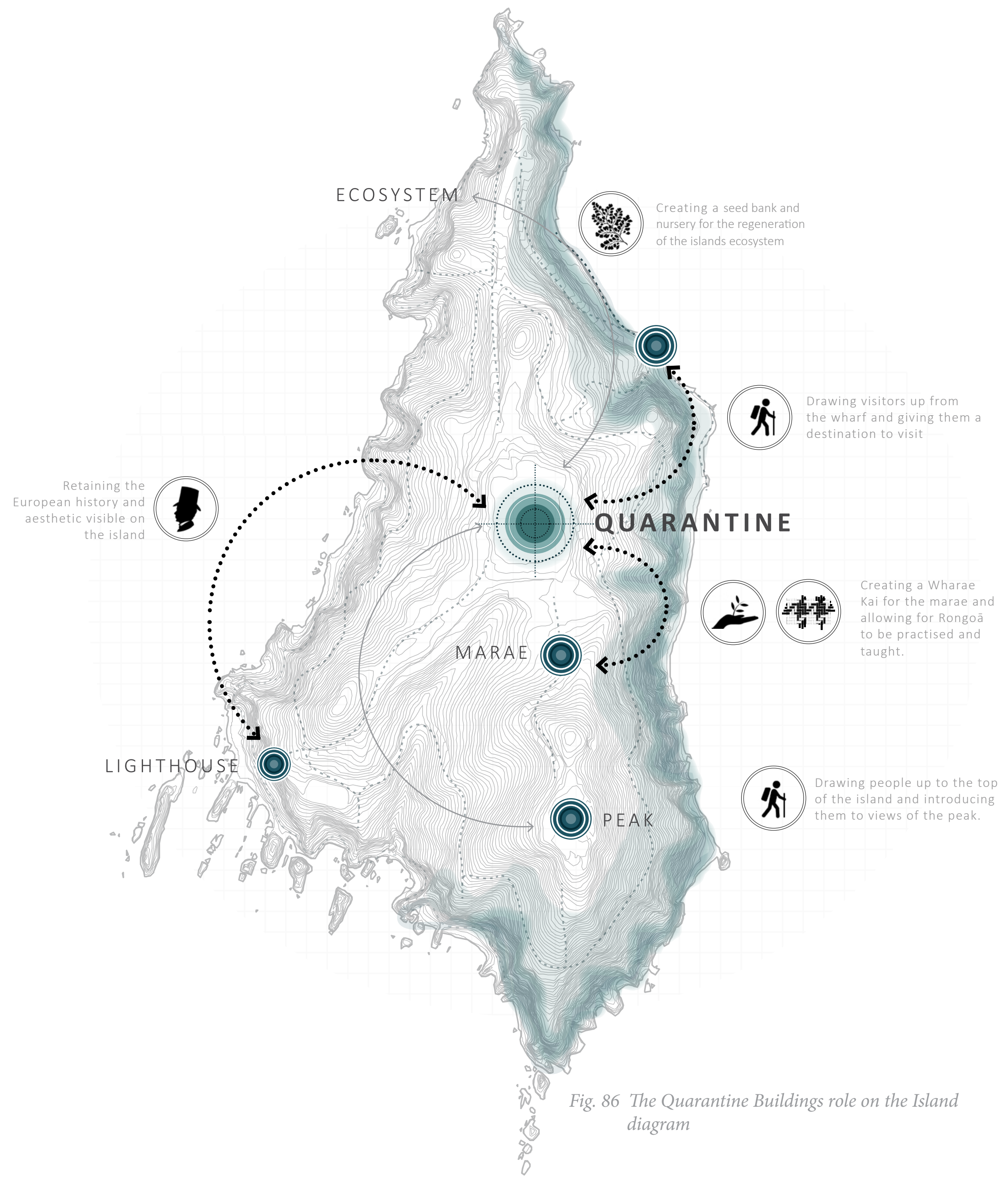

POTENTIAL ROLE

The Quarantine building will continue to be a core attraction on the island that draws people up from the wharf, retains its European aesthetic, works in with the ecological restoration efforts of DOC while servicing the marae. 


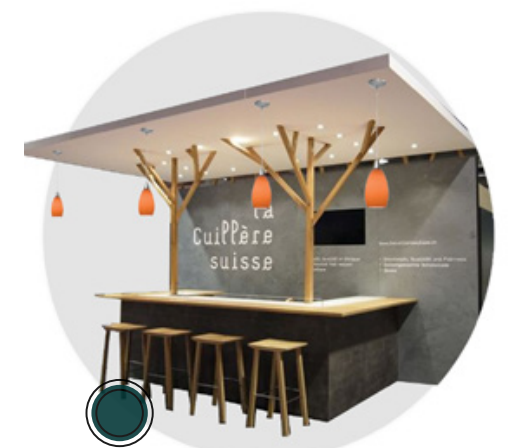

CAFE

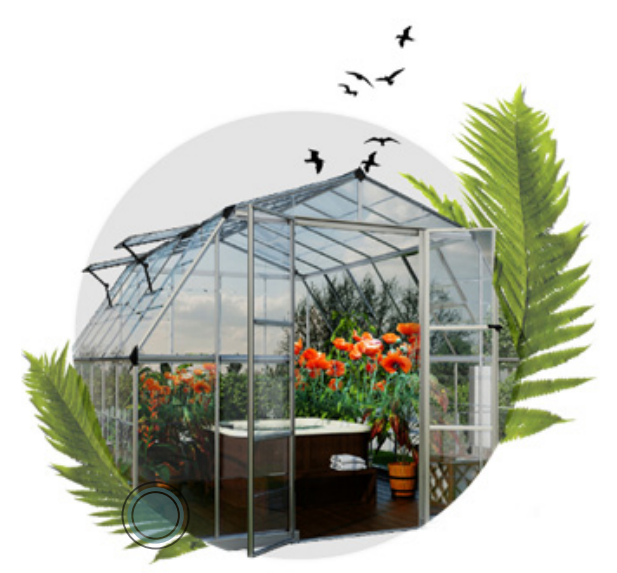

GREENHOUSE

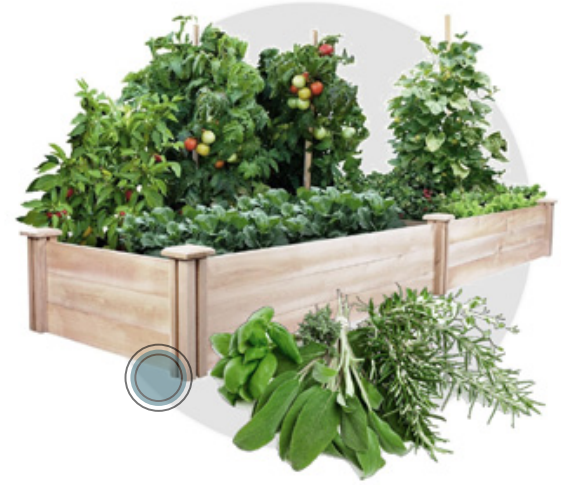

HERB GARDEN

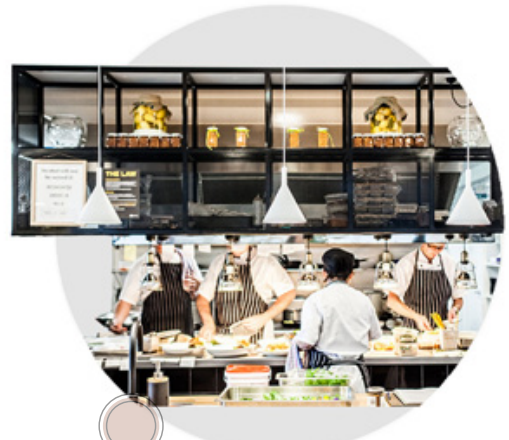

KITCHEN

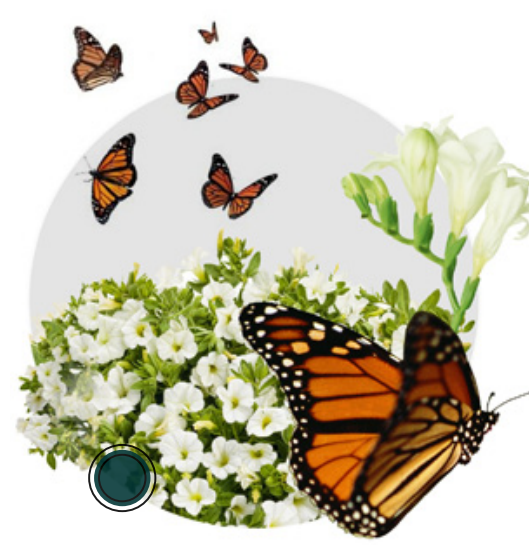

BUTTERFLY HOUSE

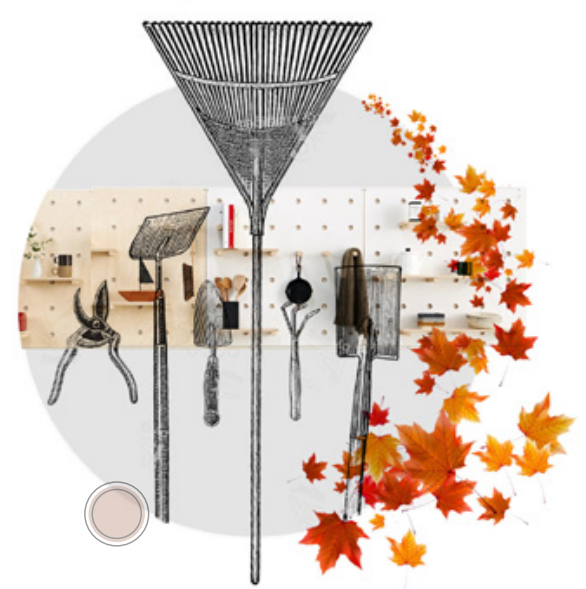

TOOL SHED

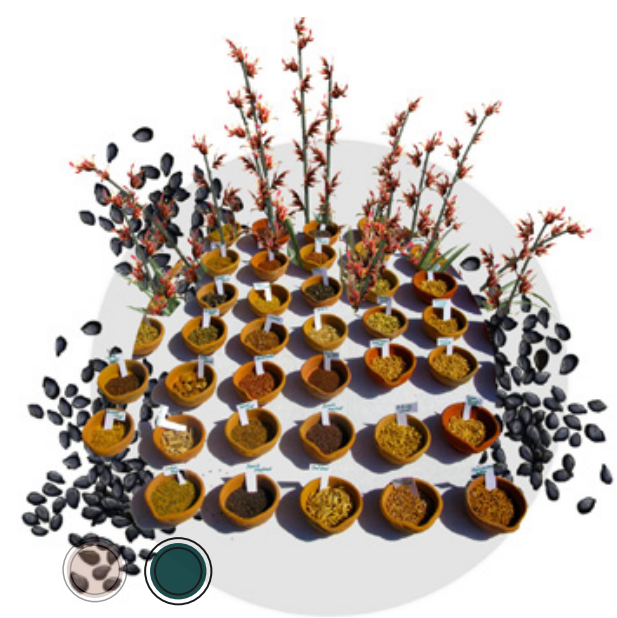

SEED BANK

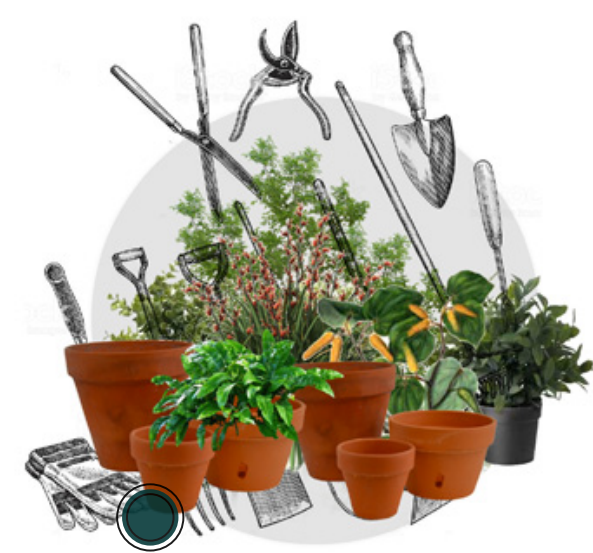

NURSERY

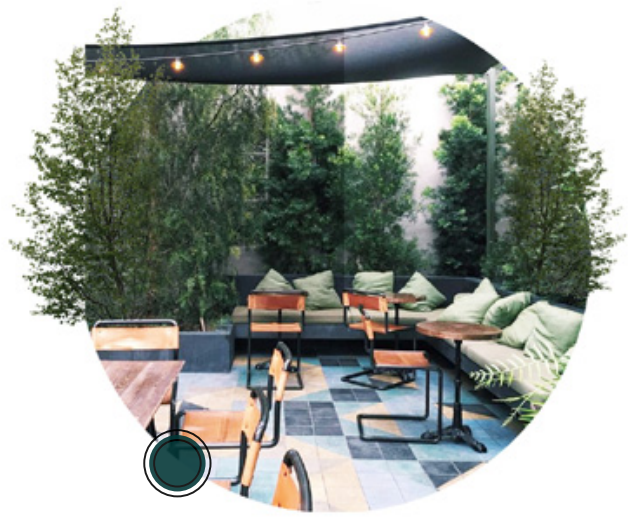

RONGOĀ GARDEN

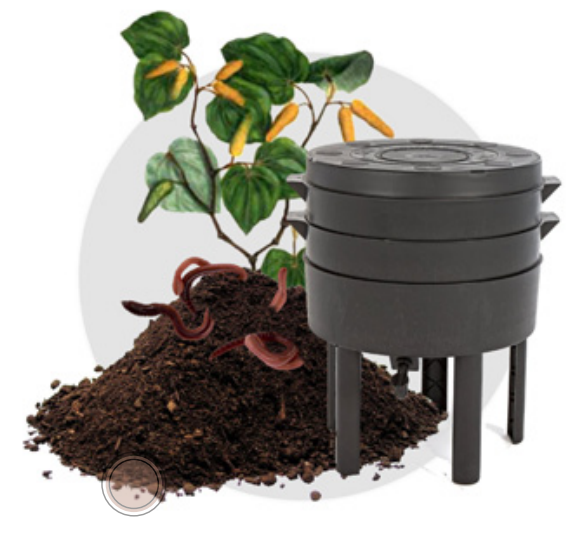

public spaces facilities
WHARE KAI

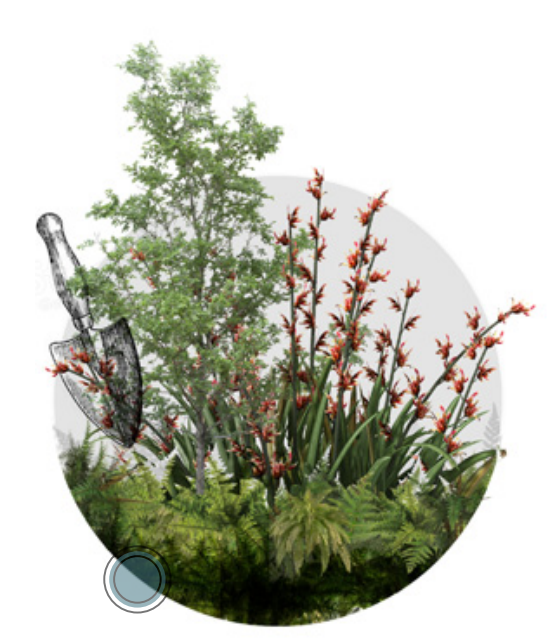

WORM FARMS

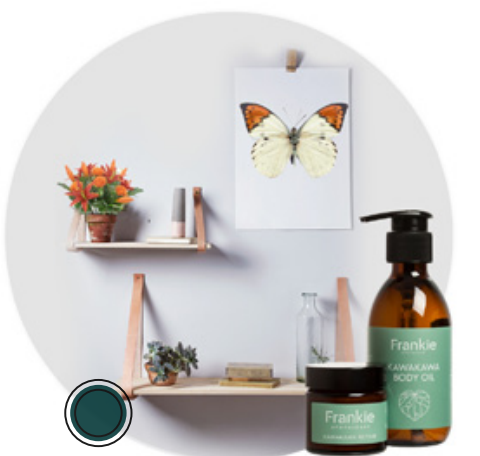

GIFTS SHOP

GARDENS

Fig. 87 Quarantine Building potential programmes collage

POTENTIAL PROGRAMMES

Analysing the capabilities of the Quarantine buiding

enabled a list of potential programmes to be

produced, creating a number of possible spaces to

play with in the iterating phase of the design process. 


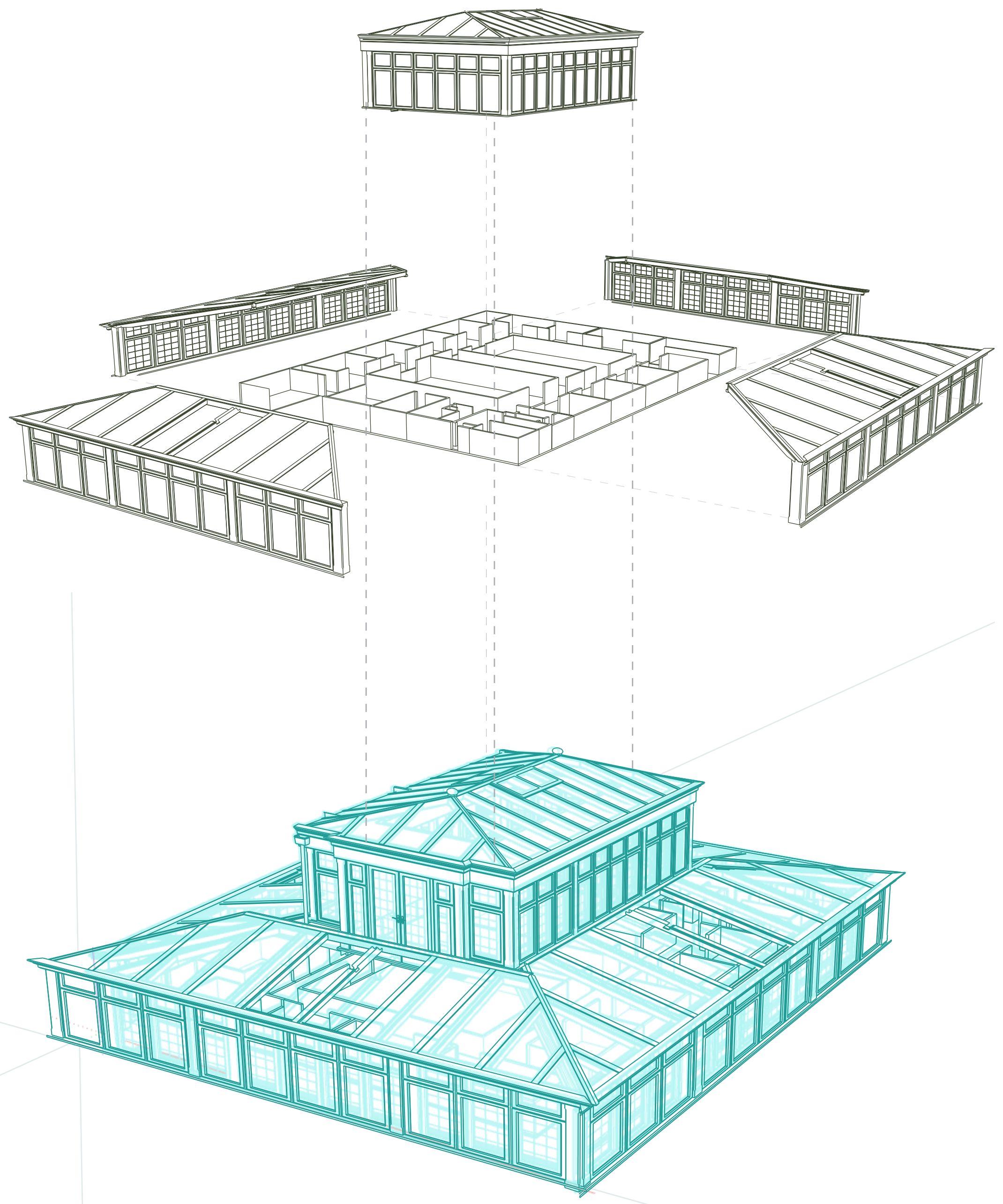

Fig. 88 Exploded diagram of the Quarantine Buildings glass shell and interior walls

\section{GLASS SHELL CONCEPT}

Removing the existing roof of the quarantine building and replacing it with an exterior glass shell would allow natural sunlight to penetrate the building so Rongoā plants can grow in controlled conditions. The aesthetic of the glass conservatory would maintain the European look of the building, referencing to its origins. 


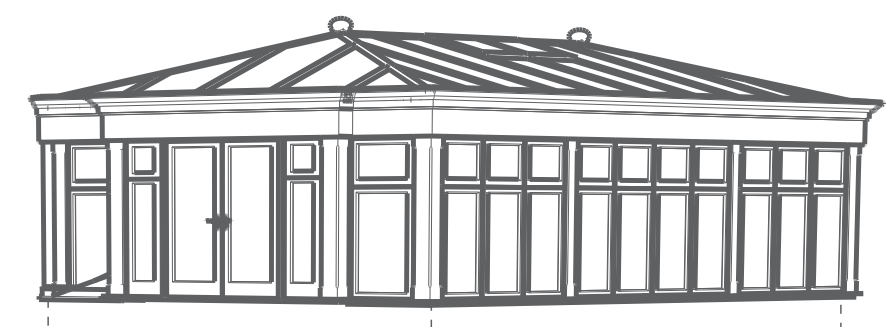

TRADITIONAL GLASS

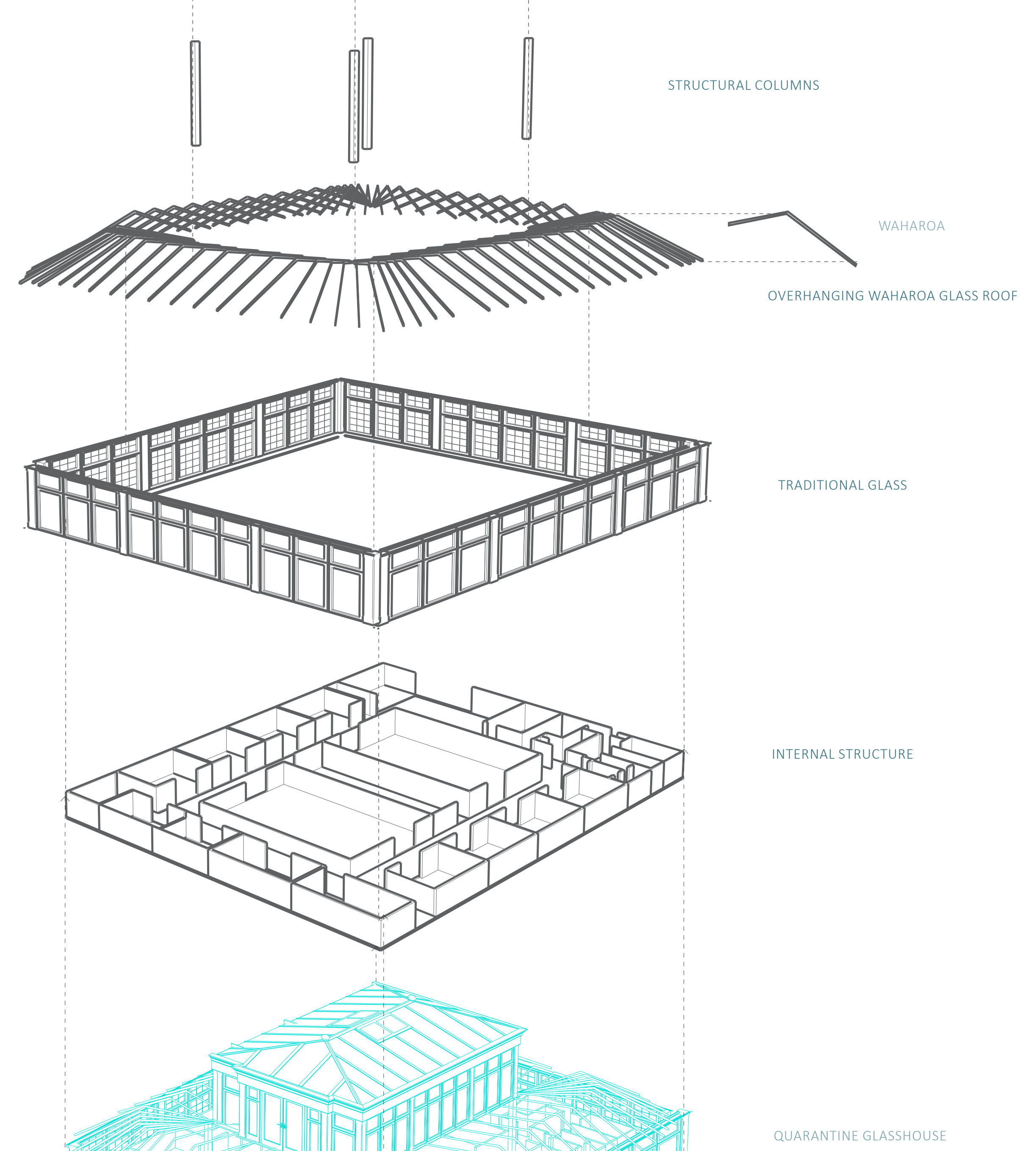

Fig. 89 Exploded diagram of all the structural elements within the Quarantine Buildings refit 


\section{CONCEPT ITERATIONS}

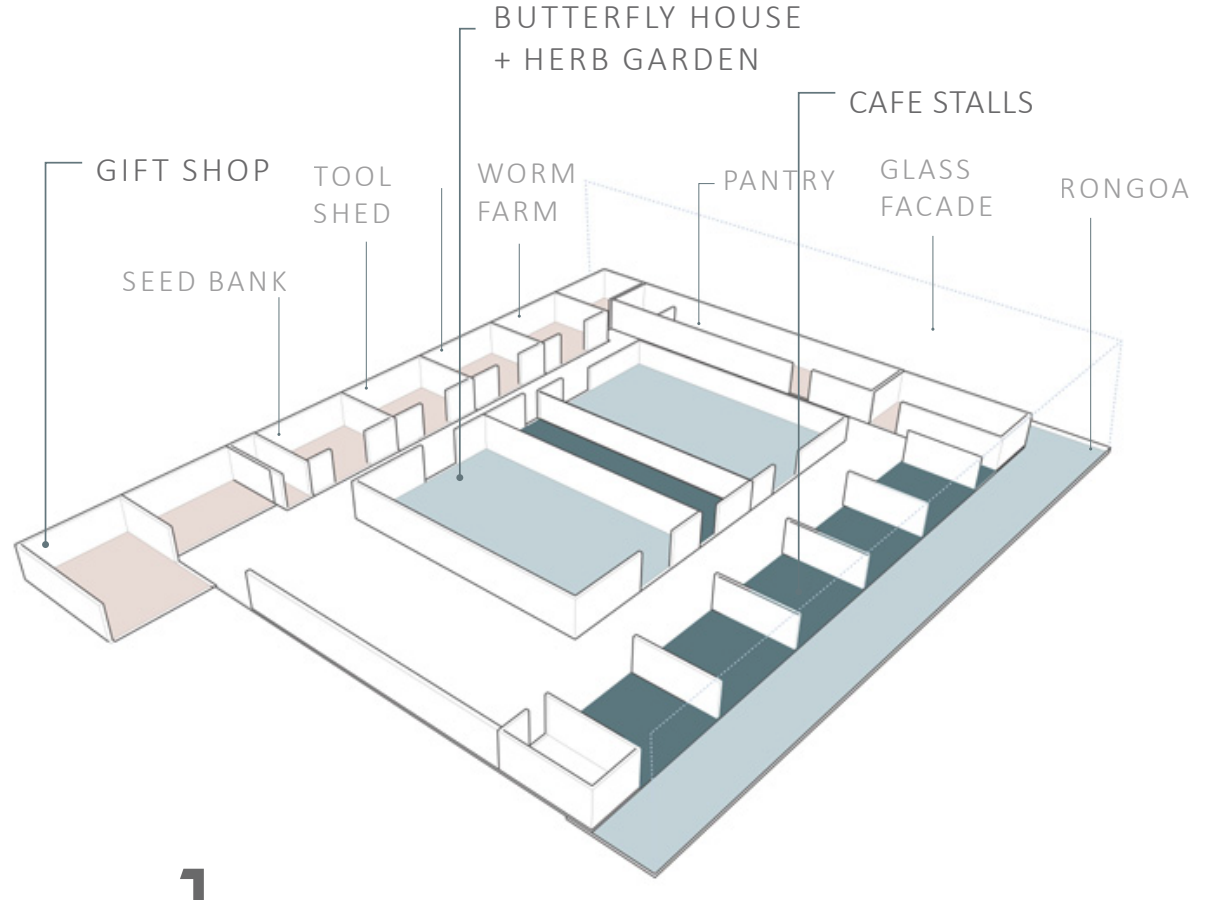

1. Playing with maintaining most of the interior walls without having to add any new ones to create functional spaces for the sharing of Rongoā.

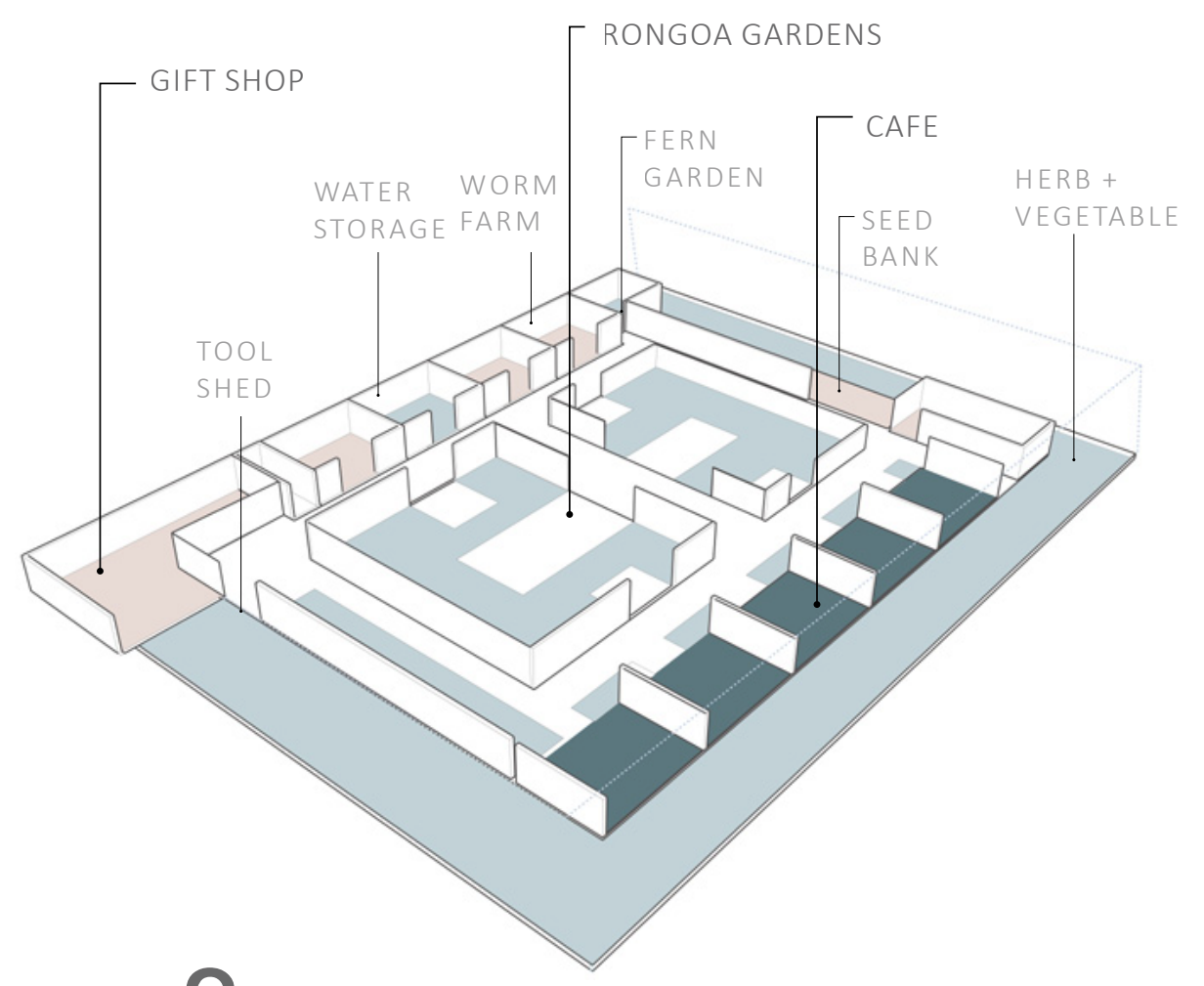

3. Testing the establishment of internal gardens to create the sense that the building is an extension of the sorrounding landscape.

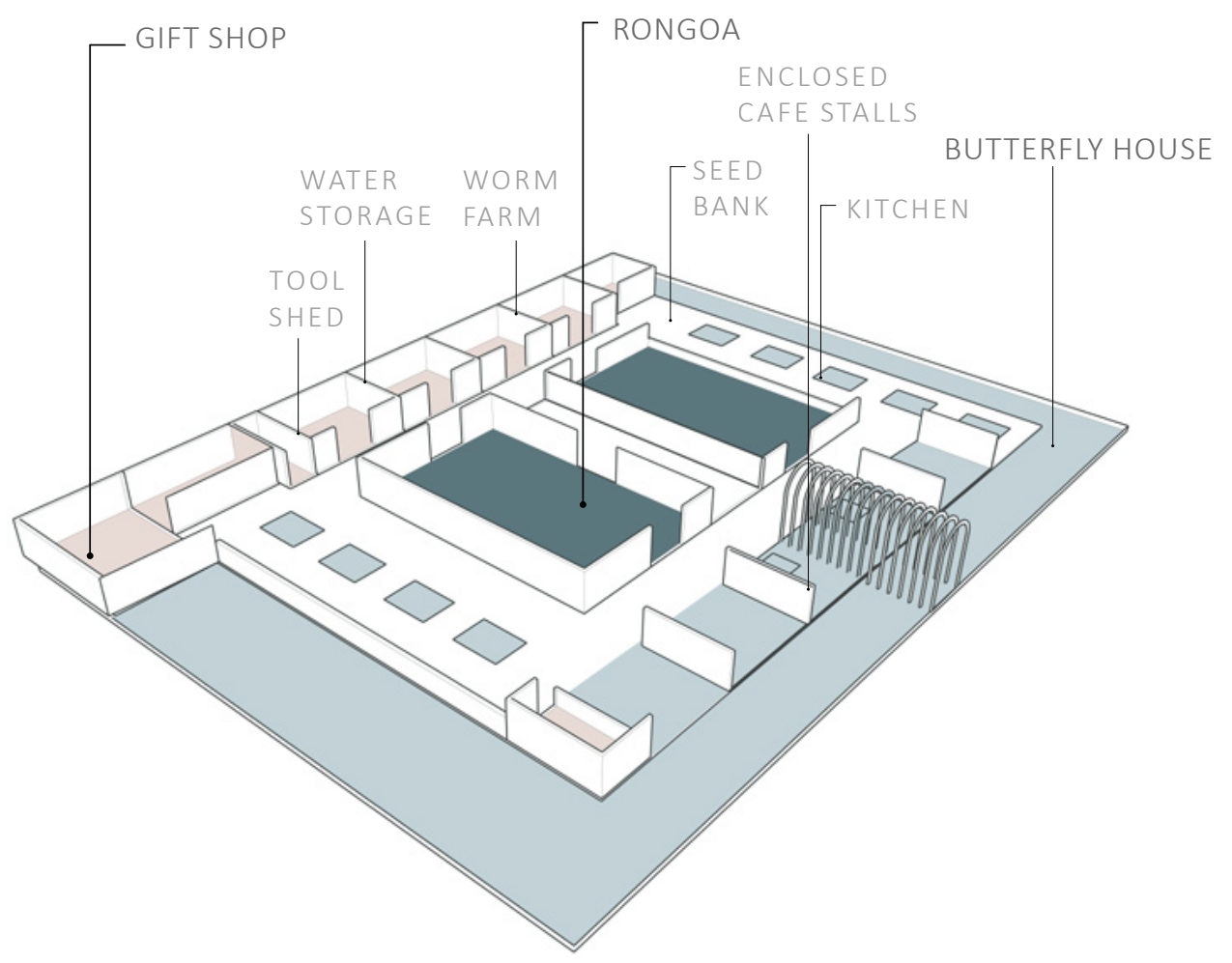

5 Creating an enclosed dining area that connects to a butterfly house so diners can have the unique experience of sitting amongst butterflies while they eat.

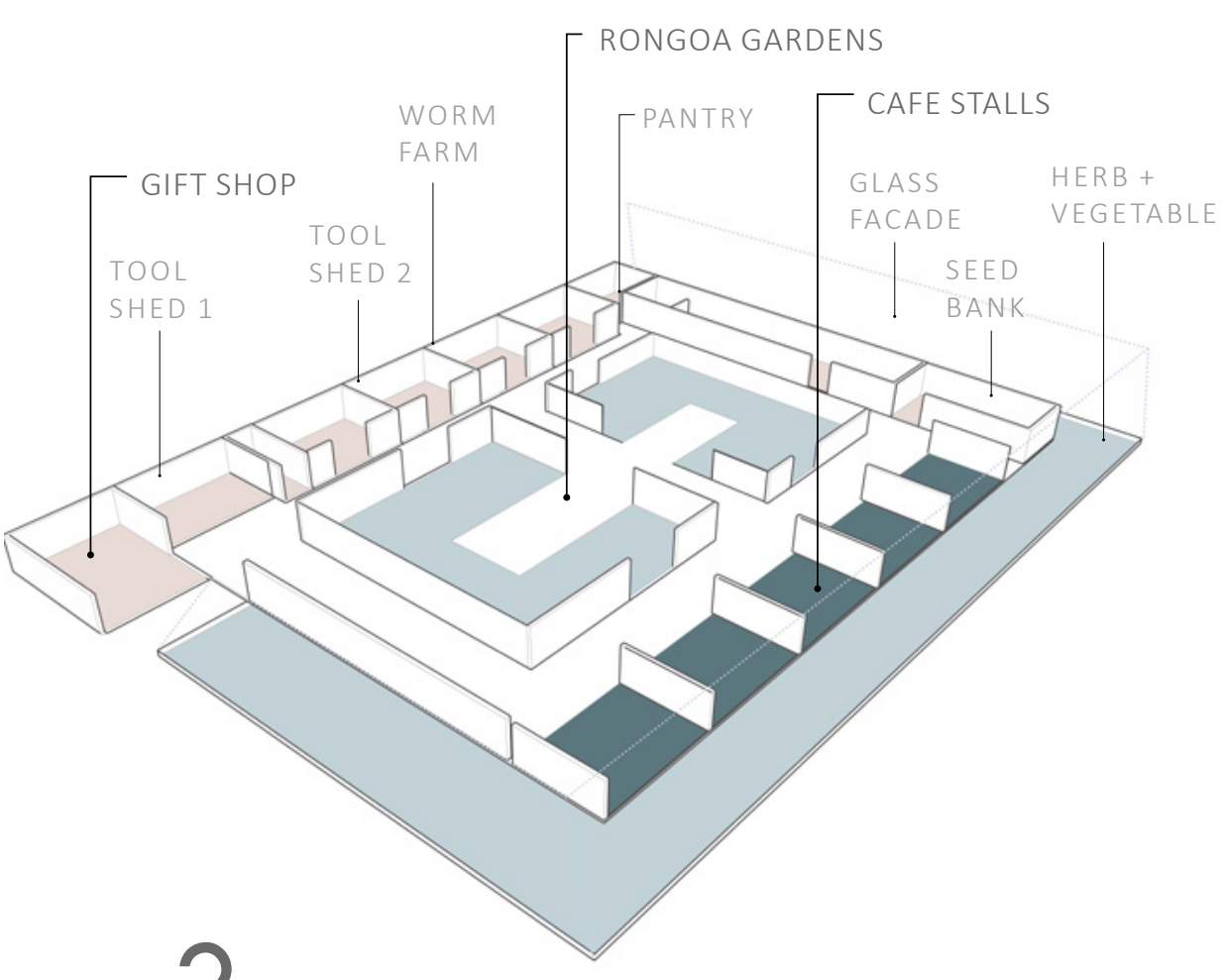

2 Playing with how the building can optimise the 360 degree views by opening up the North, West and East by using introducing glass walls instead of concrete.

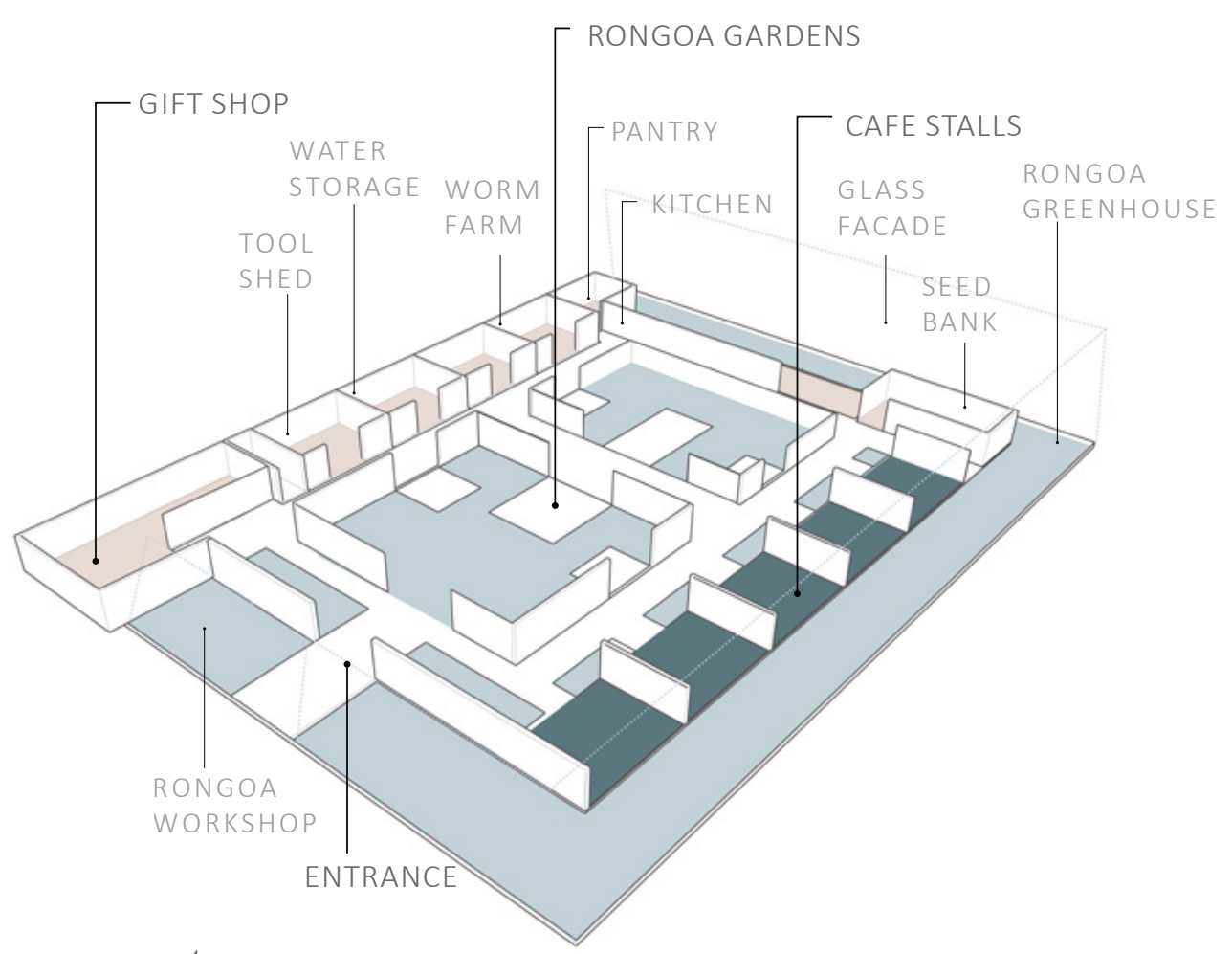

4. Manipulating the East walls of the building to create a grand entrance that provides views directly into the Rongoā gardens to entice visitors.

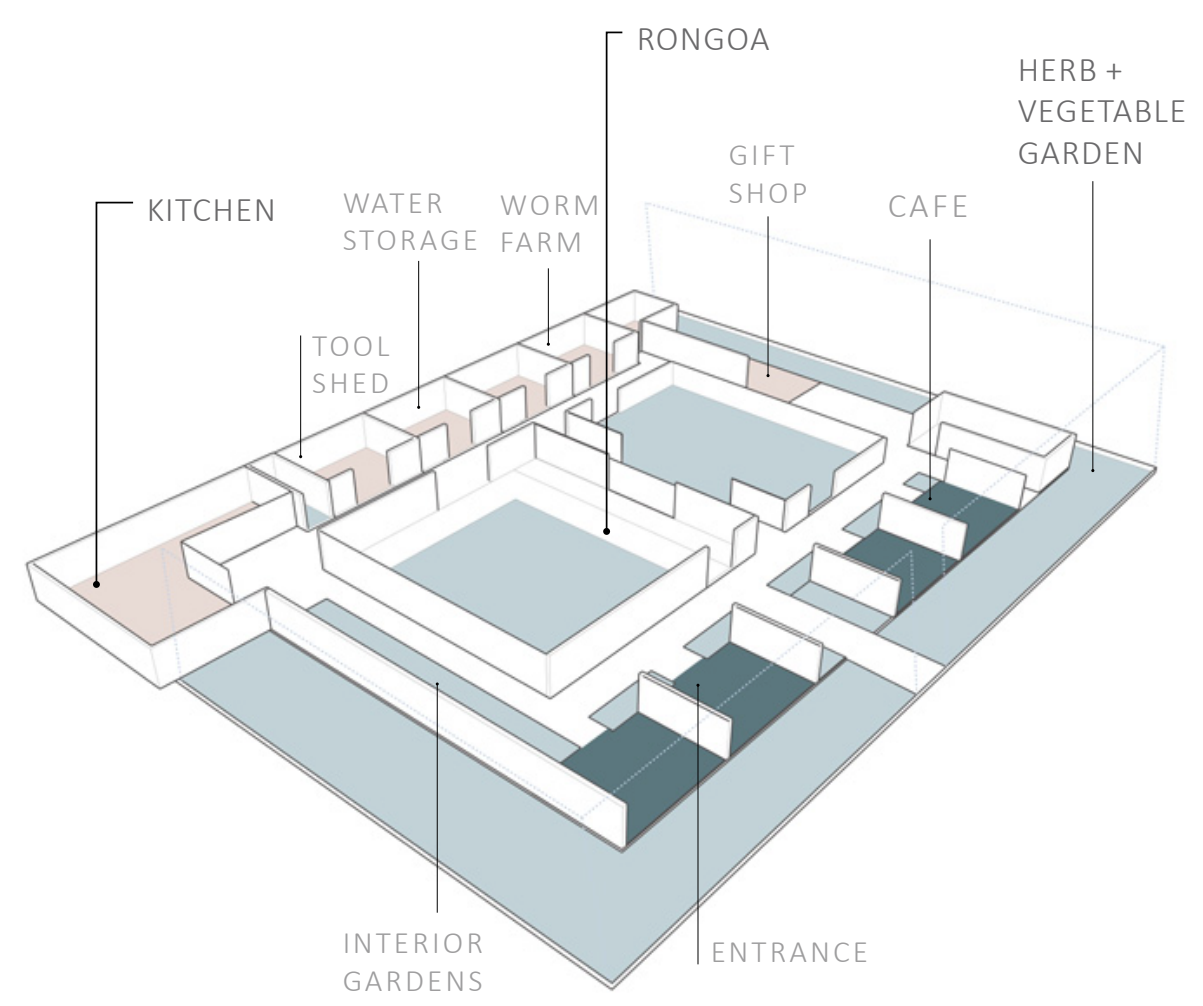

6 Repositioning the entrance to the Northern wall so it greets - visitors as they walk into the flat site, allowing them to immediately see the interior gardens and dining space. 


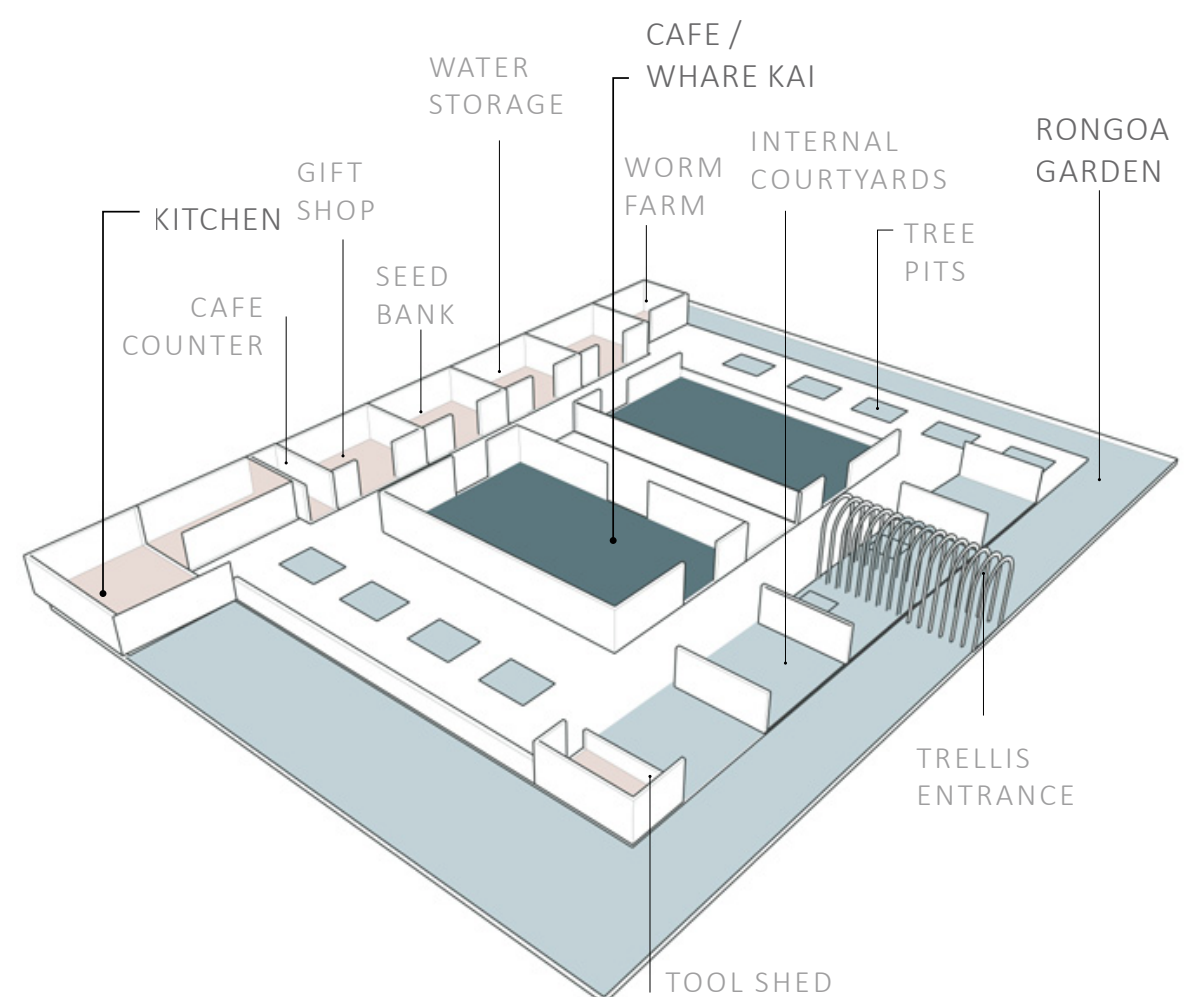

7 Exploring the potential of the entrance and connecting it with the main spine of the building to provide views and physical connections through the building.

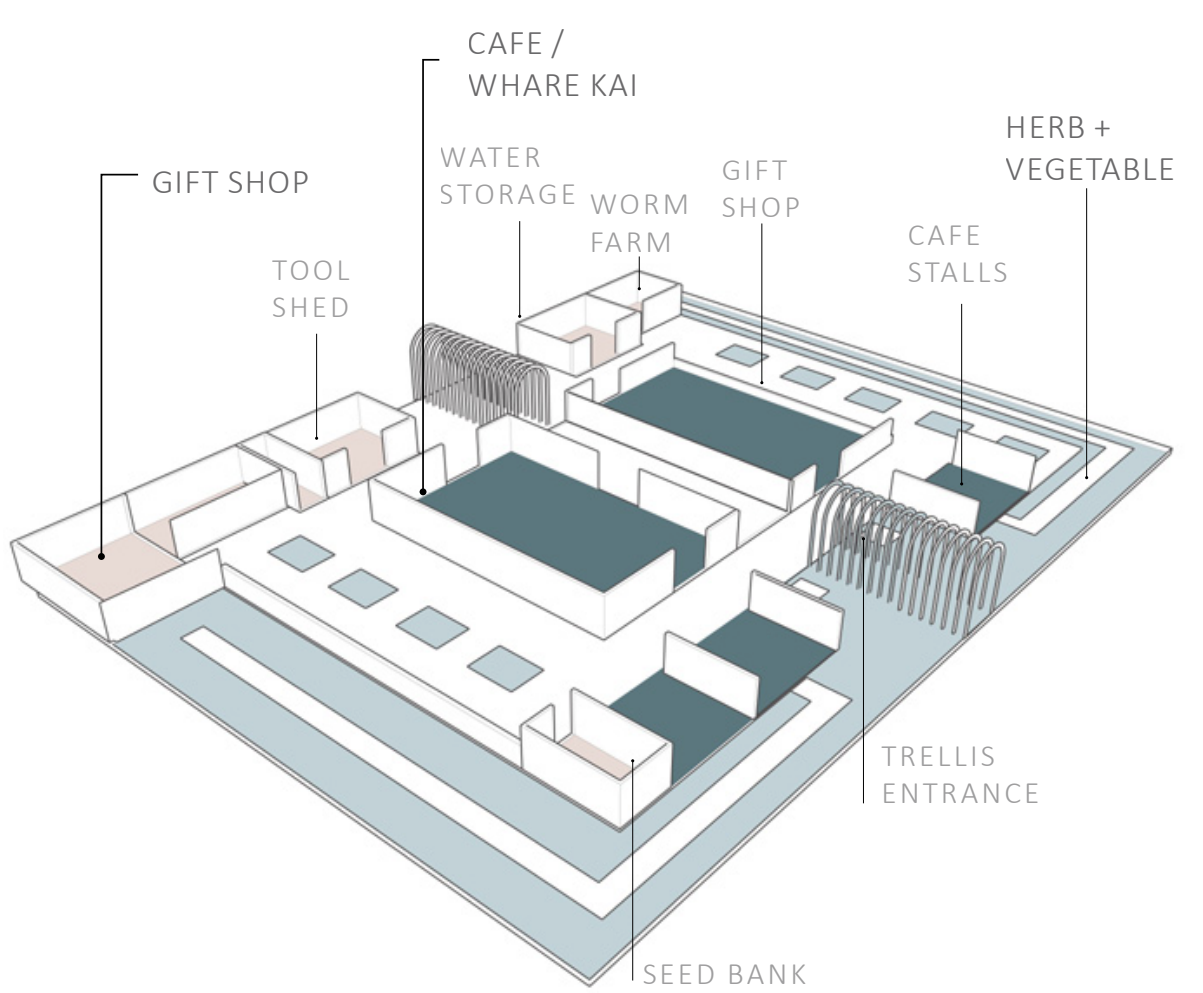

8. Looking at having two entrances creating connections to the main path and the marae area, creating a stronger visual axis through the building.

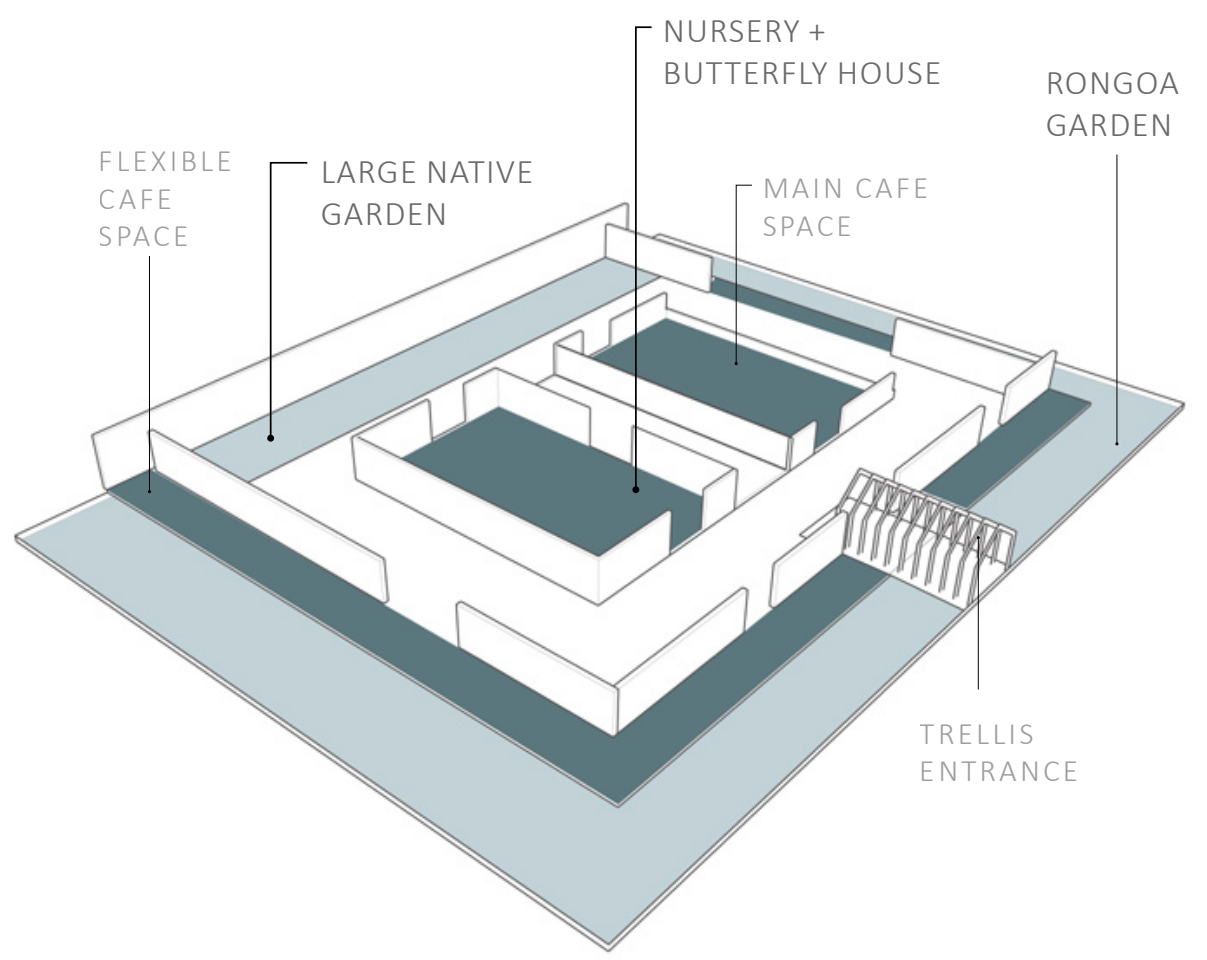

10 Playing with stripping the building right back by only having social and garden spaces, with the facility spaces moved to the surrounding buildings.

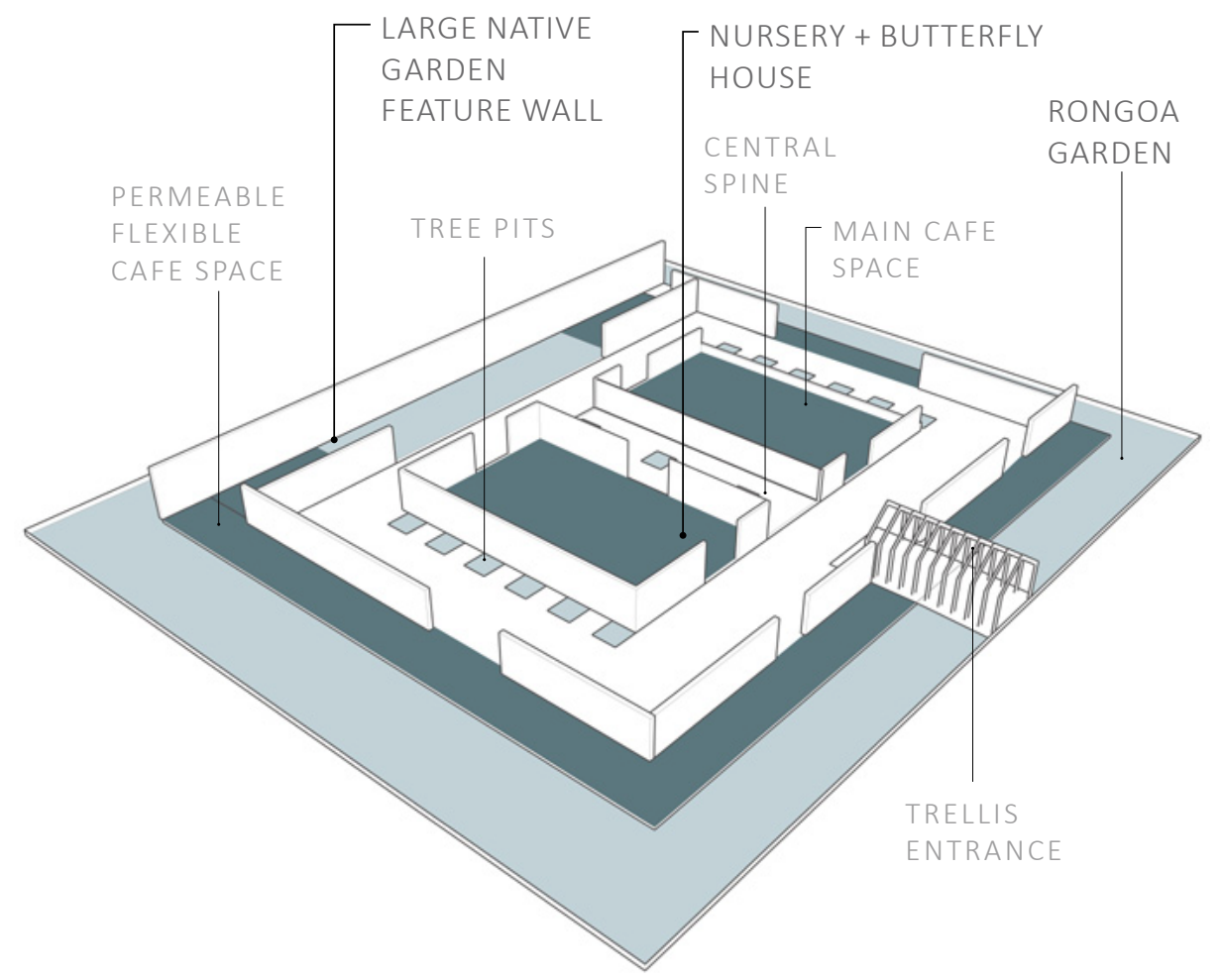

7 Looking at using as much of the interior space as possible - to create a greenhouse feel, while incorporating habitats for invertebrates, birds and reptiles.

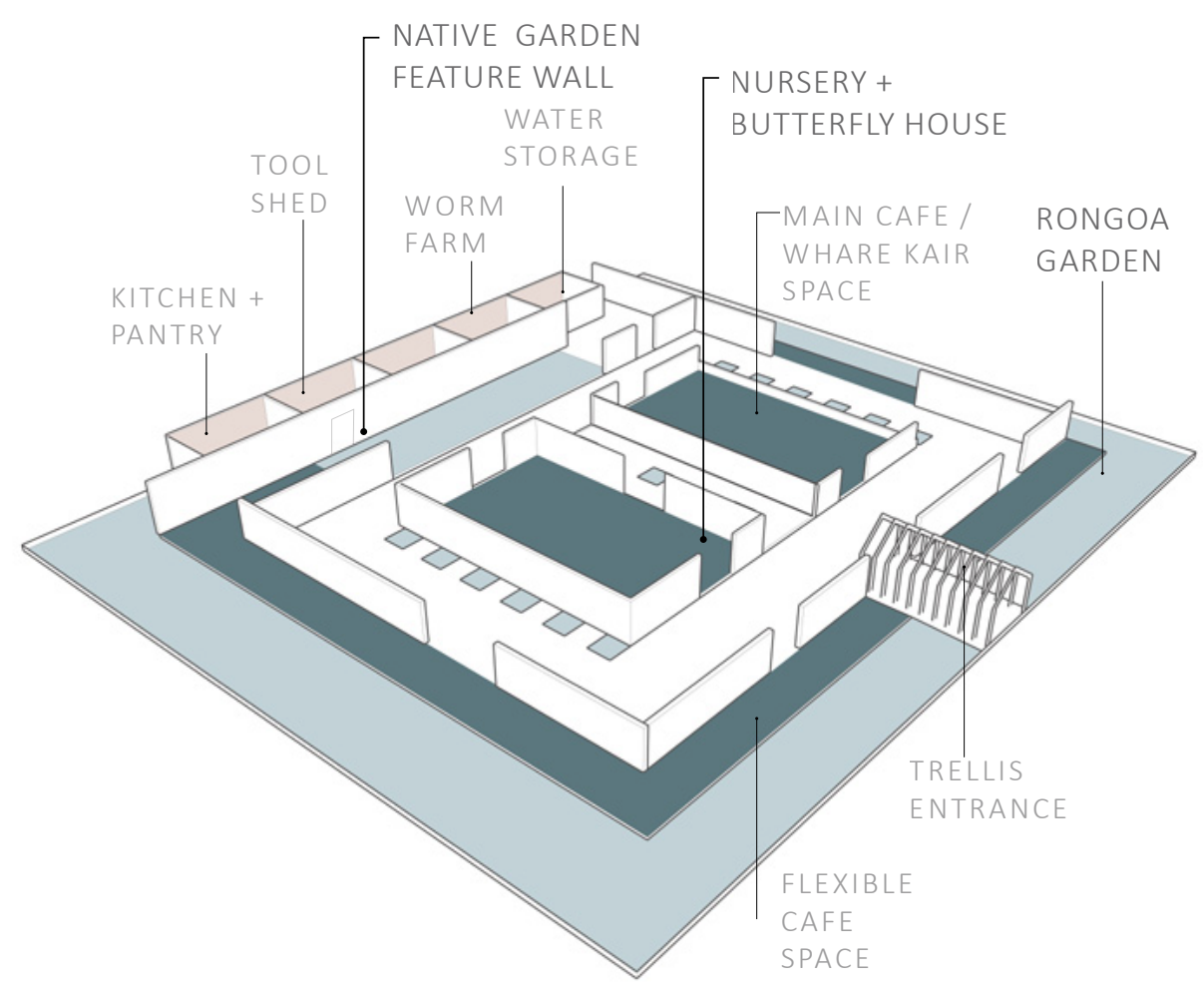

2 Creating a hybrid concept that combines the more functional iterations with the experiential ones by hiding the functional spaces out the back, allowing the main space to be dedicated to larger,open spaces for relaxing and socialising. 


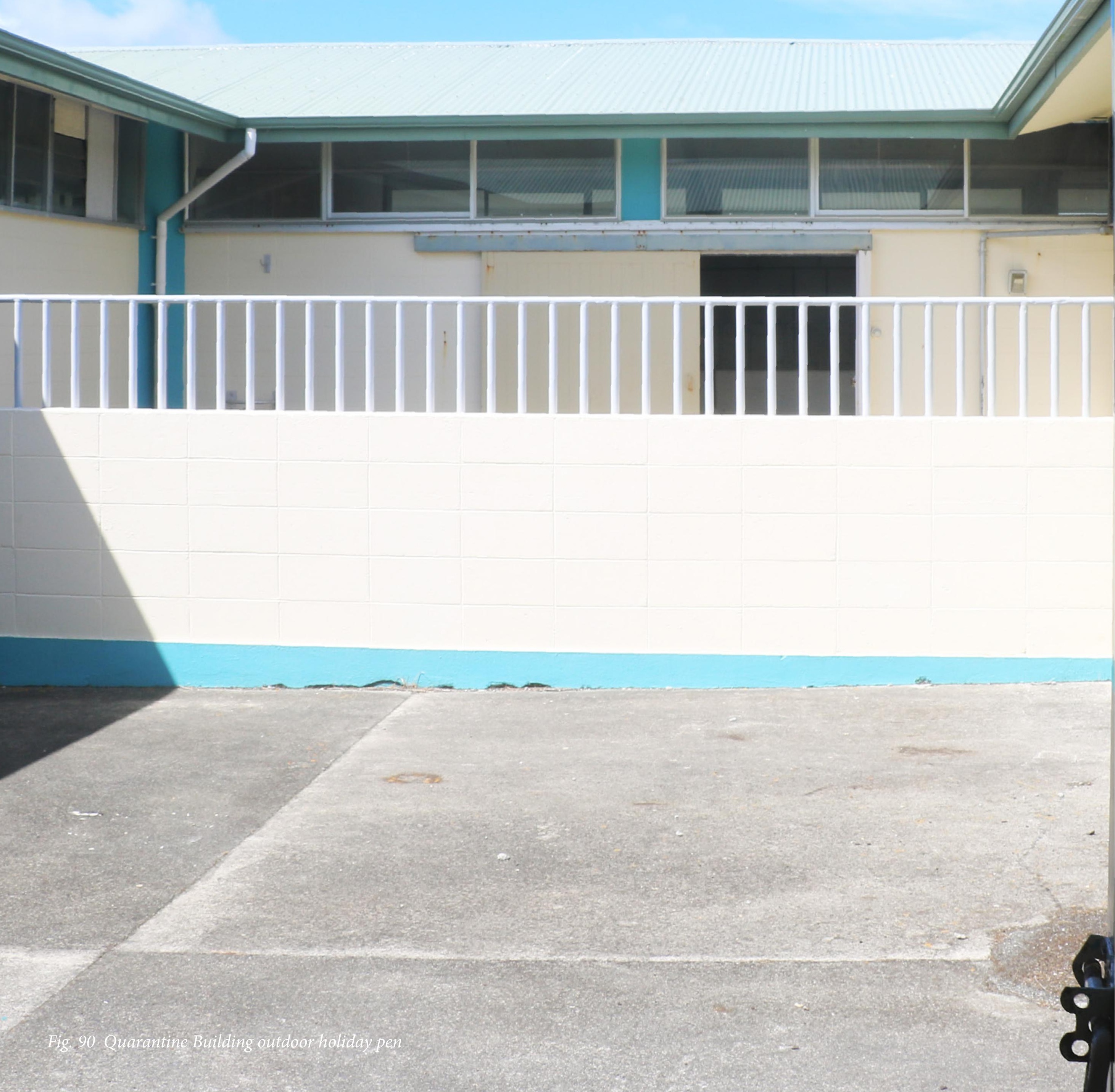




\section{REFLECTION}

The iteration process for this site looked at maintaining the existing shell structure of the building but altering the interior walls to create series of functional spaces inside. The purpose of this is to create a building that can house a range of different programmes relating to human health.

EXISTING LAYOUT: Iterations that maintained most of the existing rooms were unsuccessful as the current layout is complicated and overwhelming for visitors. The iterations that were most successful were ones that simplified the building layout to allow visitor to navigate easily through the space.

ADDED STRUCTURES: Iterations that tried to bring in added walkway structures, creating spaces for vines to grow, added an exciting element to the building but ultimately these were large, unnecessary structures that visually dominated the room and moved people's attention away from the Rongoā gardens.

UTILITY ROOMS: Most of the iterations placed the functional rooms (tool shed and worm farm room) on the south wall as this is the part of the building that would receive the least sun. This was successful as it kept them out of the way of guests but still close enough for gardeners to access easily.

HIERARCHY OF SPACES: Prioritising spaces was a difficult part of the iteration processes as the nursery, Rongoā garden, gift shop and cafe/Whare kai were all important spaces that visitors should be able to easily locate, however they could not all fit in the central space of the building. This was resolved by experimenting with different interior layouts of these spaces, examining the relationship of the spaces to one another to see which ones compositionally made sense. The cafe suited being near to the low lying plant gardens so that views out to the island, from diners tables, were not obstructed, where as the large feature garden suited being down the end of the main walkway, in the sight line of visitors as they first walked in. 


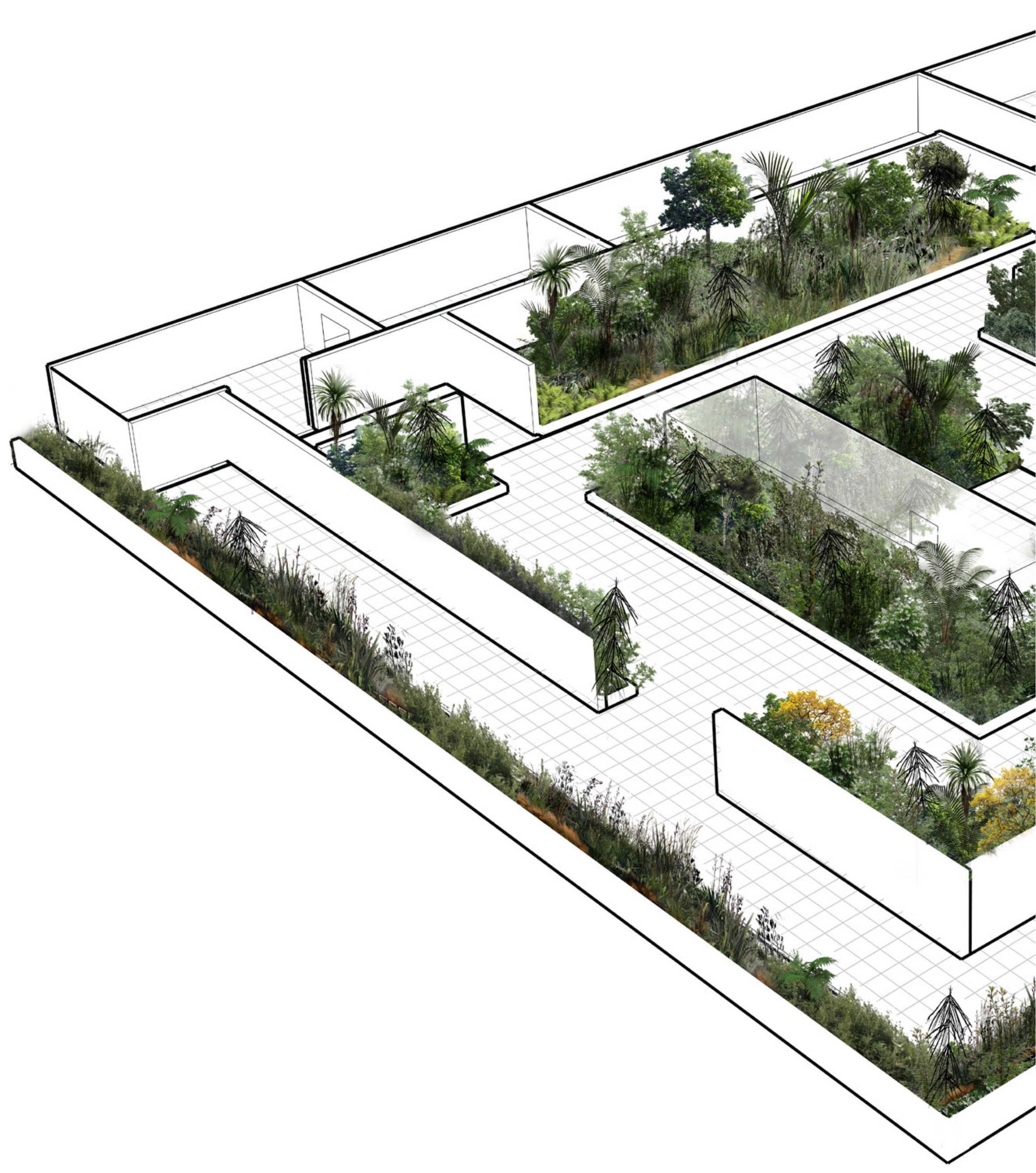




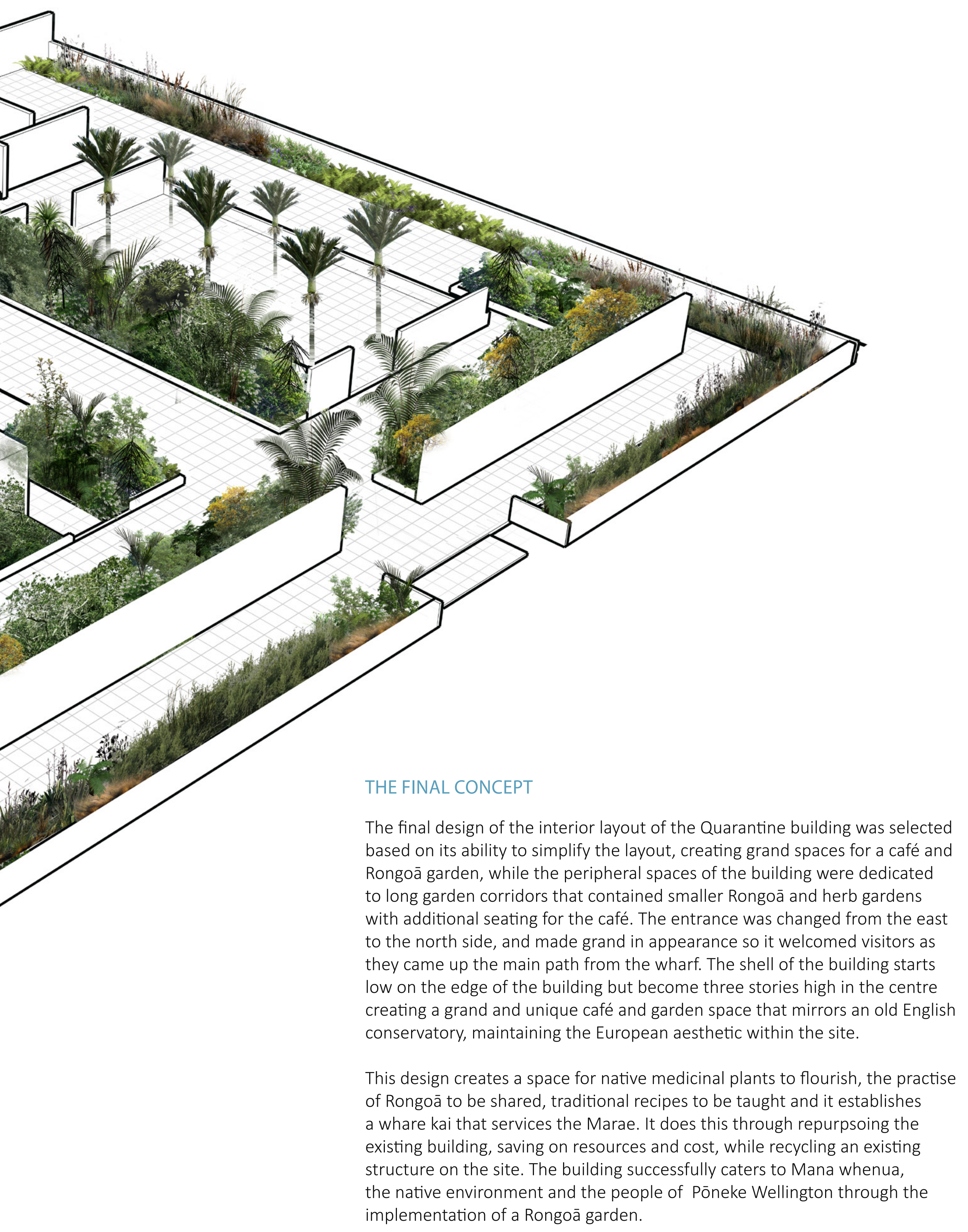



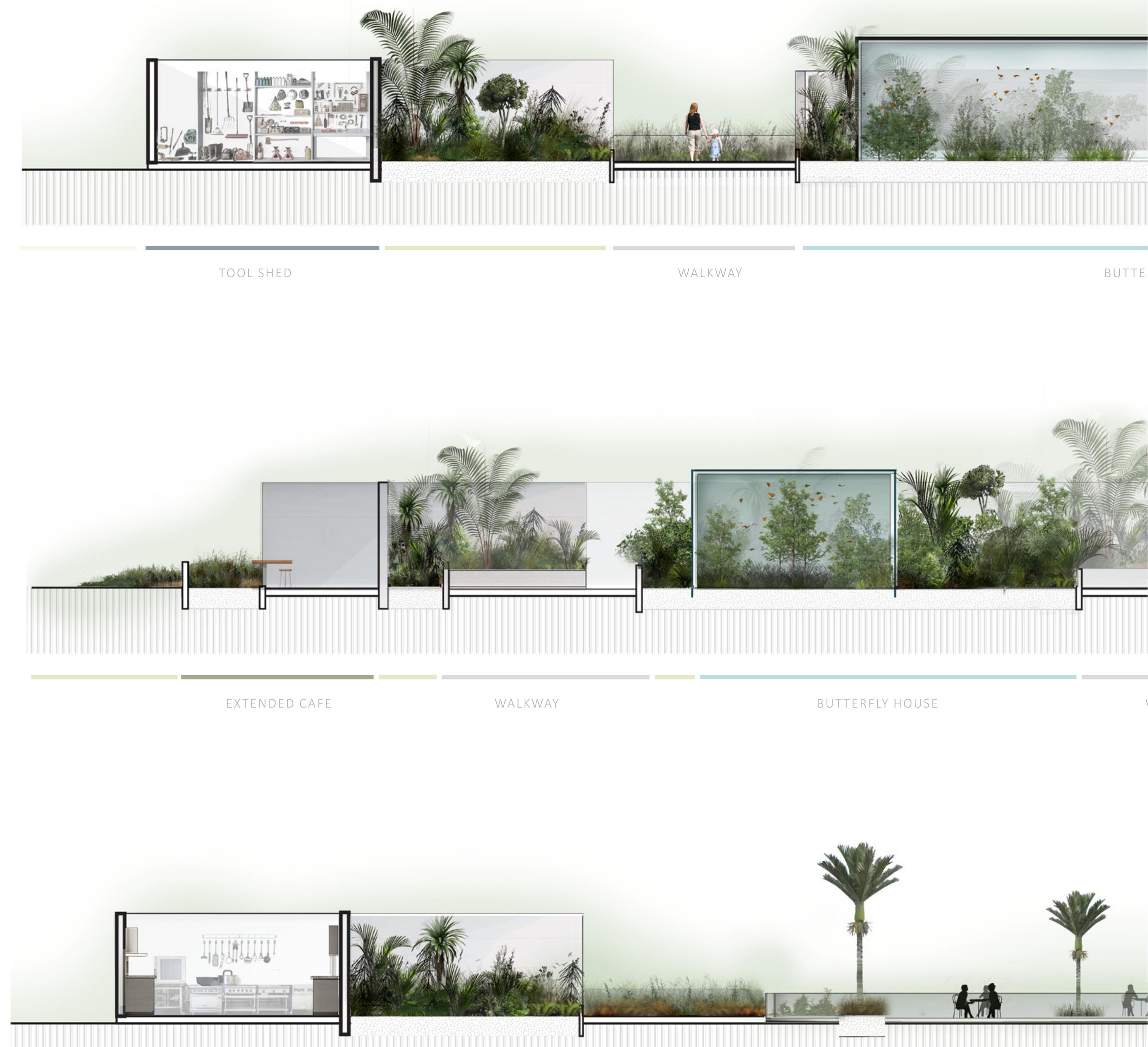


\section{FINAL CONCEPT}

\section{PROGRAM M E}

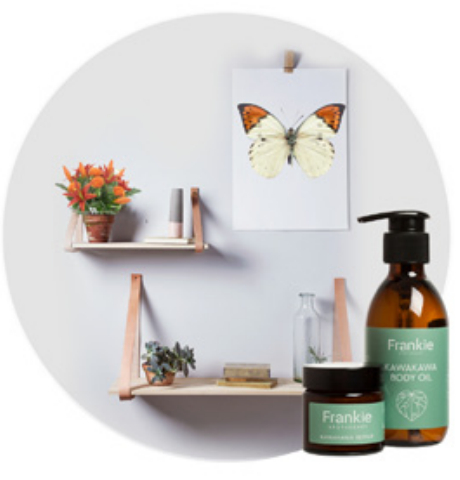

GIFT SHOP
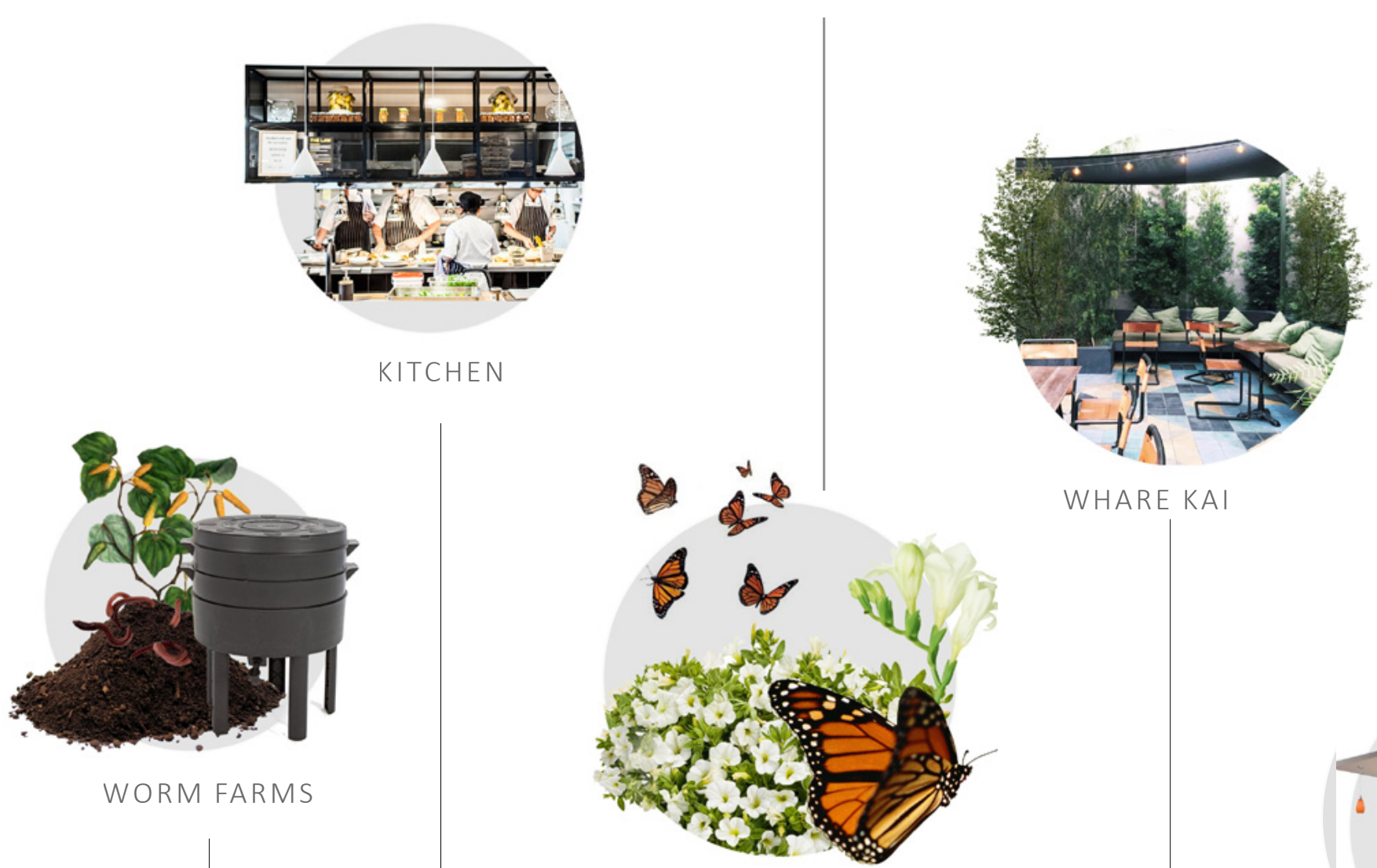

WHARE KAI

WORM FARMS
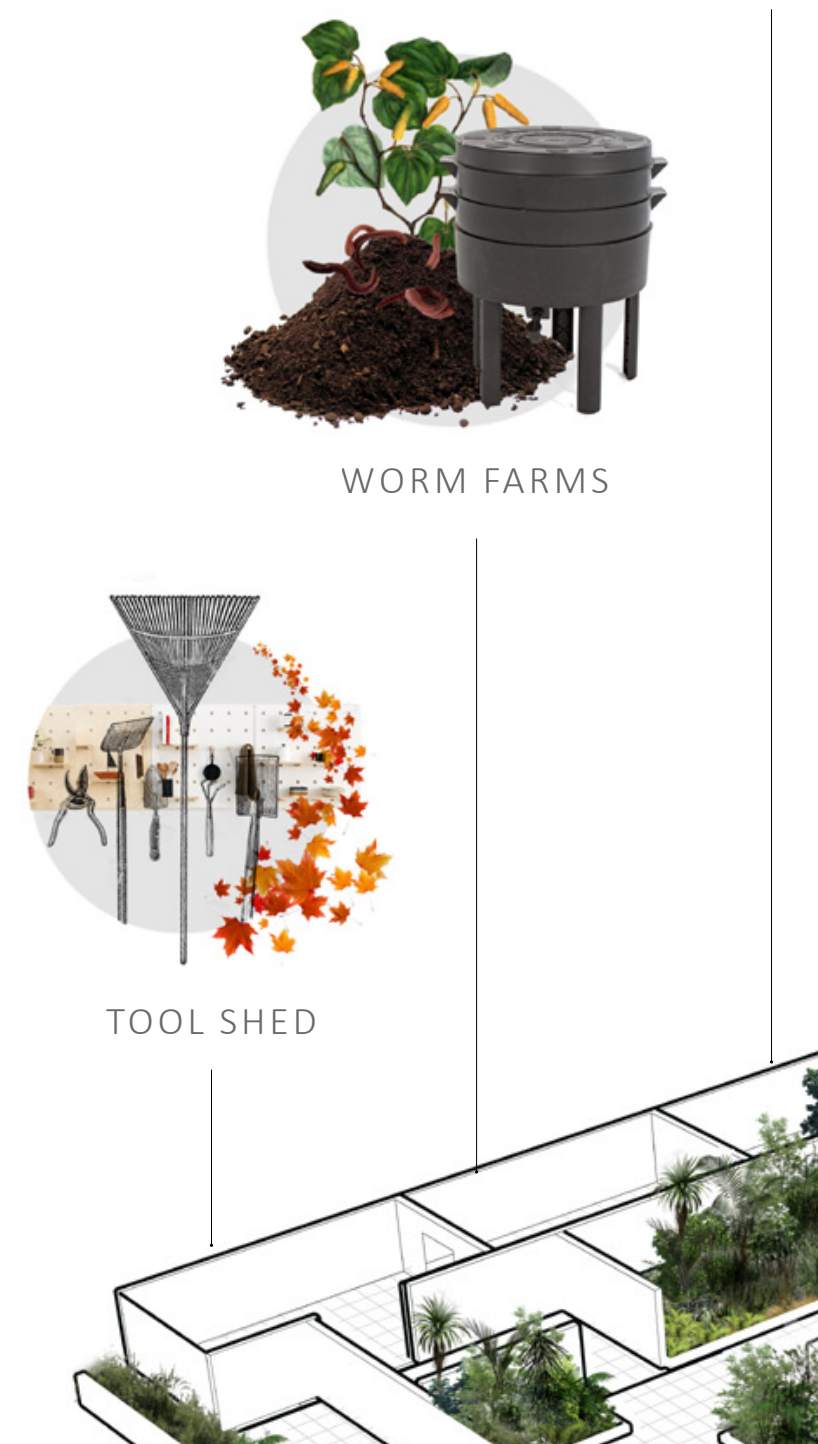

BUTTERFLY HOUSE

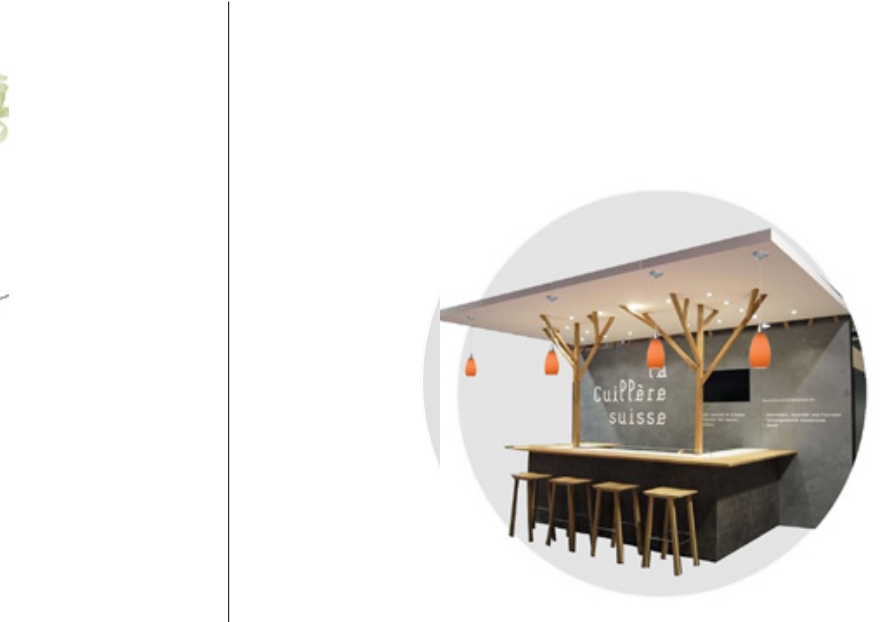




\section{FINAL CONCEPT}

\section{$P L A N T \mid N G$}

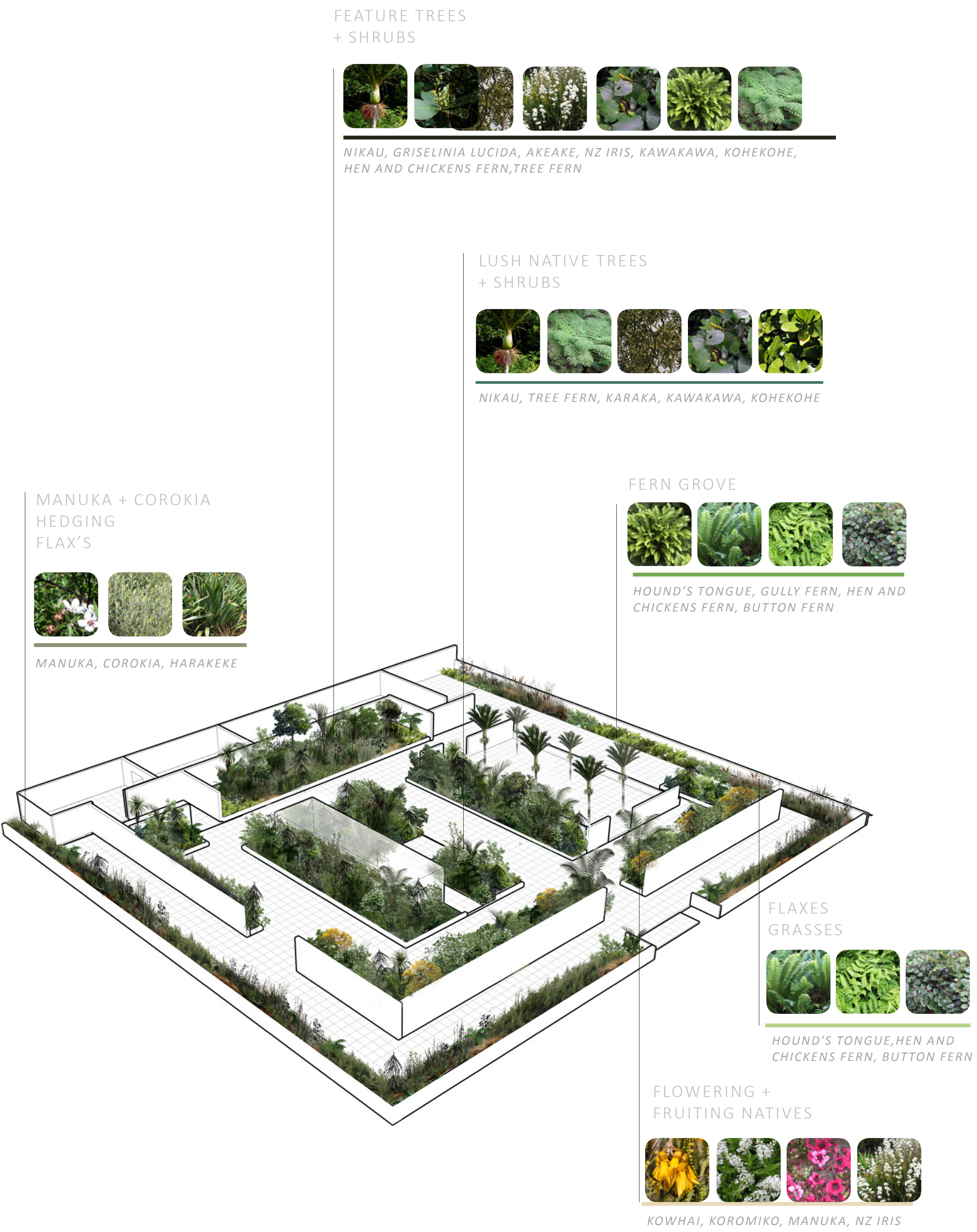




\section{SITE FOUR}

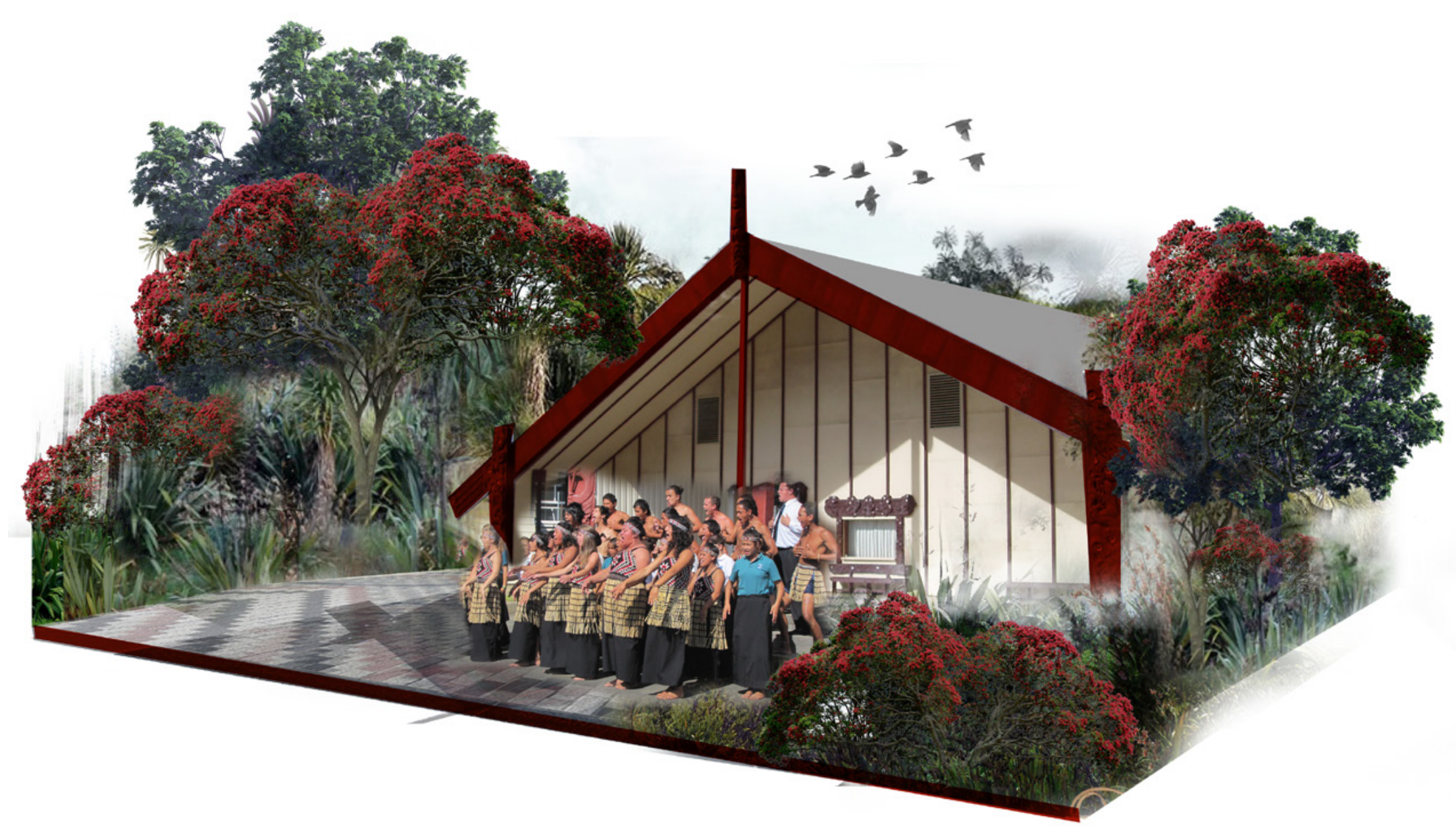

Fig. 97 The Peak Icon

\subsection{THE PEAK}

The flat space located in front of the quarantine building is a culturally significant site as it was once the Haowhenua Pā, one of two Pa's on the island. Although all the European sites on the island have information boards providing an overview of the history of each site, the Pã site is not recognised or sign posted, which means visitors do not know that the site once housed Iwi. The path that leads visitors from the Pa site to the highest peak on the island is steep and uneven, making it hard for young children and elderly to use it. The peak provides visitors with a 360-degree view to Pōneke Wellington and Petone, making it the most appreciated site on the island. Apart from the views, the space recreationally has little to offer with a few picnic benches and a flat lawn space. While the views meet visitor's expectations, the actual peak itself is a barren space. All of these spaces have the potential to be optimsed and create activities based around this unique viewpoint while speaking of its past as a significant Pā in Pōneke Wellington. 


\section{OB.JECTIVES}

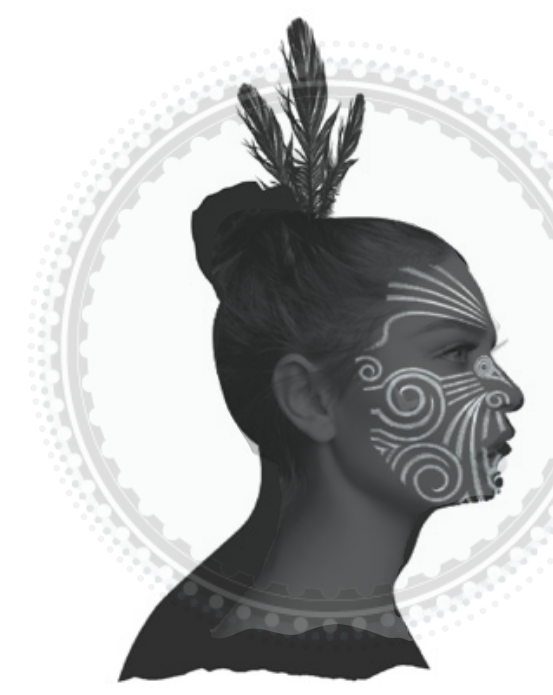

Create a Māori presence on the Island

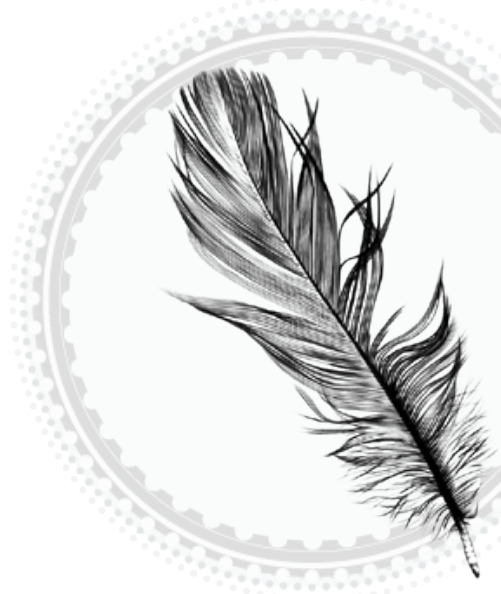

Retell important contextual narratives

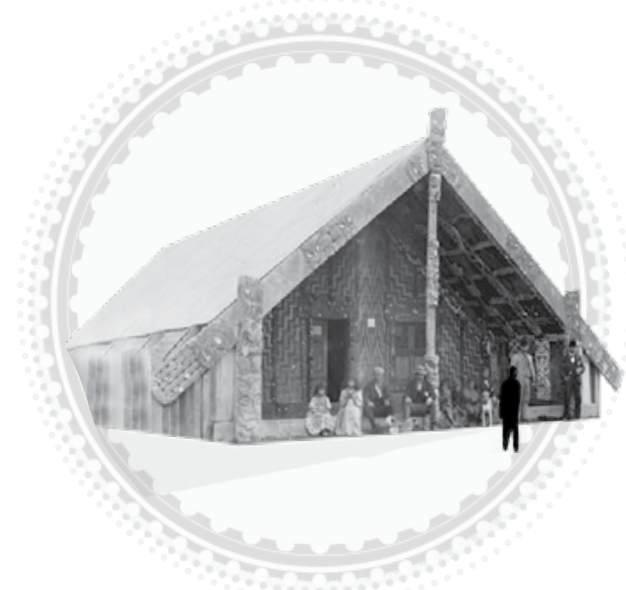

Create educational spaces that immerses people in Māori culture 


\section{FOCUSED SITES}

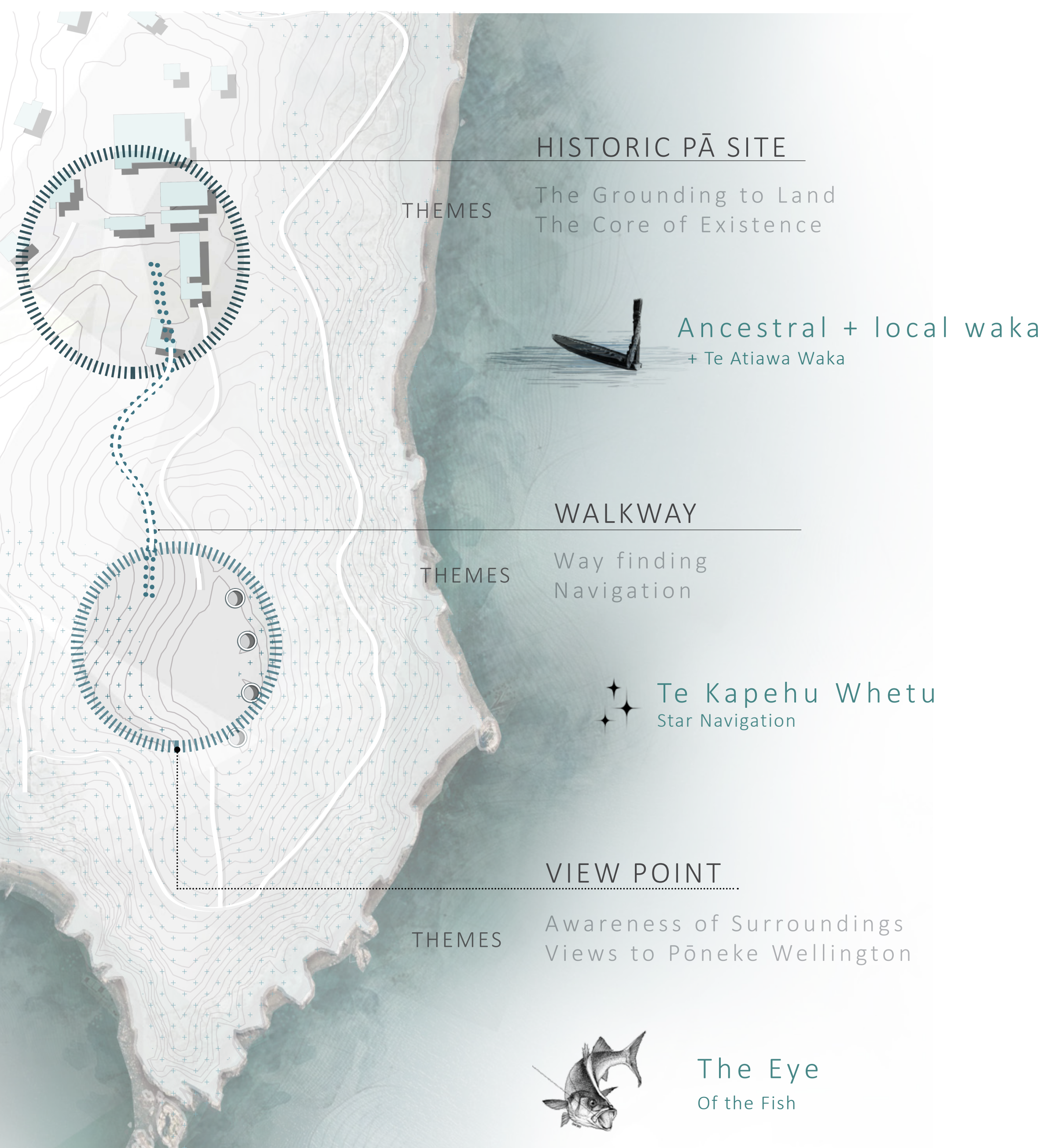




\subsection{WAKA INFLUENCE}

Waka not only brought Māori to Matiu Island but to Aotearoa. They are what grounded Māori to Aotearoa New Zealand's soil and they are at the core of Aotearoa New Zealand's cultural history. The Taranaki Whānui in Pōneke Wellington have 5 significant Waka that will be recognised within this site.

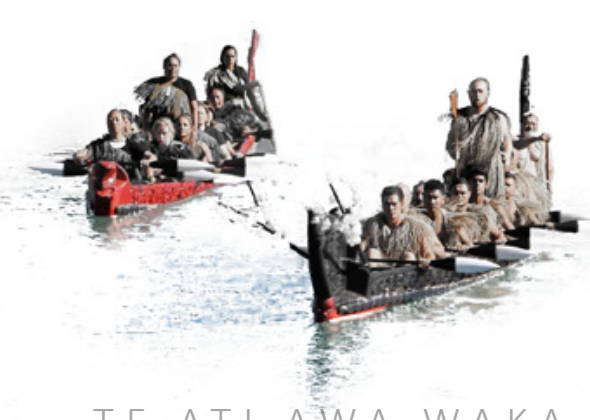

TE ATI AWA WAKA

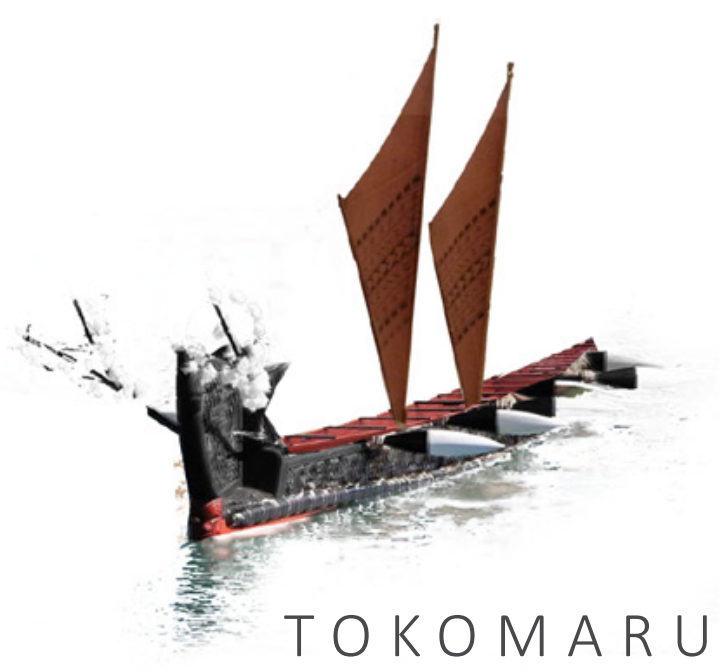

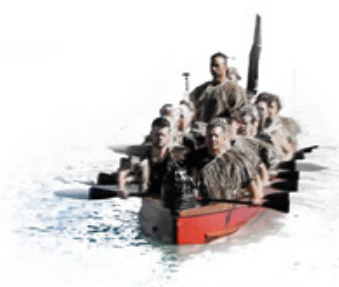

TE ATI AWA WAKA

WAKA FORMATIONS

MARAE

MARAE ATEA
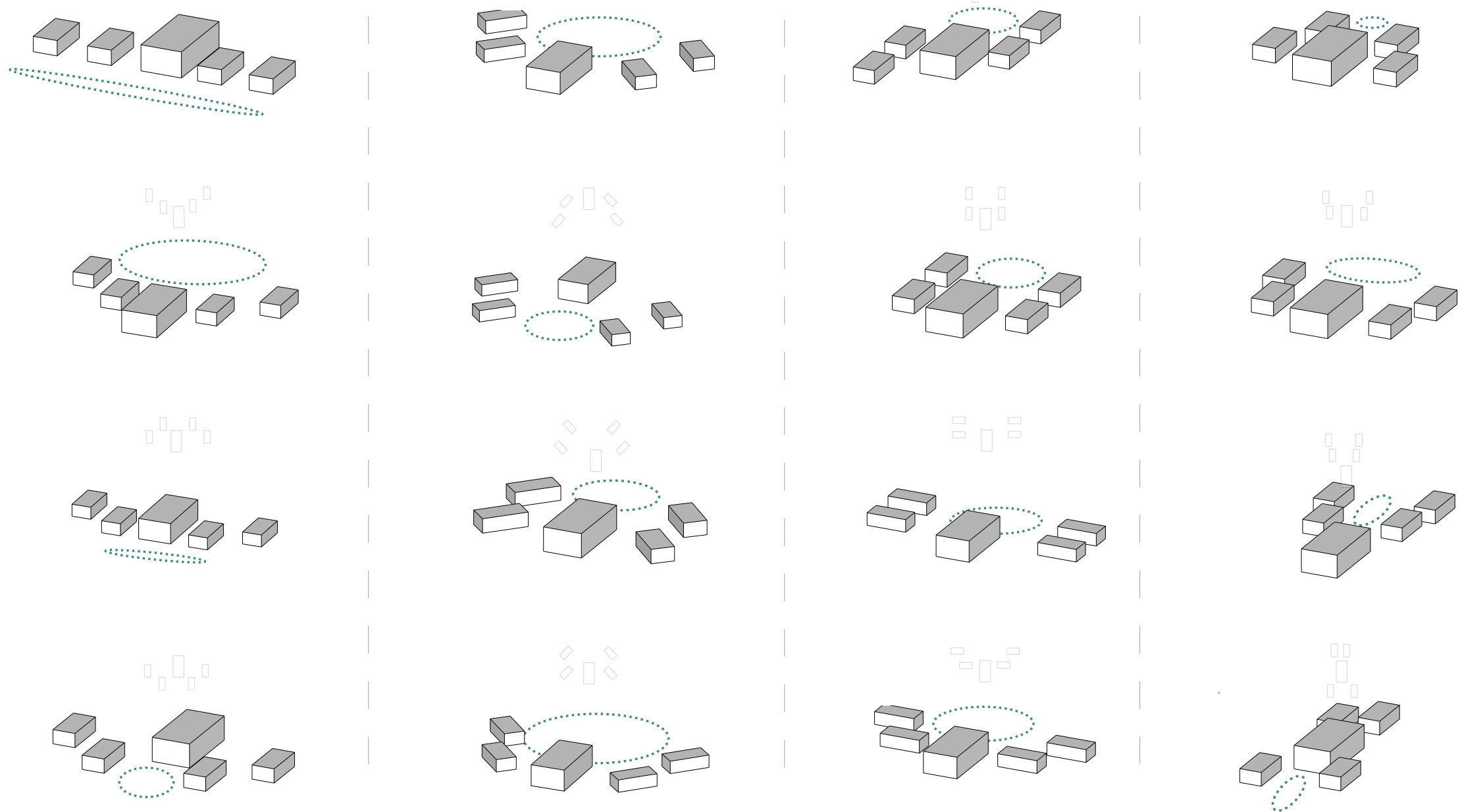

Fig. 100 Waka infuenced Marae concept exploration

\section{CONCEPT}

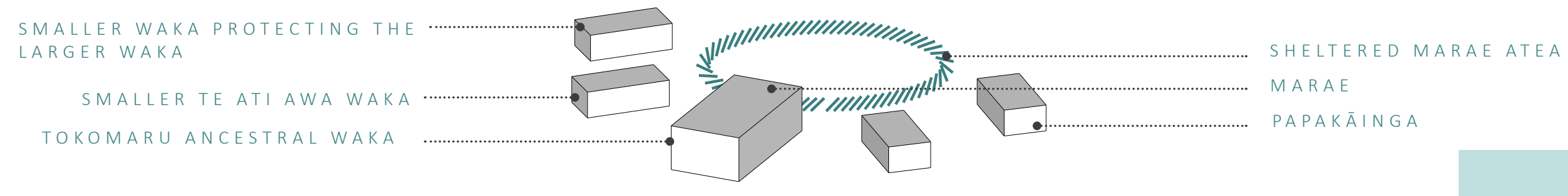




\section{CONCEPT ITERATIONS}
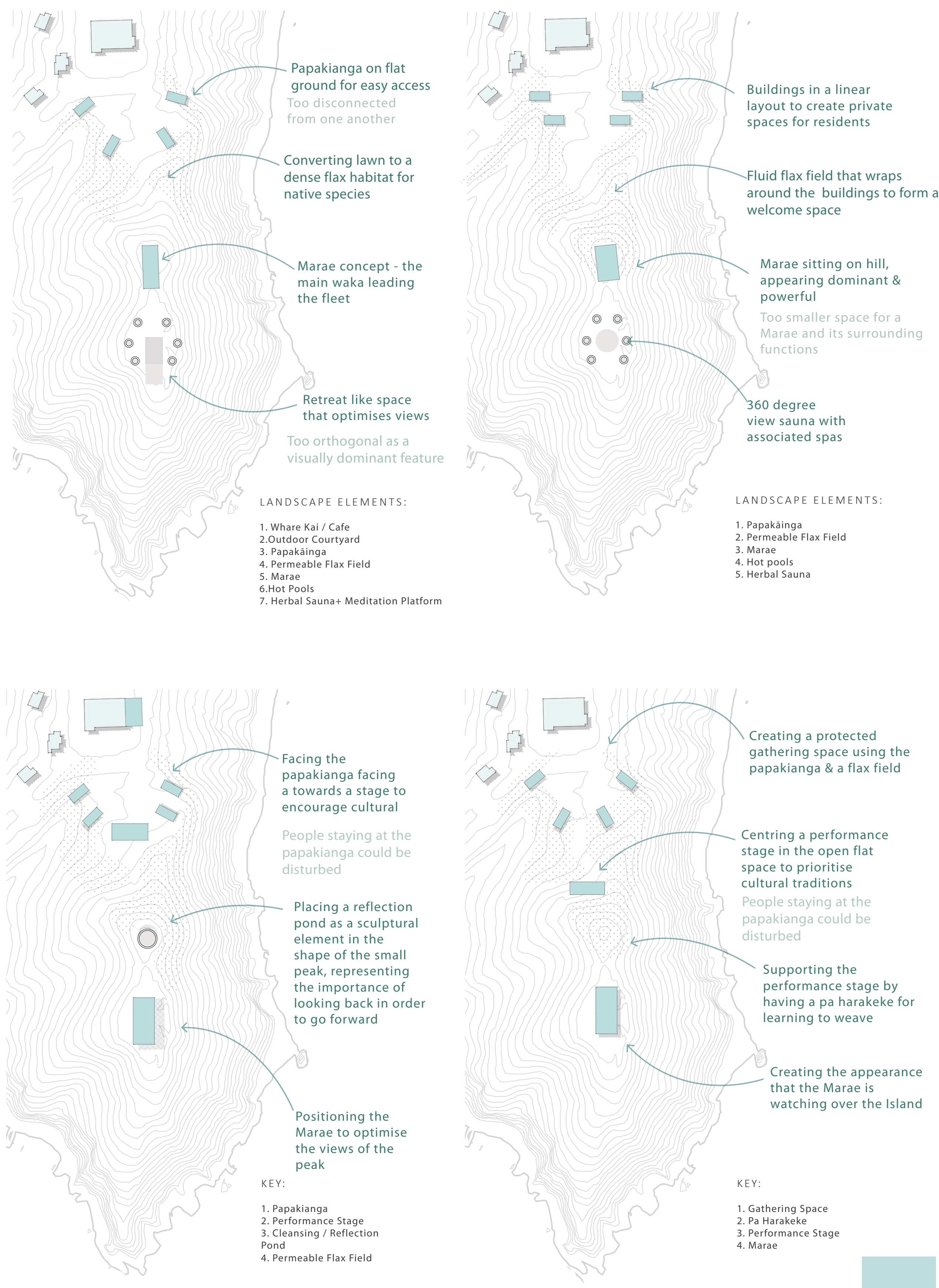

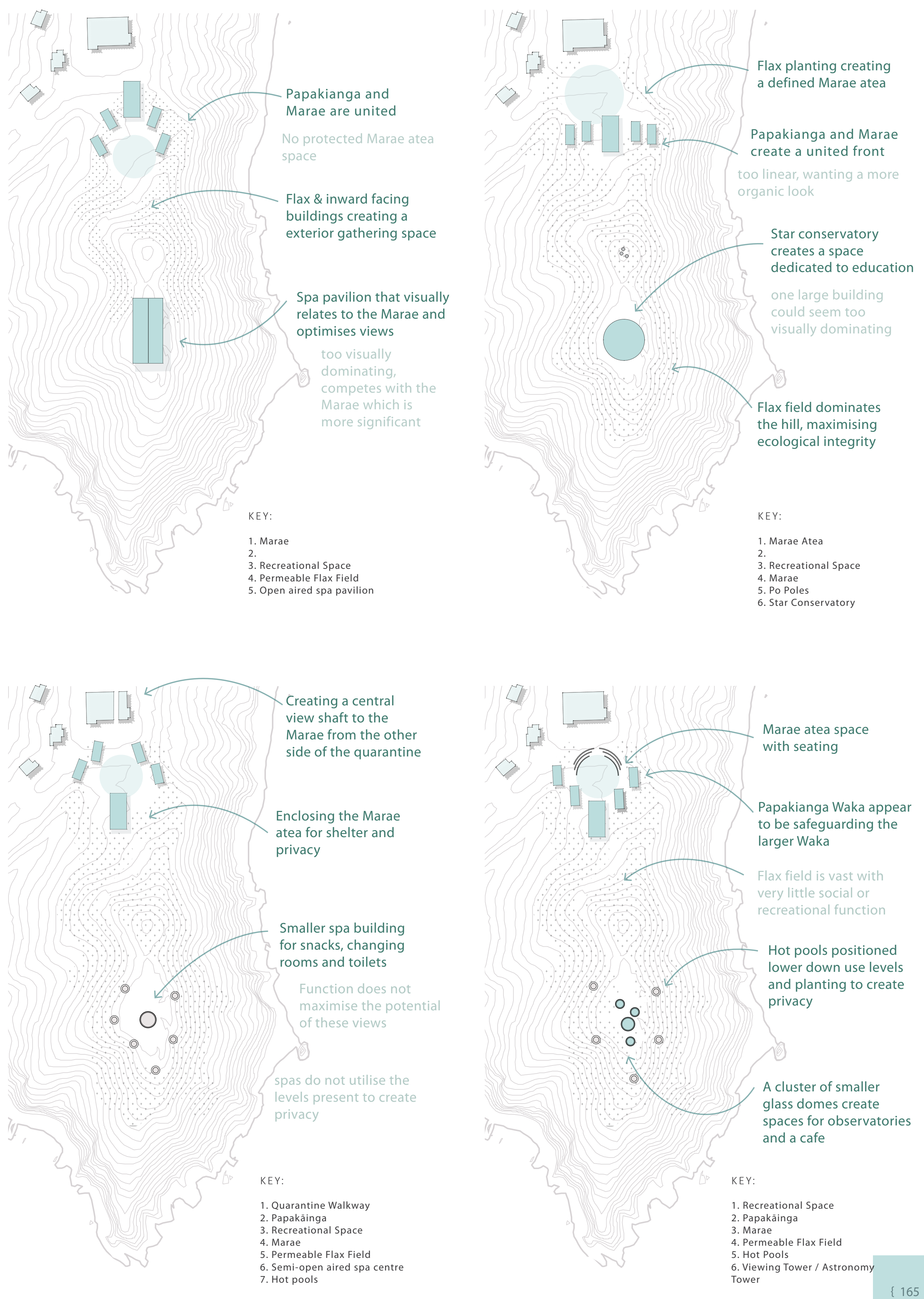

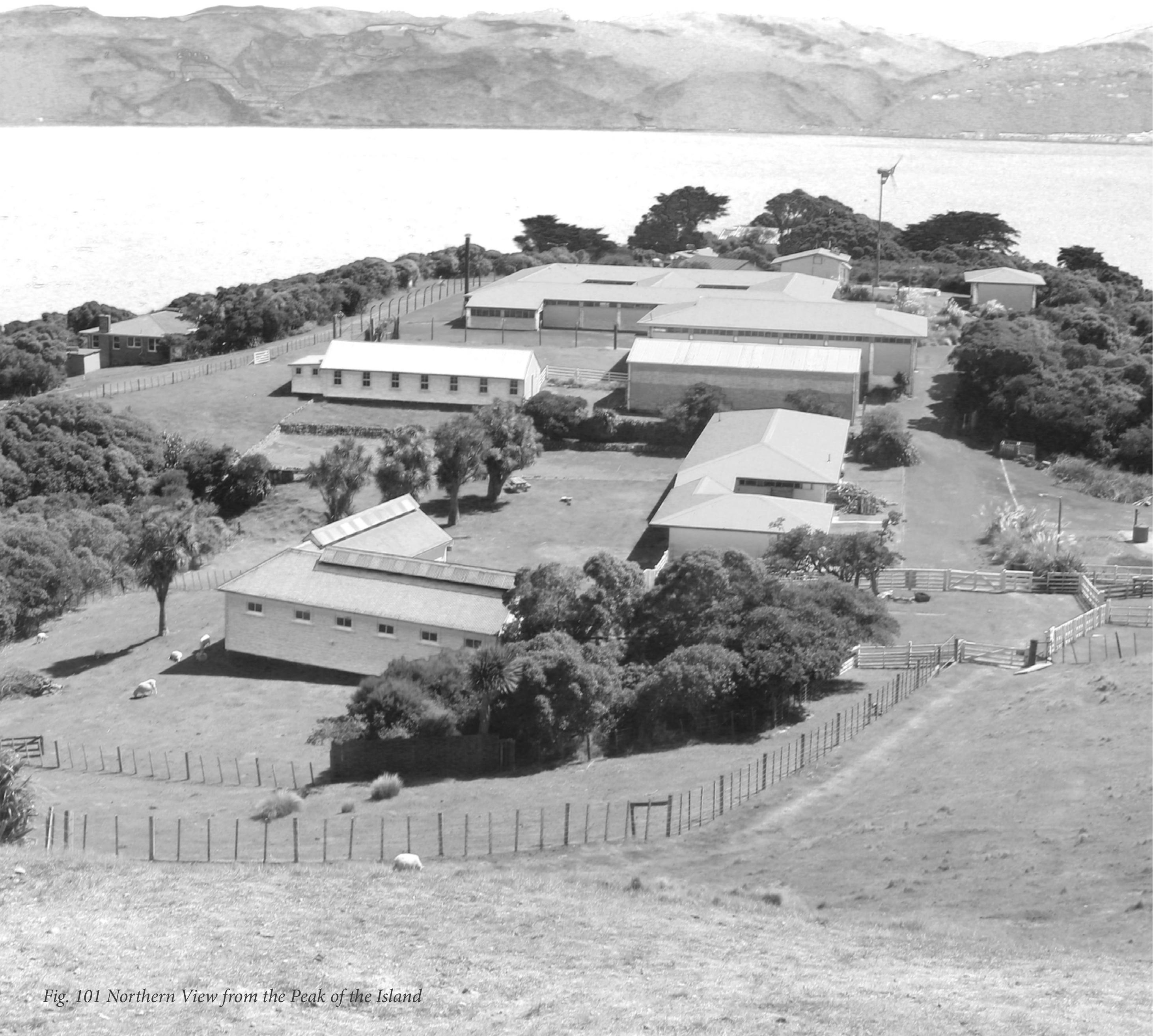


\section{REFLECTION}

The iteration process for the Pã focused on reinstating the site as a base for Iwi, allowing them to gather on the island and carry out important traditions and practises, and therefore honouring its past as a settlement site.

The iterations explored the spatial configuration of a marae that took the shape of a fleet of waka. The Tokomoaru represented the marae and the smaller waka represented significant Taranaki Whānui Waka, creating the Papakāinga for short term stays on the Island. Many of the iterations failed to create a sheltered marae atea/welcome area which is a necessity for the highly exposed site. Formations of waka that surrounded the marae atea space, sheltering guests, were most successful. These concepts also explored how the site could house large groups for powhiri. Based on the Kura Whare case study, some iterations explored natural grass terracing as a way to provide natural seating for elderly and children.

The concepts that explored the design of the peak used narratives that complimented the marae's Waka narrative, to try and create produce one cohesive space. These iterations played with ways in which planting could create the apperance of a rippling affect on the peak. Planting that followed the shape of the contours created a more flowing, natural look, compared to mass planting over the whole site.

The peak of the island was the space that was diversely explored due to the opportunity to optimise views and create a space for relaxation. Options including a star watching tower, hot pools, meditation deck, Yoga studio, café and establishing a marae were analysed. Due to the exposed nature of the space and its visibility from Pōneke Wellington and Petone, the iterations that looked at smaller structures were more successfully from a functional and visual point of view. 


\section{FINAL CONCEPT}

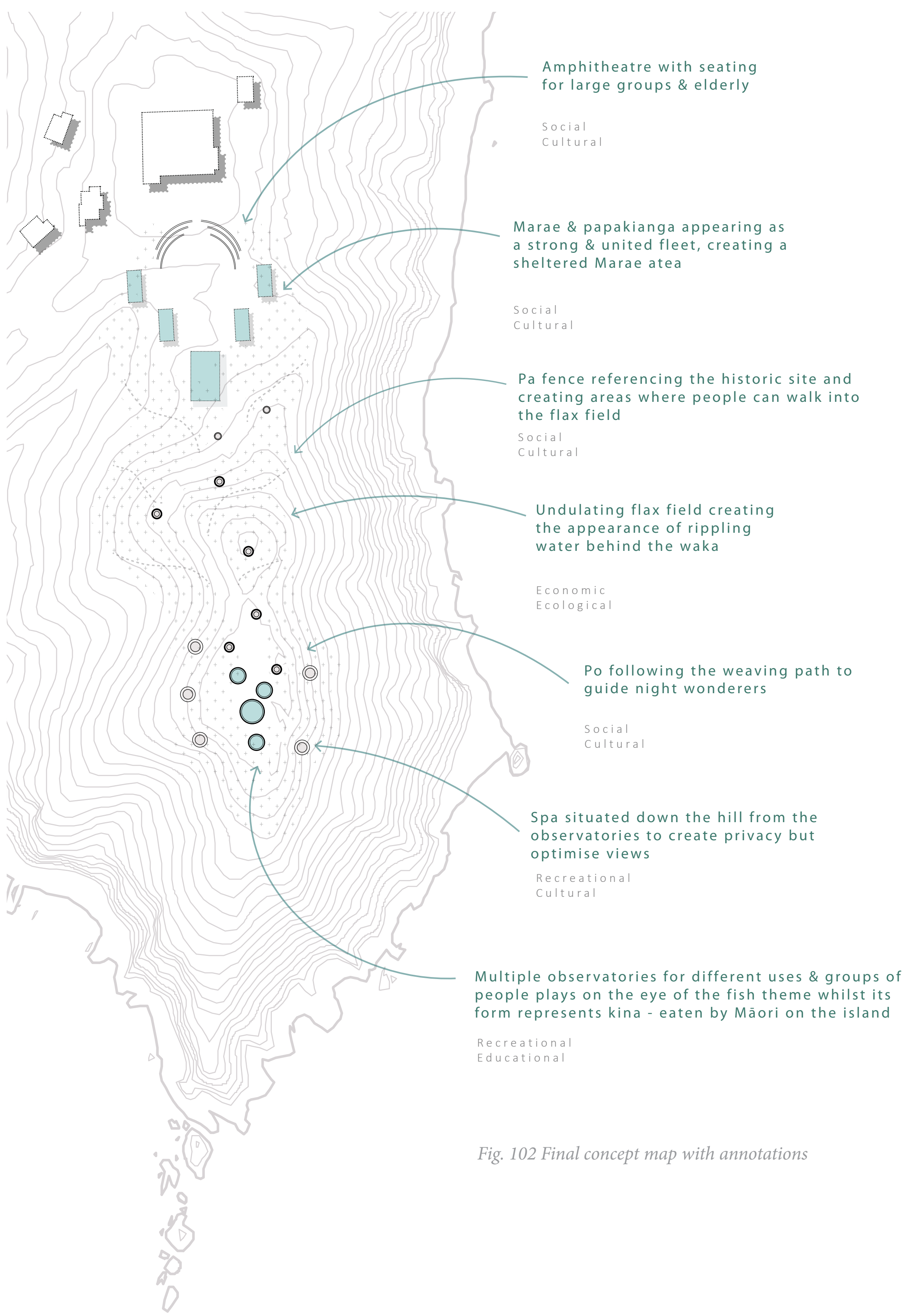




\section{MASTER PLAN}

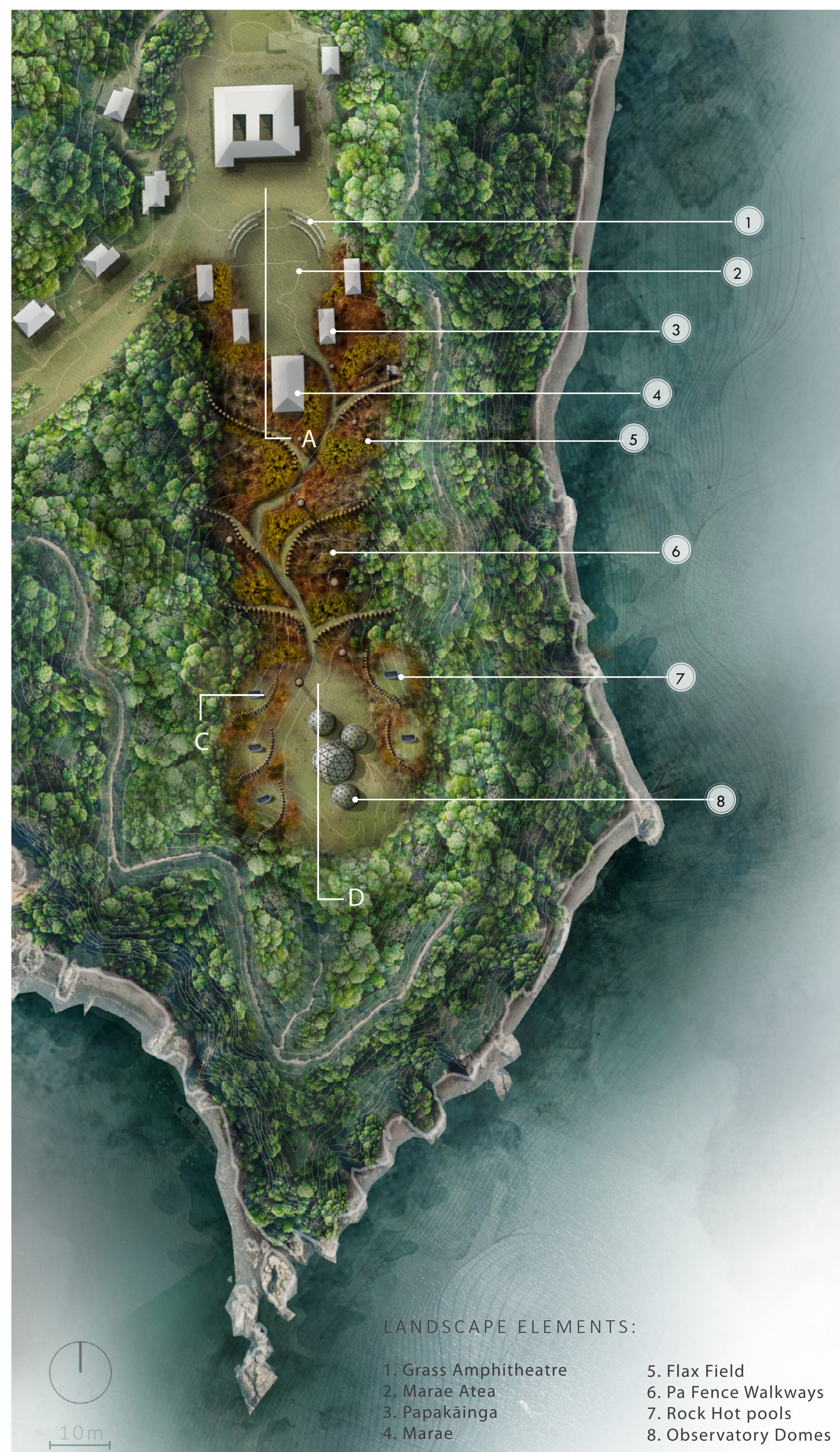




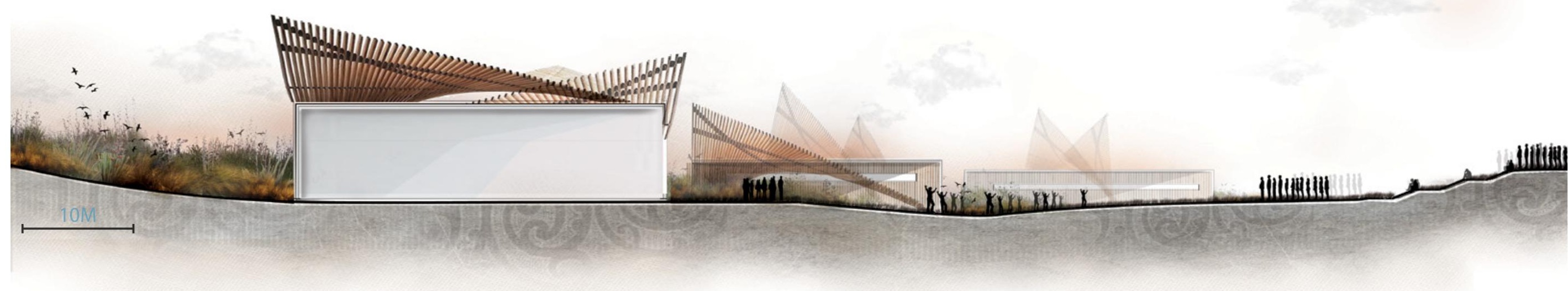

Section B-B: Hot Pools
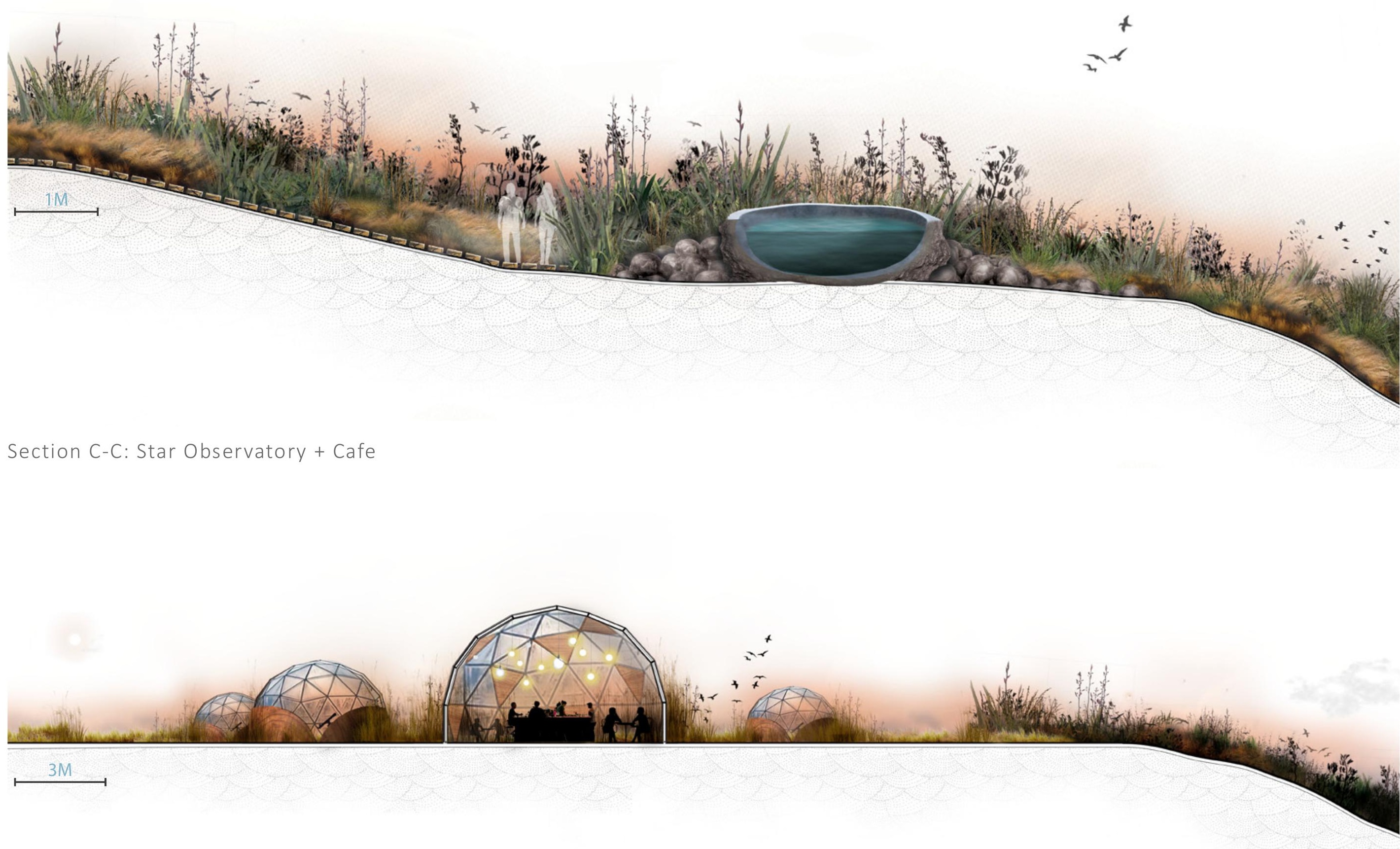

Section: Full Site

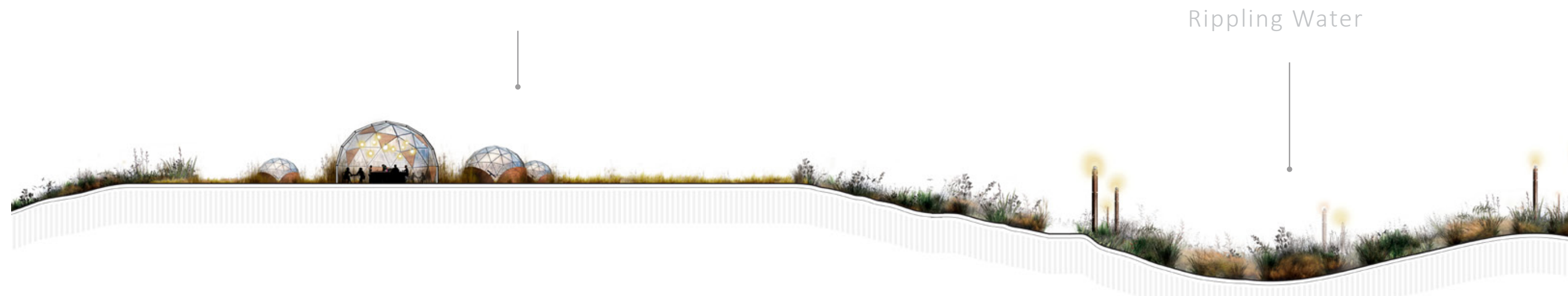




\section{FINAL DESIGN}

The final design creates a space that tells three stories that are linked to sea voyages. The Marae, which is the first space visitors reach on the site, tells the story of the Tokomaru Waka. As the Tokomaru Waka is the vessel that grounded the Taranaki Whānui to Aotearoa New Zealand, it is used as a metaphor in the site, conveying that this space is where mana whenua are grounded to the island. Four smaller waka make up the Papakāinga, which represent the local Taranaki Whānui's waka. These are placed to create a circular marae atea that is sheltered, enclosing guests and making them feel more secure.

Behind the Waka is a flax field. The mass planted area uses a range of coloured and textural flaxes, clustered in groups to create a ripple effect of flowing water behind the bodies of the Waka. The main path draws people up through the flax field, using paving that steers them in the direction of the peak. Smaller paths off the main route, are marked out with Pà fences that lead visitors deeper into the flax field. The field creates an educational opportunity for mana whenua to teach visitors and children about the way harakeke is harvested and processed, while the Pā fence hints at the sites past as a Māori settlement.

At the peak, visitors are met by a series of observatory domes that represent fish eggs, relating to the story of Maui and the fish. The eggs symbolise the birth of Aotearoa New Zealand through the uplifting of the fish. These domes are used for stargazing at night due to the unobstructed views on the peak and the minimised light pollution. During the day they are versatile spaces that can be used as classrooms for school groups or café's in summer.

Hidden in the peripheral planting of the peak are rock hot pools. The concept behind the baths plays on the traditional function of an Island in Māori history, a rejuvenating and peaceful place that Māori warriors used as a haven to recuperate after war. Rock piles around the pools allow Kawakawa to be steamed, a traditional Rongoā technique. As Pōneke Wellington does not have private hot pools, the opportunity for visitors and mana whenua to sit and watch the sunset, looking out to Pōneke Wellington or Petone, creates a unique experience that cannot be found anywhere in the region. 

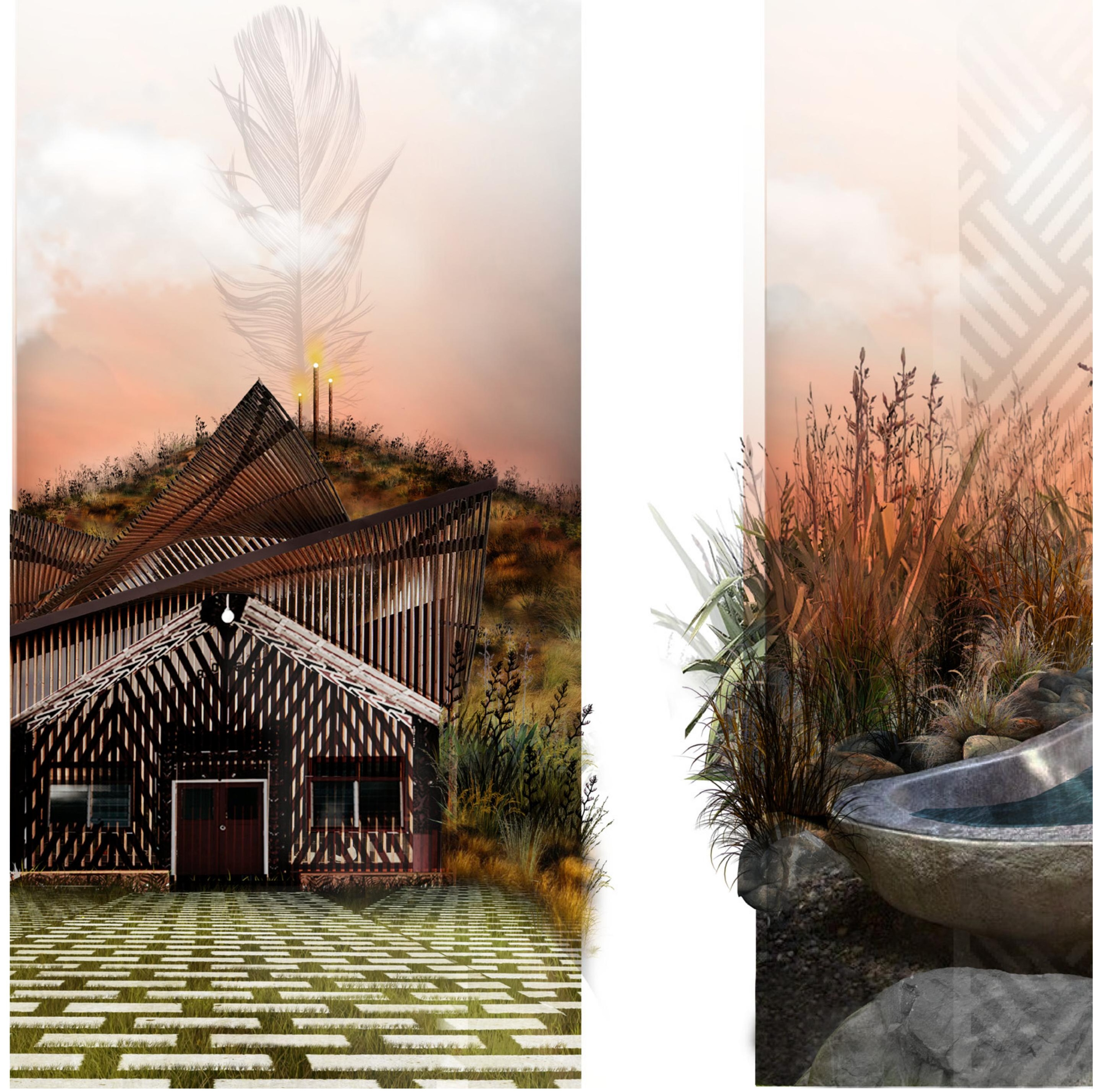



\section{DETAILED DESIGN}

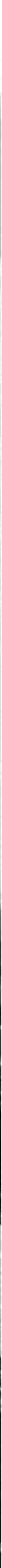




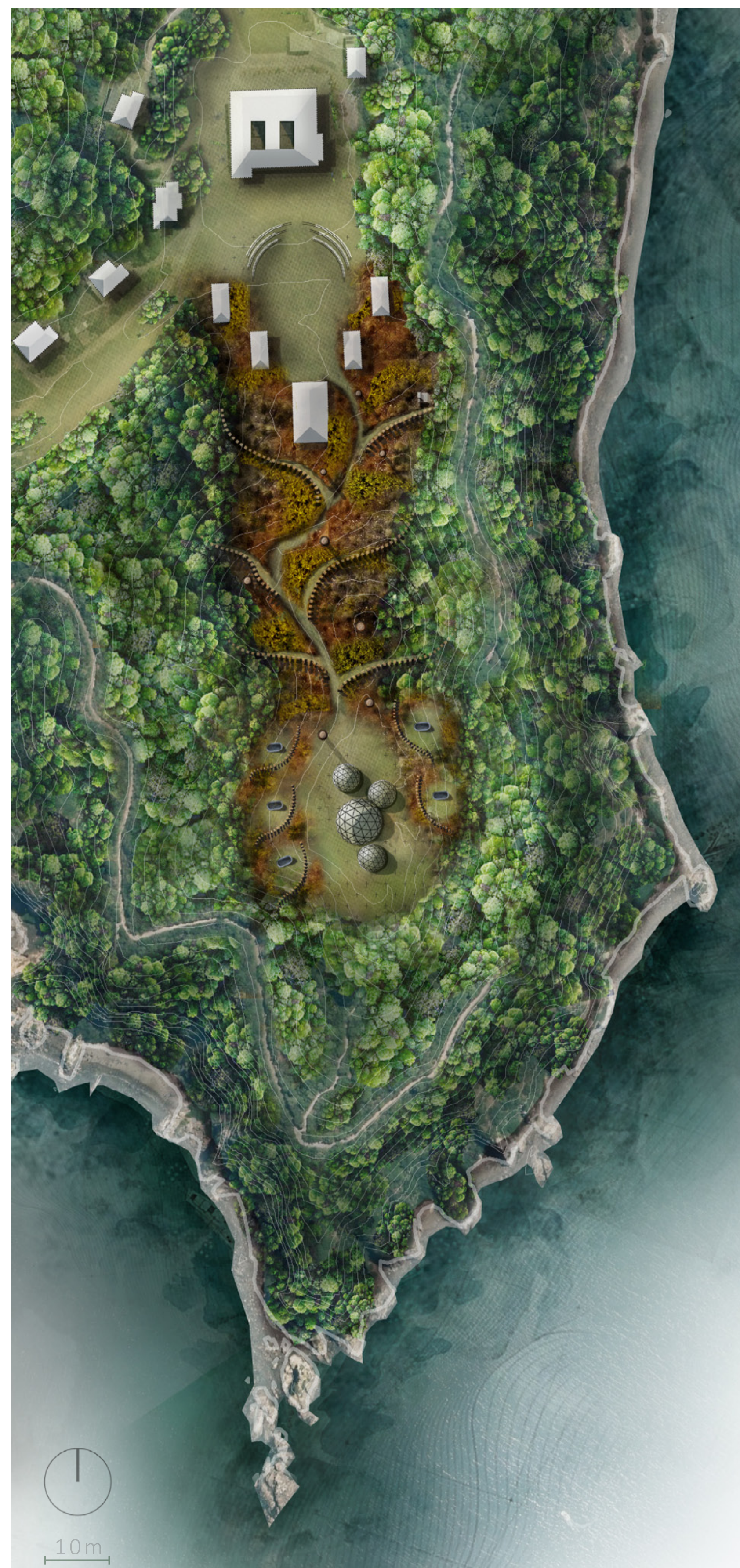




\subsection{DETAILED DESIGN}

The Peak site is the most experiential and engaging of all the sites. With the marae at the base, the flax field in the middle and the observatory pods and hot pools on top, this site that has the most impact on visitors during their time on the island. It is also the base for Māori on the island, which is used for gatherings and celebrations, making it an important space for members of the Taranaki Whānui. These factors make it the most significant site of the four selected for development, highlighting why it was chosen for further detailing. 


\section{PLANTING PLAN}

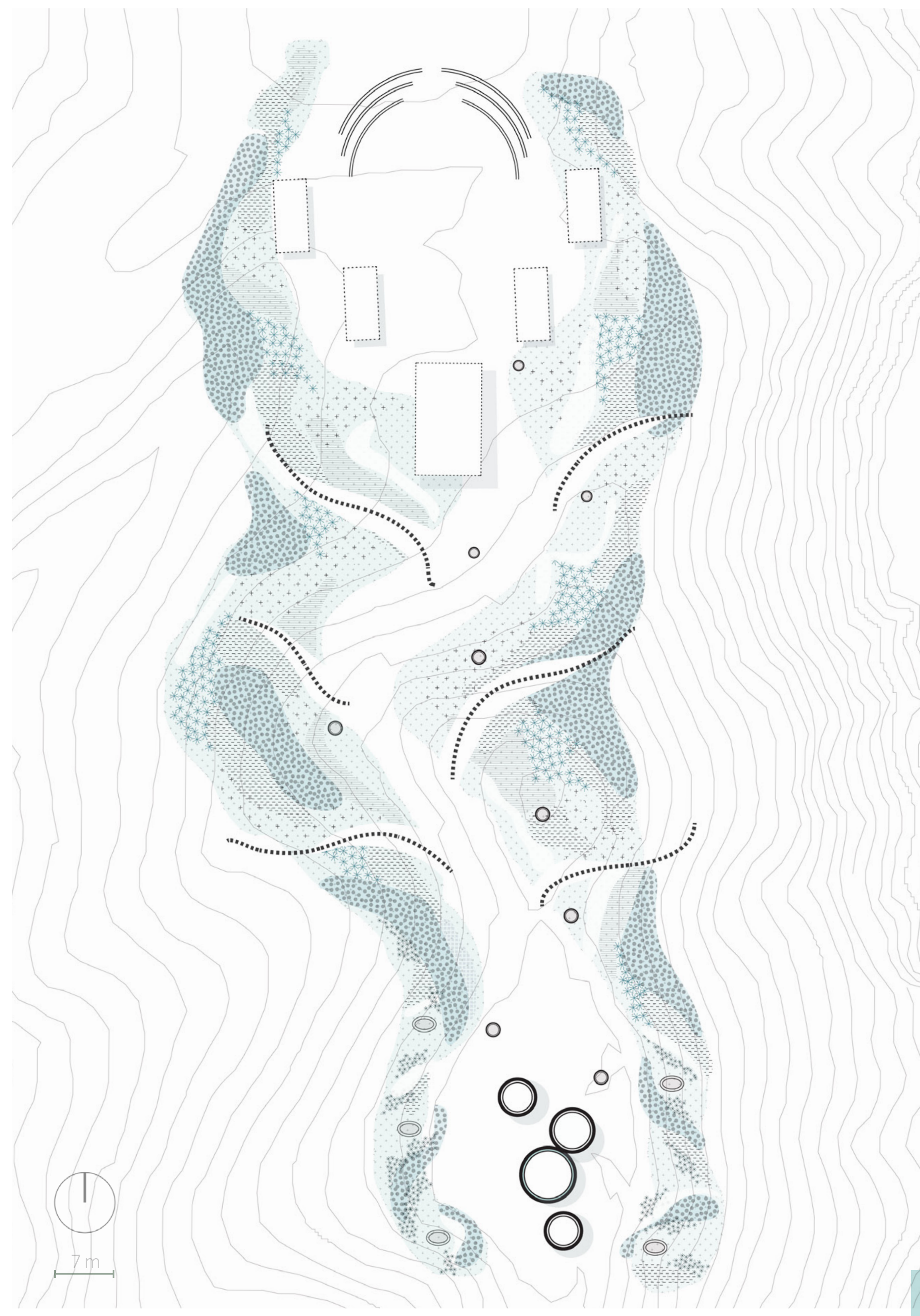




\section{PLANTING PLAN SPECIES}

The planting in this site was designed to resemblance water ripples, flowing out the back of the 5 Waka up the hill. This is achieved through adapting Piet Oldoufs compositional technique through grouping a singular species in an evident cluster to effectively create strong waves of colour and texture, recreating the appearance of moving water.

\section{KEY SPECIES}

Focusing functional plants

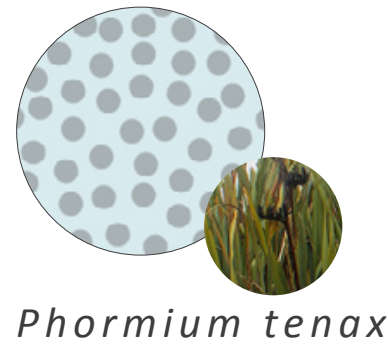

Harakeke

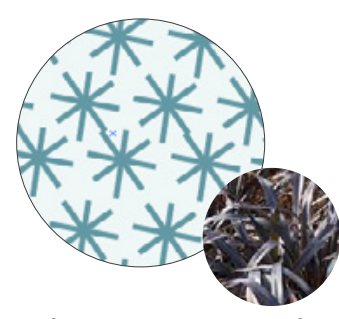

Phormium platts black Platts Black

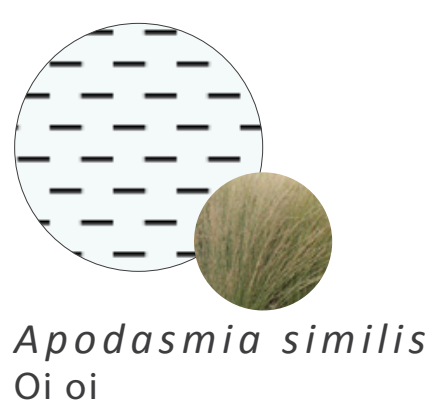

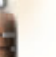

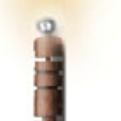

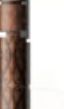

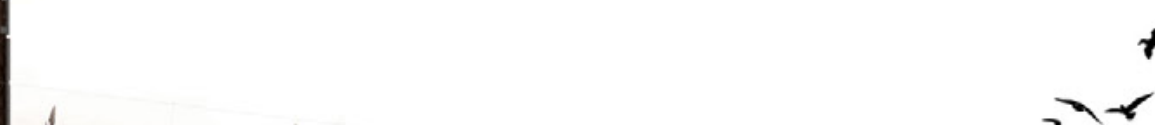

$2 \pi$

Anemanthele lessoniana

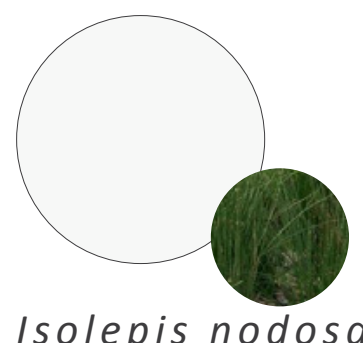

Knobby clubrush

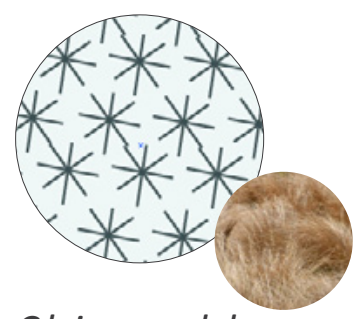

Chionochloa rubra red tussock

Wind grass

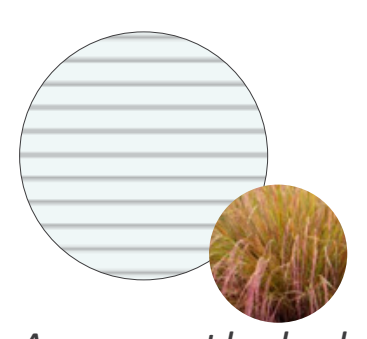

BRIGHT SPECIES

Small bright species

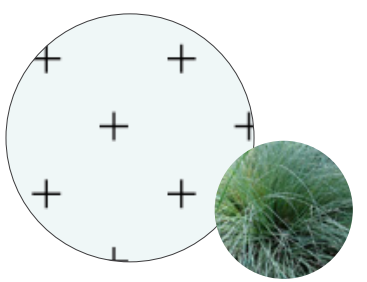

Carex albula

Frosted curls sedge
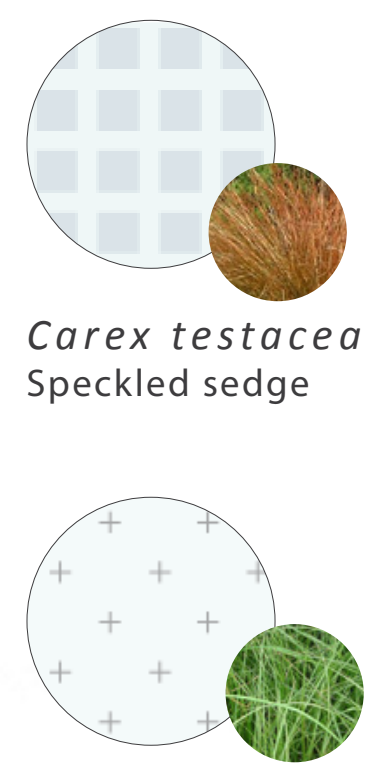

Carex geminata cutty grass

Fig. 110 Selected plant species and Swatches

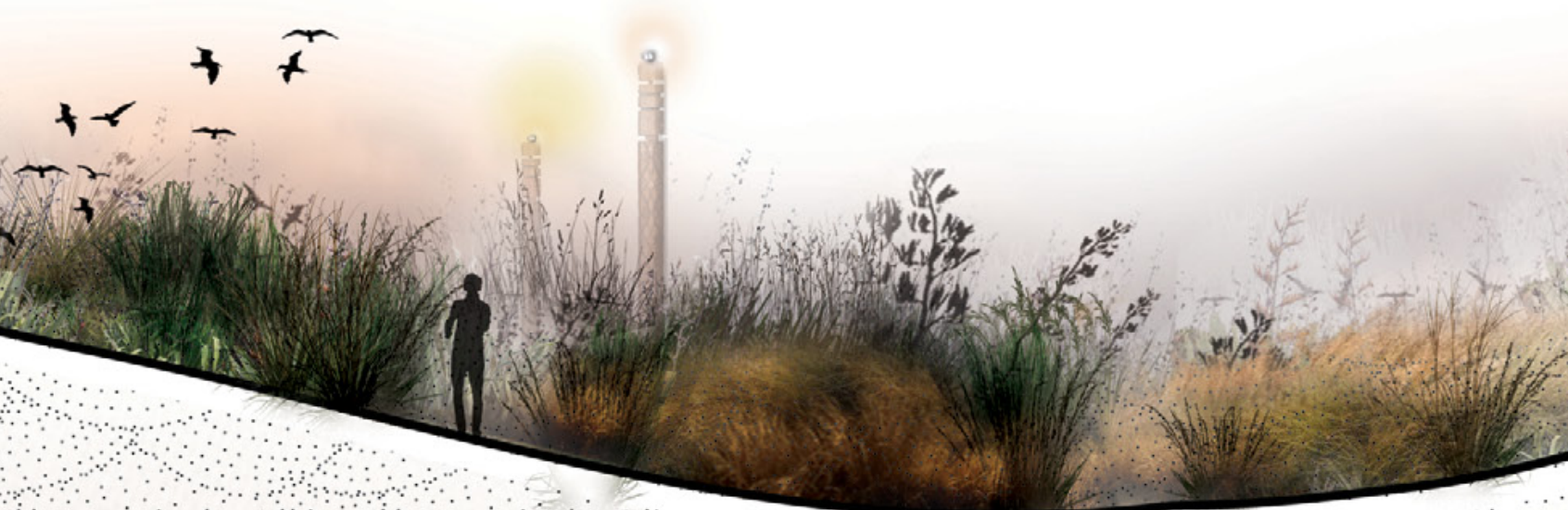




\section{PO DETAIL}

Carved poles that represent the strong presence of Māori on the island. These posts will be carved with designs significant to Te Ati Awa. The small white lights that glow from the top of the po symbolise stars, which provide light and guidance to visitors accessing the path at night, representing how Māori used stars to navigate waka.

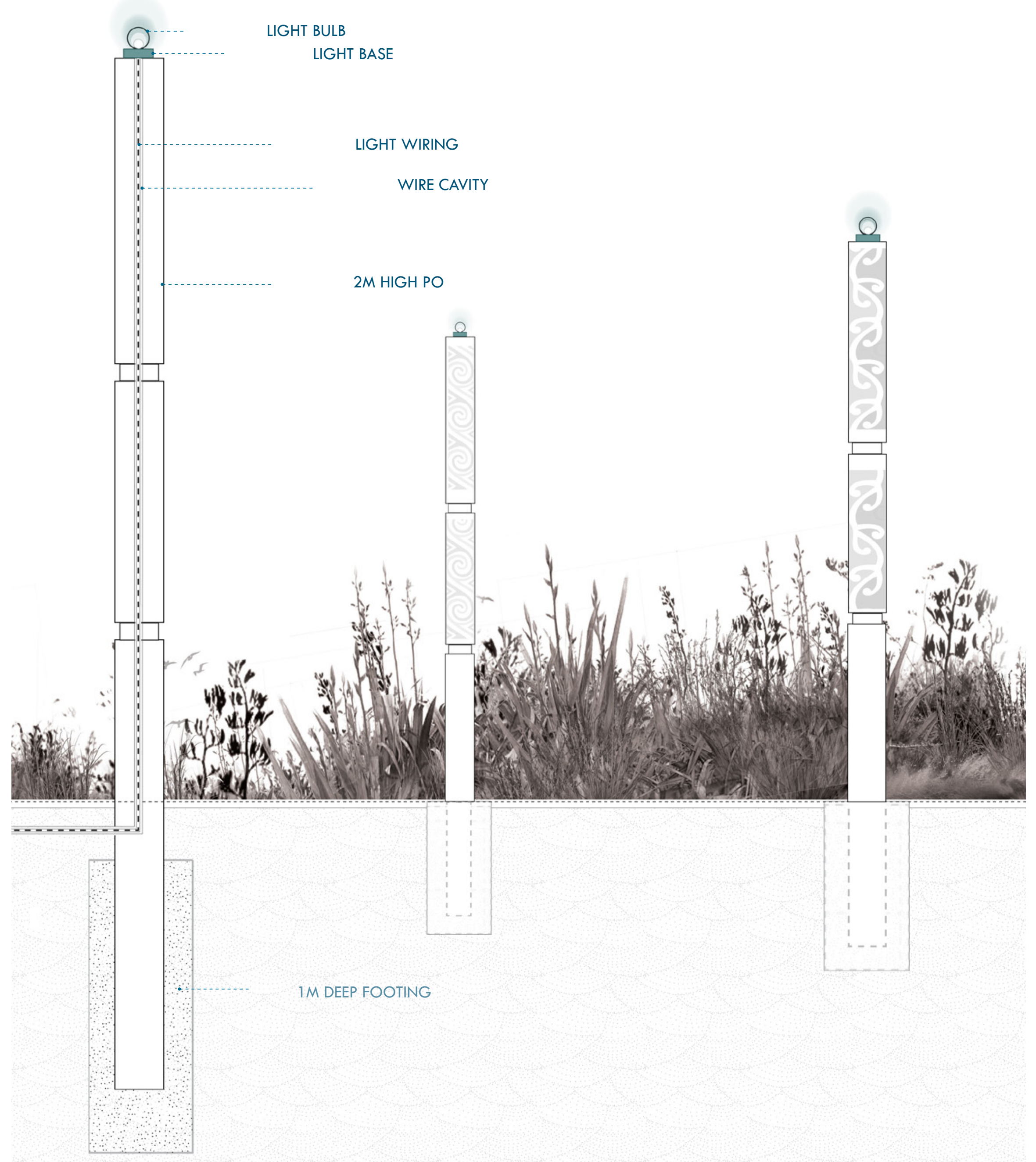




\section{HOT POOL DETAIL}

Māori once used islands as a place to rejuvinate and rest after war.

The solar powered rock-pools reference this by creating a unique and relaxing experience for guests to recuperate away from the pressure of their lives. Steaming Kawakawa on the rocks around the hot pools add to this experience by drawing on traditional Māori medicine.

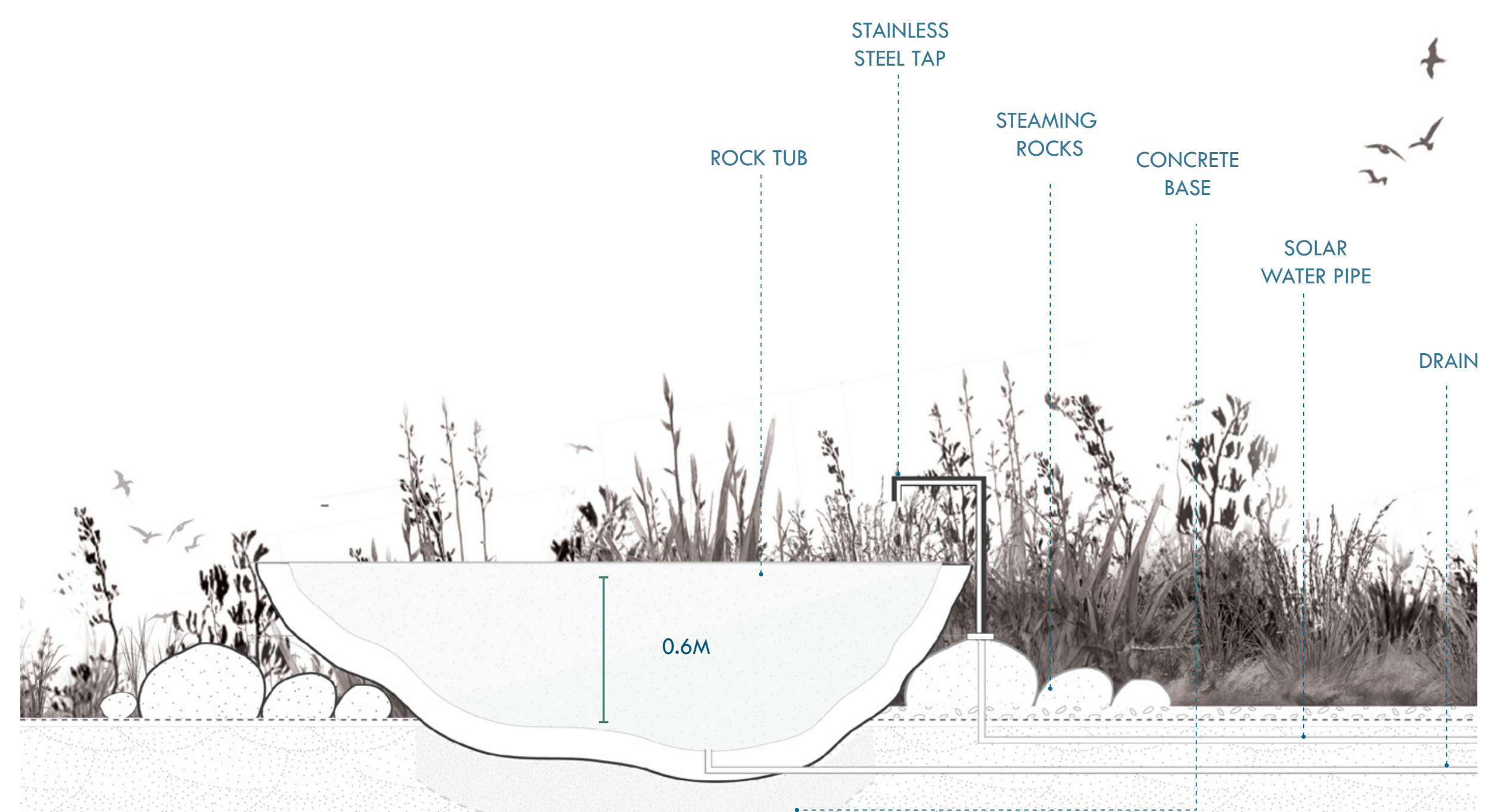




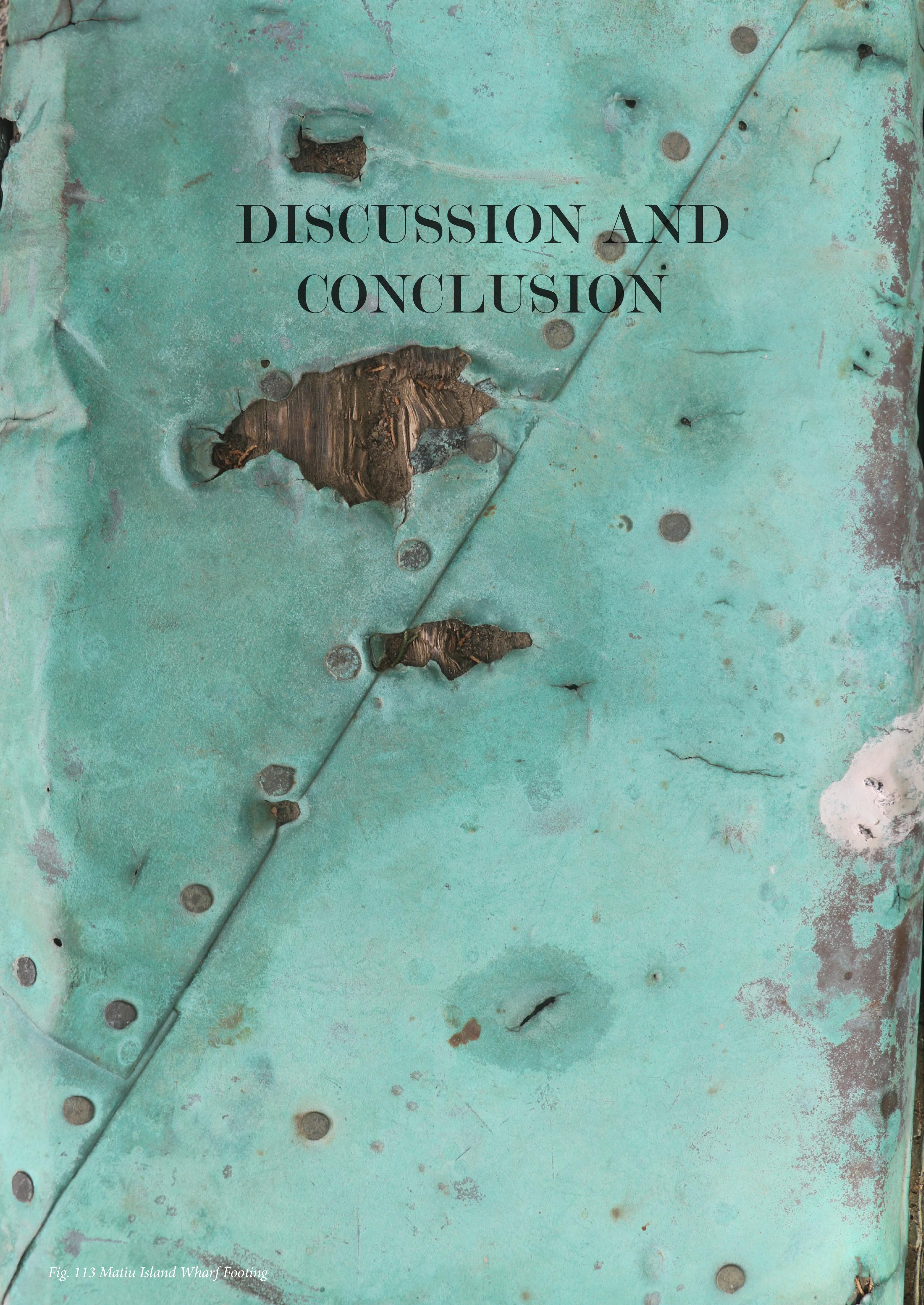




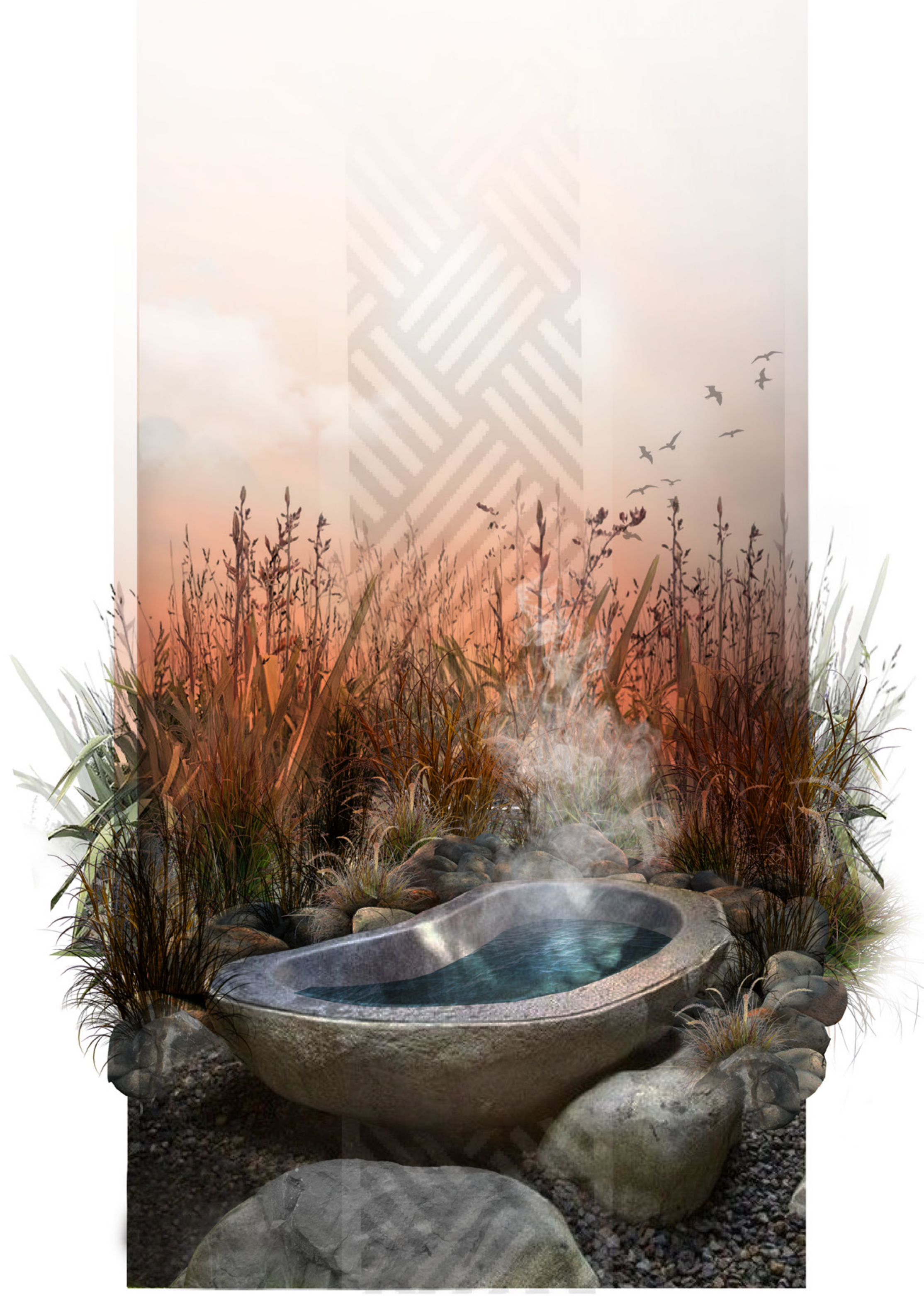

Fig. 114 Rongoā rock hotpool 


\subsection{CONCLUSION}

As most of Aotearoa New Zealand islands entered in a co-governing agreement, Māori have begun working alongside the Department of Conservation and community groups to manage and plan for the future of these islands. This has identified the need to explore how reinstated public Māori land can be designed to cater for the needs of the public, the environment and Māori as the owners of the land, ultimately finding a spatial synergy between all three significant parties in the form of physical space.

Matiu Island is an island located within a 20-minute boat ride from the capital of Aotearoa New Zealand. Its rich, bicultural history and recent ecological restoration makes it an important landscape within the Pōneke Wellington region. The island is governed by the Kaitiaki board, which is made up of Iwi, DOC and local Pōneke Wellingtonians. This unique partnership agreement creates the opportunity to explore how offshore islands can continue to act as conservation and recreation nodes but also express the cultural identity of the tribes that own them. Although this governing body has made great advances through their Kaitiaki document, the strong presence of European history physically present on the island and the absence of any relating to mana whenua, has created a landscape that is biculturally imbalanced. The island fails to represent its rich bicultural past or its guardians. Reflecting on the initial research question, how offshore islands become culturally and educationally focused spaces for iwi and local communities, the design answers this question by producing a range of journeys and social spaces that are informed by significant cultural narratives as a way to create cultural and recreational spaces for Māori to enjoy and visitors to interact and learn from.

SITE ANALYSIS: Site analysis explored historical sites significant to Māori, identifying three key areas as the richest cultural sites on the island (a Pa, its lookout and a waka landing site). These were the Wharf, the Quarantine building and the peak. This indicated that this is where Māori values and traditions should be integrated to recognise the history of Māori on the island. These sites also happened to be key destinations points on the island, however they currently fail to engage visitors during visits due to their run down nature and lack of engaging elements. Not only would acknowledging the culturally significant sites on the island revive these key destination spaces but it would also expose the majority of visitors to the full cultural history of the site (both the European and Māori). This would ultimately create an educational and experiential opportunity for visitors to learn more about Māori culture while their experience on the island was enhanced and diversified.

LITERATURE AND CASE STUDIES: The development of these spaces needed to be able to satisfy all three governing parties objectives, not just that of Māori. Through examining the mutual motivations of each of the governing groups, it became apparent that all of them had an interest in human and environmental health, culture and education. This created the basis for the development of the key areas of the island. 
Through case studies and the literature review, Mātauranga Māori was highlighted as a key concept that could facilitate the merging of traditional knowledge with modern day practises to support effective resource management and the integration of cultural values and concepts.

Cultural narratives and the use of symbolism was highlighted by literature and case studies as tools to create visually stimulating, recreational, social and educational spaces. Narratives also created the opportunity for Māori to share important pieces of their identity and history in a way that could be translated into physical space by using planting, art work, wayfinding and materiality. This is important as it enables a "spiritual connection and sense of belonging to be preserved or reinstated, and the reassertion of the Māori voice in the landscape" (Paul, 2017, P.2).

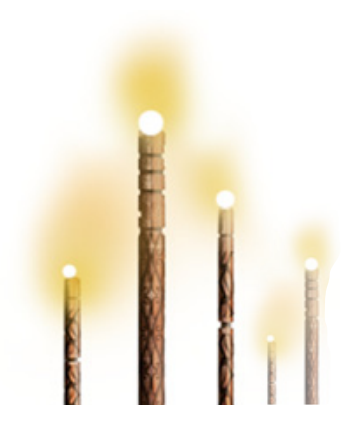

NARRATIVES

- Use structures, materiality and planting to re-tell important narratives and historical events.

CULTURAL SIGNIFICANCE : Through consultation with Iwi, narratives that were of significance to The Port Nicholson Trust were selected as a medium to create a landscape that connected to its people. A selection of general, contextual and site-specific stories were selected to set the scene, convey the Iwi's origins and finally describe the essence and historical events of the site. These narratives were then broken down, so that important symbols, learnings, characters and objects could be identified and therefore represented in the landscape. Case studies that have used narratives to inform the design process provided insight into how these stories could be spatially transformed, through symbolic or relevant planting, materiality, structures and installations.

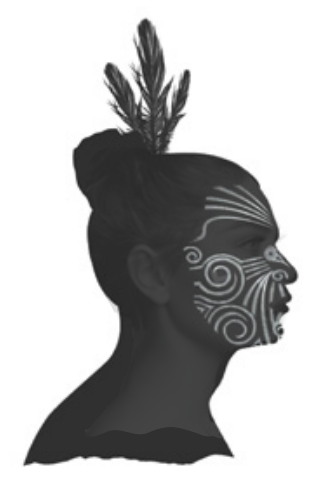

IWI COLLABORATION

- Work with Iwi to create spaces they feel represent their identity and origins giving them a presence on their land 
THE DESIGN: The design research focused on the development of four culturally significant sites, each one exploring the reintroduction and celebration of Māori culture on Matiu Island. As these sites were already core destinations on the island, the examination of their functions and programmes created the opportunity to build upon them, instead of trying to disregard or replace their existing function. This was done through the introduction of narratives that related to the sites current or past programme.

Through consultation, it became apparent that the broader narratives, relating to Iwi, would be used to inform the design in the earlier sites that visitors first come across. This would enable these initial sites to set the scene and share basic information about Māori values, customs and traditions. Narratives relating to the movements of the mana whenua's ancestors, across Aotearoa New Zealand, would then be introduced to share the origins and history of the mana whenua. Finally, site-specific narratives regarding Māori in Pōneke Wellington would be used to inform the design of the key destination sites around the top of the Island, sharing the history of the Poneke Wellington Harbour and Matiu Islands with visitors.

Each of these sites and narratives were analysed to assess what social and recreational spaces could be incorporated to engage visitors, something that was previously lacking in these sites. Marine based sites were designed to create interaction with the water and allow a range of water based, cultural activities to take place while more inland sites were explored as areas that were suitable for Māori to congregate and showcase a range of traditional customs that visitors could observe or to take part in.

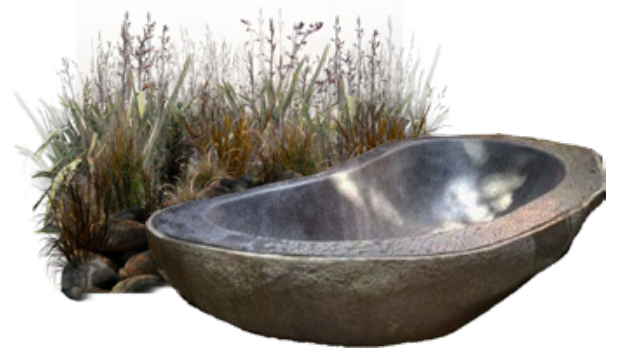

RECREATION

- Use unique recreational activities to draw people to the island.

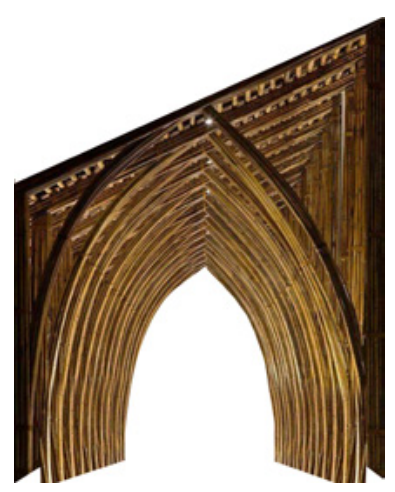

CULTURAL TRADITIONS

- Create cultural spaces for traditional activities and performances to take place to immerse visitors in Māori culture.

The core of this research focused on creating a biculturally balanced environment, through the reintegration of Māori culture upon Matiu Island, with the intention of creating highly engaging spaces for Māori and visitors. The design achieved this through using cultural narratives as a way to influence the establishment of recreational, social and ecological interventions on the island. The emphasis on the introduction of Māori practises and traditions, to the site, created spaces that showcased Māori culture, engaging and educating visitors throughout their time on the island. 
LIMITATIONS: In terms of limitations for this research, the consultation aspect of the design was limited. As this was an academic piece of work with strict deadlines, consultation with Iwi was not as thorough or elaborate as it should have been. Being able to engage more with the community would have potentially produced richer design outcomes and details in each site that may have been more attuned to what Māori and the local Pōneke Wellington community want and need.

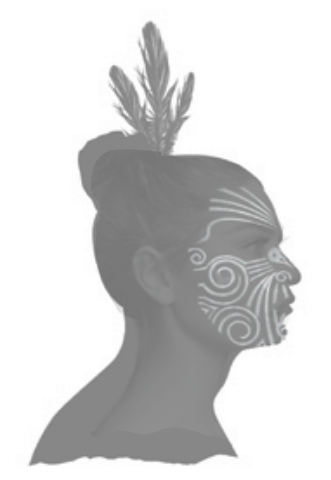

IWI CONSULTATION

The design of the Quarantine Building would need to seek architectural input to further develop and refine the design of the glass shell encasing the building.

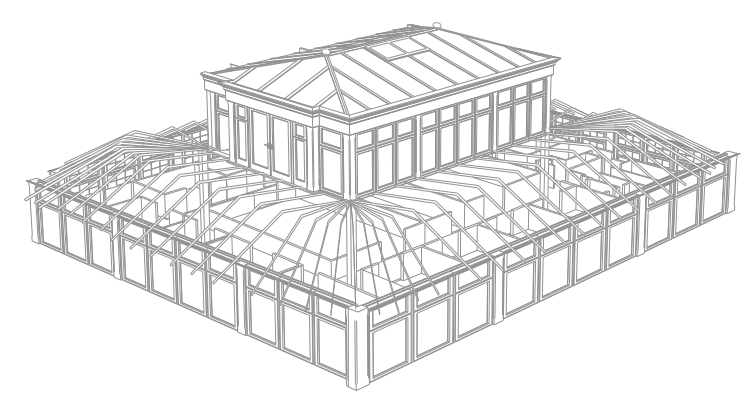

ARCHITECTURAL INPUT

The journey from the mainland to the island is an integral part of the visitors experience. Enhancing the existing experience of the ferry journey was not included in the design research but it could be something that could be explored to further enrich the overall experience of the island for Māori and visitors.

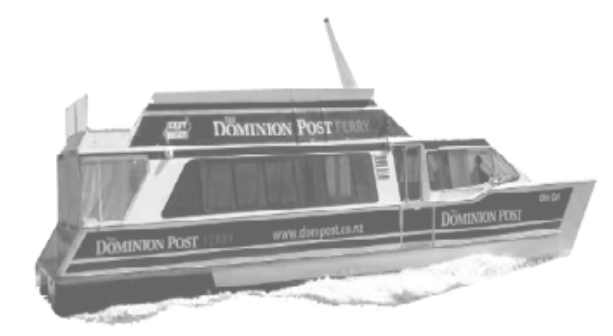

MAINLAND JOURNEY 




\section{REFERENCE}

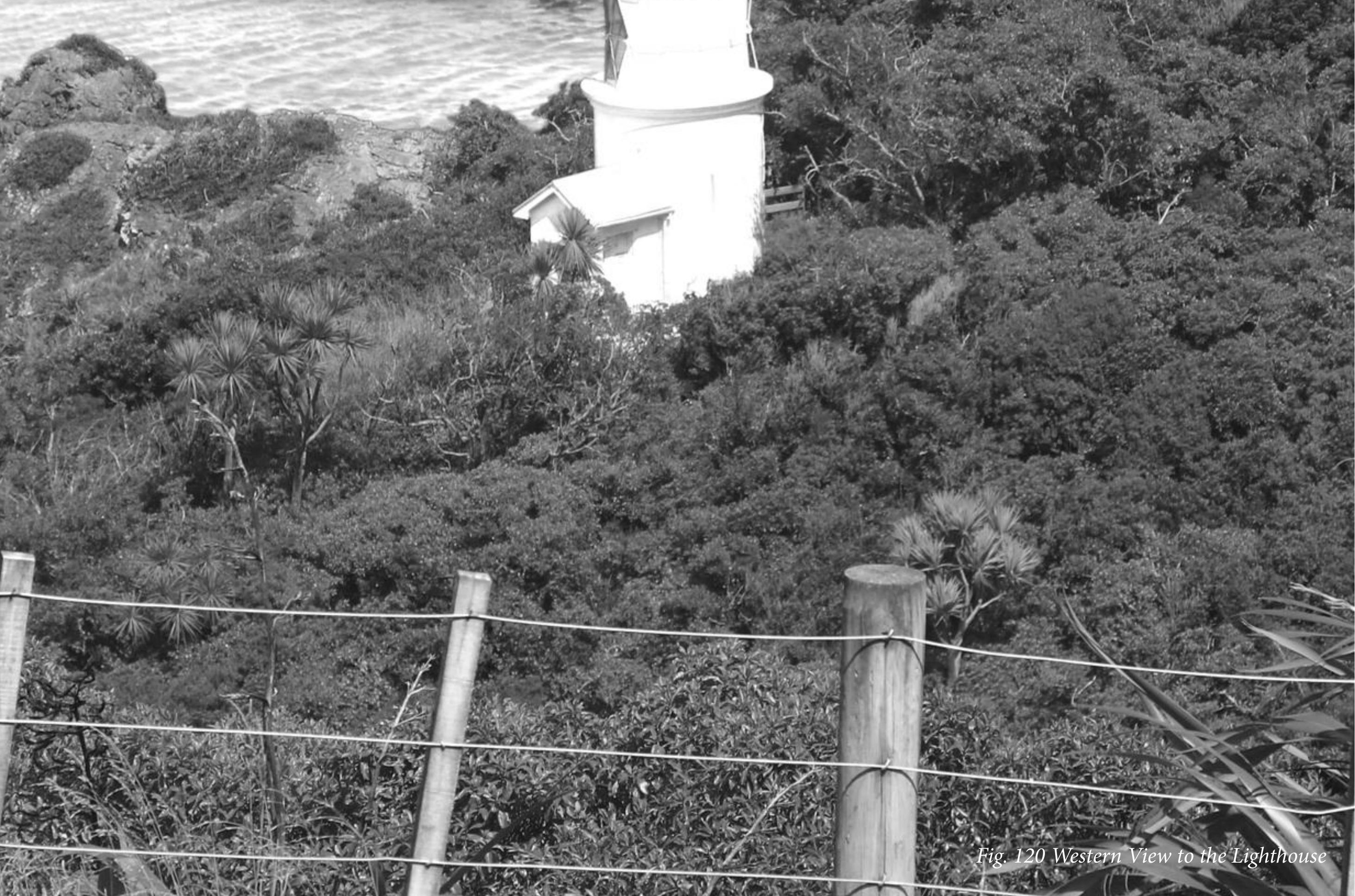




\subsection{GLOSSARY}

\section{AOTEAROA}

The Māori name for New Zealand.

\section{KAI MOANA}

Seafood, shellfish.

MĀORI

Indigenous people of New Zealand.

\section{MĀTAURANGA}

Indigenous Knowledge, wisdom, understanding, skill - sometimes used in the plural.

\section{TANIWHA}

Water spirit, monster, dangerous water creature, powerful creature, chief, powerful leader, something or someone awesome - taniwha take many forms from logs to reptiles and whales and often live in lakes, rivers or the sea.

\section{TIKANGA}

Correct procedure, custom, habit, lore, method, manner, rule, way, code, meaning, plan, practice, convention, protocol - the customary system of values and practices that have developed over time and are deeply embedded in the social context.

\section{HAPU}

Kinship group, clan, tribe, subtribe - section of a large kinship group and the primary political unit in traditional Māori society. It consisted of a number of whānau sharing descent from a common ancestor, usually being named after the ancestor, but sometimes from an important event in the group's history.

\section{IWI}

Extended kinship group, tribe, nation, people, nationality, race - often refers to a large group of people descended from a common ancestor and associated with a distinct territory.

\section{KAITIAKI}

Trustee, minder, guard, custodian, guardian, caregiver, keeper, steward. 


\section{KAITIAKITANGA}

Guardianship, stewardship, trusteeship, trustee.

\section{MANA WHENUA}

Territorial rights, power from the land, authority over land or territory, jurisdiction over land or territory - power associated with possession and occupation of tribal land. The tribe's history and legends are based in the lands they have occupied over generations and the land provides the sustenance for the people and to provide hospitality for guests.

\section{MAURI}

Life principle, life force, vital essence, special nature, a material symbol of a life principle, source of emotions - the essential quality and vitality of a being or entity. Also used for a physical object, individual, ecosystem or social group in which this essence is located.

$\mathrm{PA}$ Māori village or defensive settlement, but it can often refers to hill forts, fortified settlements with palisades and defensive terraces.

PŌWHIRI

invitation, rituals of encounter, welcome ceremony on a marae, welcome

TIPUNA

Ancestors, grandparents - plural form of tipuna and the eastern dialect variation of tūpuna.

\section{WHANAUA}

Extended family, family group, a familiar term of address to a number of people - the primary economic unit of traditional Māori society. In the modern context the term is sometimes used to include friends who may not have any kinship ties to other members. 


\subsection{BIBLIOGRAPHY}

Adger, E. L. T. a. W. N. (2004). Does Adaptive Management of Natural Resources Enhance Resilience to Climate Change? Ecology and Society, 9(2).

ArchitectureNow. (2017). Leave no footprint: Te Kura Whare. Retrieved from Architecture Now website: http://architecturenow.co.nz/articles/leave-nofootprint-te-kura-whare-awarded-living-building-challenge-certification/

Barrett, M. (2014). Auckland Airport landscapes. Retrieved from http://architecturenow.co.nz/articles/auckland-airport-landscapes/

Board, K. (2012). Kaitiaki Plan. In. Retrieved from www.doc.govt.nz/Documents/about-doc/policies-and-plans/conservation-management/wellington-harbour-islands-kaitiaki-plan.pdf

Boast, R. (2015). Te tango whenua - Māori land alienation - Crown pre-emption. In Te Ara - the Encyclopedia of New Zealand. www.TeAra.govt.nz/ en/te-tango-whenua-maori-land-alienation/page-3

Bryant M, P. A, Sam Kebbell. (2017). A Settlers' Guide: Designing for Resilience in the Hinterlands, 1-15. Retrieved froM: https://www.mdpi.com/2075$5309 / 7 / 1 / 23$

Chronis, L. (2009). Matiu/Somes Island environmental education resource. In D. o. Conservation (Ed.), (pp. 34,39,40). https://www.pnbst.maori.nz/assets/ PDFs/Matiu-Island-Educational-Resource-DOC-booklet.pdf

Clarkson B, Todd Nachowitz, Dr Hamish Rennie. (05.07.2007). Systematic measurement of effectiveness for Conservation of Biodiversity on New Zealand Islands. Paper presented at the Conser-Vision, University of Waikato.

Conservation, D. o. (2018). Matiu Somes Island, 1-4. Retrieved from http:// www.doc.govt.nz/Documents/parks-and-recreation/places-to-visit/wellington/matiu-somes-island-brochure.pdf

Conservation, T. D. o. (2018). The Department of Conservation. Retrieved from https://www.doc.govt.nz

Coombes, B. (2005). Prospects for Comanagement of Te Urewera National Park. Society and Natural Resources, 18(2), 135-152. https://www.tandfonline.com/doi/abs/10.1080/08941920590894516 
Coombes, B. (2003). The Historicity of Institutional Trust and the Alienation of Maori Land for Catchment Control at Mangatu, New Zealand. Environment and History, 9(3), 333-359.

Council, A. C. (2017). Te Aranga Principles. Retrieved from aucklanddesignmanual.co.nz/design-thinking/maori-design/te_aranga_principles

Council, A. C. (2018a). Otahuhu Station. Retrieved from www.aucklanddesignmanual.co.nz/resources/case-studies/otahuhustation\#/resources/casestudies/otahuhustation

Council, A. C. (2018b). Taumanu Reserve. Retrieved from www.aucklanddesignmanual.co.nz/resources/case-studies/taumanureserve

Council, G. R. W. (2010). Wellignton Regional Native Plant Guide. In. Retrieved from http://www.gw.govt.nz/assets/Be-the-Difference/Biodiversity/Wellington-Regional-Native-Plant-Guide-Revised-Edition-2010-Web.pdf

Council, W. C. (2004). Waititi Landing. Retrieved from https://wellington.govt. $\mathrm{nz} /$ recreation/enjoy-the-outdoors/parks-and-reserves/suburban-andcity-reserves/wai-titi-landing

Dearborn D, S. K. (2009). Motivations for Conserving Urban Biodiversity. Conservation Biology, 2, 1-9.

Foundation, E. (2018, 13.02.2018). Enviroment Guide NZ: Habitat Loss. Retrieved from http://www.environmentguide.org.nz/issues/biodiversity/ key-threats/habitat-loss/

Girot, C. (1999). Four Trace Concepts in Landscape Architecture. In J. Corner (Ed.), Four Trace Concepts in Landscape Architecture (pp. 59-67). Retrieved from https://mycourses.aalto.fi/pluginfile.php/179255/mod_resource/content/1/Christoph\%20Girot.pdf

Grace, W. (2015b). Maui and the Giant Fish. Retrieved from http://eng.mataurangamaori.tki.org.nz/Support-materials/Te-Reo-Maori/Maori-MythsLegends-and-Contemporary-Stories/Maui-and-the-giant-fish

Grace, W. (2015c). Ngake and Whātaitai the taniwha of Wellington harbour. Retrieved from http://eng.mataurangamaori.tki.org.nz/Support-materials/ Te-Reo-Maori/Maori-Myths-Legends-and-Contemporary-Stories/Ngake- 
and-Whataitai-the-taniwha-of-Wellington-harbour

Harmsworth, G. (Producer). (2017). Unlocking the potential of Māori land: A kaupapa Māori approach to using and developing integrated knowledge, models and tools. [ Seminar] Retrieved from https://www.landcareresearch.co.nz/_data/assets/pdf_file/0010/140203/Unlocking-the-Potential-of-Maori-Land.pdf

Hay, R. (1989). A Rooted Sense Of Place in Cross Cultural Perspective Rooted Sense of Place In Cross-cultural Perspective.The Canadian Geographer, 42(3), 245-266.

Hayward, J. (2012). Biculturalism - Biculturalism in the state sector. Retrieved from https://teara.govt.nz/en/biculturalism/page-2

Heritage, M. f. C. a. (2017, 22.08.2017). Maori land loss, 1860-2000. Retrieved from https://nzhistory.govt.nz/media/interactive/maori-land-1860-2000

Hibbard, M. B. L. M. (2005). Doing It for Themselves: Transformative Planning by Indigenous Peoples. Journal of Planning Education and Research, 25(2), 172-184.

Houkamau, C. (2010). The Multi-dimensional Model of Māori Identity and Cultural Engagement. New Zealand Journal of Psychology, 29(1), 8-28. www.psychology.org.nz/wp-content/uploads/Houkamau.pdf

Howe, K. R. (2005). Ideas of Māori origins - 1840s-early 20th century. Retrieved from https://teara.govt.nz/en/ideas-of-maori-origins/page-3

Institute, I. L. F. (2018). Healing From Within, Te Kura Whare. Retrieved from https://living-future.org/biophilic/case-studies/te-kura-whare/

Jasmax. (2014). Te Kura Whare Retrieved from https://www.jasmax.com/work/ te-kura-whare/

Jones, R. (2007). Rongoā - medicinal use of plants. Retrieved from www.TeAra. govt.nz/en/rongoa-medicinal-use-of-plants

Kerridge, D. (2017). Everything is related: an introduction to rongoā Māori medicine. Retrieved from https://thespinoff.co.nz/atea/13-10-2017/ 
everything-is-related-an-introduction-to-rongoa-maori-medicine/

King, J. (2017). Human Impact on New Zealand Ecosystem. Retrieved from https://sciencing.com/human-impact-new-zealand-ecosystem-22710. html

Love, M. (2005). Te Āti Awa of Wellington. Retrieved from https://teara.govt.nz/ en/te-ati-awa-of-wellington

Maclean, C. (2007). Wellington region - Climate. In Te Ara - the Encyclopedia of New Zealand, 3-7.

Marques, B. G.G. M. J. (2018). Fostering Landscape Identity Through Participatory Design With Indigenous Cultures of Australia and Aotearoa/New Zealand. Space and Culture. Retrieved from www.researchgate.net/ publication/326020833_Fostering_Landscape_Identity_Through_Participatory_Design_With_Indigenous_Cultures_of_Australia_and_AotearoaNew_Zealand

McAloon, J. (2008). Land ownership - Māori and land ownership. In Te Ara - the Encyclopedia of New Zealand.

Menzies, D. D. (2018). Ngāi Tūhoe do things differently: interview with Tāmati Kruger. Retrieved from https://www.landscape.org.nz/home/2018/2/21/ ngi-thoi-do-things-differently-interview-with-tmati-kruger

Mulligan, J. (2015, 16.07.2015). NZ A-Z: Matiu Somes Island. Retrieved from http://www.radionz.co.nz/national/programmes/afternoons/galleries/ matiu-somes

Nester, T. W. R. (2001). Maitu/Somes Island Maori History. Retrieved from http://www.doc.govt.nz/Documents/science-and-technical/MatiuSomes-Island-Maori-History.pdf

O'Neal, A. $(2015,15.04 .2015) .150$ years of news - Matiu/Somes Island's tantalising and miserable history. Retrieved from http://www.stuff.co.nz/ dominion-post/news/68364049/150-years-of-news--somes-islands-tantalising-and-miserable-history

Ora, T. A. W. (2013, 11.11.2013). Māori Models of Health \& Wellbeing. Retrieved from http://tearawawhanauora.org.nz/2013/11/maori-models- 
Paul, J. (2017). Exploring Te Aranga Design Principles in Tamaki, 1-11. Retrieved from http://www.buildingbetter.nz/publications/SRA4/Paul_2017_exploring_te_aranga_design_principles.pdf

Research, M. W. L. (2015). What is Matauranga Maori. Retrieved from https:// www.landcareresearch.co.nz/about/sustainability/voices/mataurangamaori/what-is-matauranga-maori

Richards, S. (2018). Wellington's homeless find belonging in new garden. Retrieved from https://dailyencourager.co.nz/wellingtons-homeless-growgarden-of-hope/

Smith, S. P. (1910). The Tokomaru Canoe. In History and Traditions of the Maoris of the West Coast North Island of New Zealand Prior to 1840 (pp. 95-99). New Plymouth: Polynesian Society. Retrieved from http://nzetc. victoria.ac.nz/tm/scholarly/tei-SmiHist-t1-body1-d6-d2.html.

Smith, W. (2012, 04.12.2012). Time Travel on Maitu Somes Island. Retrieved from www.stuff.co.nz/national/blogs/in-our-nature/8080631/Time-travel-on-Matiu-Somes-Island

Spoonley, P. 'Ethnic and religious intolerance - Intolerance towards Māori', Te Ara - the Encyclopedia of New Zealand, http://www.TeAra.govt.nz/en/ ethnic-and-religious-intolerance/page-1 (accessed 20 February 2019)

Todd Taiepa, P. L., Peter Horsely, Jane Davis. (1997). Co-management of New Zealand's conservation estate by Maori and Pakeha: a review. Enviromental Conservation, 24(3), 236-250.

Toorn, M. v. d. (2007). Enviromental Education and Design; The role of landscape architecture. Paper presented at the Enviroment, Ecosystems and Development, Tenerife, Spain. http://www.wseas.us/e-library/ conferences/2007tenerife/papers/572-524.pdf

Towns D, Theo Stephens. (2009). Systematic measurement of effectiveness of conservation fo biodiversity on New Zealand Islands. Paper presented at the Conser-Vision, The University of Waikato.

Trust, P. N. B. S. (2018). Welcome to the Port Nicholson Block Settlement Trust. Retrieved from https://www.pnbst.maori.nz/ 
Tuhoe, N. (2014). Te Kura Whare. Retrieved from http://www.ngaituhoe.iwi.nz/ te-kura-whare

Turenscape. (2014, 09.12.2014). Shenyang Jianzhu University Campus by Turenscape. Retrieved from http://www.descroll.com/design/shenyangjianzhu-university-campus-by-turenscape

University, A. (2016). Mātauranga Māori. Retrieved from https://www.aut. ac.nz/study/study-options/maori-and-indigenous-development/research/research-expertise/matauranga-maori

Voyde, E. (2012). Identifying Commonalities between Indigenous Values and Current Sustainable Design Concepts in Aotearoa New Zealand. Department of Civil and Environmental Engineering, 8(2), 215-229.

Waatea, R. (2017). Sustainability Key For Ruatahuna Community Hub. Retrieved from http://www.ngaituhoe.iwi.nz/Sustainability-key-for-Ruatahuna-community-hub

\subsection{LIST OF FIGURES}

All images were taken on by the Author.

All Diagrams were produced by the Author. 